Florida International University FIU Digital Commons

FIU Electronic Theses and Dissertations

University Graduate School

6-11-2018

\title{
Study on Strut and Node Behavior in Strut-and-Tie Modeling
}

Nazanin Rezaei

nreza002@fiu.edu

DOI: $10.25148 /$ etd.FIDC006887

Follow this and additional works at: https://digitalcommons.fiu.edu/etd

Part of the Civil Engineering Commons, Construction Engineering and Management Commons, and the Structural Engineering Commons

\section{Recommended Citation}

Rezaei, Nazanin, "Study on Strut and Node Behavior in Strut-and-Tie Modeling" (2018). FIU Electronic Theses and Dissertations. 3749. https://digitalcommons.fiu.edu/etd/3749

This work is brought to you for free and open access by the University Graduate School at FIU Digital Commons. It has been accepted for inclusion in FIU Electronic Theses and Dissertations by an authorized administrator of FIU Digital Commons. For more information, please contact dcc@fiu.edu. 


\section{FLORIDA INTERNATIONAL UNIVERSITY}

Miami, Florida

STUDY ON STRUT AND NODE BEHAVIOR IN STRUT-AND-TIE MODELING

A dissertation submitted in partial fulfillment of

the requirements for the degree of

DOCTOR OF PHILOSOPHY

in

CIVIL ENGINEERING

by

Nazanin Rezaei

2018 
To: Dean John L. Volakis

College of Engineering and Computing

This dissertation, written by Nazanin Rezaei, and entitled Study on Strut and Node Behavior in Strut-and-Tie Modeling, having been approved in respect to style and intellectual content, is referred to you for judgment.

We have read this dissertation and recommend that it be approved.

Irtishad Ahmad

Atorod Azizinamini

Arindam Gan Chowdhury

Ton-Lo Wang

David Garber, Major Professor

Date of Defense: June 11, 2018

The dissertation of Nazanin Rezaei is approved.

Dean John L. Volakis

College of Engineering and Computing

Andrés G. Gil

Vice President for Research and Economic Development and Dean of the University Graduate School

Florida International University, 2018 
(C) Copyright 2018 by Nazanin Rezaei

All rights reserved. 


\section{DEDICATION}

I am extremely grateful to be able to finish this dissertation which is the result of dedicating more than 20 years of my life to education. It is definitely one of the most valuable achievements I have ever had, and I want to dedicate it to the most lovely and respectful people.

I would like to dedicate this dissertation to children all over the world who feel oppressed, defenseless, unsheltered, and voiceless. Girls and boys who need protection, education, and love. I would also like to dedicate it to strong and independent women especially in my home country (Iran), who are struggling day and night for equality, freedom, and human rights. To my parents who taught me to be brave and fearless, faithful to my dreams, and confident to my power. To my beloved sisters, Elham and Elnaz, and my dearest cousin, Fereshteh, for their unconditional love and support from near and from far.

Last, but not least, I want to dedicate this dissertation to researchers who have worked on my area of research, strut-and-tie method. Their studies took me to the edge of human knowledge. I also dedicate this work to all scientists who put their time and effort to push the boundaries of knowledge to make a safe and peaceful world for people. I hope this research would be a small step toward this goal. 


\section{ACKNOWLEDGMENTS}

First and foremost, I would like to express my deepest gratitude to my major professor, Dr. David Garber, who always stood by my side in this difficult path, and helped me with his well-thought-out advices. Without his support, valuable guidance, contribution, and patience, this dissertation would not have been possible.

I would like to thank Gary Klein, one of the most knowledgeable and well-known civil engineers especially in strut-and-tie field, for his valuable advice, and crucial contribution, which made him a backbone of this dissertation. His truly scientific intuition, ideas and passions in science has inspired and nourished my intellectual maturity.

Sincere thanks to the members of my doctoral committee, Dr. Atorod Azizinamini, Dr. Irtishad Ahmad, Dr. Ton-Lo Wang, and Dr. Arindam Gan Chowdhury for their input, valuable discussions, and accessibility.

I also want to acknowledge the help of undergraduate and graduate students at the Titan America Structures and Construction Testing Laboratory of the Florida International University, Lamar Case, Manual Matus, Francisco Chitty, and Dewan Hossain.

Last, but not least, I would like to thank my parents and my sisters (Elham and Elnaz) for their continuous encouragement and unwavering love. 


\begin{abstract}
OF THE DISSERTATION
STUDY ON STRUT AND NODE BEHAVIOR IN STRUT-AND-TIE MODELING

by

Nazanin Rezaei
\end{abstract}

Florida International University, 2018

Miami, Florida

Professor David Garber, Major Professor

The strut-and-tie method (STM) is a simple and conservative method for designing concrete structures, especially deep beams. This method expresses complicated stress patterns as a simple truss or kinematic model made up of compression elements (struts), tension elements (ties), and the joints between elements (nodes). STM is based on lowerbound plasticity theorem, so using it properly will lead to a conservative design. Although the concepts of STM have been around in concrete design since the late $19^{\text {th }}$ century, STM was first introduced in AASHTO LRFD in 1994 and ACI 318-02 in 2002. ACI 318 defines two different types of struts (prismatic and bottle-shaped) based on whether compression stress can spread transversely along the length of the strut. Recent work has brought into question whether these two types of struts do exist and whether current design provisions conservatively estimate failure loads for all members.

The performance of struts and nodes were investigated experimentally by testing six fullscale concrete deep beams. The specimens had two different shapes (rectangular and trusslike), two different shear span-to-depth ratio (1 and 1.6), and three different types of development (externally unbonded bars, internally bonded hooked bars, and internally bonded bars with welded external plates). All the specimens were supported vertically and 
tested under a three-point load setup. Based on the results, the truss-like specimen failed at higher loads than rectangular specimens with the same shear span-to-depth ratio. According to these results and recent debate in the literature, bottle-shaped struts are not weaker than prismatic struts because of their shape. They are weaker due to shear failure where struts cross a diagonal tension field. Therefore, the structures should be separately checked for shear strength when they are designed with STM. In this dissertation, the development of the design equation for shear strength of discontinuity regions was introduced, and the procedure is under consideration for adoption in ACI 318-19. This research was expanded numerically by studying the effect of development type and length, strut type, and strut angle on the behavior of concrete deep beams. The crack patterns and load-displacement curves, which were obtained from experimental tests, were used to validate numerical models. The strength of concrete deep beams was assessed by modeling thirty-five specimens in a nonlinear finite element software. According to the results, development length and development types influenced the presence of tensile stress in the support nodes. Additionally, the effect of the tensile stresses from reinforcement development and diagonal tension were not additive in rectangular specimens. 


\section{TABLE OF CONTENTS}

CHAPTER

PAGE

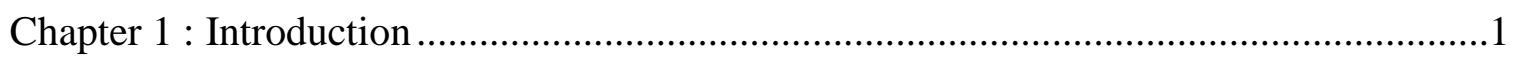

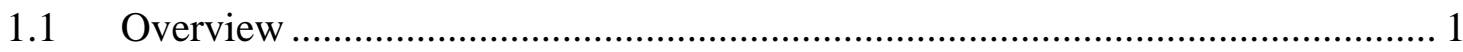

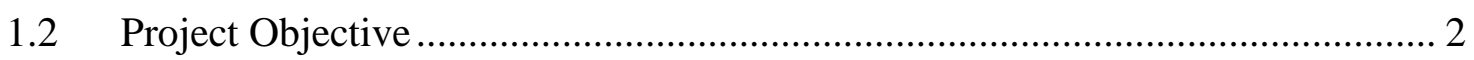

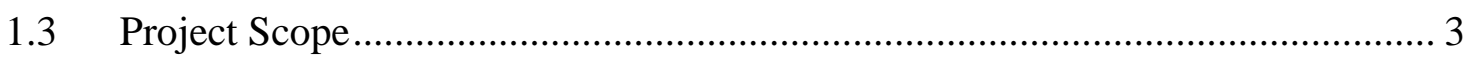

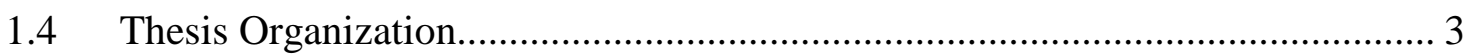

Chapter 2 : Background of Strut-and-Tie Method ........................................................6

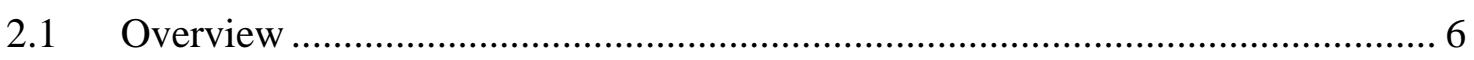

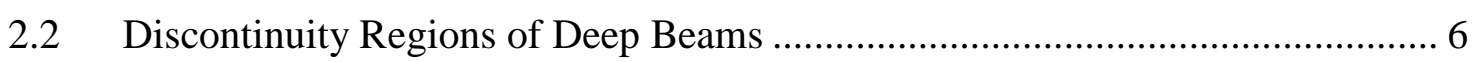

2.3 Theoretical Background of Strut-and-Tie Modeling.......................................... 9

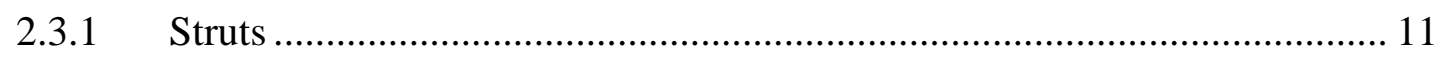

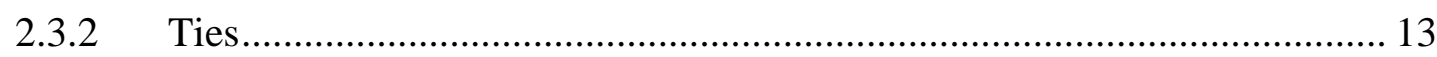

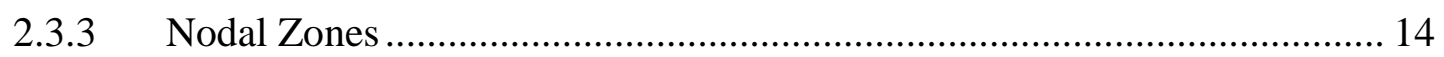

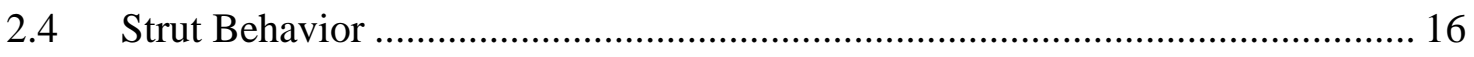

2.4.1 Vertically-Oriented Struts................................................................ 17

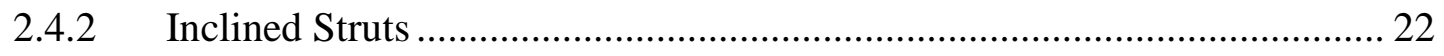

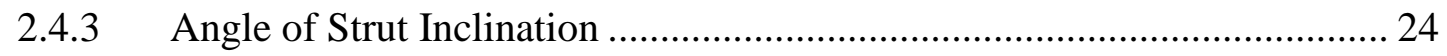

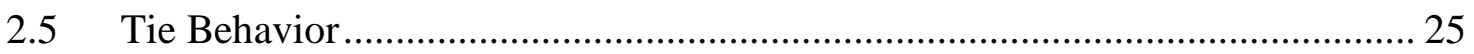

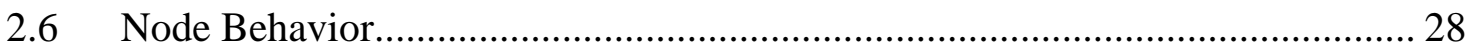

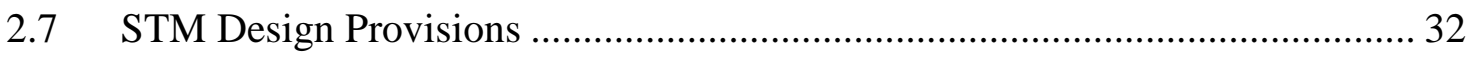

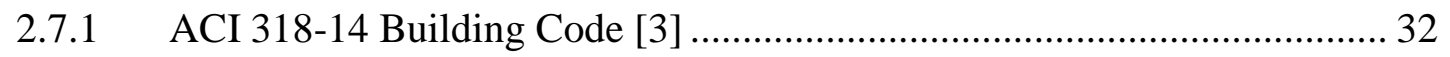

2.7.2 AASHTO LRFD Bridge Design Specification [19] .................................... 34

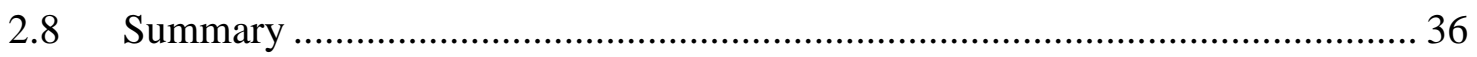

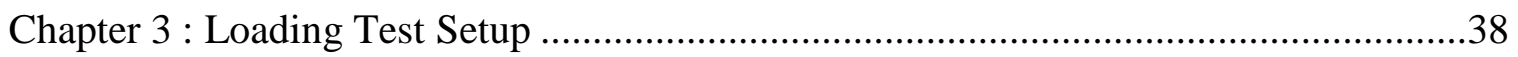

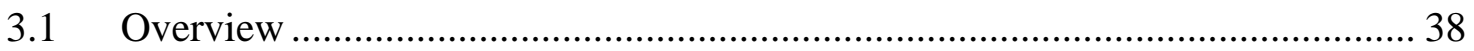

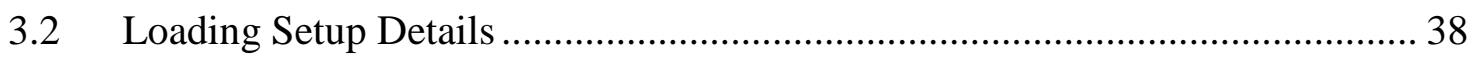

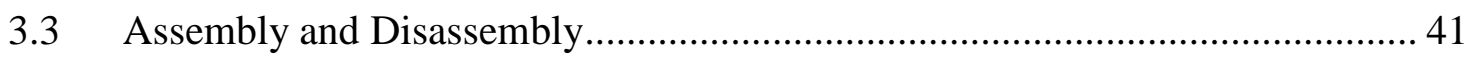

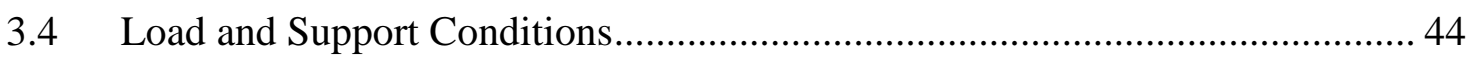

3.5 Load Application and Measurement .............................................................. 45 


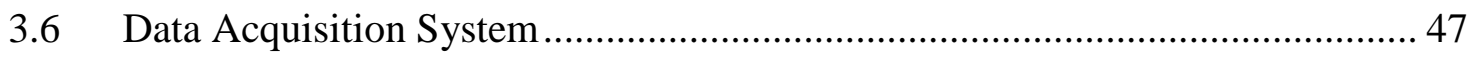

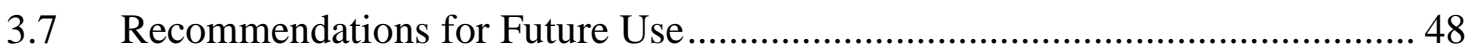

Chapter 4 : Strut Strength and Failure in Full-Scale Concrete Deep Beams .....................49

$4.1 \quad$ Abstract n...................................................................................... 49

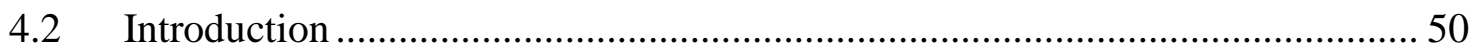

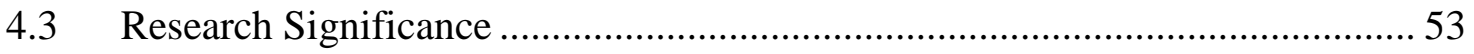

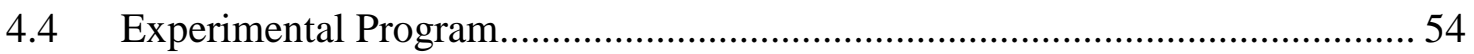

4.4.1 Specimen Geometry and Design........................................................ 54

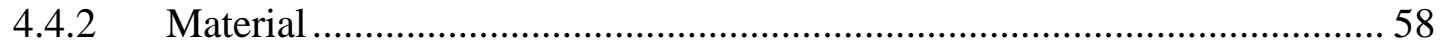

4.5 Set up, Instrumentation, and Testing Procedure ……………........................ 58

4.5.1 Loading Protocol........................................................................... 59

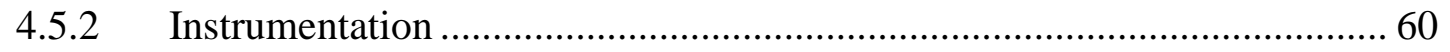

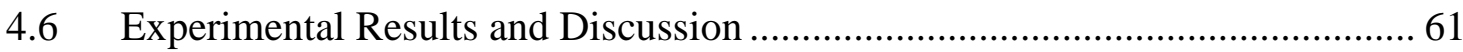

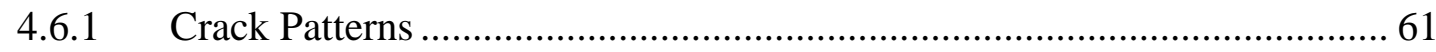

4.6.2 Observed Failure Modes .......................................................................... 62

4.6.3 Low-Cycle Fatigue of Internally Reinforced Rectangular Specimen......... 65

4.6.4 Analysis of Test Results and Discussion .................................................. 66

4.7 Comparison with Current STM Estimates …………...................................... 72

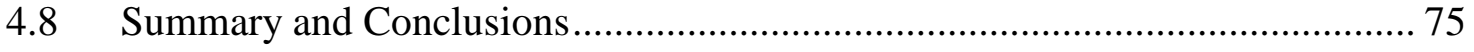

4.9 Acknowledgements .............................................................................. 77

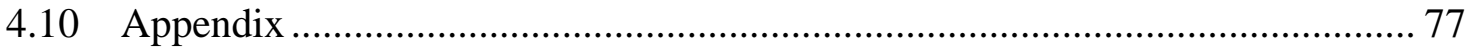

Chapter 5 : Effect of Development and Beam Geometry on Behavior of Concrete

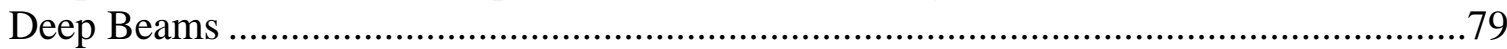

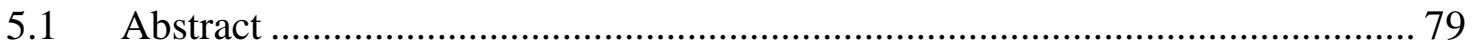

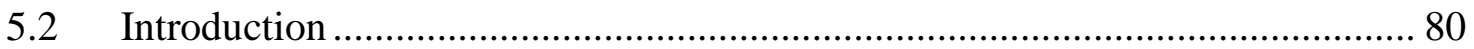

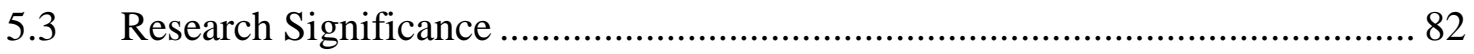

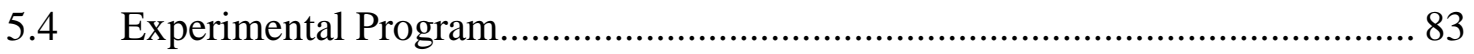

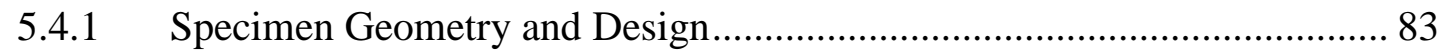

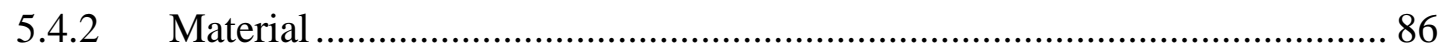

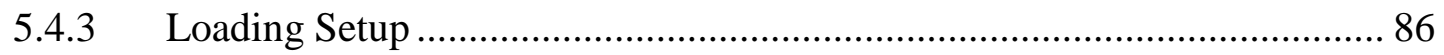

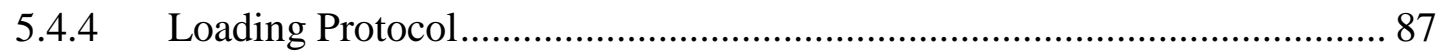

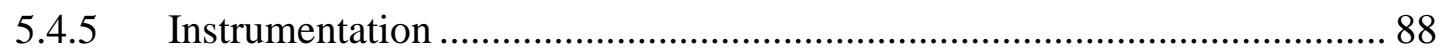




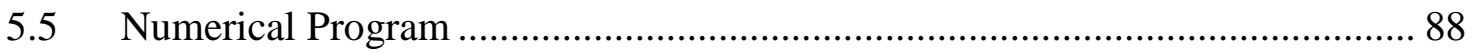

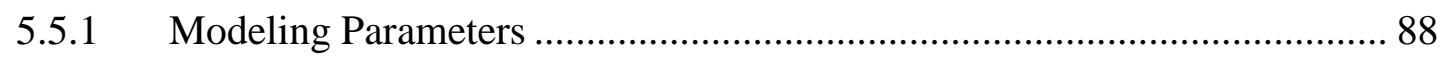

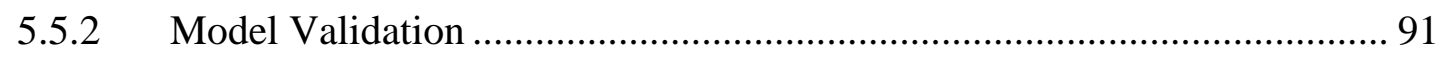

5.5.3 Numerical Specimen Details.................................................................... 94

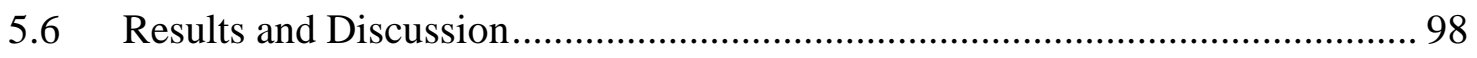

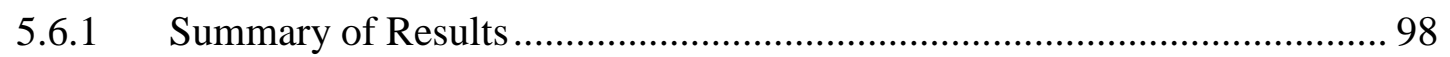

5.6.2 Effect of Development Length.............................................................. 99

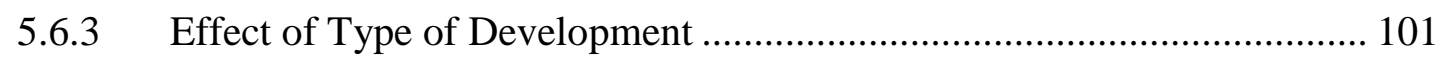

5.6.4 Effect of Beam Type …………………………...................................... 103

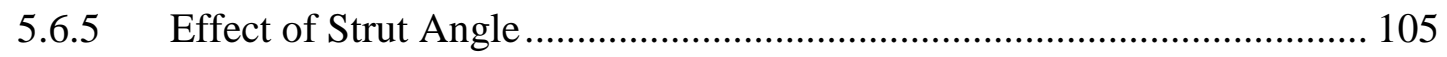

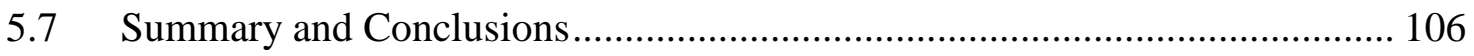

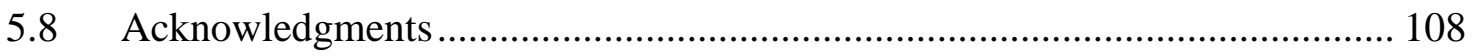

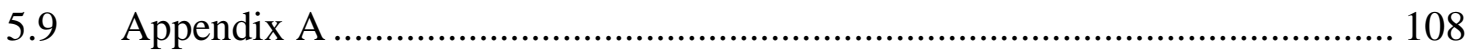

Chapter 6 : Shear in Discontinuity Regions.................................................................109

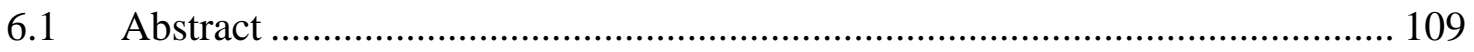

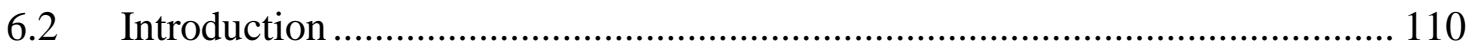

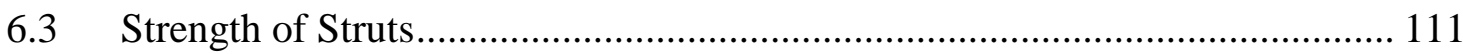

6.3.1 Bottle-shaped Struts ............................................................................. 111

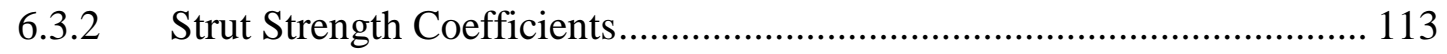

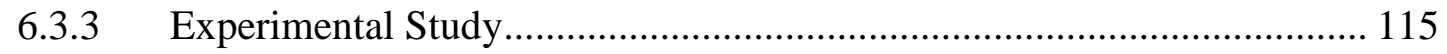

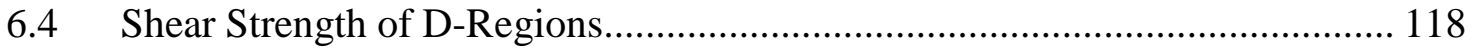

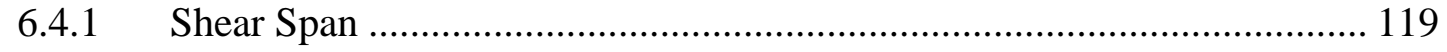

6.4.2 Size Effect and Lightweight Concrete Factors .......................................... 120

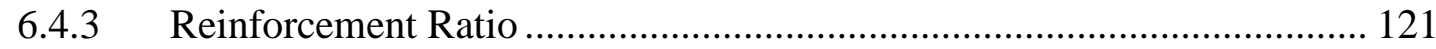

6.5 Conclusions and Recommendations....................................................... 122

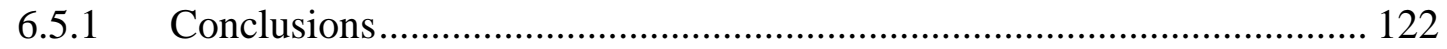

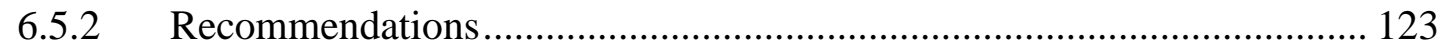

6.6 Acknowledgements ........................................................................... 124

Chapter 7 : Summary, Conclusions, and Recommendations ..........................................125

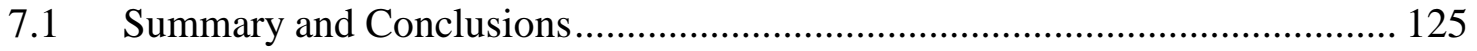

7.1.1 Experimental Testing ........................................................................ 125 


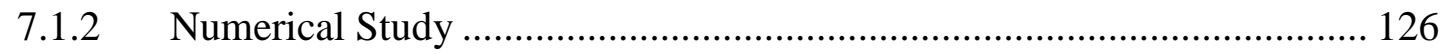

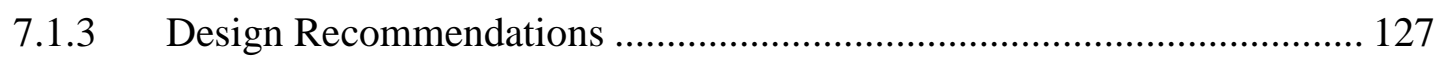

7.2 Recommendations for Future Work ......................................................... 129

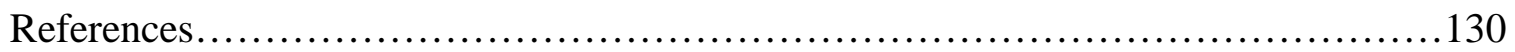

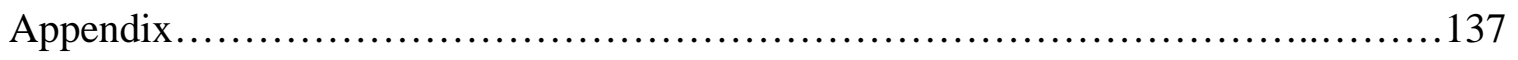

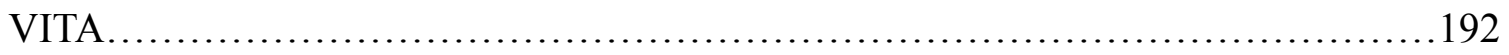




\section{LIST OF TABLES}

TABLE

PAGE

Table 2-1: test results of deep beams in Sahoo et al. [7] ............................................23

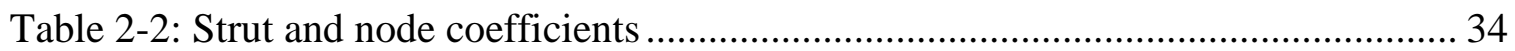

Table 2-3: Concrete efficiency factor (v), if minimum crack-control reinforcement is

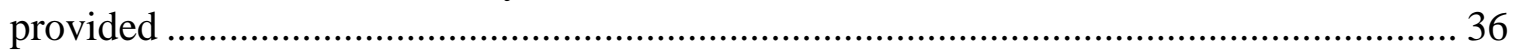

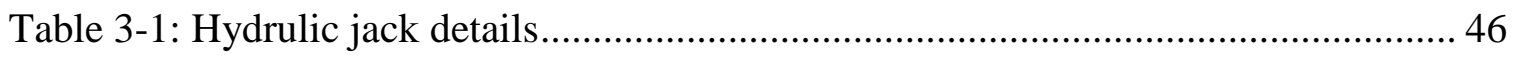

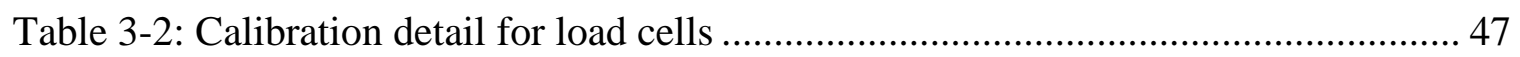

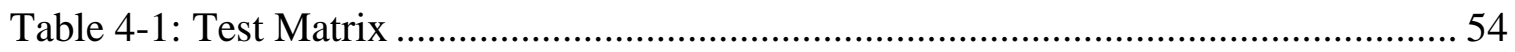

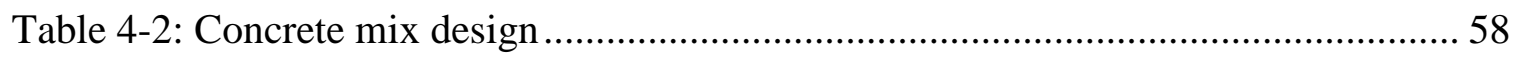

Table 4-3: Measured and Estimated Failure Loads .................................................... 73

Table 4-4: Predicted versus observed failure modes ................................................ 75

Table 5-1: Details of experimental test specimens ("(E)" subscript identifies

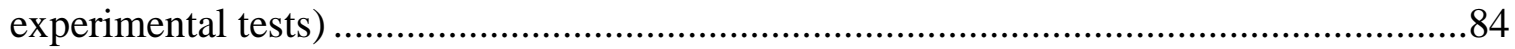

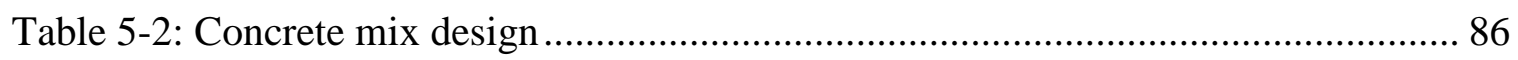

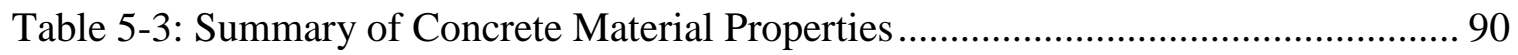

Table 5-4: Summary of the numerical specimen details and results ............................ 94

Table 5-5: Summary of the numerical specimen details and results for different strut

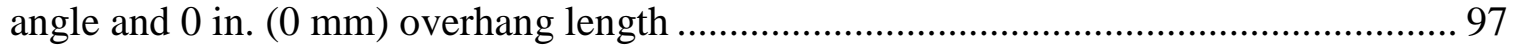

Table 5-6: Summary of failure loads for all beams with 45-degree strut angle in numerical investigation (underlined* number indicates sufficient development length

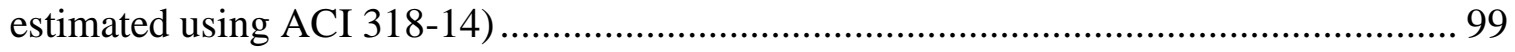

Table 6-1: Specimen details and test results ..................................................... 115

Table B.1: Material properties used in STM calculations ...................................... 141

Table B.2: Element forces for Re-45-Ex ................................................................. 144 
Table B.2: Summary of loads required to cause failure in different componenet of

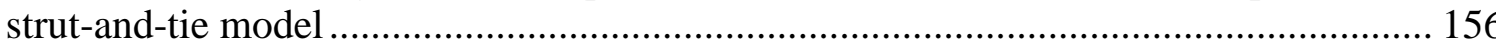

Table B.3: Concrete efficiency factor (v), if minimum crack-control reinforcement is

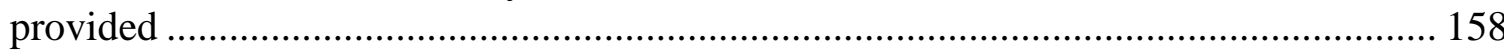

Table B.2: Summary of loads required to cause failure in different componenet of

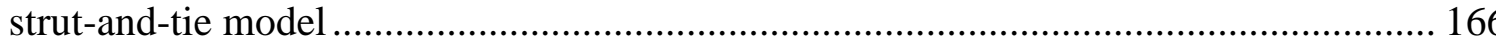




\section{LIST OF FIGURES}

FIGURE

PAGE

Figure 2-1: (a) Simply-supported beam with uniform loading, (b) typical cross-section of reinforced concrete beam, and (c) linear strain distribution across depth of crosssection

Figure 2-2: Examples of deep beam members: (a) hammerhead cap, (b) bent cap, (c) ledged members like corbels and inverted-tee beams, (d) coupling beams, and (e) pile caps

Figure 2-3: Stress trajectories in B- and D-regions ( adapted from Birrcher et al. 2009)

Figure 2-4: Stress trajectories within D-region in simply supported concrete deep beam

Figure 2-5: Strut-and-tie model: simply supported deep beam supporting a concentrated load

Figure 2-6: Strut-and-tie model with truss elements: prismatic and bottle-shaped struts

Figure 2-7: Assumed stress flow in (a) bottle-shaped and (b) prismatic struts according to ACI 318-14

Figure 2-8: Tie reinforcement provided at the location of tension ties.

Figure 2-9: Type of the nodes in simple supported deep beam .................................. 15

Figure 2-10: Non-hydrostatic nodes versus hydrostatic node.................................... 16

Figure 2-11: Testing of isolated strut specimen and the variables [5] .......................... 17

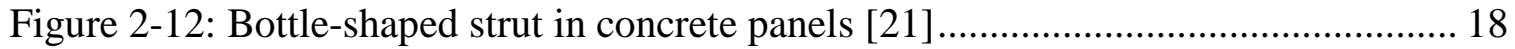

Figure 2-13: Different failure in bottle-shaped struts: (a) non-reinforced specimens, (b) typical failure, and (c) failure in nodal zone [22]............................................. 19

Figure 2-14: Specimens tested in (a) Sahoo et al. [7] (b) Pujol et al. [8] (c) Laughery and Pujol [9] (d) Adebar and Zhou [26] 
Figure 2-15: Mean experimental efficiency factors across various studies for selected W/B [9]

Figure 2-16: the detail of tested deep beams in Sahoo et al. [7] .................................... 23

Figure 2-17: Beam and truss model tested by Beeby [29]............................................. 24

Figure 2-18: Comparison of the code provisions with the proposed efficiency factor models for normal-weight concrete of $5.8 \mathrm{ksi}$ (40MPa) [34] ........................................ 25

Figure 2-19: Development length of a tie [4] .............................................................. 26

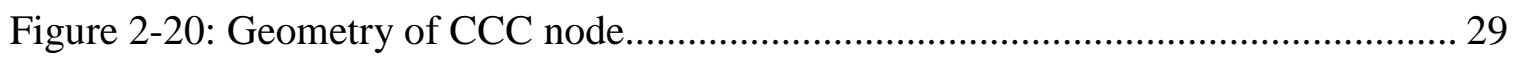

Figure 2-21: Details of CCC node (Node 1 from above)................................................. 30

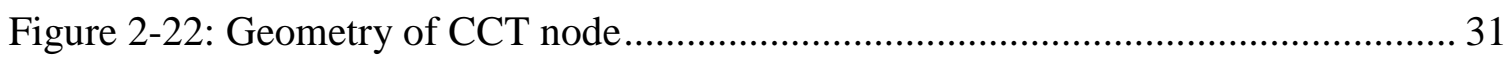

Figure 3-1: Available tie-downs in the Structures Laboratory ........................................ 39

Figure 3-2: The steps of loading set-up and specimen installation................................. 40

Figure 3-3: installing the first rods in the ground ........................................................... 41

Figure 3-4: installing rods to connect the beams .......................................................... 42

Figure 3-5: Assembling specimens with load and support conditions ............................. 43

Figure 3-6: failure in specimen with deficiency in Gypsum.......................................... 45

Figure 3-7: Dimensions of 250-kip capacity load cells: (a) top and (b) side................... 46

Figure 4-1: (a) specimens for Pujol et al. [8] tests and (b) specimens for Sahoo et al.

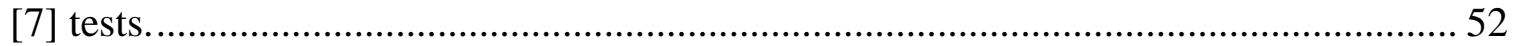

Figure 4-2: Geometry of the specimens: (a) rectangular specimen with unbonded reinforcement, (b) truss-like specimen with unbonded reinforcement, and (c) rectangular specimen with bonded reinforcement. ....................................................... 56

Figure 4-3: Specimens with external unbonded: (a) rectangular and (b) truss-like; and with (c) internal bonded reinforcement (figure has transparent specimen to show

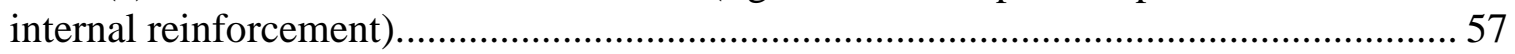

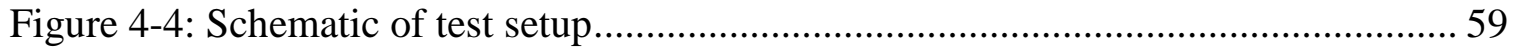


Figure 4-5: Location of instrumentation

Figure 4-6: Crack pattern for (a) unbonded (Re-45-Ex) and (b) bonded (Re-45-In) specimens

Figure 4-7: Before, during, and after failure for five tests 64

Figure 4-8: (a) Load-displacement curve for bonded specimen and (b) curve relating number of cycles to failure to ultimate strength $($ ACI 215, 1992) $(1 \mathrm{kip}=4.44 \mathrm{kN}),(1$ in $=25.4 \mathrm{~mm}$ )

Figure 4-9: Load versus displacement curve for unbonded specimens with (a) 30degree and (b) 45-degree strut angles $(1 \mathrm{kip}=4.44 \mathrm{kN}),(1 \mathrm{in}=25.4 \mathrm{~mm})$.

Figure 4-10: Summary of the experimental failure loads (a) normalized based on strut

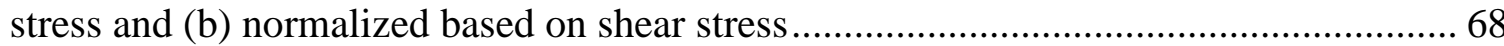

Figure 4-11: Failure modes of rectangular versus truss specimens ............................ 70

Figure 4-12: (a) Load versus longitudinal strain curve and (b) strain versus distance curve at 0.9Pmax for Re-45-Ex and (c) Load versus strain curve and (d) strain versus distance curve at $0.9 \mathrm{Pmax}$ for $\operatorname{Tr}-45-\mathrm{Ex}(1 \mathrm{kip}=4.44 \mathrm{kN})$.

Figure 4-13: Load versus perpendicular strut strain for (a) Re-30-Ex and (b) Tr-30-Ex $(1 \mathrm{kip}=4.44 \mathrm{kN})$.

Figure 4-14: Measured strength divided by estimated strength using ACI 318-14 [3] and AASHTO LRFD [19].

Figure 5-1: Description of strut-and-tie model with ACI 318-14 [3] strut definitions ..... 82

Figure 5-2: Typical specimens geometry for beam series (a) Re-H, (b) Re-EP, (c) Re$\mathrm{S}$, (d) Re-ExU, (e) Tr-ExU, (f) Re-EP, where $\ell_{2}$ is overhang length and $\mathrm{h}$ is 8.5 inches $(215 \mathrm{~mm})$

Figure 5-3: The steps of loading setup and specimen installation

Figure 5-4: $\operatorname{Re}_{(\mathrm{E})}-\mathrm{H}-0$ (a) before loading, (b) during loading, (c) after failure 88

Figure 5-5: (a) Tensile stress-strain curve for concrete with stages of crack opening, and (b) exponential crack opening law, adapted from [60] 89

Figure 5-6: Comparing load-displacement results from experimental and numerical outputs (a) Re-H-0, (b) Re-ExU-0, (c) Tr-ExU-0, and (d) Re-EP-9.5 . 
Figure 5-7: Actual and predicted crack patterns in Re-H-0

Figure 5-8: Failure load versus overhang length

100

Figure 5-9: Load versus deflection curves for rectangular beams with fully developed longitudinal reinforcement 102

Figure 5-10: FE model for (a) Tr-EP-0 at 20 percent of $\mathrm{P}_{\max }$, (b) Tr-ExU-0 at 20 percent of $\mathrm{P}_{\max }$ (c) Tr-EP-0 at 50 percent of $\mathrm{P}_{\max }$, (d) Tr-ExU-0 at 50 percent of $\mathrm{P}_{\max }$, (e) TrEP-0 after failure and (f) Tr-ExU-0 after failure 103

Figure 5-11: Summary of the numerical failure loads versus specimens 104

Figure 5-12: Normalized strut stress versus series 106

Figure 6-1: Illustrations of (a) rectangular prismatic strut, (b) 2-D rectangular bottle strut, and (c) 3-D rectangular bottle strut. After Laughery and Pujol.

Figure 6-2: Example of stress flow in a deep beam

Figure 6-3: $V_{\text {test }} / V_{\text {calc }}$ versus $f^{\prime}{ }_{c}$ ( $V_{\text {calc }}$ in accordance with the strut-and-tie method in ACI 318-14)

Figure 6-4: Schematic of test setup and specimen with supports (truss-like specimen shown)... 116

Figure 6-5: Failure crack pattern and image of instant of failure: Specimen Re-45-Ex. 118

Figure 6-6: Transfer girder at an offset in the column grid

Figure 6-7: Shear stress $v_{c}$ vs ratio of shear span to effective depth, $a_{v} / d$. 120

Figure A-1: Construction drawings for beams B-1 and B-2 ............................... 138

Figure A-2: Construction drawings for B-3, node beams, loading and support plates.. 139

Figure B-1: Re-45-Ex specimen 140

Figure B-2: Dimensions for Re-45-Ex: (a) elevation and (b) cross-section 141

Figure B-3: Strut-and-tie model used for Re-45-Ex 142

Figure B-4: Distance between nodes C and D for Re-45-Ex. 143

Figure B-5: Nodes under the load plate (Nodes C and D) 148 
Figure B-6: Reaction node (Nodes A and B): (a) faces and (b) dimensions 152

Figure C-1: CR6 with detail of wiring panel 170

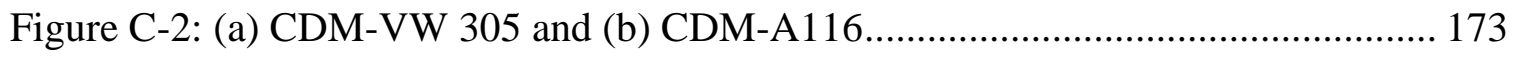

Figure C-3: Sensors and devices window in LoggerNet software.............................. 175

Figure C-4: Wiring diagram in LoggerNet software ............................................ 176

Figure C-5: Output window in LoggerNet software ............................................. 177

Figure C-6: Finish window in LoggerNet software .............................................. 178

Figure C-7: Device Configuration Utility (DevConfig) ......................................... 179

Figure C-8: Connect screen in LoggerNet software ............................................ 180 


\section{Chapter 1: Introduction}

\section{$1.1 \quad$ Overview}

Axial and bending stresses will cause a stress distribution across the section depth of concrete members. The Bernoulli hypothesis that plane sections remain plane is usually assumed for these sections, which assumes that strains vary linearly across the depth of the section. Regions where strains actually vary linearly across the depth (i.e. where the Bernoulli hypothesis is accurate) are considered as Bernoulli or beam regions (also called B-regions), which can be designed using typical sectional design approaches (e.g. rectangular stress block approach for determining nominal moment strength).

Strains do not always vary linearly across the depth of a section. Disturbed or discontinuity regions (D-regions) are regions where stresses vary nonlinearly across the depth. D-regions are typically found within a distance $d$ (distance from the compression face to centroid of the tension steel) of concentrated point loads, supports, or geometric discontinuity. Some examples of members with D-regions are transfer girders, pile supported foundations, and bridge bents.

Typical sectional design approaches are not valid in D-regions. Empirically derived design expressions were traditionally used in these regions before the introduction of the strutand-tie method (STM) into design codes and specifications toward the end of the $20^{\text {th }}$ century (1994 for AASHTO LRFD [1] and 2002 in ACI 318-02 [2]). STM involves modeling the stress flow through a structure using a hypothetical truss or kinematic model. Compression members in the truss are called struts, tension members are ties, and the joints are nodes. When designing using STM, sufficient reinforcement must be provided to resist 
the forces of the tension ties and struts must have sufficient strength to carry the compression forces.

ACI 318-14 [3] defines two types of struts, prismatic and bottle-shaped, based on the geometry and the location of the struts in the structure. Bottle-shaped struts are struts where stresses can spread transversely along their length, i.e. they have a larger width and area at the mid-length of the strut than at its ends. As mentioned by many researchers ([4]-[6]), the lateral spreading in theses struts creates tensile stresses transverse to the strut, which must be resisted by minimum strut reinforcement. Prismatic struts have a uniform section along their length, either because of geometric discontinuities or from bordering tension regions (e.g. region below the rectangular stress block in bending).

The current design philosophy [3] suggests that bottle-shaped struts are weaker than prismatic struts. There has been recent research that has suggested otherwise [7]-[9]. A thorough review of the literature indicated that few studies have focused on the effect of struts on the strength and behavior of deep beams.

\subsection{Project Objective}

The primary objective of this research was to further investigate the behavior of struts in concrete deep beams. The experimental and numerical studies were designed to investigate the effect of the strut type (prismatic versus bottle-shaped), strut angle $\left(30^{\circ}, 45^{\circ}, 60^{\circ}\right)$, and presence of bonded tensile reinforcement on the strength and behavior of struts in concrete deep beams. The conservatism and accuracy of the current ACI 318 STM provisions were assessed and recommendations for the improved estimation of strut strength were made. 


\subsection{Project Scope}

The above objectives were achieved through the following primary tasks:

- Literature Review: Conduct a literature review to indicate the current state of knowledge on strut behavior and design in concrete deep beams.

- Test Setup Design: Design, fabrication, and installation of three-point loading setup with 800-kip capacity to test constructed deep beams.

- Experimental Testing: Full-scale experimental testing of concrete deep beams with different geometries (rectangular and truss-like), strut angle $\left(30^{\circ}\right.$ and $\left.45^{\circ}\right)$, and presence of bonded and unbonded reinforcement.

- Numerical Study: Numerical investigation of concrete deep beams using nonlinear finite element software specifically calibrated for concrete structures with the purpose of further investigating the behavior of struts. Additionally strut angles $\left(60^{\circ}\right)$ and reinforcement development types and lengths were investigated to further understand the effect of resulting tension fields on strut behavior.

- Design Recommendations: Make a recommendation for ACI 318 and AASHTO provisions based on findings.

\section{$1.4 \quad$ Thesis Organization}

This dissertation is written based on the format of 'Thesis Containing Journal Papers'. The dissertation includes three manuscripts for scholarly journals and magazine, of which all are under review. Additional chapters are provided to complete the dissertation and summarize work not adequately captured in the three journal papers. The organization is as follows: 
- Chapter 2 - Background of STM: This chapter introduces STM and a summary of the relevant literature and previous research results.

- Chapter 3 - Loading Test Setup: This chapter contains an overview of the design of the 800-kip test setup that was designed for this research.

- Chapter 4 - "Strut Strength and Failure in Full-Scale Concrete Deep Beams" (submitted to ACI Structural Journal) [10]: This paper discusses results from fullscale testing conducted at FIU. It includes the experimental results of five full-scale concrete deep beams: three rectangular and two truss-like specimens with the shear span-to-effective depth ratio $(a / d)$ of 1 (45 degree) and 1.6 (30 degree).

- Chapter 5 - "Effect of Development and Beam Geometry on Behavior of Concrete Deep Beams" (submitted to ACI Structural Journal ) [11]: The second paper is an extension of the first paper, including additional experimental results for one additional experimental specimens, the validation of numerical models, and results for numerical modeling of an additional 35 specimens. The specimens were modeled to investigate the effect of development length, development type, strut type, and strut angle on the behavior of nodal zones in discontinuity regions.

- Chapter 6 - "Shear in Discontinuity Regions" (submitted to Concrete International) [12]: The final paper is the answer of why STM can be unconservative for so-called bottle-shaped struts, despite already low strut efficiency factors. This paper includes suggestions to use interior strut instead of bottle-shaped strut, and edge struts instead of prismatic struts. Interior struts are weaker than edge struts because interior struts cross a diagonal tension field and the sections fails in shear. The developed design equations for shear strength of 
discontinuity are proposed based on shear span, section depth, and lightweight concrete and is under consideration for inclusion in ACI 318-19.

A conclusions section is then provided to summarize conclusions from all the three papers and propose recommended future work. 


\section{Chapter 2: Background of Strut-and-Tie Method}

\subsection{Overview}

This chapter includes an overview of the theoretical background of the strut-and-tie method (STM). The current state of knowledge of the behavior of struts, ties, and nodes is summarized with an expanded discussion on struts, since this is the focus of this dissertation. A summary of two of STM provisions primarily used in the US (ACI 318-14 and AASHTO LRFD Bridge Design Specification) is also provided.

\subsection{Discontinuity Regions of Deep Beams}

As previously introduced, applied loads and moments will cause stresses in members. These stresses vary across the section depth. According to the Bernoulli hypothesis and traditional beam theory, the strain distribution is assumed to vary linearly across the depth of the section (i.e. plane sections remain plane). Assuming a linear strain profile across the depth of a section allows for the derivation of traditional sectional behavior and design expressions. Regions where plane sections remain plane are called Bernoulli or beam regions (B-regions) and can be designed using traditional sectional design approaches. An example of a beam designed using conventional sectional design approaches is shown in Figure 2-1. As mentioned, a linear strain distribution is assumed across the cross-section depth, as shown in Figure 2-1 (c). 


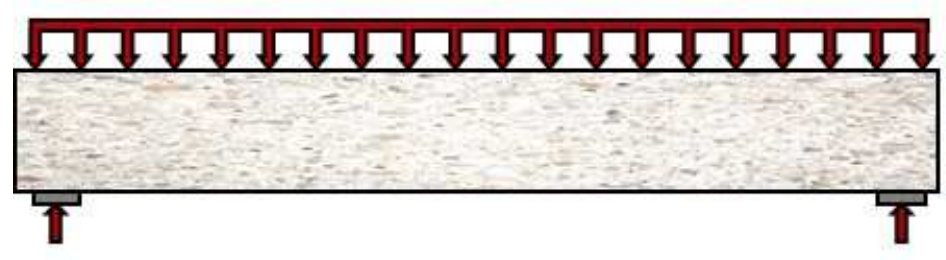

(a)

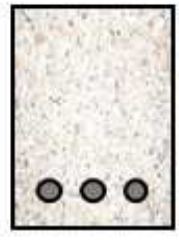

(b)

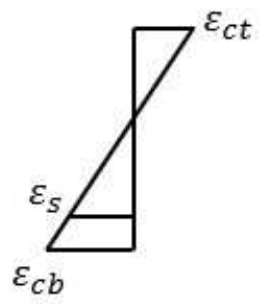

(c)

Figure 2-1: (a) Simply-supported beam with uniform loading, (b) typical cross-section of reinforced concrete beam, and (c) linear strain distribution across depth of cross-section

Strains do not always vary linearly across the depth of a section. Disturbed or discontinuity regions (D-regions) are regions where stresses vary nonlinearly across the depth. D-regions are typically found within a distance $d$ (distance from the compression face to centroid of the tension steel) of concentrated point loads, supports, or geometric discontinuity. Some examples of members with D-regions are shown in Figure 2-2 and include: hammerhead pier caps, bent caps, ledged members like corbels and inverted-tee beams, coupling beams between shear walls, and pile caps. 


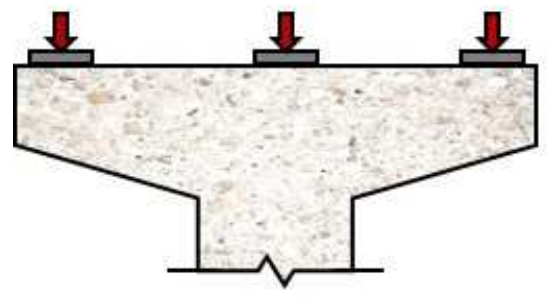

(a)

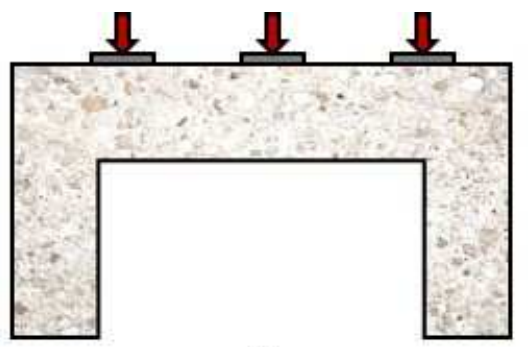

(b)

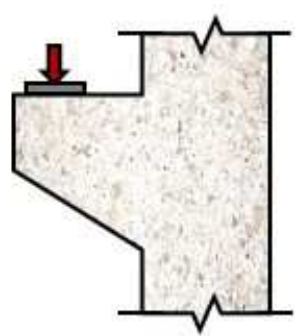

(c)

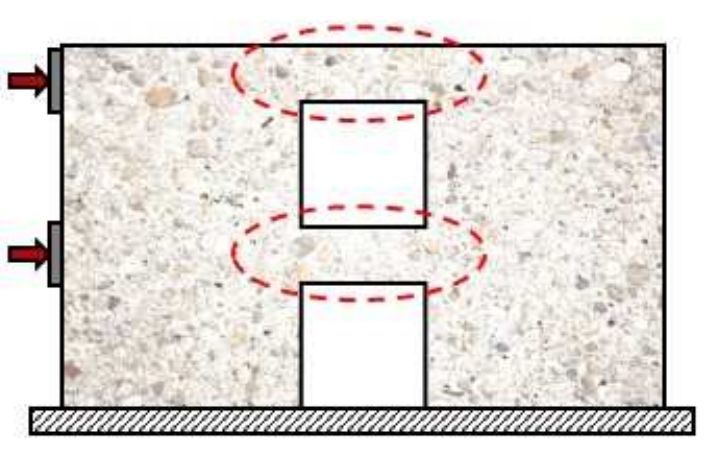

(d)

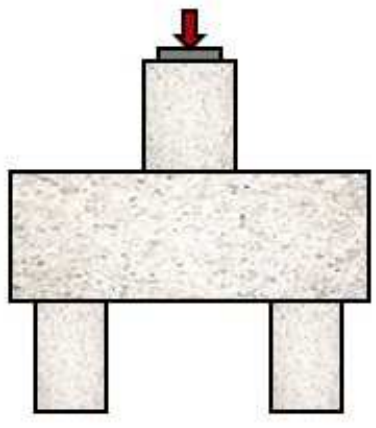

(e)

Figure 2-2: Examples of deep beam members: (a) hammerhead cap, (b) bent cap, (c) ledged members like corbels and inverted-tee beams, (d) coupling beams, and (e) pile caps

The principle compression and tension strain diagram for a simply-supported beam with a point load placed toward one support is shown in Figure 2-3. Saint-Venant's principle allows for the strain diagram to be simplified as linear further from the load points, allowing for sectional approaches to be valid [13]. Strains do vary non-linearly across the section depth within a distance $d$ from the load and support points, so these regions are considered D-regions. The shear span $(a)$ is also highlighted in this figure.

The shear span is the distance from the point load to the support point. Another means for determining whether a region is a D-region is by looking at the shear span-to-depth $(a / d)$ ratio. Shear span-to-depth ratios less than 2 to 2.5 signify regions are D-regions; a limit of 2.0 is used in ACI 318-14 [3]. 


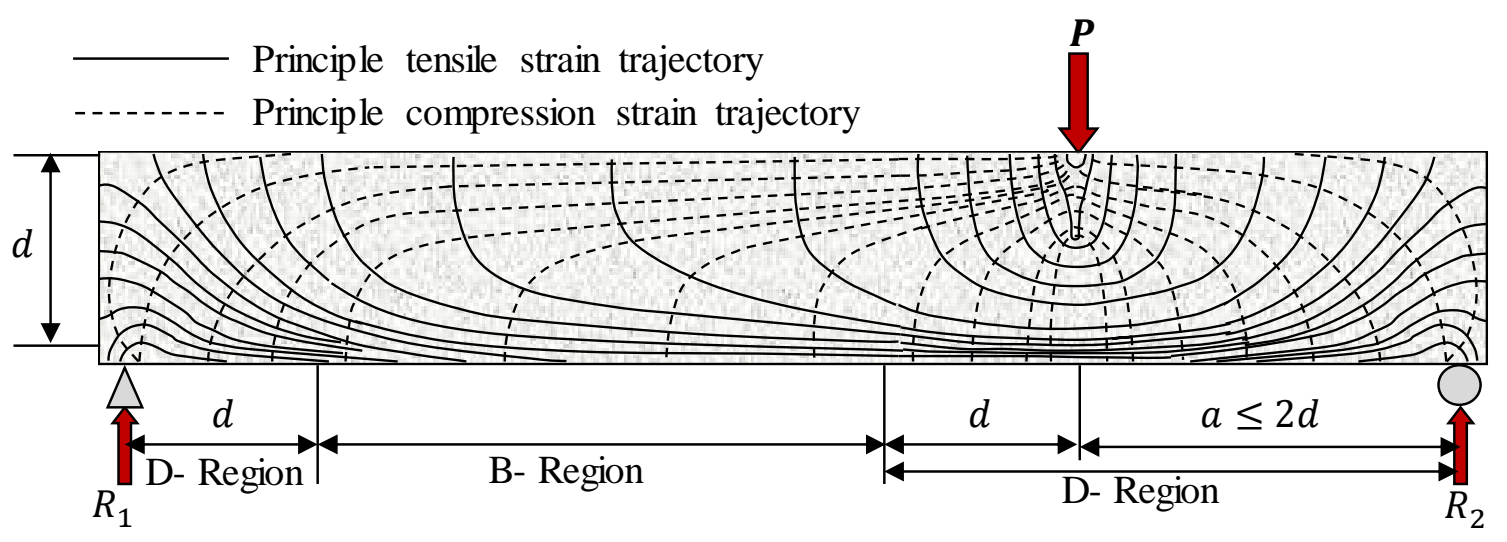

Figure 2-3: Stress trajectories in B- and D-regions ( adapted from Birrcher et al. 2009)

Since these regions do not satisfy the Bernoulli hypothesis (i.e. plane sections do not remain plane), sectional analysis and design procedures are not valid in D-regions. Therefore, designers use empirically derived design methods or STM. The empirically derived methods are typically specific to certain member types for specific applications (e.g. ledges in inverted-tee members). On the other hand, STM is a reasonable and versatile method to safely design all deep beams (and non-deep beams if desired).

\subsection{Theoretical Background of Strut-and-Tie Modeling}

As mentioned in the previous section, strains are distributed nonlinearly within D-regions. The principle tensile and compression strain trajectories in a simply-supported beam with a single point load are shown in Figure 2-4. STM allows for this complex state of stresses in the specimen to be simplified with a collection of uniaxial force elements in a truss or kinematic model, as shown in Figure 2-5. This model includes compression members (struts), tension elements (ties), and the intersection of struts and ties (nodes). STM is a lower-bound plasticity theorem, so as long as equilibrium is satisfied (i.e. forces in these elements are in equilibrium with the external forces) and the distribution of forces are 
compatible with the concrete deformation capacity, using STM will lead to a conservative design [14].

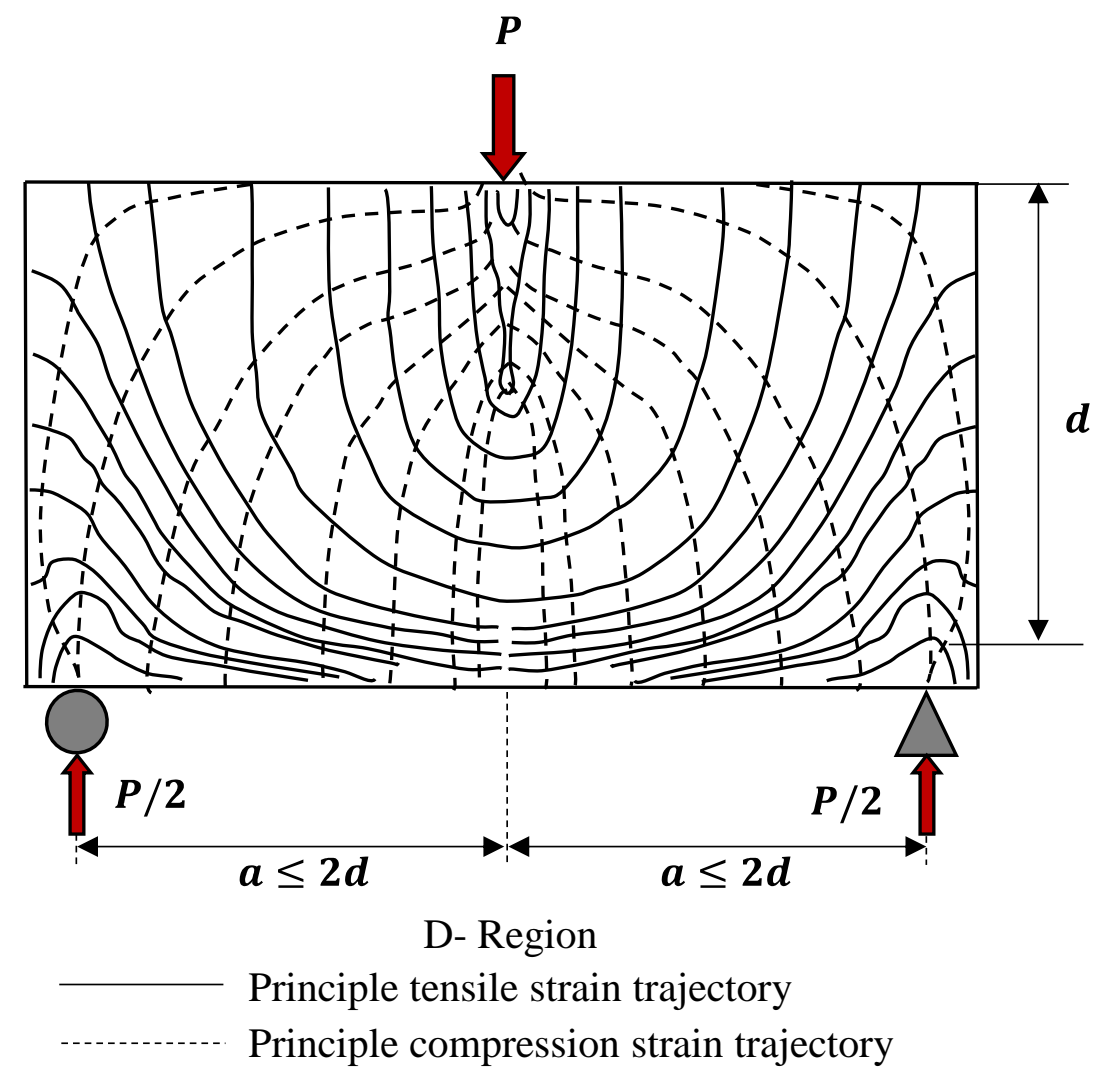

Figure 2-4: Stress trajectories within D-region in simply supported concrete deep beam

To design a member using this method, one must ensure several things:

- Sufficient Tie Reinforcement: Sufficient reinforcement must be placed at the location of the tension ties to resist the tension force in the tie.

- Adequate Concrete Strength in Struts and Nodes: Enough concrete strength and member area must be provided in the struts, strut-to-node interfaces, and other node faces to resist the strut and node forces.

- Proper Detailing: Tie reinforcement must be properly anchored to develop the required tie force and other reinforcement must be provided so that the member has 
the deformation capacity to properly distribute the forces. Improper detailing can lead to lower capacities than desired [15].

There are many resources available to help engineers to design structures in discontinuity regions using STM [16], [17].

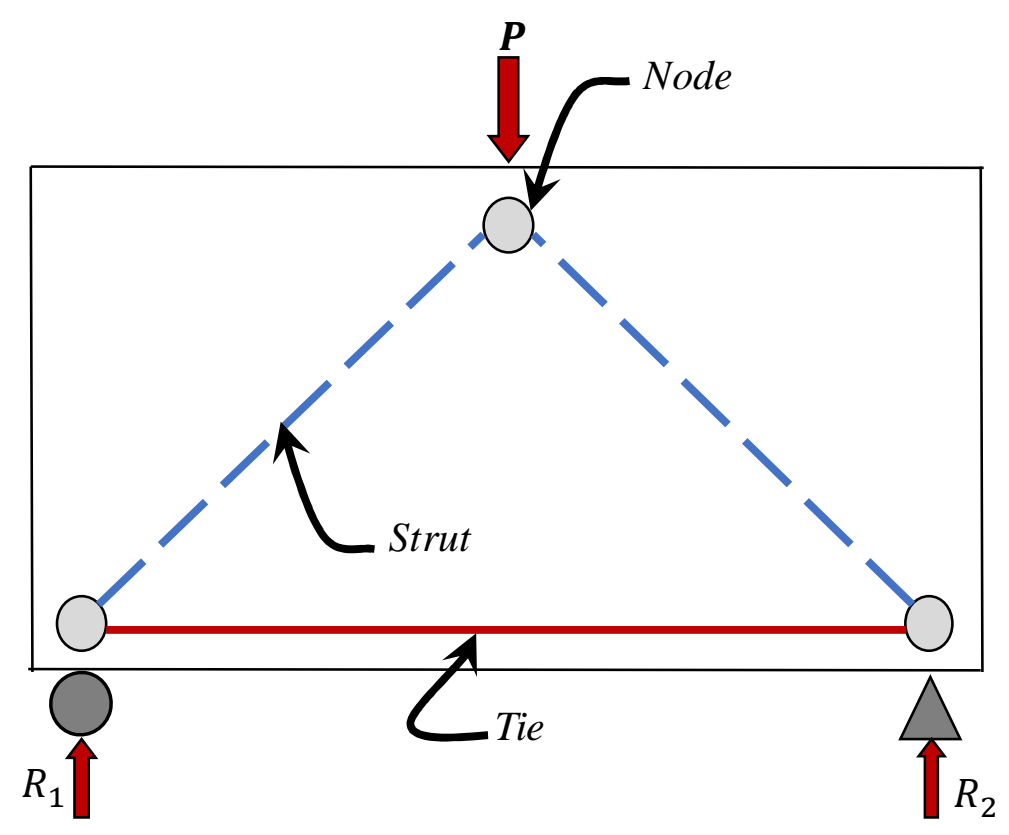

Figure 2-5: Strut-and-tie model: simply supported deep beam supporting a concentrated load

\subsubsection{Struts}

The compression elements in a strut-and-tie model are called struts and are typically represented by a blue dotted line, as shown in Figure 2-5. Current ACI 318-14 [3] STM provisions assume that there are two different types of struts based on geometry and tensile stresses: bottle-shaped struts and prismatic struts, shown in Figure 2-6. Bottle-shaped struts have minimum cross-sectional area at the ends of the strut and maximum crosssectional area in the mid-length. The spreading of compression stress in bottle-shaped struts is thought to develop transverse tensile stress, as shown in Figure 2-7 (a). This transverse 
tensile stress is resisted by the minimum strut reinforcement, according to ACI 318-14 [3].

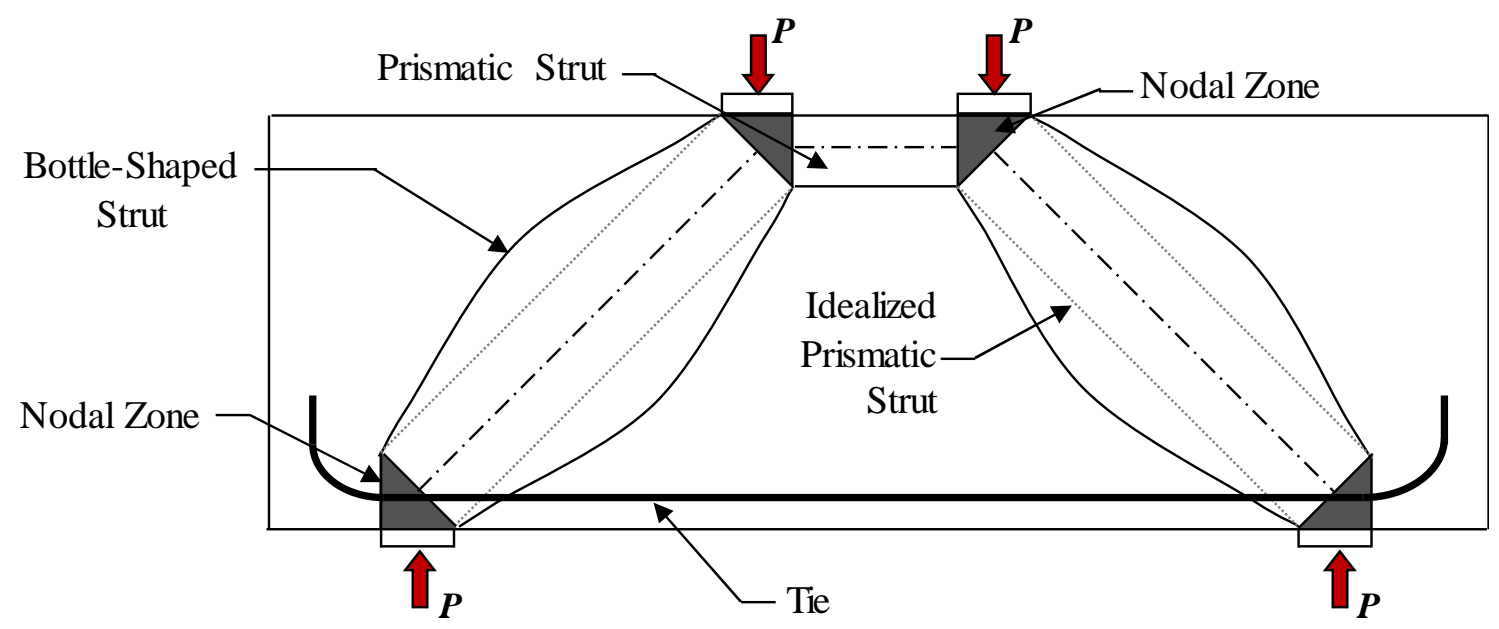

Figure 2-6: Strut-and-tie model with truss elements: prismatic and bottle-shaped struts

Struts located in regions where stresses are not able to spread (i.e. having a uniform section along the length of the strut) are currently called prismatic struts. The prismatic strut shown in Figure 2-6 is formed by the bordering tensile stress region caused by bending. A prismatic strut has only unilateral compression stresses, as shown in Figure 2-7, and no transverse tensile stresses. Because there are no transverse tensile stresses, prismatic struts are thought to be stronger than bottle-shaped struts. 


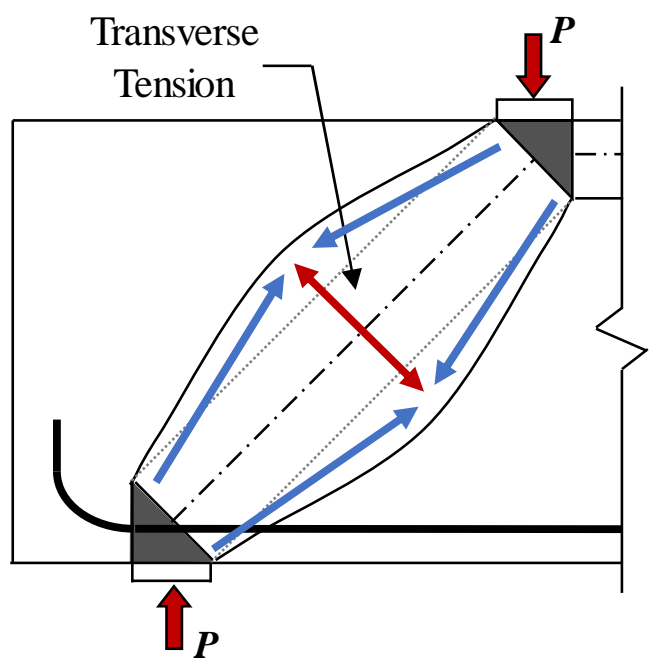

(a)

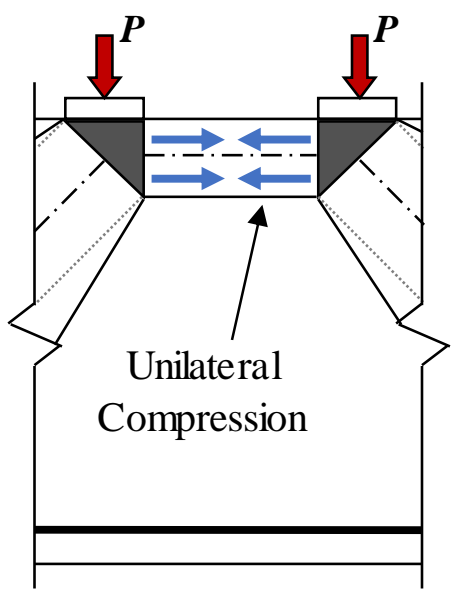

(b)

Figure 2-7: Assumed stress flow in (a) bottle-shaped and (b) prismatic struts according to ACI $318-14$

\subsubsection{Ties}

The tension elements in a strut-and-tie model are called ties and are typically represented by a solid black line, as shown in Figure 2-5. Reinforcement must be provided to resist the tensile force of a tie element, as shown in Figure 2-6 and Figure 2-8. The tie element is located at the centroid of the reinforcement. Tie reinforcement must be fully developed by the time the reinforcement leaves the extended nodal zone. 


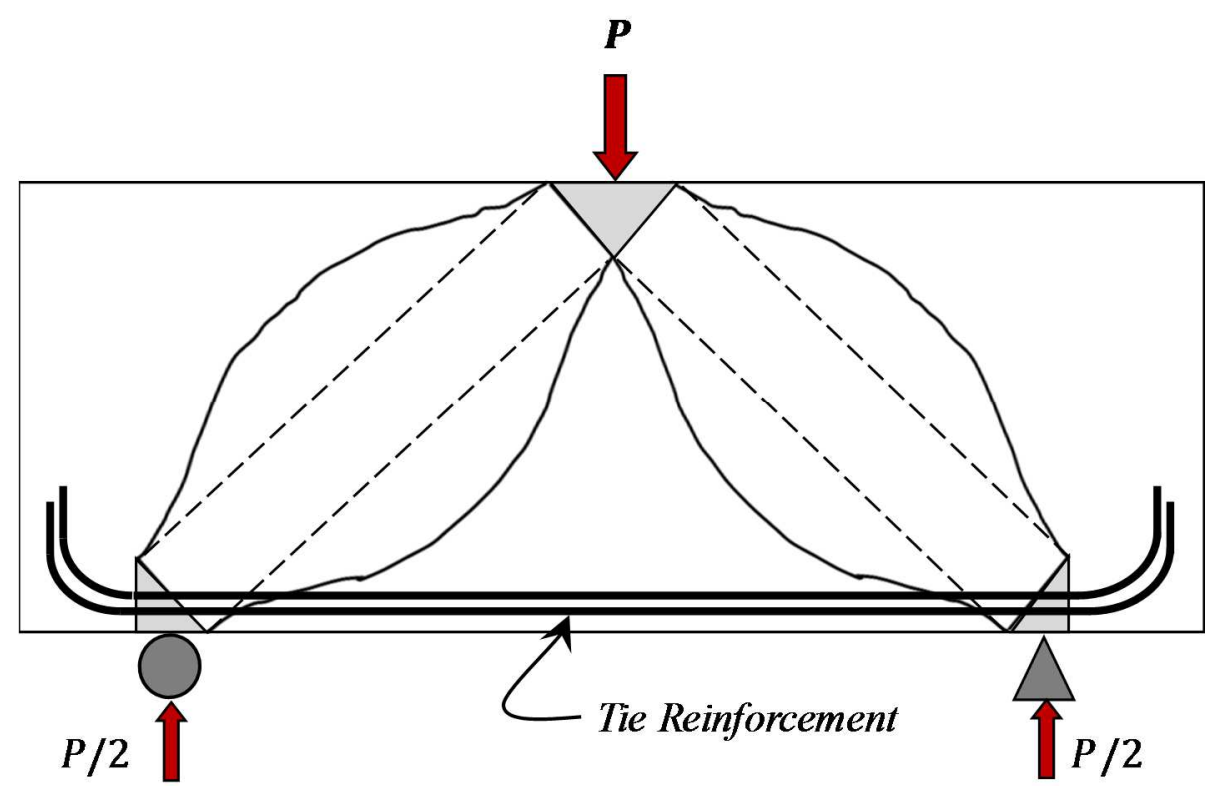

Figure 2-8: Tie reinforcement provided at the location of tension ties

\subsubsection{Nodal Zones}

The intersection of struts and ties are called nodes, as shown in Figure 2-5. Like struts, nodes will have a three-dimensional shape dependent on the intersecting element dimensions. This region formed by the intersecting elements is called a nodal zone. These zones are critical to the behavior of the whole system, because they are typically the most highly stressed regions member. Nodal zones are generally named based on the type of the elements (compression or tension) connected in nodes, where "C" represents intersecting compression elements and " $\mathrm{T}$ " represents tension elements. Nodes with only struts intersecting are CCC nodes. Nodes having a tie only in one direction are CCT nodes. If the node has ties intersect in two different directions, it is a CTT node. Since the type of the node governs the behavior and strength of the specimen, the type of the node is determined in the design process. The types of nodes for the abovementioned beam are highlighted in 
Figure 2-9.

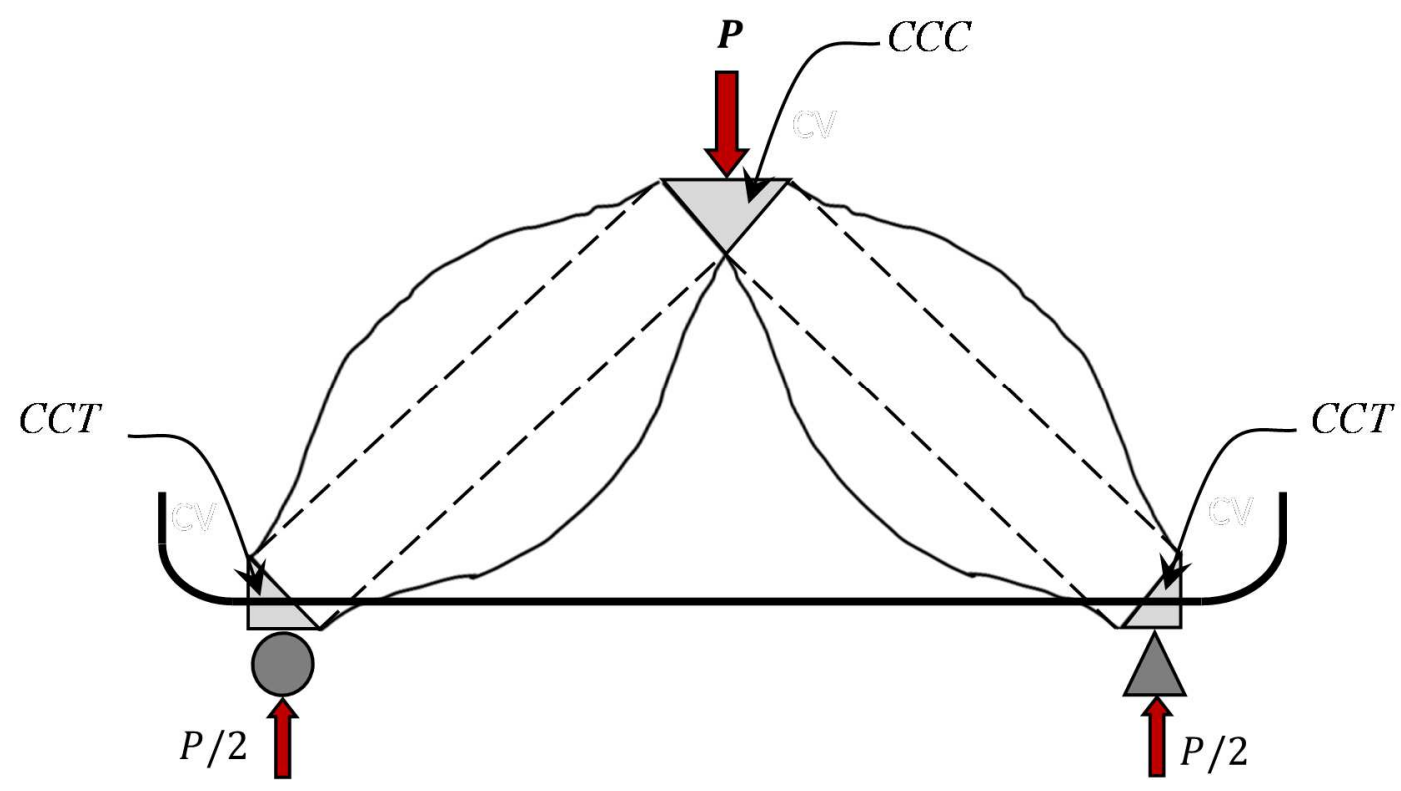

Figure 2-9: Type of the nodes in simple supported deep beam

Nodes can also be defined based on the presence of shear stresses in the nodal zone. A hydrostatic node is a node with equal stresses on all faces of the node, as shown in Figure 2-10 (b). These types of nodes are thought to have no shear stresses developing in the nodal zone, since principal stresses are equal on all side faces. In hydrostatic nodes, the ratio of the area of the side face is proportional to the applied load. Nodes with different stresses on different faces of the node are called non-hydrostatic nodes, as shown in Figure 2-10 (a) and (c). Shear stresses occur in the nodal zone of these nodes. Proportioning techniques and a further discussion on the use of hydrostatic and non-hydrostatic nodes are found in Birrcher et al. [4]. 


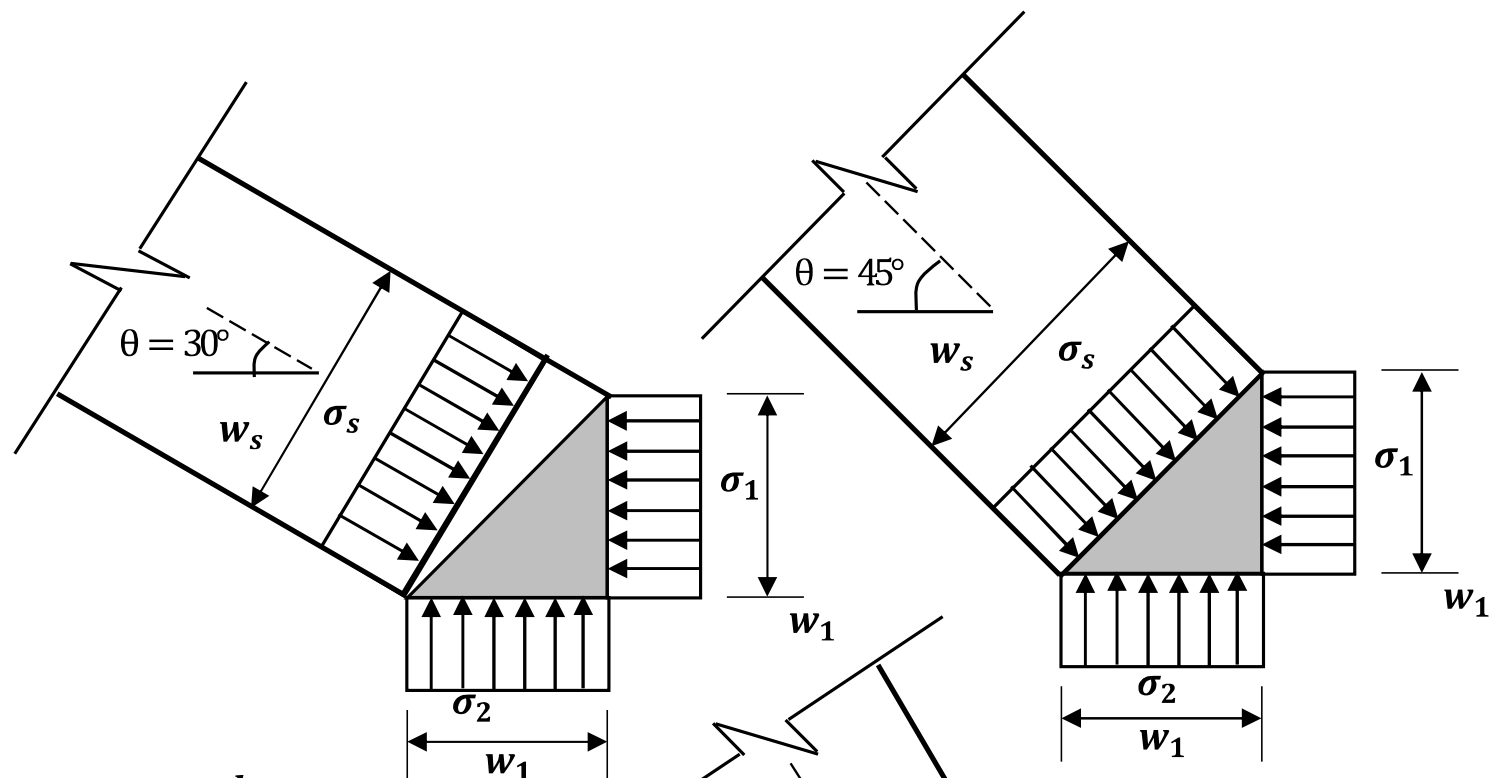

$\sigma_{1}>\sigma_{s} \rightarrow$ shear non-hydrostatic node (a) (b)

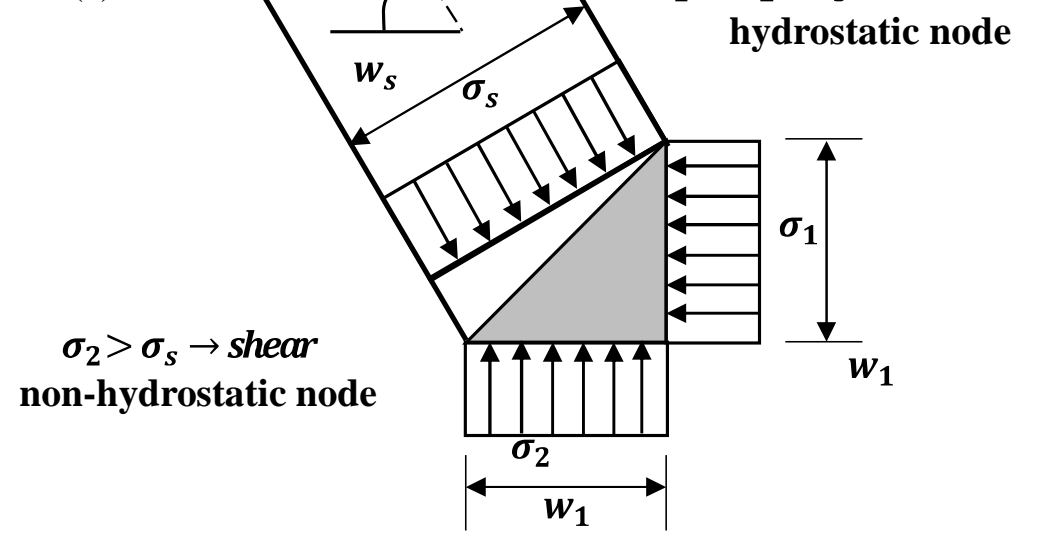

(c)

Figure 2-10: Non-hydrostatic nodes versus hydrostatic node

\subsection{Strut Behavior}

Struts are the compressive elements in strut-and-tie modeling. As mentioned above, ACI 318-14 [3] currently divides struts in two types (prismatic and bottle-shaped) based on the ability for stress to spread perpendicular to the strut axis. Previous research related to the behavior of struts and the validity of this assumption is summarized in this section. 


\subsubsection{Vertically-Oriented Struts}

One way of investigating the behavior of struts is to test vertically-oriented panels of different dimensions in unilateral compression. Brown et al. [5] investigated the performance of "bottle-shaped" struts by testing 26 vertical concrete panels with different variables including: web reinforcement size, location and angle; specimen dimensions; bearing area dimensions; and concrete compressive strength. One of the specimens in the loading setup is shown in Figure 2-11.

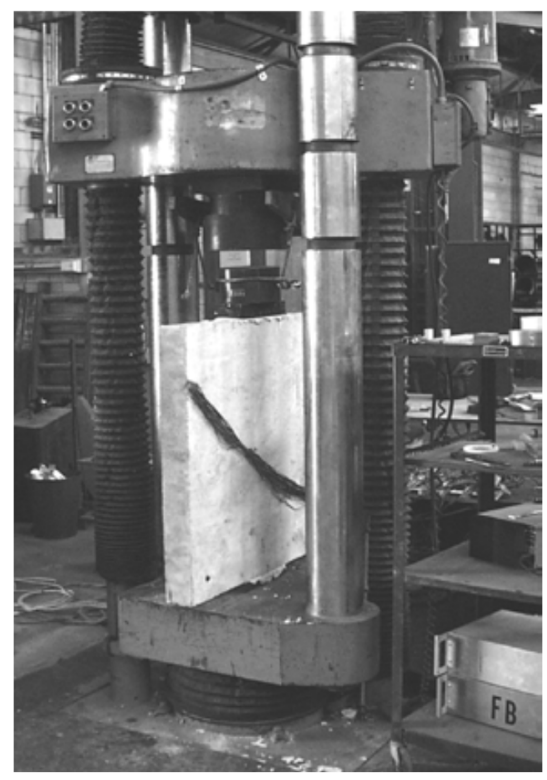

Figure 2-11: Testing of isolated strut specimen and the variables [5]

The same failure mode was observed in all the specimens: crushing of the strut-to-node interface. There were no significant differences between the failure mode or failure load of the most heavily reinforced and unreinforced specimens. Results were compared with estimates from ACI 318-05 [18] and AASHTO LRFD [19] to evaluate the efficiency factor for node and strut strength and reinforcement requirements. Estimates were found to be conservative and erratic using ACI 318-05 [18] and more consistent but less conservative 
using AASHTO LRFD [19]. Brown and Bayrak [20] later concluded that adequate reinforcement must be located within the struts because of the transverse tension that develops in bottle-shaped struts.

Sahoo et al. [21] also investigated vertically-oriented panels through an analytical study. They also presented that the bottle-shaped struts formed when the load was applied to the small area compared to the dimension of the whole specimen. Their research investigated the effect of aspect ratio on the behavior of bottle-shaped struts. One of their specimens with an aspect ratio of 2.0 is shown in Figure 2-12.

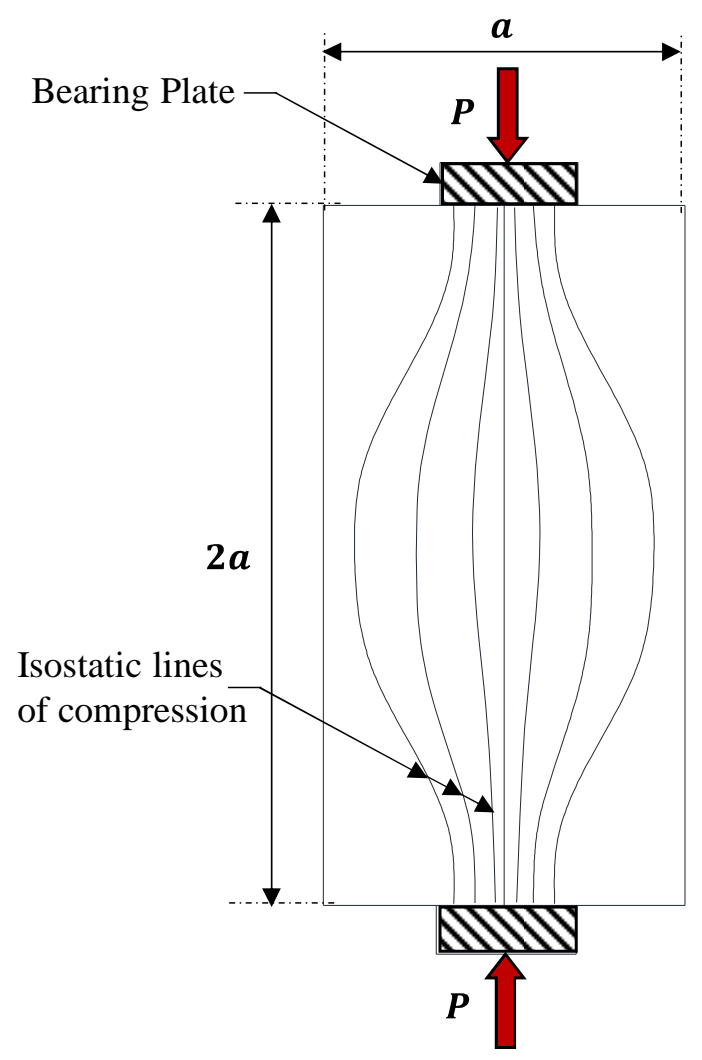

Figure 2-12: Bottle-shaped strut in concrete panels [21]

Ghanei and Aghayari [22] also tested vertically-oriented concrete panels with different dimensions and reinforcement; the failure of three of these panels is shown in Figure 2-13. 
Unreinforced specimens, shown in Figure 2-13 (a), typically failed when an initially formed crack in the middle led to the specimen splitting in half. Specimens with typical amounts of shear reinforcement, shown in Figure 2-13 (b), had both an initial crack down the center of the specimen and secondary cracks developing toward the edges. Failure of these occurred when concrete crushed at the support or load points. Heavily reinforced specimens, shown in Figure 2-13 (c), had minimal cracking during loading and failed due to crushing of concrete at the support or load points.

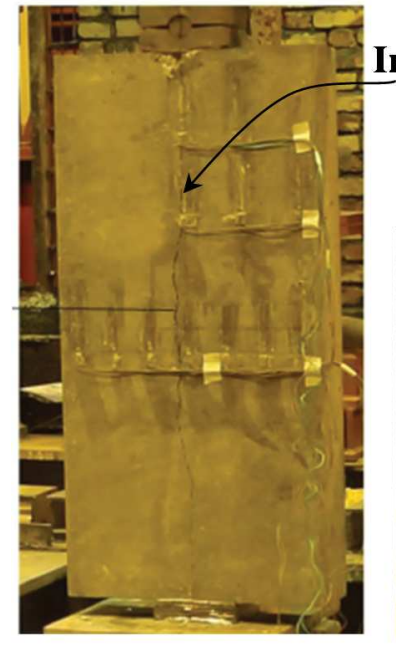

(a)
Initial crack

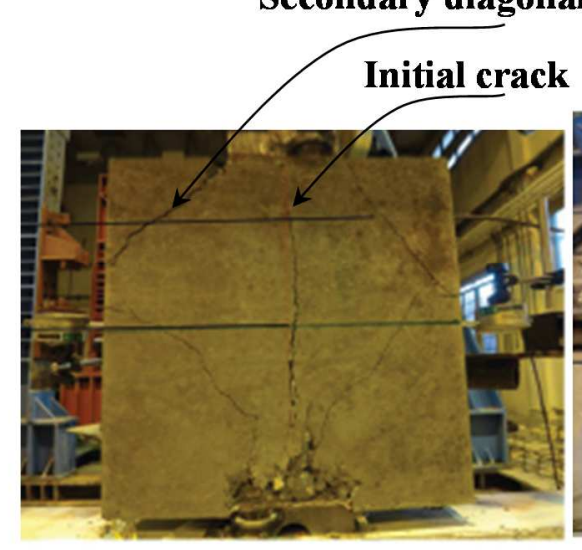

(b)
Failure in nodal zone

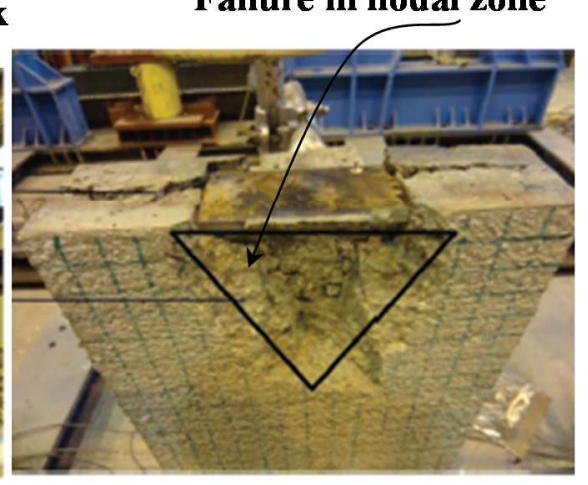

(c)

Figure 2-13: Different failure in bottle-shaped struts: (a) non-reinforced specimens, (b) typical failure, and (c) failure in nodal zone [22]

The authors of these studies all concluded that the stress can spread outward in bottleshaped struts, which will create transverse tensile stress. Because concrete is weaker in tension than compression, the bottle-shaped struts are weaker than prismatic one. This idea was suggested in several other studies [23]-[25].

Several additional research efforts were conducted on vertically-oriented struts with varying widths and exactly the same support and loading conditions [7]-[9], [26]. A 
summary of the specimen geometry for all of these research efforts is provided in Figure 2-14. Note that all specimens were rectangular except those tested by Adebar and Zhou [26], which were circular. Also, the specimen depth was equal to the bearing width $(b)$ in all tests.

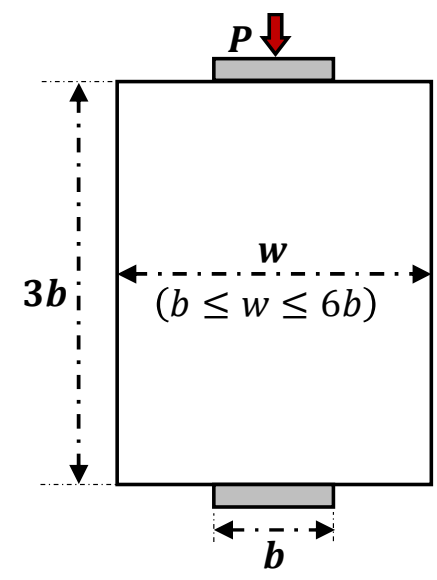

(a)

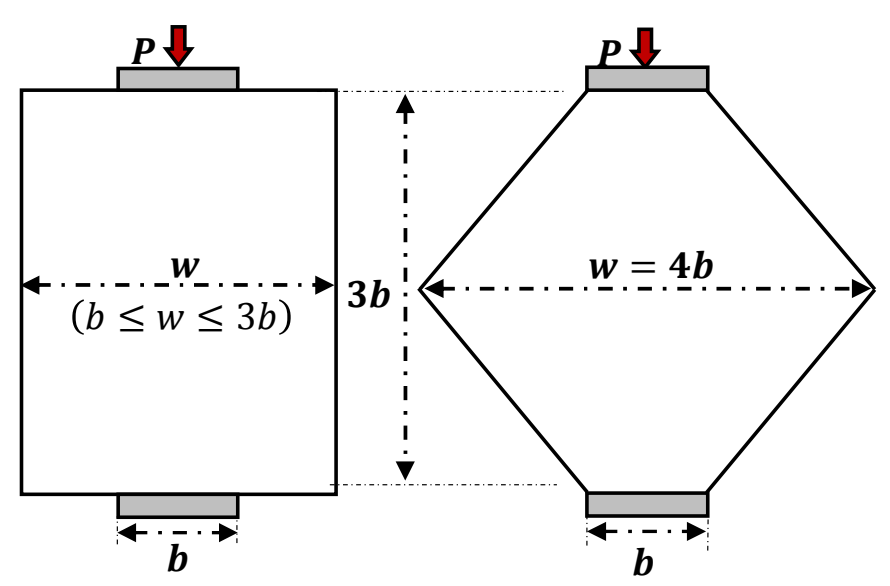

(c)

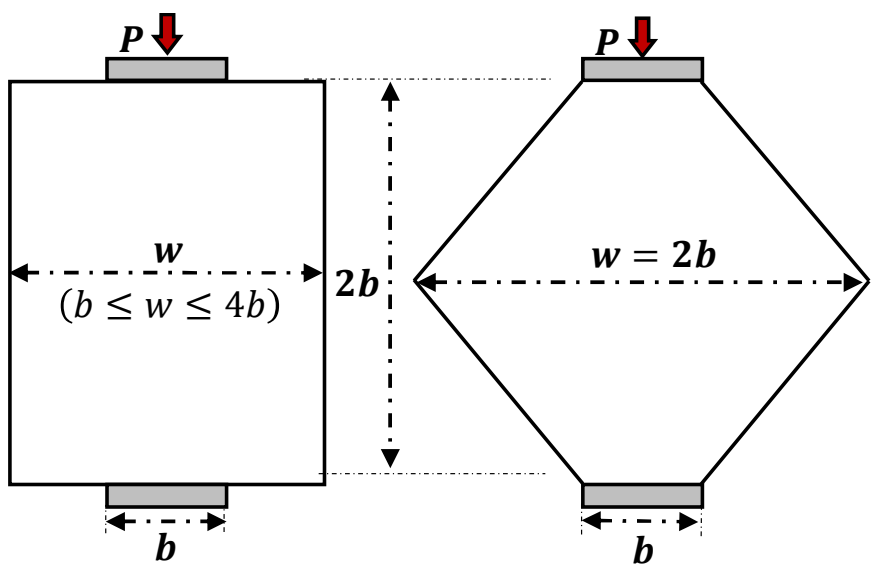

(b)

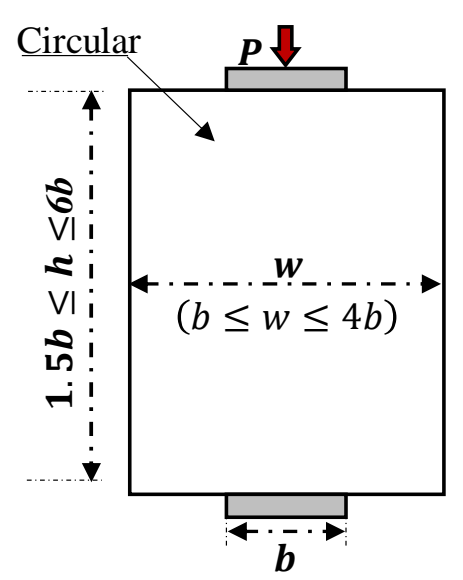

(d)

Figure 2-14: Specimens tested in (a) Sahoo et al. [7] (b) Pujol et al. [8] (c) Laughery and Pujol [9] (d) Adebar and Zhou [26]

Sahoo et al. [7] tested seven unreinforced vertically-oriented struts with varying widths, as shown in Figure 2-14 (a) and found all specimen widths to have about the same strength. Generally, specimens started to crack in the middle of the specimens and then the crack propagated towards the top and bottom plates. 
Pujol et al. [8] tested 42 unreinforced specimens categorized in three series with dimensions shown in Figure 2-14 (b). Series 1 specimens included rectangular specimens with two widths ( $b$ and $2 b$ ) and irregular hexagonal-shaped specimens with one width at mid-height (2b), all specimens had similar strength. Series 2 specimens were all rectangular with widths varying from $b$ to $4 b$. There was not a significant difference in strength between the specimens with widths of $b$ and $2 b$, but there was a slight drop in strength for specimens with widths of $3 b$ and $4 b$. Series 3 was like Series 2 except with a higher water-to-cement ratio. There was no difference in strength between any of the specimen widths ( $b$ to $4 b)$ in this series.

Laughery and Pujol [9] conducted similar testing on 32 additional unreinforced strut specimens, shown in Figure 2-14 (c). They combined their results with results from several previous studies [5], [7], [8], [26], [27], as shown in Figure 2-15. This graph includes results for struts with equal section and bearing depths (called "2-D Dispersion" in Figure 2-15) and struts with section depths greater than the bearing depth (called "3-D Dispersion" in Figure 2-15). Stresses in sections with 2-D dispersion can only spread in one direction transverse to the strut axis. Stresses in sections with 3-D dispersion can spread in two directions transverse to strut axis. There is little difference in strut efficiency for specimens with 2-D dispersion with various aspect ratios. There is a significant difference in strength between specimens with 3-D dispersion and varying aspect ratios, shown in the results of Adebar and Zhou [26]. 


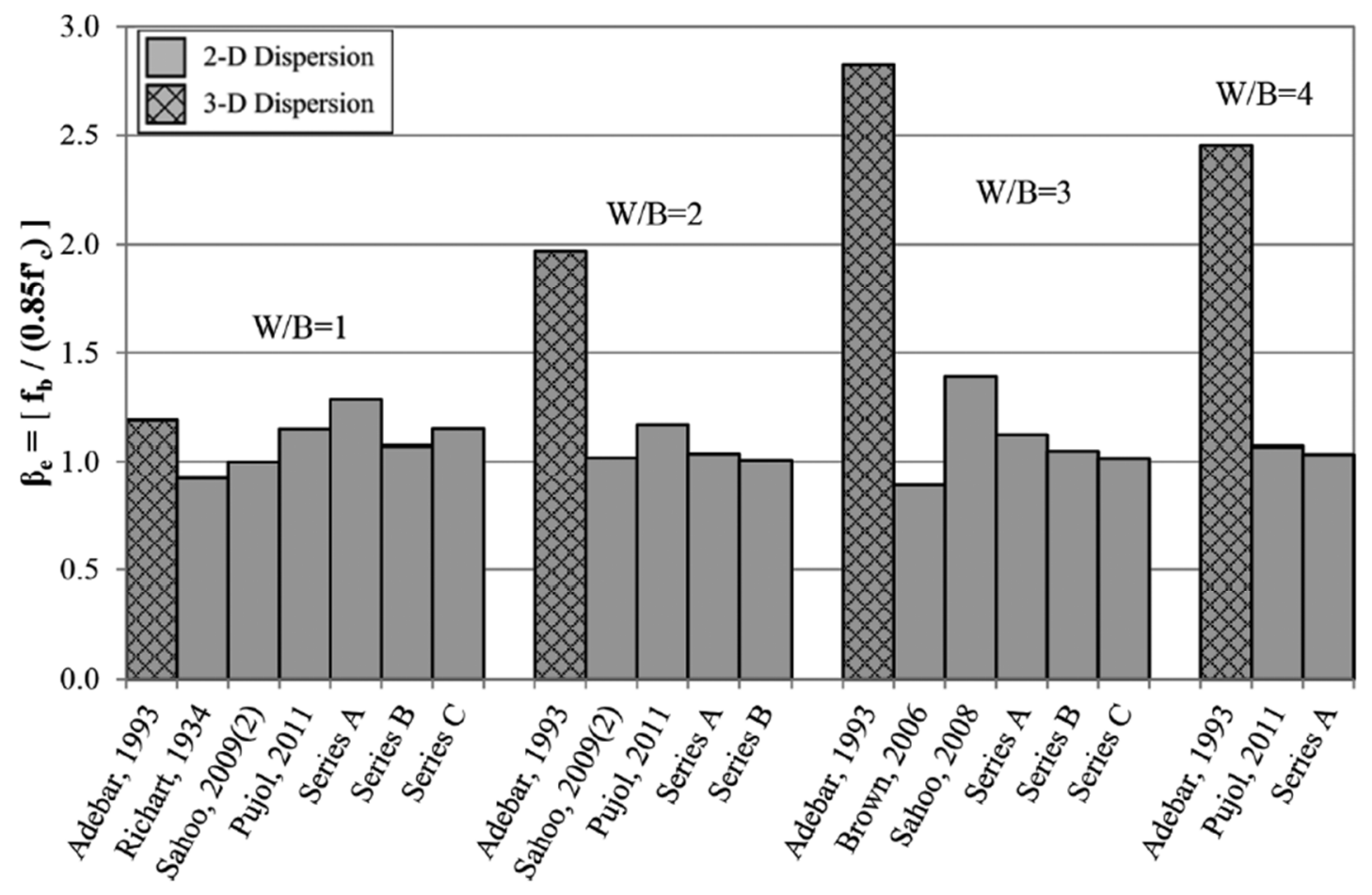

Figure 2-15: Mean experimental efficiency factors across various studies for selected W/B [9]

\subsubsection{Inclined Struts}

While vertically-oriented idealized struts may be the simplest to test, they do not accurately represent the behavior of inclined struts. Sahoo et al. [7] understood the need for testing inclined struts and expanded their vertical-oriented strut testing to include two unreinforced deep beam specimens. The width, height, and depth of the specimens were 39.37 inches $(1000 \mathrm{~mm}), 17.71$ inches $(450 \mathrm{~mm})$, and 3.94 inches $(10 \mathrm{~mm})$, respectively. The details of these specimens are shown in Figure 2-16. 


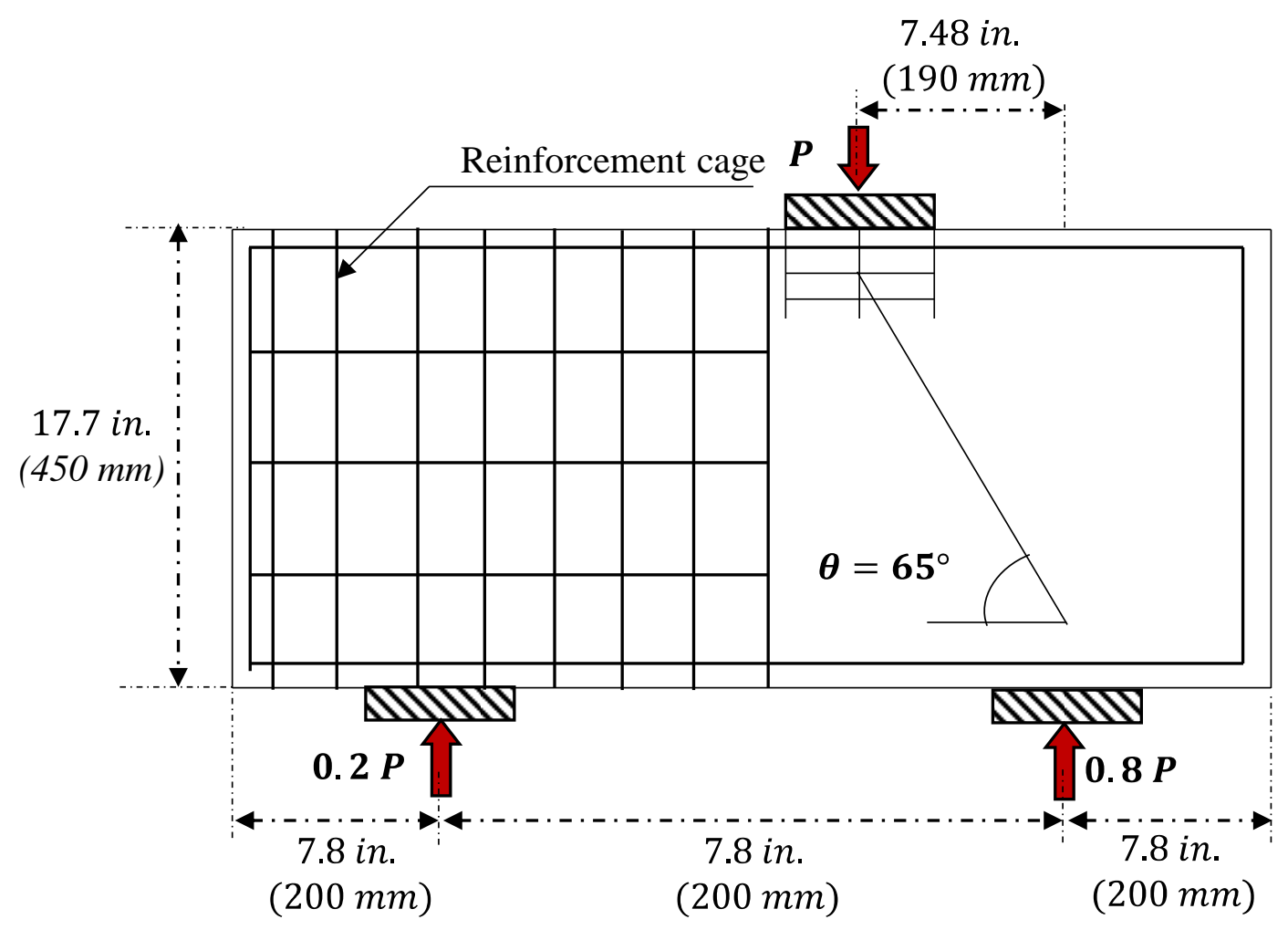

Figure 2-16: the detail of tested deep beams in Sahoo et al. [7]

The compressive strength of concrete, failure load, and the calculated efficiency factor for

Sahoo et al. [7] tests are presented in Table 2-1. Sahoo et al. [7] found strut efficiency factors similar to those found through their vertically-oriented strut tests.

Table 2-1: test results of deep beams in Sahoo et al. [7]

\begin{tabular}{|c|c|c|c|}
\hline Specimen ID & $\begin{array}{c}\text { Cylinder Compressive } \\
\text { strength, ksi (MPa) }\end{array}$ & $\begin{array}{c}\text { Peak Load, kips } \\
(\mathbf{k N})\end{array}$ & $\begin{array}{c}\text { Experimental Strut } \\
\text { Efficiency Factor }\end{array}$ \\
\hline BN-0-0 & $36.6(5.74)$ & $429.2(96.5)$ & 1.07 \\
\hline BN-0-0 (R) & $45.2(6.55)$ & $464.3(104.4)$ & 1.01 \\
\hline
\end{tabular}

Van den Hoogen [28] was the first to look into the behavior of deep beams where stresses were not able to spread in the strut between load and support. Van den Hoogen [28] 
referenced unpublished experimental results by Beeby [29] that compared the capacity of a beam with a cut-out of the concrete with a solid beam with no cut-out and the same dimensions, shown in Figure 2-17.

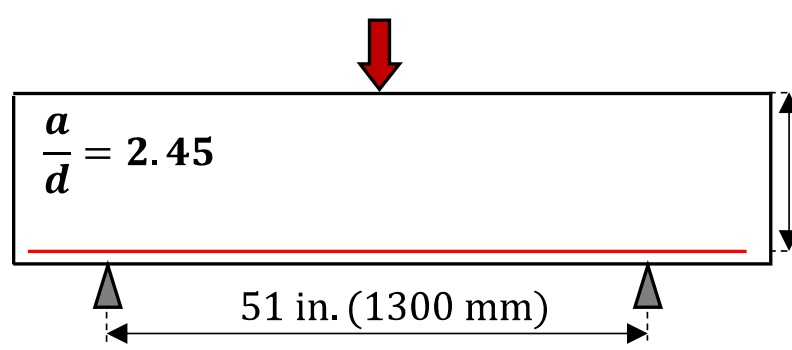

(a)

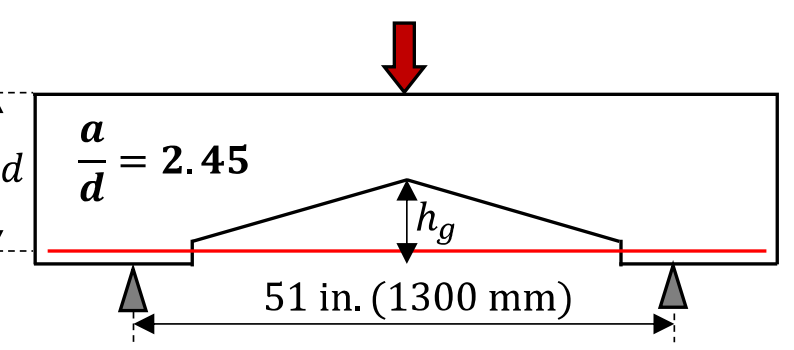

(b)

Figure 2-17: Beam and truss model tested by Beeby [29]

Beeby [29] found the beam with a cut-out to be 1.5 times stronger than the beam (i.e. less material resulted in a stronger structure). Van den Hoogen [28] created numerical models verified by the experimental results developed by Beeby [29]. From the analysis results, Van den Hoogen [28] concluded that the tension stresses developed by the bending of the beam without a cut-out decreased the shear strength of the beam. This diagonal tension (the tension caused by bending) disrupted the compression strut forming from the load to the support. They also determined that the gap height $\left(h_{g}\right)$ did not have a noticeable effect on the failure load or the failure mechanism. Note that the testing by Beeby [29] was done on beams in the transition between deep beam $(\mathrm{a} / \mathrm{d} \leq 2.0)$ and sectional shear behavior $(\mathrm{a} / \mathrm{d} \geq$ 2.5), so these observations should be confirmed for deep beams.

\subsubsection{Angle of Strut Inclination}

The behavior of struts is also impacted by the angle of strut inclination. ACI 318-14 [3] restricts that strut angles be between 25 and 65 degrees in a strut-and-tie model, which is 
based on several researches [30]-[32]. This limitation is based on the idea that the struts loss their capacity when their axis approaches a ties axis [33]. Sahoo et al. [34] conducted an analytical investigation investigating strut angle and its effect on strut behavior, which can be measured by a strut efficiency factor $\left(\beta_{s}\right)$. Results from Sahoo et al. [34] are summarized in Figure 2-18. The researchers concluded that current ACI 318-14 [3] strut efficiency factors can be unconservative for struts with angles less than 54 degrees.

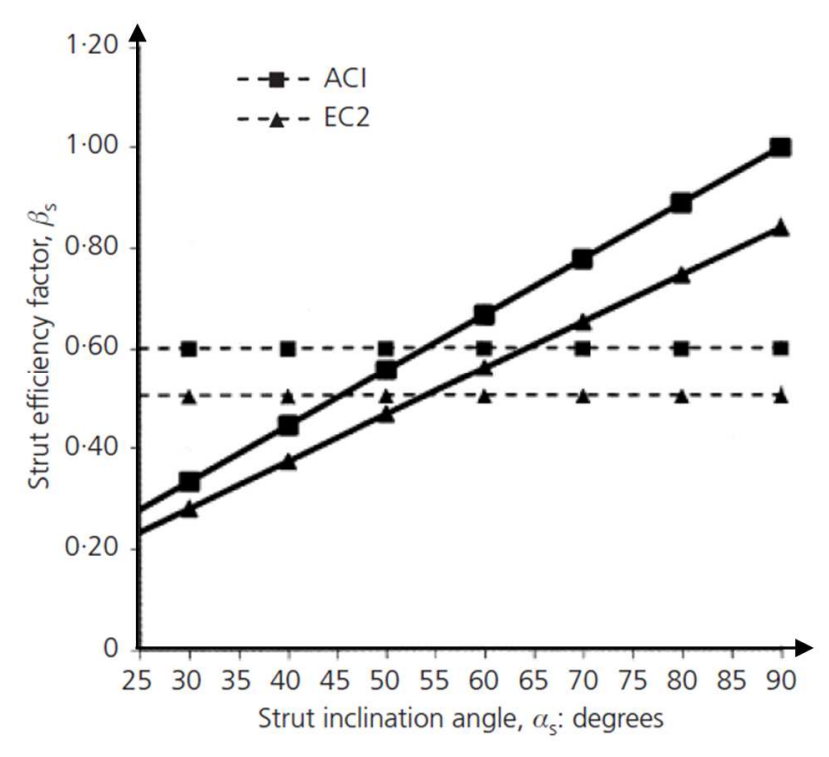

Figure 2-18: Comparison of the code provisions with the proposed efficiency factor models for normal-weight concrete of $5.8 \mathrm{ksi}(40 \mathrm{MPa})$ [34]

Contrary results were found by Su and Looi [35]. Su and Looi [35] experimentally tested nine asymmetrical specimens with varying strut angles (i.e. varying a/d ratios). They concluded from their results that a constant strut efficiency factor should be used.

\subsection{Tie Behavior}

Tension elements in a strut-and-tie model (ties) must be designed with reinforcement to hold tensile forces in the ties. Reinforcement is provided based on the location of ties in 
the model, and the location of ties in the model are located at the centroid of the tie reinforcement, as shown in Figure 2-19. This interdependence can make designing tie reinforcement an iterative process if the location of ties needs to be changed as reinforcement is detailed.

The sufficiency of the tie strength is not only dependent on enough reinforcing area being provided, but also requires that the reinforcement is properly developed by the time it leaves the extended nodal zone. The critical section for development of the tie is highlighted in Figure 2-19.

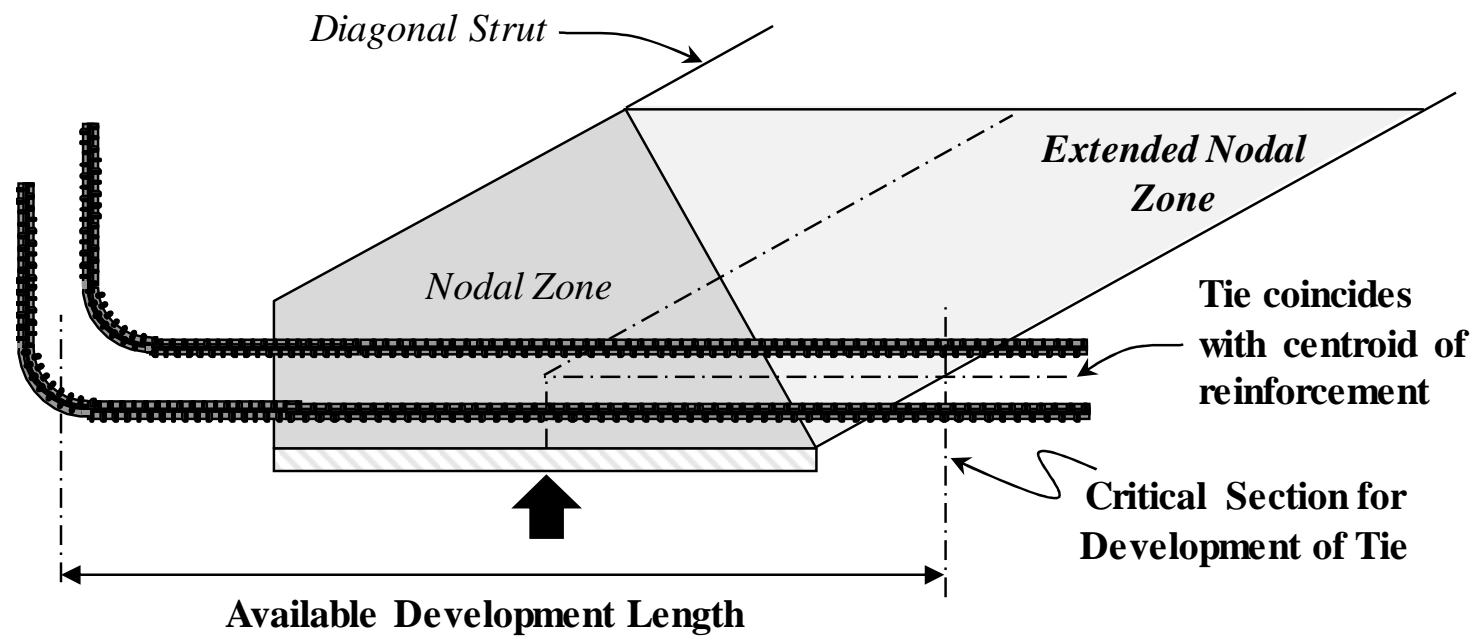

Figure 2-19: Development length of a tie [4]

Different types of development such as straight bars, hooked bars, headed bars, or bars welded to the external plates can be used to properly develop tie reinforcement. The development length formulas for different types of development from ACI 318-14 [3] are shown in Equation 2-1 to Equation 2-3. Reinforcement welded to steel plates is assumed to develop fully at the location of the steel plate. The specified required development length found using the below equations must be less than the total available development length 
found from reinforcement detailing, bearing dimensions, and strut geometry, shown in Figure 2-19.

Straight Bars (Detailed Method): $\quad l_{d}=\left(\frac{3}{40} \frac{f_{y}}{\lambda \sqrt{f_{c}^{\prime}}} \frac{\psi_{t} \psi_{e} \psi_{s}}{\left(\frac{c_{b}+K_{t r}}{d_{b}}\right)}\right) d_{b}$

Equation 2-1

$l_{d}$

Equation 2-2

Hooked Bars:

$$
\begin{aligned}
& =\max \left\{\left(\frac{f_{y} \psi_{e} \psi_{c} \psi_{r}}{50 \lambda \sqrt{f_{c}^{\prime}}}\right) d_{b}, 8 d_{b}, 6 i n .\right\} \\
& l_{d}
\end{aligned}
$$

Equation 2-3

Headed Bars $\left(f_{c}^{\prime} \leq 6000\right.$ psi $): \quad=\max \left\{\left(\frac{0.016 f_{y} \psi_{e}}{\sqrt{f_{c}^{\prime}}}\right) d_{b}, 8 d_{b}, 6\right.$ in. $\}$

ACI 318-14

Where:

$$
\begin{aligned}
& K_{t r} \quad=\quad \min \left\{2.5, \frac{40 A_{t r}}{S n}\right\} \\
& \text { transverse reinforcement index, in. } \\
& \text { total cross-sectional area of all transverse reinforcement within spacing } s \\
& A_{t r}=\text { that crosses the potential plane of splitting through the reinforcement } \\
& \text { being developed, in. }{ }^{2} \\
& \begin{aligned}
S=\quad \begin{array}{l}
\text { center-to-center spacing of items, such as longitudinal reinforcement, } \\
\text { transverse reinforcement,tendons, or anchors, in. }
\end{array}
\end{aligned} \\
& \begin{array}{l}
n=\quad \begin{array}{l}
\text { number of items, such as, bars, wires, monostrand } \\
\text { anchorage devices, anchors, or shearhead arms }
\end{array}
\end{array} \\
& f_{y} \quad=\quad \text { specified yield strength for nonprestressed reinforcement,psi } \\
& f_{c}^{\prime} \quad=\quad \text { specified compressive strength of concrete, psi } \\
& d_{b} \quad=\quad \text { nominal diameter of bar, wire, or prestressing strand, in. }
\end{aligned}
$$


lesser of: (a) the distance from center of a bar or wire to nearest concrete

$c_{b}=\quad$ surface, and (b) one-half the center-to-center spacing of bars or wires being developed, in.

modification factor to reflect the reduced mechanical properties of

$\lambda=$ lightweight concrete relative to normalweight concrete of the same compressive strength

$\psi_{c}=$ factor used to modify development length based on cover

$\psi_{e}=\begin{aligned} & \text { factor used to modify development length based on reinforcement } \\ & \text { coating }\end{aligned}$

$\psi_{r} \quad=\quad$ factor used to modify development length based on confining reinforcement

$\psi_{s}=\quad$ factor used to modify development length based on reinforcement size

$\psi_{t}=\quad=\quad$ factor used to modify development length for casting location in tension

\subsection{Node Behavior}

As previously introduced, there are three different types of nodes (CCC, CCT, and CTT) dependent on the types of elements framing into the node (compression or tension). The nodal zone under the load in Figure 2-8 is a CCC node and is further broken down in Figure 2-20. In this picture, the load is applied in the center of the load node, and both the left side and the right side are symmetrical. The total load applied $(P)$ is equal to the sum of the force applied on each of the nodal zones $\left(C_{b 1}\right.$ and $\left.C_{b 2}\right)$. Additionally, the force on the back face of each of the nodes is equal ( $C_{k 1}$ equals $\left.C_{k 2}\right)$ to satisfy equilibrium of the node. If the load is not located at the center of a member, the bearing face of each of the nodes ( 1 and 2) will be proportional to the amount of force going in each direction. The back-face forces will always be equal, although the magnitude will change. 


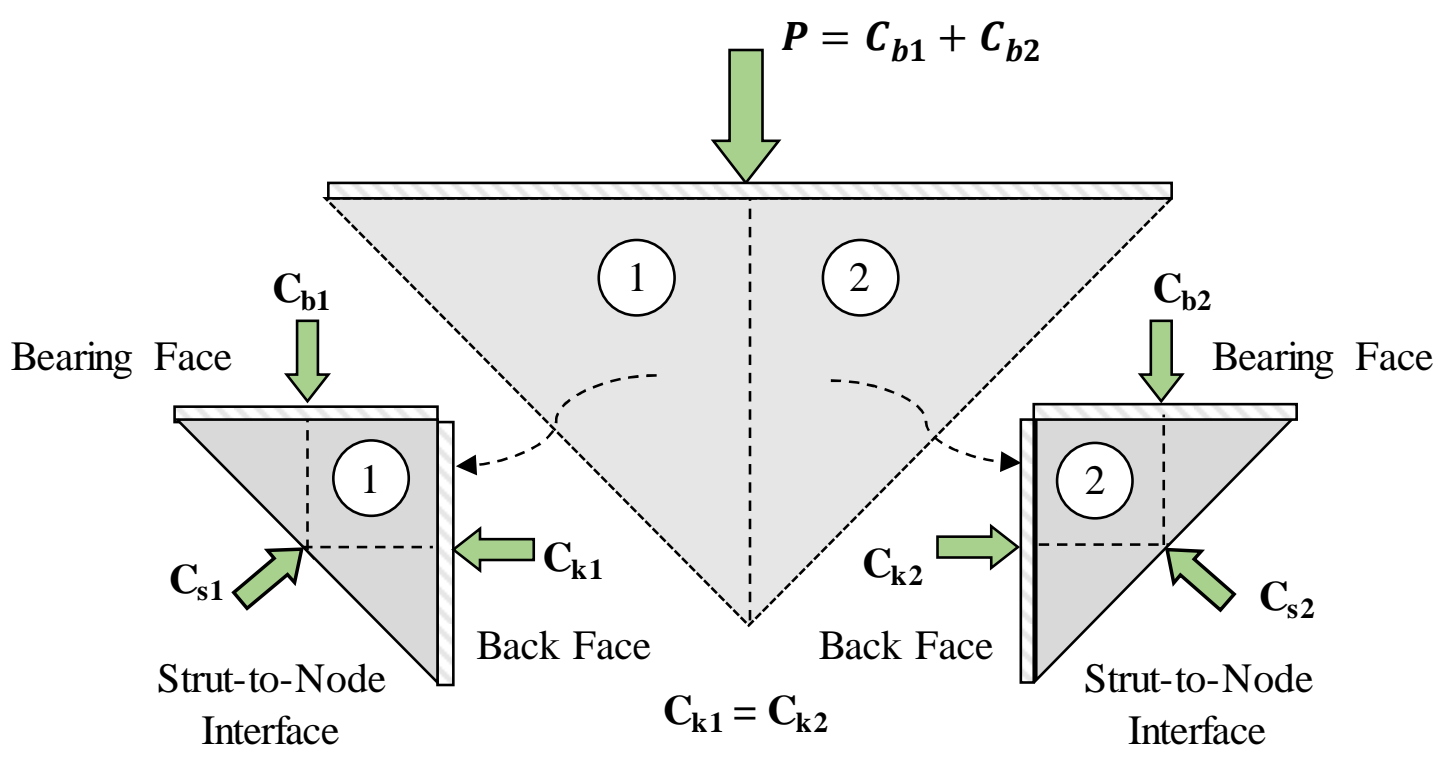

Figure 2-20: Geometry of CCC node

The dimensions of the bearing face $\left(l_{b 1}\right)$, back face $\left(h_{k}\right)$, and strut-to-node interface $\left(w_{s}\right)$ must be determined to find the strength of the node; these dimensions are shown in Figure 2-21. The bearing face length is dependent on the total bearing length $\left(l_{b}\right)$ and proportional to the amount of force entering the node $\left(C_{b 1}\right)$ compared to the total applied load $(P)$. For this example, half the total load is applied to Node $1\left(C_{b l}=0.5 P\right)$, so the bearing length is half of the total bearing length $\left(l_{b l}=0.5 l_{b}\right)$. The height of the back face $\left(h_{k}\right)$ can be found by finding the depth of the rectangular stress block from a typical nominal flexural moment analysis, as shown in Equation 2-4. The strut-to-node interface length $\left(w_{s}\right)$ depends on the height of the back face, length of the bearing, and the angle of the incoming strut $(\theta)$, as shown in Equation 2-5.

$$
h_{k}=\frac{A_{s} f_{y}-A_{s}^{\prime} f_{y}^{\prime}}{0.85 b_{w} f_{c}^{\prime}}
$$

Equation 2-4 


$$
w_{s}=l_{b} \sin \theta+h_{k} \cos \theta
$$

Where:

$$
\begin{array}{lll}
A_{s} & = & \text { area of longitudinal tension steel }\left(\mathrm{in}^{2}\right) \\
f_{y} & = & \text { yield strength longitudinal tension steel }(\mathrm{psi}) \\
A_{s}^{\prime} & = & \text { area of longitudinal compression steel }\left(\mathrm{in}^{2}\right) \\
f_{y}^{\prime} & = & \text { yield strength longitudinal compression steel (psi) } \\
b_{w} & = & \text { web width (in.) } \\
f_{c}^{\prime} & = & \text { specified compressive strength of concrete }(\mathrm{psi}) \\
\theta & = & \text { angle of incoming strut }
\end{array}
$$

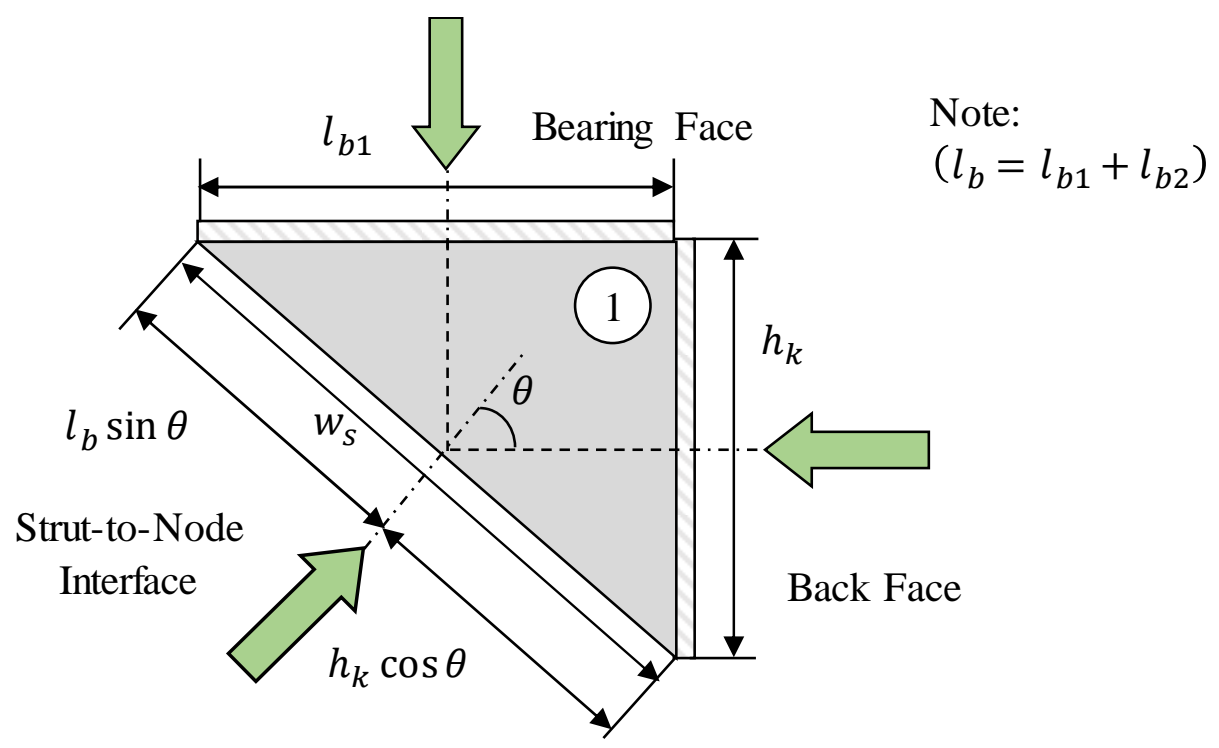

Figure 2-21: Details of CCC node (Node 1 from above)

Typical dimensions for a CCT node with relevant details are shown in Figure 2-22 with the length of the bearing plate $\left(l_{b}\right)$, the height of the back face $\left(w_{t}\right)$, and the length of the strut-to-node interface $\left(w_{s}\right)$ highlighted. The height of the back face $\left(w_{t}\right)$ is calculated as 
twice the distance from the bottom of the beam to the centroid of the ties. The length of the strut-to-node surface in CCT node is calculated in Equation 2-6.

$$
w_{s}=l_{b} \sin \theta+w_{t} \cos \theta
$$

For additional details on calculating the dimension of different types of nodes refer to Birrcher et al. [4], Williams et al. [36], and Larson et al. [37].

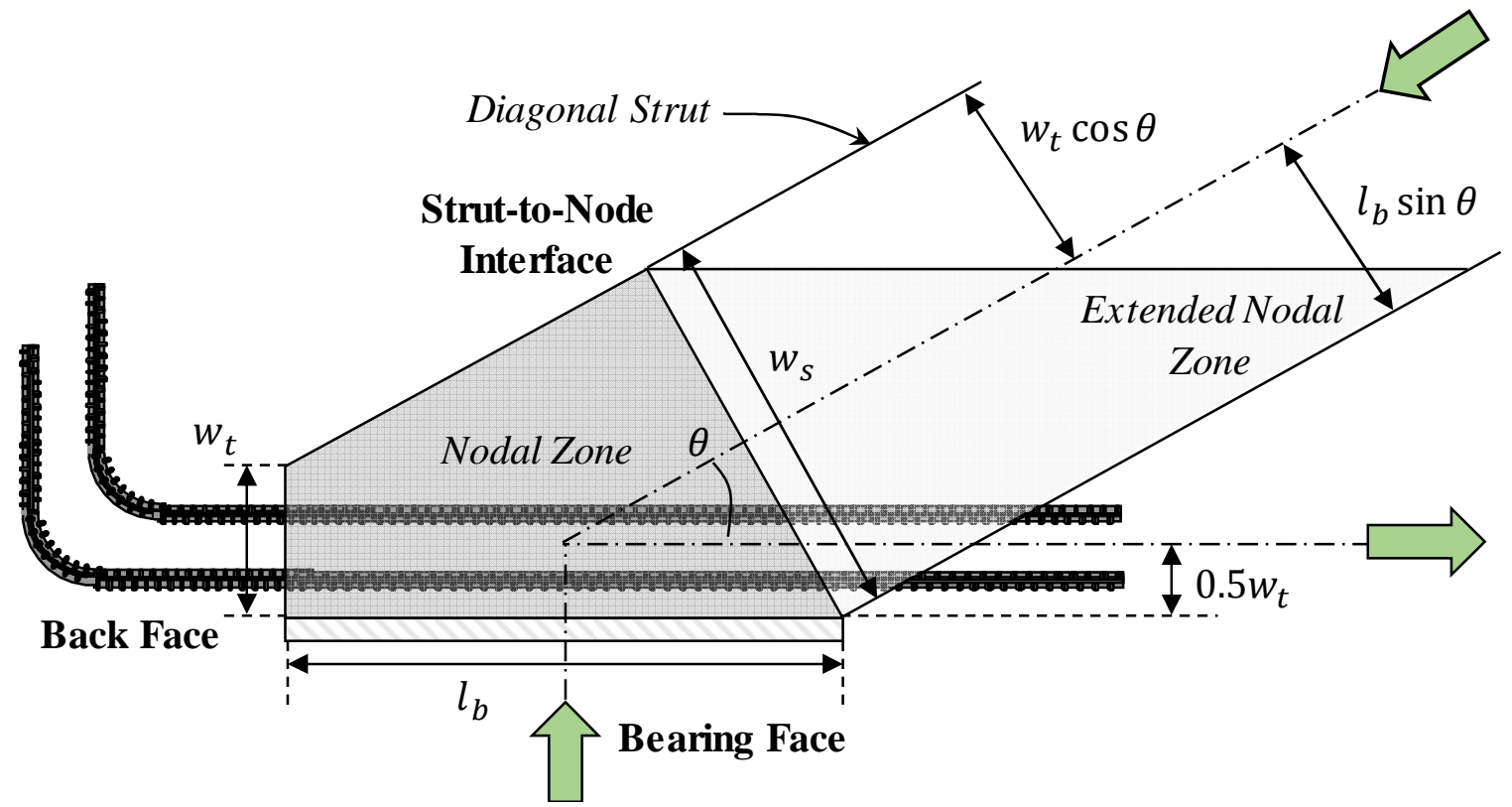

Figure 2-22: Geometry of CCT node

A final distinction made when discussing nodal zones is based on whether the node has measurable dimensions. Nodes that are located adjacent to a support or load point have a defined geometry based on the bearing dimensions and bordering elements. Most of the other nodes in a strut-and-tie model do not have a definite geometry. Nodes without a defined geometry are called smeared nodes and typically do not need to be checked. For further details on smeared nodes refer to Wight and Parra-Montesinos [38], and Birrcher et al. [4]. 


\subsection{STM Design Provisions}

The two STM design provisions that are primarily used in practice in the US are found in ACI 318-14 [3], and the AASHTO LRFD Bridge Design Specification [19]. An overview of these two design provisions is given in this section.

\subsubsection{ACI 318-14 Building Code [3]}

The ACI 318-14 Building Code [3] has separate design checks for the strength of struts, ties, and nodes. The reduced design strength ( $\phi F_{n s}$ for struts and $\phi F_{n n}$ for nodes) must be greater than the factored element force ( $F_{u s}$ for struts and $F_{u n}$ for nodes) for both struts and nodes, as shown in Equation 2-7 and Equation 2-8.

$$
\begin{array}{ll}
\phi F_{n s} \geq F_{u s} & \text { Equation 2-7 } \\
\phi F_{n n} \geq F_{u n} & \text { Equation 2-8 }
\end{array}
$$

The strength of the struts and nodes is dependent on the area of concrete at the interface between the struts and nodes ( $A_{c s}$ for struts and $A_{n z}$ for nodes) and the effective concrete strength of the elements $\left(f_{c e}\right)$. Relationships for these design strengths are shown in Equation 2-9 through Equation 2-12.

$$
\begin{array}{cc}
F_{n s}=f_{c e} A_{c s} & \text { Equation 2-9 } \\
f_{c e}=0.85 \beta_{s} f^{\prime}{ }_{c} & \text { Eqn. (23.4.1a) } \\
F_{n n}=f_{c e} A_{n z} & \text { Equation 2-10 } \\
& \text { Eqn. (23.4.3) } \\
f_{c e}=0.85 \beta_{n} f^{\prime}{ }_{c} & \text { Equation 2-11 } \\
& \text { Eqn. (23.9.1) } \\
\text { Equation 2-12 } \\
\end{array}
$$

The effective concrete strength $\left(f_{c e}\right)$ for struts and nodes is dependent on the strut coefficient 
$\left(\beta_{\mathrm{s}}\right)$ and node coefficient $\left(\beta_{\mathrm{n}}\right)$, respectively, and the concrete compressive strength $\left(f^{\prime}\right)$. The strut coefficient $\left(\beta_{\mathrm{s}}\right)$ depends on the geometry and location of a strut and are summarized in Table 2-2. The minimum of the strut and node coefficients should be used when designing the strut-to-node interface. Relevant to the members investigated in this research, struts with uniform cross-sectional areas along their length have a strut coefficient of 1.0, and struts located in regions where stresses can spread along the strut length without the minimum strut reinforcement have a strut coefficient of $0.6 \lambda$. The truss-like specimens have a uniform area along the length, so the strut coefficient is equal to 1.0. The rectangular specimens allow stress to spread along the strut length, so the strut coefficient is 0.6 (with $\lambda$ equal to 1.0 for normal-weight concrete).

The node coefficient $\left(\beta_{\mathrm{n}}\right)$ depends on the number of ties that are anchored into the node. Relevant to the members investigated in this research, the node coefficient is equal to 1.0 for nodes with no ties and 0.8 for nodal zones anchoring one tie. Members with external unbonded reinforcement have no ties anchoring in the nodal zones, so the node coefficient was taken as 1.0. Members with internal bonded reinforcement have one tie anchoring in the nodal zone, so the node coefficient was taken as 0.8 .

These were some of the factors that were the focus of this testing program. There are several other resources with a more comprehensive explanation of the ACI 318-14 STM procedures [16], [17]. 
Table 2-2: Strut and node coefficients

\begin{tabular}{|c|c|c||c|c|c|}
\hline \multicolumn{3}{|c||}{ Strut $\left(\boldsymbol{\beta}_{\boldsymbol{s}}\right)$} & \multicolumn{3}{c|}{ Node $\left(\boldsymbol{\beta}_{\boldsymbol{n}}\right)$} \\
\hline Prismatic & \multicolumn{2}{|c|}{ Bottle-shaped } & CCC & $\boldsymbol{C C T}$ & $\boldsymbol{C T T}$ \\
\hline \multirow{2}{*}{1.0} & $\begin{array}{c}\text { with min. } \\
\text { reinforcement }\end{array}$ & $\begin{array}{c}\text { Without min. } \\
\text { reinforcement }\end{array}$ & \multirow{2}{*}{1.0} & 0.8 & 0.6 \\
\cline { 2 - 3 } & 0.75 & $0.6 \lambda$ & & \\
\hline
\end{tabular}

A complete example to determine the strength of one of the experimental specimens using ACI 318-14 is provided in Appendix B.

\subsubsection{AASHTO LRFD Bridge Design Specification [19]}

Like ACI 318-14 [3], AASHTO LRFD [19] also requires that the reduced design strength $\left(\phi P_{n}\right)$ be greater than the factored element force $\left(P_{r}\right)$ for struts, ties, and nodes, as shown in Equation 2-13.

$$
\begin{array}{ll}
\phi P_{n} \geq P_{r} & \text { Equation 2-13 } \\
& \text { Eqn. (5.8.2.3-1) }
\end{array}
$$

For struts and nodes, AASHTO LRFD 2016 requires only a check of the nominal resistance of the node faces, as shown in Equation 2-14, which is dependent on the limiting compressive stress of the node face $\left(f_{c u}\right)$ and the effective cross-sectional area of the node face $\left(A_{c n}\right)$.

$$
\begin{array}{ll}
P_{n}=f_{c u} A_{c n} & \text { Equation 2-14 } \\
\text { Eqn. (5.8.2.5.1-1) }
\end{array}
$$

The limiting compressive stress of the node face $\left(f_{c u}\right)$ depends on the type of node (CCC, $\mathrm{CCT}$, or CTT), the face where the nominal resistance is being found (bearing face, back face, or strut-to-node interface), the compressive strength of the concrete $\left(f^{\prime} c\right)$, and any confinement effects from surrounding concrete (accounted for through $m$ ), as shown in Equation 2-15. 


$$
f_{c u}=m v f^{\prime}{ }_{c}
$$

Equation 2-15

Eqn. (5.8.2.5.3a-1)

Note that unlike ACI 318-14, AASHTO LRFD [19] does not account for the effect of stresses being able to spread along the length of struts or not being able to in members with constant cross-sectional areas along the length of struts.

Benefits from confinement are accounted for when the bearing area $\left(A_{1}\right)$ is smaller than the notional area $\left(A_{2}\right.$, defined in AASHTO) and uniform loading is applied by using Equation 2-16.

$$
m=\sqrt{\frac{A_{2}}{A_{1}}} \leq 2.0
$$

Note that no confinement benefits will be achieved when the loading plate has the same width as the specimens ( $m$ equals 1.0 ).

The concrete efficiency factor (v) depends on the type of node (CCC, CCT, or CTT), the face where the nominal resistance is being found (bearing face, back face, or strut-to-node interface), the presence of minimum strut reinforcement, and the compressive strength of the concrete $\left(f^{\prime}{ }_{c}\right)$. For beams with minimum crack control reinforcement, the concrete efficiency factors $(v)$ are summarized in Table 2-3. 
Table 2-3: Concrete efficiency factor (v), if minimum crack-control reinforcement is provided

\begin{tabular}{|c|c|c|c|}
\hline \multirow{2}{*}{$\begin{array}{c}\text { Node } \\
\text { Type }\end{array}$} & $\begin{array}{c}\text { Bearing } \\
\text { Face }\end{array}$ & $\begin{array}{c}\text { Back } \\
\text { Face }\end{array}$ & Strut-to-Node Interface \\
\cline { 2 - 5 } & 0.85 & 0.85 & $0.45 \leq 0.85-\frac{f_{c}^{\prime}}{20 k s i}$ \\
\hline CCC & 0.7 & 0.7 & $0.45 \leq 0.85-\frac{f_{c}^{\prime}}{20 k s i}$ \\
\hline$C C T$ & \multicolumn{3}{|c|}{$0.45 \leq 0.85-\frac{f_{c}^{\prime}}{20 k s i} \leq 0.65$} \\
\hline$C T T$ & \multicolumn{3}{|c|}{0.65} \\
\hline
\end{tabular}

For beams without minimum crack control reinforcement, the concrete efficiency factor (v) is equal to 0.45 .

A complete example to determine the strength of one of the experimental specimens using the AASHTO LRFD Bridge Design Specification is provided in Appendix B.

\subsection{Summary}

Fundamental concepts and background information about STM were presented in this chapter. STM is a design procedure applicable to any section in any member but required in D-regions. It is a lower-bound plasticity theorem, so as long as equilibrium is satisfied and a beam is detailed so forces can redistribute, using STM will produce a safe design. A strut-and-tie model modeling the stress flow through a member using a hypothetical truss or kinematic model. The tension elements in the truss are ties, compression members are struts, and points of intersection are nodes. Design using STM requires ensuring sufficient capacity for struts and nodes and providing adequate steel reinforcement to resist tie forces. 
Current ACI 318 terminology defines two different types of struts (bottle-shaped struts and prismatic struts) and has different strength coefficients for each. Previous research has brought into question whether bottle-shaped and prismatic are adequate descriptions of strut type and whether there is a difference in strength between them. The objective of this research was to further investigate the behavior of these struts when inclined. 


\section{Chapter 3: Loading Test Setup}

\subsection{Overview}

Concrete without shear reinforcement is impacted by size (size effect), so specimens need to be sufficiently large to represent the true behavior of members found in actual structures. A high-capacity (800-kip) test frame was required to test the specimens in the experimental program. The design, construction, and capabilities of the test frame are given in this section.

\subsection{Loading Setup Details}

The load setup was designed to have an 800-kip capacity and tie into the already existing strong floor in the Titan America Structures Laboratory at FIU. The strong floor in the structures lab has groups of four threaded rod tie downs spaced at three feet center to center in the East-West direction and six feet center to center in the North-South direction. Each of the tie-down groups has a 100-kip capacity (25 kips in each of the four threaded rods), so eight of these tie down groups needed to be engaged to achieve an 800-kip capacity. The eight tie-down points selected for the design of the load frame are shown in Figure 3-1. One set of tie-down groups was not engaged in the center of the East-West direction to allow room for the test specimens. 


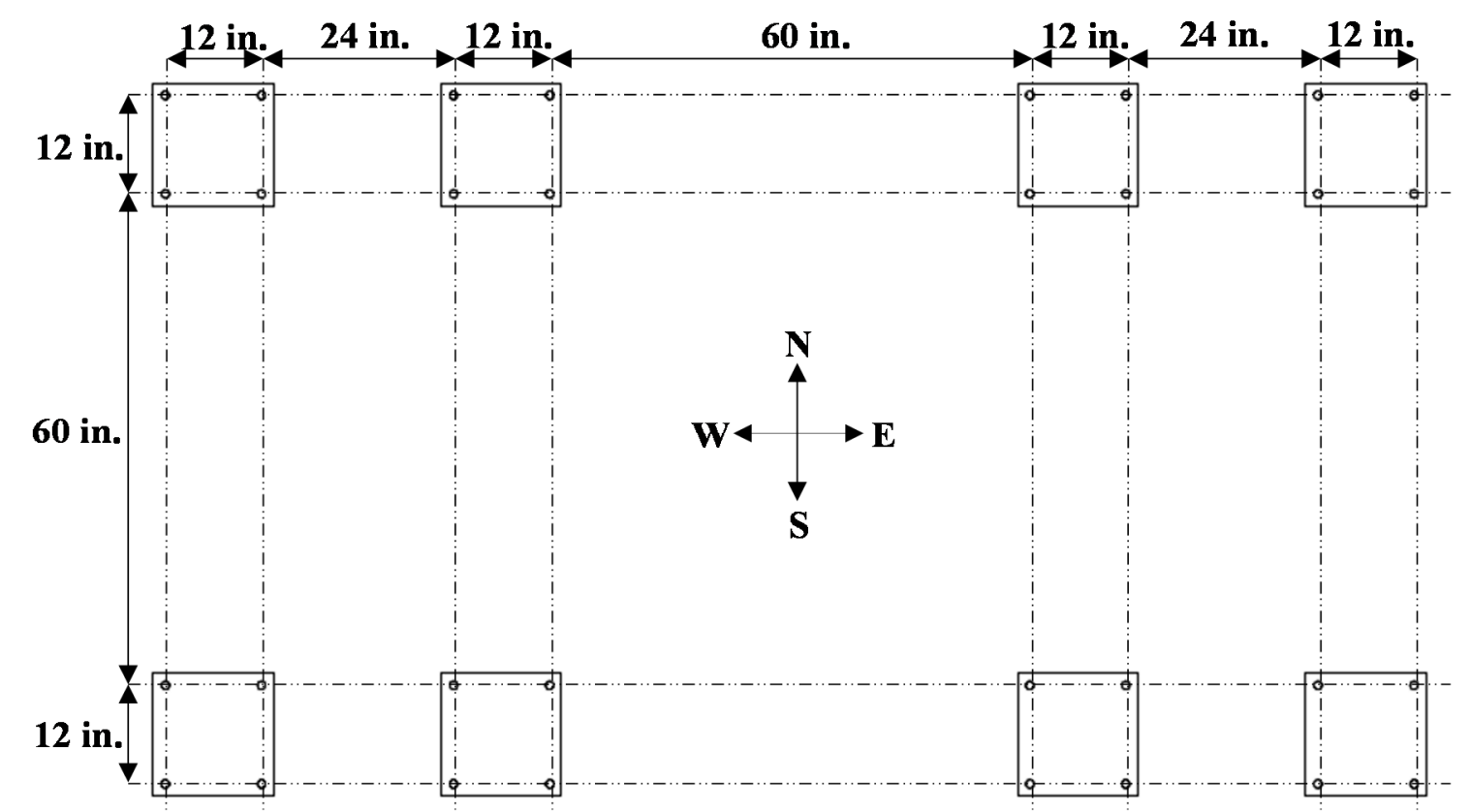

Figure 3-1: Available tie-downs in the Structures Laboratory

The load frame was then designed based on the available tie-down groups. The different components of the load setup are highlighted in Figure 3-2. Steel plates are located at each of the tie-down groups to engage all the four threaded rods, shown in Figure 3-2 (a). A beam (B-3) consisting of two channel steel sections (C15x40) connected with $\frac{3}{4}$-inch steel plates welded to the top and bottom of the channel sections and plate stiffeners located where needed was used to connect adjacent plates on the tie-down groups, shown in Figure 3-2 (b). These B-3 beams were connected on each side using similar double channel steel beams (B-2), shown in Figure 3-2 (c). A large plate-girder spreader beam (B-1) was then used to connect the B-2 beams together, shown in Figure 3-2 (d). B-1 was connected to B2 using large diameter threaded rods, which allows for easy vertical adjustment of the loading frame depending on the size of the test specimen. Two plates parallel to each other 
and connected with a pin were welded on top of beam B-1 allow for easy connection with the crane.

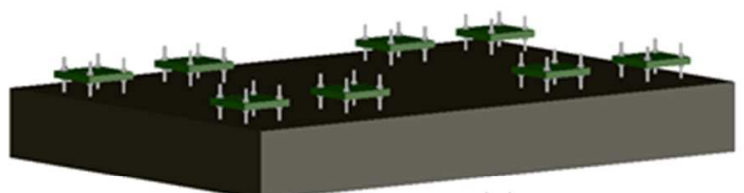

(a)

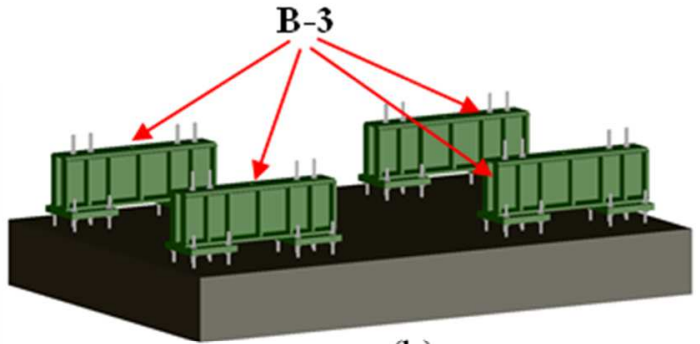

(b)

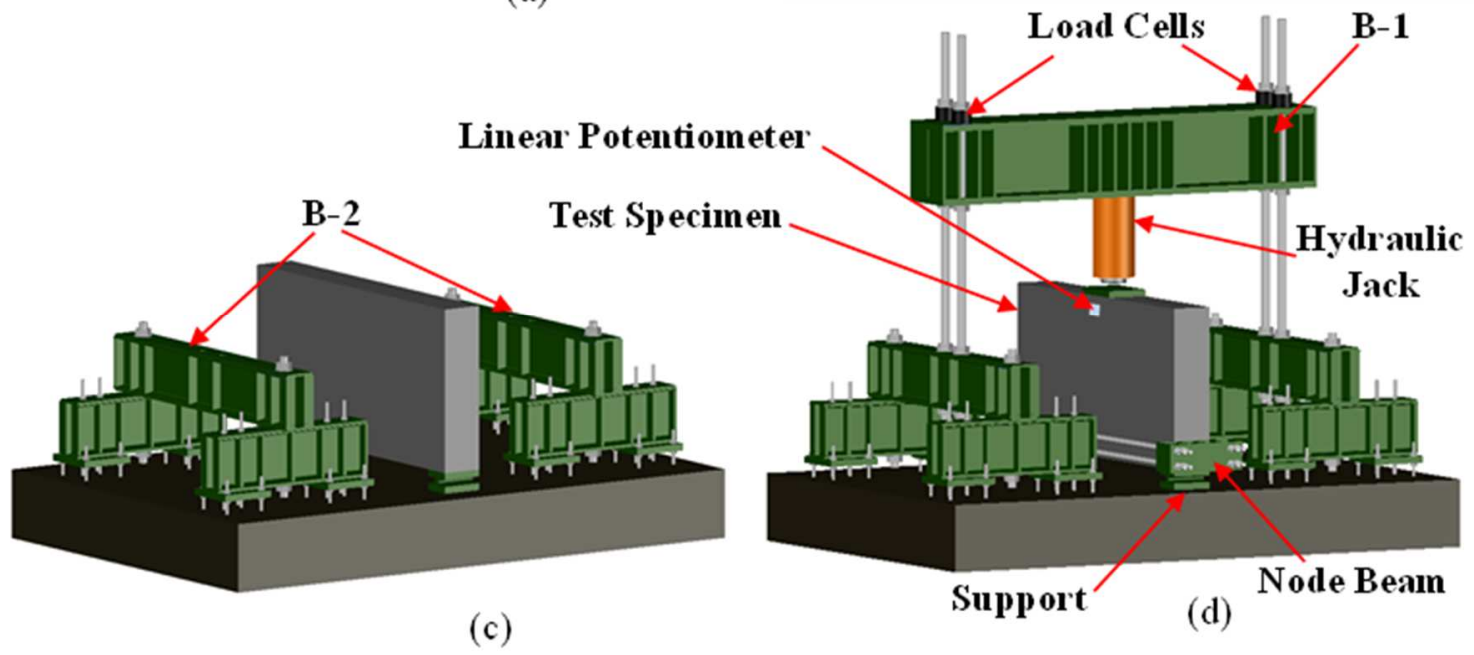

Figure 3-2: The steps of loading set-up and specimen installation

The load is applied by an 800-kip hydraulic jack (10,000 psi) attached to the spreader beam B-1 using four high-strength bolts. Load cells with 250-kip capacity were designed to be located on each of the four threaded rods between beam B-1 and the nut on the end of the rod. These load cells measure the load in each rod and ensure that the load is being applied symmetrically on the load frame. The load applied to the specimen is then equal to the total load measured in all four of the load cells plus the weight of B-1 and the hydraulic jack. Construction drawings of each component of the test setup are provided in Appendix A. 


\subsection{Assembly and Disassembly}

The procedure for assembling and disassembling the test setup is described in this section. First, all the threaded rods and steel plates need to be installed at each of the tie-down groups, shown in Figure 3-2 (a) and Figure 3-3. One practical recommendation for installing the first rods in the tie-downs is that the rods should be tied to the ground while they are in the plates, as shown in Figure 3-3. Because of imperfections in the tie-downs, it is difficult to put the plate over the rods after they are already threaded into the strong floor.

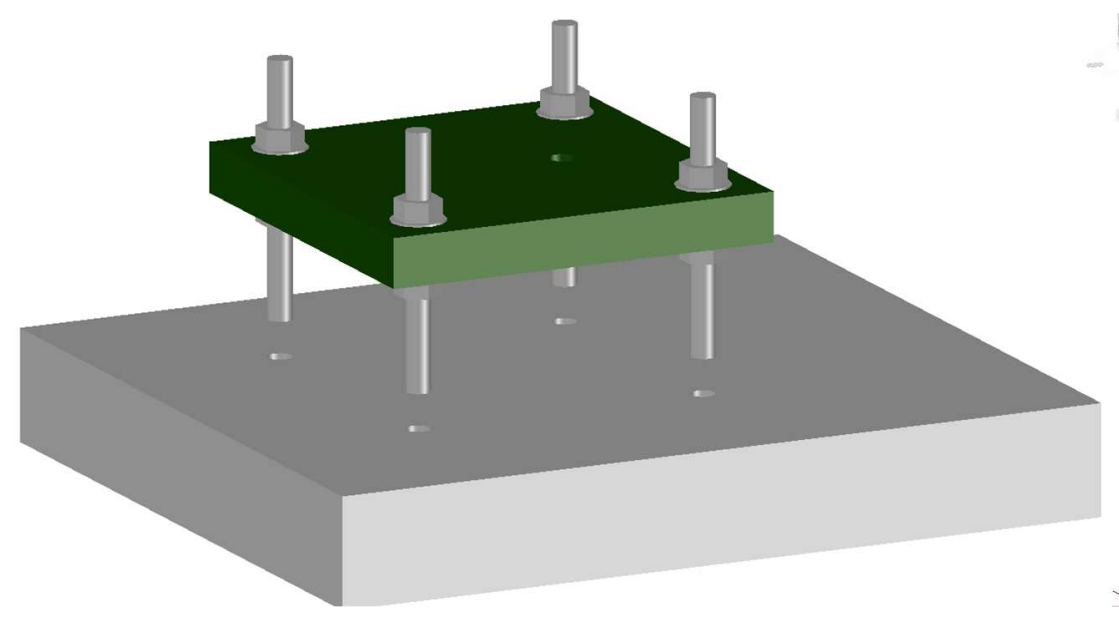

Figure 3-3: installing the first rods in the ground

After installing all the rods to the ground, the distance of all the plates to the ground was measured to make sure they have the same clearance. Each plate was leveled with a small beam level, and the adjoining plates were leveled with a longer one. Beams B-3 were then attached to each plate using threaded rods and checked again to ensure they were level, as shown in Figure 3-2 (b). Beams B-2 were then placed and attached to Beams B-3, as shown in Figure 3-2 (c). The different threaded rods required for installation of the load setup are highlighted in Figure 3-4. 


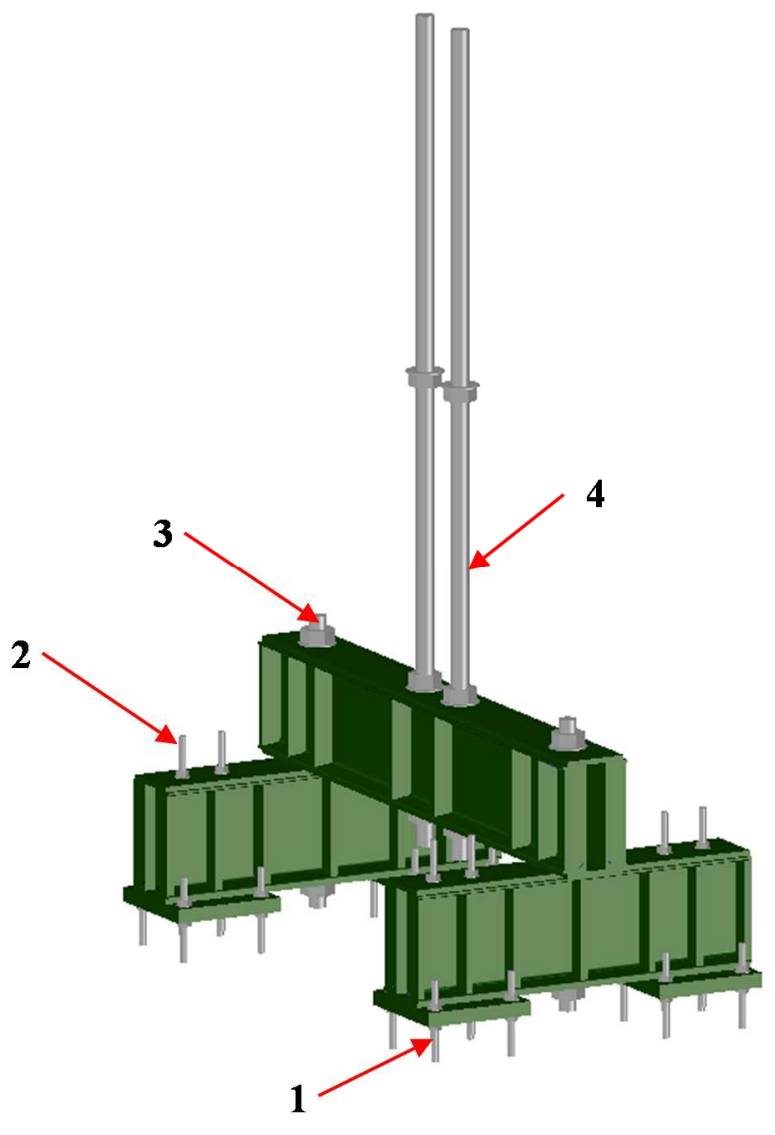

Figure 3-4: installing rods to connect the beams

The specimen was placed into the test setup after installing all the rods, but before the placement of the spreader beam (B-1). The component of the specimens tested in this program are highlighted in Figure 3-5. The pin supports were first placed in the correct location relative to the testing frame. Next, the beam was moved into position and gypsum cement mortar (hydro-stone) was placed on top of the support plate and the beam carefully lowered into position. Gypsum cement mortar is used to ensure that the force is equally distributed on the specimen at the location of the support plate. The node beam and threaded rods used for tension steel was then placed for the specimens with external unbonded reinforcement, shown in Figure 3-5 (c). Node beams were held in position using 
wood spacers. These wood spacers were removed during testing after a small amount of load was placed on the beams. Gypsum cement mortar was also placed between the back of the specimens and the node beams. Finally, the load plate was placed on top of the specimen with gypsum cement mortar between the place and specimen.
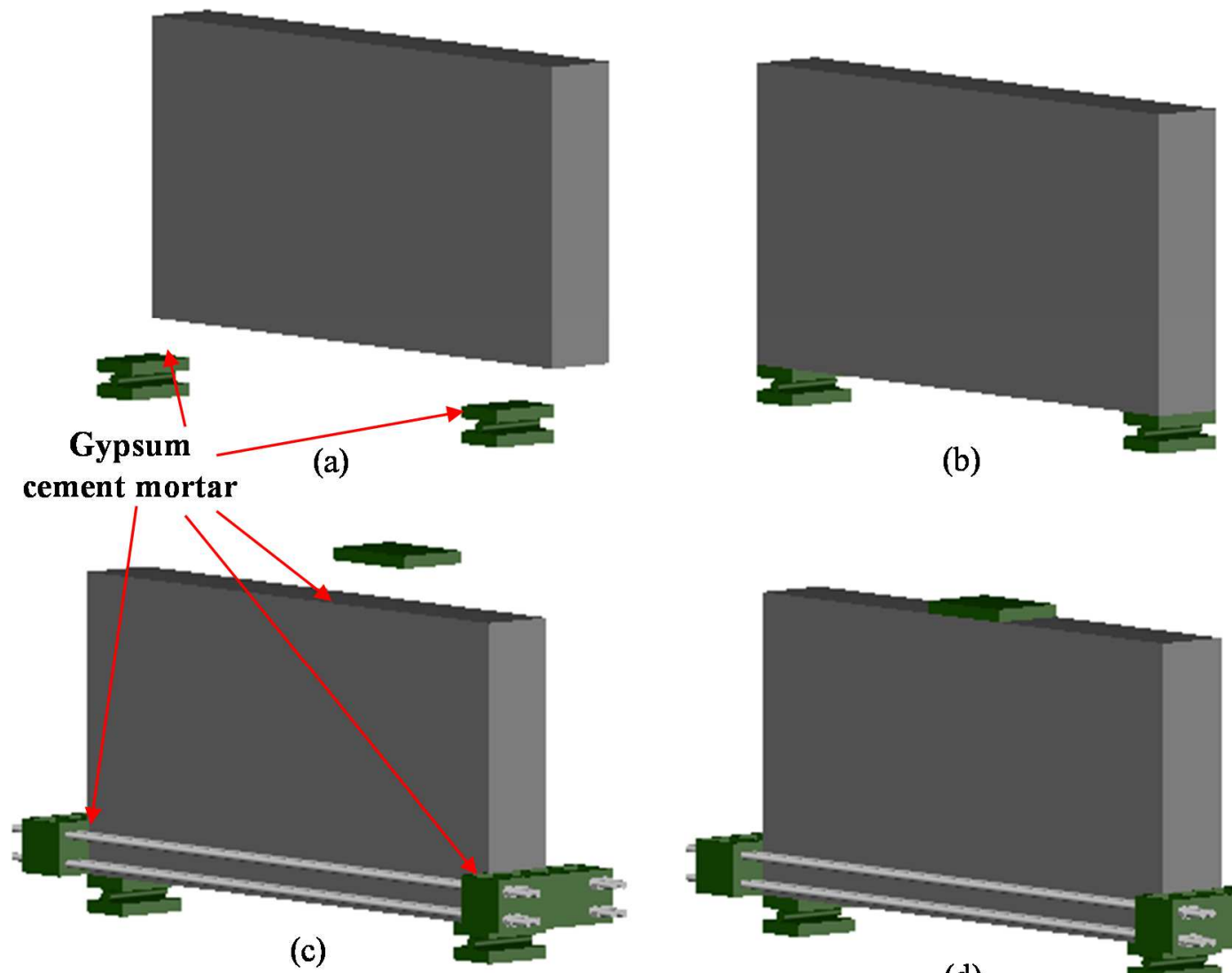

(b)

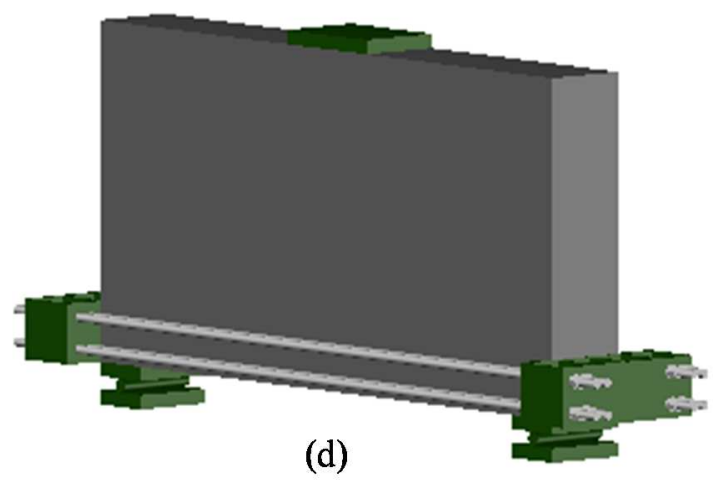

Figure 3-5: Assembling specimens with load and support conditions

After the specimen was in its proper location, Beam B-1 with the hydraulic jack already attached was lowered into place in the test setup over the specimen. Load cells were placed on each of the four main threaded rods and then washers and nuts were installed.

Disassembly of the setup can be achieved by following the above procedure in reverse. Also note that if any rods need to be replaced (other than the four rods supporting the 
spreader beam B-1), they can be removed and replaced without disassembly of the entire load frame.

\subsection{Load and Support Conditions}

Gypsum cement mortar was used between the plates (loading and reactions) and the concrete specimen to ensure the loads were distributed evenly.

Pin-pin supports under all of the specimens were provided for vertical reaction against the strong floor of the laboratory. The external unbonded reinforced specimens were restricted horizontally by a node beam and high-strength threaded rods, as shown in Figure 3-2 (c) and (d).

One of the test specimens failed because of deficient gypsum cement mortar beneath the load plate. The gypsum cement mortar was not sufficiently mixed prior to placement, so a more concentrated load was applied to part of the beam under the load plate. A photograph of this test specimen after failure is shown in Figure 3-6. The importance of properly mixing and placing the gypsum cement mortar is highlighted by this specimen. 


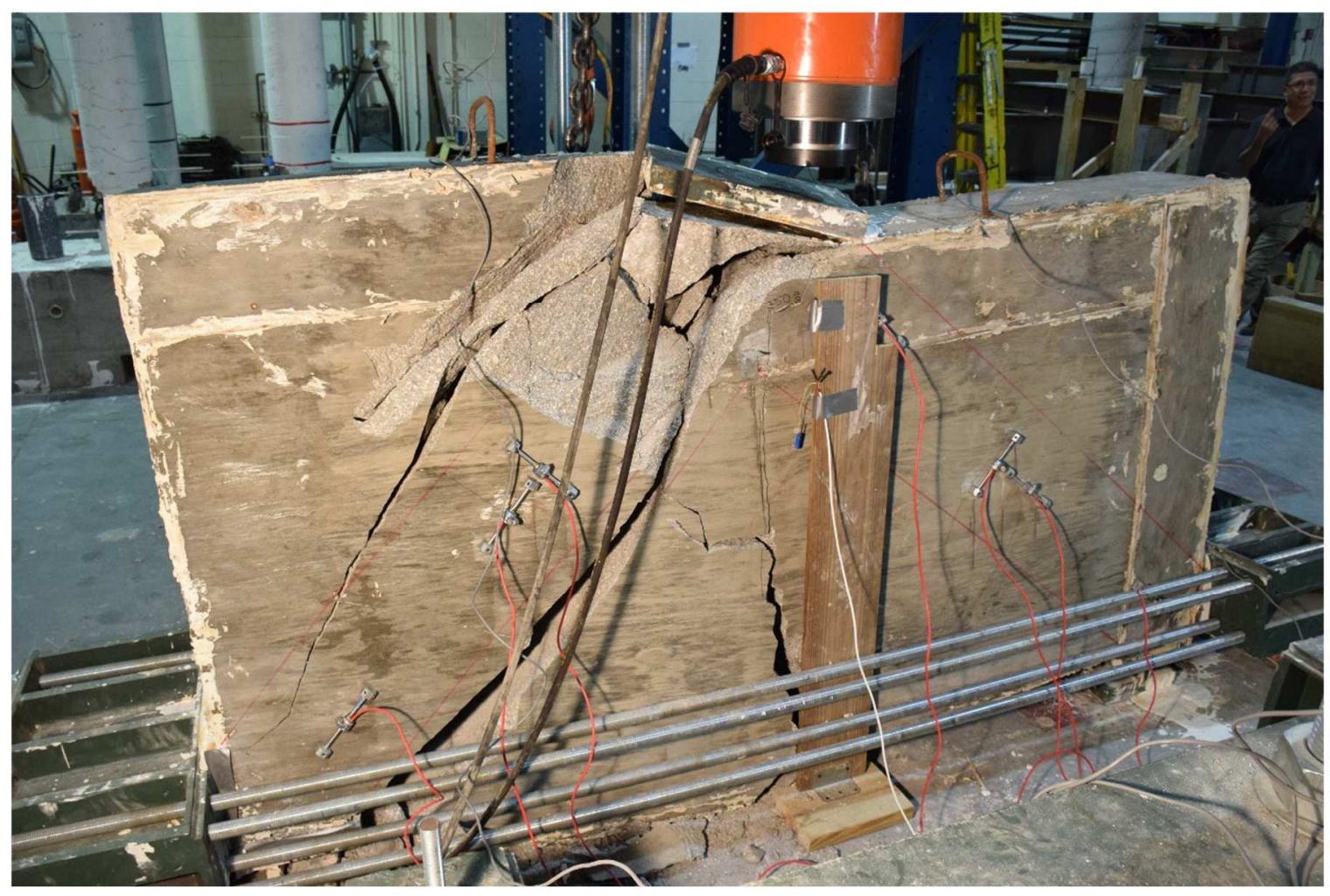

Figure 3-6: failure in specimen with deficiency in Gypsum

\subsection{Load Application and Measurement}

The specimens were loaded on top by an 800-kip hydraulic jack attached to the load frame connected to the strong floor. The details of the hydraulic jack are shown in Table 3-1. This jack was connected to an Enerpac ZE6-series pump. 
Table 3-1: Hydrulic jack details

\begin{tabular}{|l|c|}
\hline Type of hydraulic Jack & Powerteam \#RD40013 \\
\hline Cylinder Capacity-Push & $800 \mathrm{kips}$ \\
\hline Stroke & $13.00 \mathrm{in.}$ \\
\hline Oil Capacity - Push & $1021.0 \mathrm{in}^{3}$ \\
\hline Retracted Height & $269 / 32 \mathrm{in}$. \\
\hline Outside Diameter & $125 / 8 \mathrm{in}$. \\
\hline $\begin{array}{l}\text { Cylinder Effective Area- } \\
\text { Push }\end{array}$ & $78.54 \mathrm{in}^{2}$ \\
\hline $\begin{array}{l}\text { Internal Pressure at Cap.- } \\
\text { Push }\end{array}$ & $10185 \mathrm{psi}$ \\
\hline Product Weight & $770 \mathrm{lbs}$. \\
\hline
\end{tabular}

Load was measured using four 250-kip capacity load cells. These load cells were custom designed and build by StrainSense Enterprises, Inc. (www.strainsense.com). The dimensions for the load cells are provided in Figure 3-7.

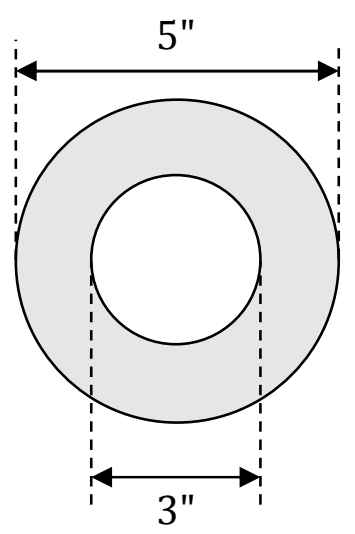

(a)

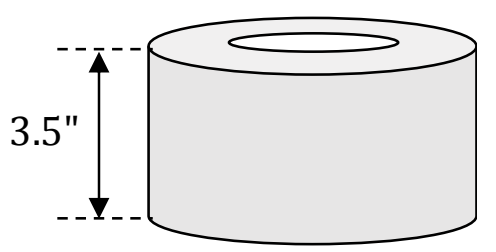

(b)

Figure 3-7: Dimensions of 250-kip capacity load cells: (a) top and (b) side

Initial calibration details were provided by the company that produced the load cells, 
StrainSense Enterprises, Inc. Calibration details are shown in Table 3-2. A voltage reading was found for several different loads within the capacity of the load cell. A linear regression could then be done to find the load calibration equation shown. This equation was then used to convert the voltage reading to load in the data acquisition program.

Table 3-2: Calibration detail for load cells

\begin{tabular}{|c|c|c|c|c|}
\hline Load Cell Number & 160612 & 160613 & 160614 & 160615 \\
\hline Load, kips (kN) & \multicolumn{4}{|c|}{ Voltage (mV/V) } \\
\hline $25(111)$ & 0.2348 & 0.2212 & 0.2445 & 0.2249 \\
\hline $50(222)$ & 0.4641 & 0.4639 & 0.4822 & 0.4658 \\
\hline $100(444)$ & 0.9124 & 0.9105 & 0.9493 & 0.9117 \\
\hline $125(556)$ & 1.1352 & 1.1417 & 1.1821 & 1.1425 \\
\hline 150 (667) & 1.3572 & 1.3695 & 1.4136 & 1.3686 \\
\hline 200 (889) & 1.7999 & 1.8159 & 1.8758 & 1.8169 \\
\hline $250(1112)$ & 2.2411 & 2.2582 & 2.3365 & 2.2592 \\
\hline $\begin{array}{c}\text { Load Calibration } \\
\text { Equation (kips) }\end{array}$ & $112.24 \mathrm{~V}-2.02$ & $110.61 \mathrm{~V}-0.70$ & $107.61 \mathrm{~V}-1.85$ & $110.75 \mathrm{~V}-0.99$ \\
\hline
\end{tabular}

\subsection{Data Acquisition System}

A new data acquisition system was designed, purchased, and set up to collect data from all the load cells, linear potentiometers, vibrating wire gages (VWGs), and other sensors. The data acquisition consisted of the following different components from Campbell Scientific:

- CR6 Measurement and Control Datalogger: This is a datalogger that is compatible with their CDM series measurement and control peripherals. This series allows for easy customization of the data acquisition system by connecting the 
needed peripherals using ethernet cables.

- $\quad C D M-V W 305:$ This is an interface that connects with up to eight VWGs and allows for dynamic reading of the VWG sensor. Previous interfaces only allowed for measurement rates of around $1 \mathrm{~Hz}$. This interface allows for dynamic measurement rates of 20 to $333 \mathrm{~Hz}$.

- CDM-A116: This is a multiplexer interface that allows for 16 differential inputs and four excitation channels.

The data acquisition system was programmed using a Campbell Scientific data logger software. Code was developed to collect the data and an Excel sheet macro was designed to have a continuous output of the data. The code developed and used for this testing program is provided in Appendix C.

\subsection{Recommendations for Future Use}

The author would like to make several recommendations for future use of the test frame:

1. Make sure that the gypsum cement mortar is mixed in a clean bucket or container. The properties of the mortar can be negatively affected if the bucket contains any debris or partially hydrated mortar.

2. Ensure that all the nuts on the test setup are tight before testing. This will help to guarantee that all the beams and plates will remain balanced during testing.

3. The load setup was designed for static testing of loads up to $800 \mathrm{kips}$. The rods high strength threaded rods should be visually inspected before and after cyclic testing at loads near the 800-kip capacity. 


\title{
Chapter 4: Strut Strength and Failure in Full-Scale Concrete Deep Beams ${ }^{\text {a }}$
}

\author{
*Nazanin Rezaei ${ }^{\mathrm{b}}$, Gary Klein ${ }^{\mathrm{c}}$, and David Garber ${ }^{\mathrm{d}}$
}

\subsection{Abstract}

There has been some recent debate in the actual behavior and performance of some components of strut-and-tie models specifically struts. This research aims to shed additional light on the behavior and performance of struts. Five full-scale concrete deep beams with two different shapes (rectangular and truss-like) were tested under a three-point load setup. The shear span-to-effective depth ratio $(a / d)$ for the specimens were 1 and 1.6, which led to strut angles of 30 and 45 degrees. All the specimens were simply-supported vertically and reinforced with bonded or unbonded bars horizontally. The results indicate that the truss-like specimens have substantially more capacity compared to the rectangular specimens with similar dimension. The unbonded reinforced beam results were similar to bonded results. The ultimate shear strength obtained from the experimental tests was compared with STM estimates using current design codes to evaluate their safety and accuracy.

Keywords: deep beams, strut-and-tie method, node behavior, failure mode, strut strength

\footnotetext{
${ }^{a}$ Submitted to ACI Structural Journal

b Corresponding Author. $\mathrm{PhD}$ candidate, Civil and Environmental Engineering, Florida International University, Miami, Fl, USA. E-mail: nreza002@ fiu.edu.

c Executive Vice President and Senior Principal, WJE (Wiss, Janney, Elstner) Associates, Northbrook, Illinois, USA. E-mail: gklein@wje.com.

d Assistant Professor, Civil and Environmental Engineering, Florida International University, Miami, Fl, USA. E-mail: dgarber@ fiu.edu.
} 


\subsection{Introduction}

One of the most universally applicable methods to design a concrete structure is the strutand-tie method (STM). In this method, a concrete member is modeled as a truss (or collection of axially loaded elements) in which compression members (struts) and tension members (ties) are connected at nodes. Current ACI design provisions define two different types of struts depending on strut geometry: prismatic and bottle-shaped. Bottle-shaped struts have the same dimension at the ends and a wider width at the mid-length. It is assumed that stresses spread in these struts, which creates tensile stress perpendicular to the strut axis. Prismatic struts have the same section along their entire length, either caused by geometric boundaries or bordering tensile stress regions.

The strength of a member found using STM is heavily dependent on the strength estimation of compressive struts, tension ties, and nodes where they intersect. While the behavior of ties is fairly well comprehended, various factors affect the strut strength and behavior. These factors include type of strut, concrete strength, strut angle, orientation, width and extent of cracking, and degree of lateral confinement [35].

The history of designing concrete beams using STM started in the late 1890's. Wilhelm Ritter, a German civil engineer, equated the reinforcing steel in concrete beams to tensile truss elements and the concrete to the compressive truss elements [39]. In the early 1900's, Emil Mörsch [40] followed this idea to determine required shear reinforcing steel in Bregions of concrete beams by truss analogy. In 1987, Schlaich et al. published a special report that included procedures and rules of designing an entire concrete beam using STM [14]. Based on this method, they introduced a unified design and detailing concept for all concrete structures [6]. They believed that this conceptual method helps designers to 
understand the function of internal forces in the structure, and design and check the details better. Cook and Mitchell [41] and Breen et al. [42] then used STM to extend its use to determine the nominal capacity for other structures. In 1989, STM was first published into US code provisions in the AASHTO Guide Specifications for Design and Construction of Segmental Concrete Bridges [43]. Recently, this method has gained popularity for designing diaphragms, reinforcing details in discontinuity regions, anchor reinforcement, pile caps, foundations, members with opening, and other complicated concrete structures. A significant amount of research has been conducted examining the behavior of struts. According to Brown et al. [5], Brown and Bayrak [20], and Sahoo et al [21], when stress can spread outward a bottle-shaped strut will be present. The outward spreading of stress will result in transverse tensile stress developing in the strut. Since concrete is weaker in tension than compression, this tensile force causes failure of the specimens before they reaches their compressive capacity.

Pujol et al. [8] tested various vertically-oriented specimens with different strut widths (L) to investigate this idea. Their specimens were loaded under the same boundary conditions and loading plates (6 in. [0.15m] x 6 in. [0.15 m]), as shown in Figure 4-1(a). They did not observe any trends between the shape of the specimens and their strength. As ACI 318-14 [3] Chapter 23 recommends different efficiency factors for prismatic and bottle-shaped struts. Sahoo et al. [7] also developed some experimental tests, as shown in Figure 4-1(b), to asses these recommendations for design. The boundary condition and loading plates were the same (3.94 in. $[0.1 \mathrm{~m}]$ x 3.94 in. $[0.1 \mathrm{~m}])$, but with various strut widths (L') and strut lengths. They found that bottle-shaped struts have similar strength to prismatic struts suggesting that the efficiency factor of bottle-shaped struts should be modified. They also 
made recommendations for the minimum effective transverse reinforcement in bottleshaped struts.

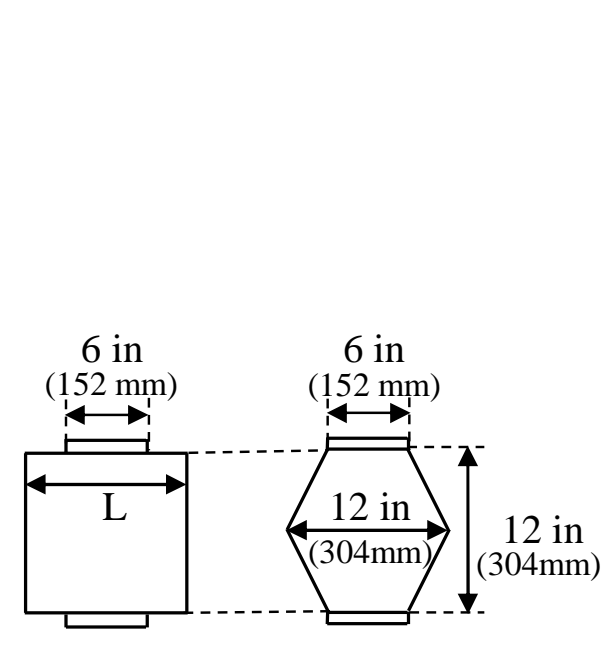

(a)

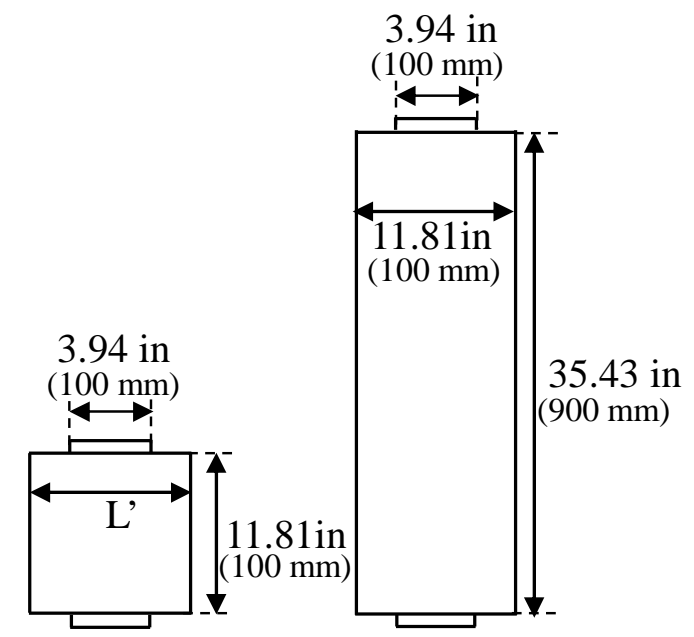

(b)

Figure 4-1: (a) specimens for Pujol et al. [8] tests and (b) specimens for Sahoo et al. [7] tests.

As mentioned before, one of the effective factors to estimate strut strength is strut angle, which recently has been considered in rectangular specimens with longitudinal reinforcement. An analytical investigation was conducted by Sahoo et al. [34] about the effect of strut inclination on strength. It is indicated that there is a direct linear relationship between the strut inclination angle and strut efficiency factor. Another recent experimental effort (Su and Looi [35]) investigated the efficiency factors in unreinforced deep beams. In this study, efficiency factors were defined based on uniaxial concrete strength and strut angle. Concrete with various strengths (4 to $12.54 \mathrm{ksi}$ ) were used in nine asymmetry specimens with strut angles of 30,45, and 60 degrees to investigate how these parameters affect strut efficiency factor. These specimens had no shear reinforcement but did contain bonded longitudinal reinforcement. The researchers suggested 0.7 as a nominal strut efficiency factor based on the results of the experimental testing. 
An additional experimental study was performed by Beeby summarized by Van den Hoogen et al. [44] on a series of normal beams and beams with specific cut-outs in the concrete at midspan. They observed different shear failure mechanisms between the two specimens. They concluded from their observations that cracking caused by beam bending cut off the line of compression of the strut, preventing truss behavior. Diagonal tensile failure cracks occur before the beam can perform as a truss.

Different international codes have different provisions for designing based on STM. One of the primary differences between these is how the strength of the strut and strut efficiency factor are estimated. The strut efficiency factor is typically varied based on either:

- Strut type: ACI 318-14 [3], FIP Recommendations [45], fib Model Code [46]

- Concrete strength: AASHTO LRFD Bridge Design Specification [19], Eurocode $2[47]$

- Strut angle: CSA Standard A23.3-14 [48].

The presented research will shed additional light on the performance of struts, the effect of tension fields introduced by bending, and how their strength should be properly estimated.

\subsection{Research Significance}

Recent research has brought into question how current design specifications treat the behavior of struts, which typically controls member strength in STM. This study was designed to isolate the behavior of diagonal compression struts in typical deep beams. Two different beam types (rectangular and truss-like) with two different strut angles and either internal bonded or external unbonded longitudinal steel were constructed and tested to failure. In this way, the behavior of struts extending through diagonal tension fields is 
directly compared to truss-like struts. Results were used to show the behavior of these struts and compare to current estimation procedures.

\subsection{Experimental Program}

\subsubsection{Specimen Geometry and Design}

The primary experimental variables explored in this testing program were (1) specimen type (rectangular or truss-like), (2) strut angle (30 or 45 degrees) and (3) type of longitudinal reinforcement (external unbonded or internal bonded reinforcement). In total, five deep beams were constructed to investigate the effect of each of these variables on the strut behavior and design provision performance, as shown in Table 4-1. Specimen labels reflect the shape ("Re" for rectangular and "Tr" for truss-like), strut angle (30 or 45), and type of longitudinal reinforcement ("Ex" for external, unbonded and "In" for internal, bonded). No shear reinforcement was provided in these specimens.

Table 4-1: Test Matrix

\begin{tabular}{|c|c|c|c|c|c|}
\hline No. & $\begin{array}{c}\text { Specimen } \\
\text { Name }\end{array}$ & $\begin{array}{c}\text { Strut } \\
\text { Angle }\end{array}$ & $\begin{array}{c}\text { Specimen } \\
\text { Type }\end{array}$ & $\begin{array}{c}\text { Reinforcement } \\
\text { Type }\end{array}$ & $\begin{array}{c}\mathbf{f} \text { 'c, ksi } \\
(\mathbf{M P a})\end{array}$ \\
\hline 1 & $\operatorname{Re}-30-E x$ & $30^{\circ}$ & Rectangle & External & $7.44(51)$ \\
\hline 2 & Tr-30-Ex & $30^{\circ}$ & Truss & External & $7.37(50)$ \\
\hline 3 & $\operatorname{Re}-45-E x$ & $45^{\circ}$ & Rectangle & External & $5.63(38)$ \\
\hline 4 & Tr-45-Ex & $45^{\circ}$ & Truss & External & $5.63(38)$ \\
\hline 5 & Re-45-In & $45^{\circ}$ & Rectangle & Internal & $7.89(54)$ \\
\hline
\end{tabular}

The geometry of the specimens is shown in Figure 4-2. The length of the beams was fixed at 96 inches $(2.44 \mathrm{~m})$ and width fixed at 12 inches $(0.305 \mathrm{~m})$. The height of the beam $(\mathrm{Z})$ was modified to change the strut angle, which also changed the shear span-to-effective 
depth ratio $(\mathrm{a} / \mathrm{d})$. Two different heights were tested: 48 inches $(1.22 \mathrm{~m})$ (giving a/d $=1.0$ and 45-degree strut angle) and $\mathrm{Z}=31.3$ inches $(0.795 \mathrm{~m})$ (giving $\mathrm{a} / \mathrm{d}=1.6$ and 30 -degree strut angle).

Two different geometries were also tested: rectangular (as shown in Figure 4-2 (a) and (c)) and truss-like (as shown in Figure 4-2 (b)). These two geometries were selected to investigate the impact of removing the excess concrete on the strut behavior. The truss-like specimens have a consistent cross-sectional area along their entire length (i.e. they have the same cross-sectional area at the strut-to-node interfaces at the support and loading points as they do at the mid-length of the struts). The rectangular specimens allow stresses to spread as they leave the nodal region into the strut. These specimens also allow for the tension developed by flexural stresses from bending to influence the behavior of the struts. 


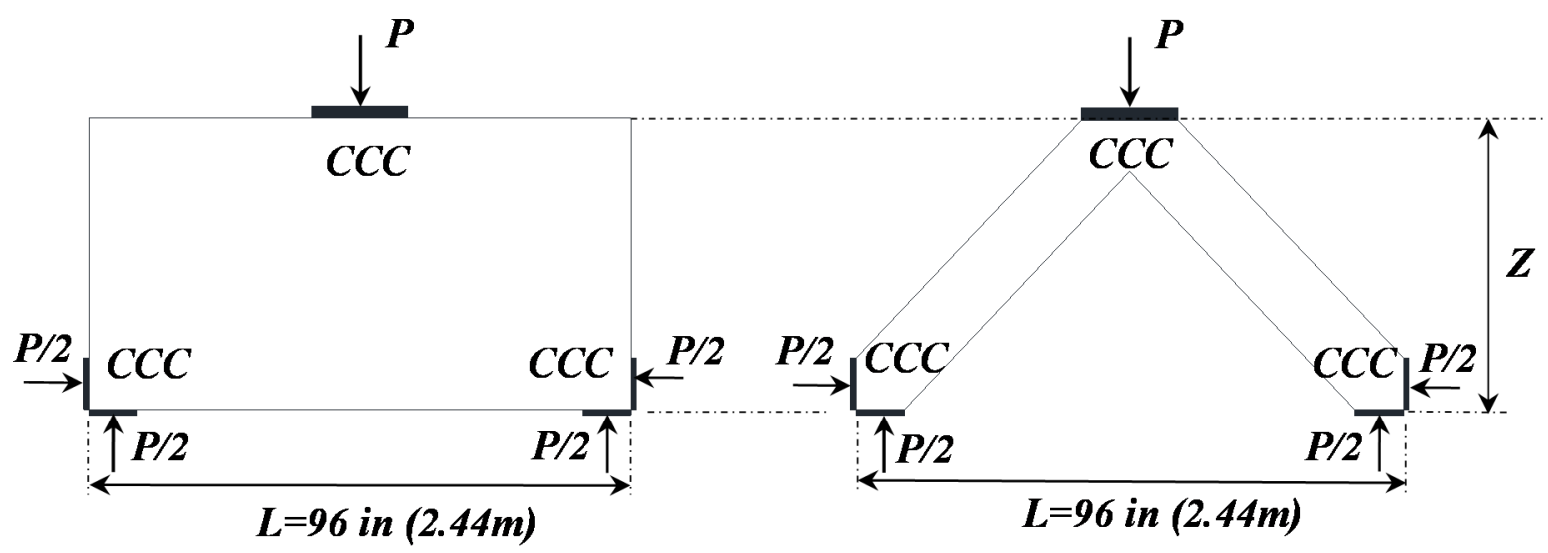

(a)

(b)

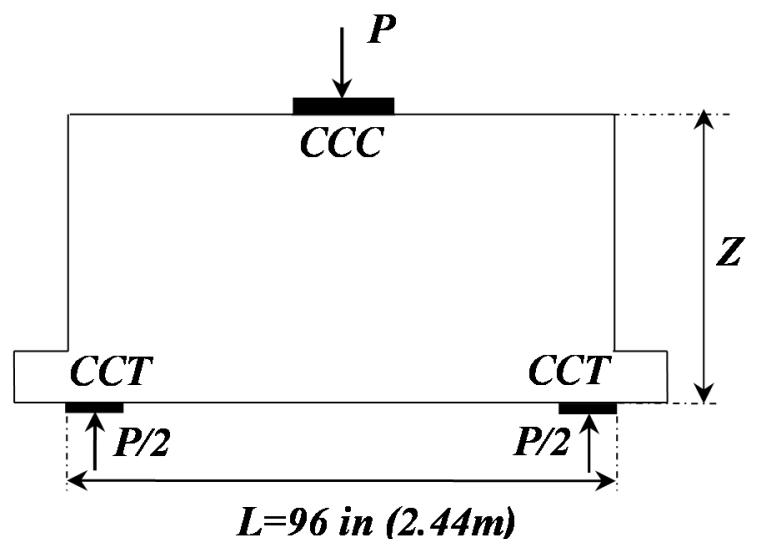

(c)

Figure 4-2-Geometry of the specimens: (a) rectangular specimen with unbonded reinforcement, (b) truss-like specimen with unbonded reinforcement, and (c) rectangular specimen with bonded reinforcement.

Two different types of longitudinal reinforcement were also tested: external unbonded and internal bonded reinforcement. The external unbonded reinforcement, shown in Figure 4-3 (a) and (b), was comprised of two stiffened steel W shapes and eight high-strength steel threaded rods. The steel section was held at the correct height with wood and the bolts on the threaded rods were hand tightened prior to testing. The internal bonded specimen was reinforced with eight Grade 60 \#11 bars, as shown in Figure 4-3 (c). The amount of internal bonded reinforcement was provided to have a similar total tie capacity to the external 
unbonded reinforcement. The internal reinforcement was extended past the node and welded to an external steel plate to ensure the bars were properly anchored. Having internal bonded reinforcement changed the type of node at the support from a CCC node (with all compression boundary faces for the externally reinforced beams) to a CCT node (with one tension element intersecting the node). These different node types are highlighted in Figure 4-2. The node type does not impact the estimated design strength using ACI 318-14, but does impact the estimated design strength using AASHTO LRFD. The internal bonded reinforcement was also thought to possibly introduce additional tension stresses in the beam, as was shown by results from Sahoo et al. [7] mentioned above.

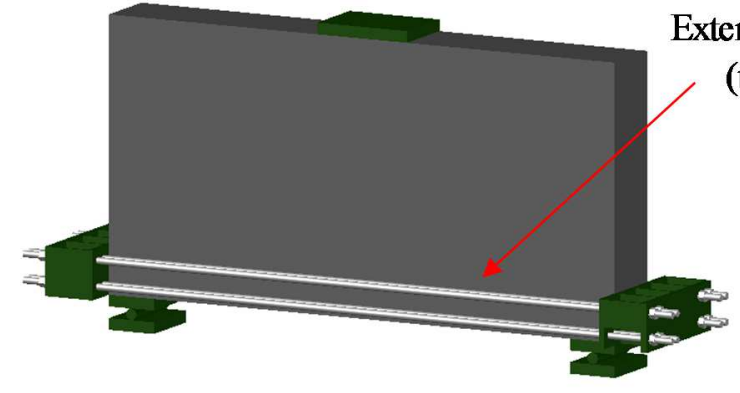

(a)

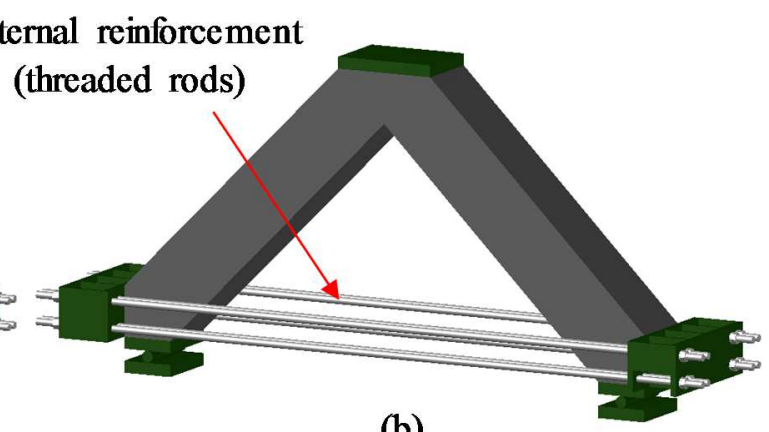

(b)

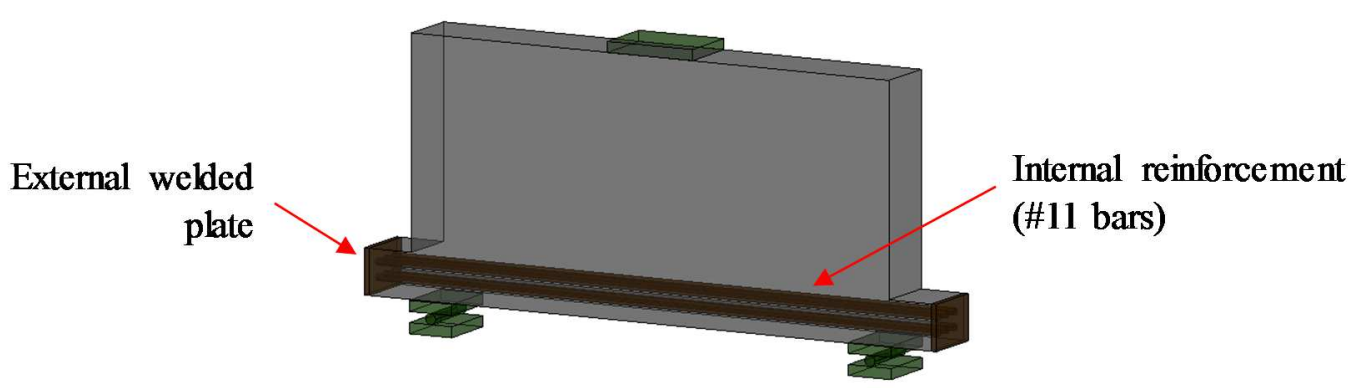

(c)

Figure 4-3-Specimens with external unbonded: (a) rectangular and (b) truss-like; and with (c) internal bonded reinforcement (figure has transparent specimen to show internal reinforcement). 


\subsubsection{Material}

The set of beams were cast on two different days using ready mix concrete with the same mixture design, shown in Table 4-2. Course (uncrushed granite) and fine (uncrushed sand) aggregates were used with a maximum size of 0.5 inches $(12.7 \mathrm{~mm})$. The water-to-cement ratio for both casts was specified at 0.48 . The specified compressive strength was $4 \mathrm{ksi}(6.9$ $\mathrm{MPa}$ ) for all the specimens. Actual measured concrete strengths on test days are shown in Table 4-1.

The specified yield strength of the threaded rods used for the external tie reinforcement was $100 \mathrm{ksi}(690 \mathrm{MPa})$ and the internal reinforcement had a specified yield strength of 60 ksi (413 MPa). The tie was overdesigned to not control the capacity of the beams, so the actual yield strength of the bars should not have impacted the behavior.

Table 4-2: Concrete mix design

\begin{tabular}{|c|c|c|c|c|c|c|c|}
\hline & $\begin{array}{c}\text { Cement } \\
\mathbf{l b}(\mathbf{k g})\end{array}$ & $\begin{array}{c}\text { Water } \\
\mathbf{l b}(\mathbf{k g})\end{array}$ & $\begin{array}{c}\text { Fine } \\
\mathbf{a g g} \\
\mathbf{l b} \\
\mathbf{( k g})\end{array}$ & $\begin{array}{c}\text { Coarse } \\
\mathbf{a g g} \\
\mathbf{l b} \mathbf{( k g})\end{array}$ & $\begin{array}{c}\text { Admixtures } \\
\mathbf{o z} / \mathbf{y d} \\
\mathbf{( k g / m )}\end{array}$ & $\begin{array}{c}\text { Specified } \\
\text { slump } \\
\mathbf{i n}(\mathbf{m m})\end{array}$ & air \\
\hline Quantities & $\begin{array}{c}690 \\
(312)\end{array}$ & $\begin{array}{c}333 \\
(151)\end{array}$ & $\begin{array}{c}1,808 \\
(820)\end{array}$ & $\begin{array}{c}920 \\
(417)\end{array}$ & $38(1.18)$ & $\begin{array}{c}5-7 \\
(127-\end{array}$ & $\begin{array}{c}1.5- \\
178)\end{array}$ \\
\hline
\end{tabular}

\subsection{Set up, Instrumentation, and Testing Procedure}

All the specimens were tested using a three-point bending set-up, as shown in Figure 4-4. The load was applied to the top of the specimens by an 800 -kip $(3,560-\mathrm{kN})$ hydraulic jack attached to the load frame connected to the strong floor. The specimens were supported by pin-pin supports reacting against the strong floor of the laboratory. Gypsum cement mortar 
was applied between the steel plates and the specimens at the supports and load point to ensure the specimens were level and the load was distributed evenly. As previously mentioned, a transverse "node beam" and high strength threaded rods were used to reinforce the bottom tie for the external unbonded reinforced specimens.

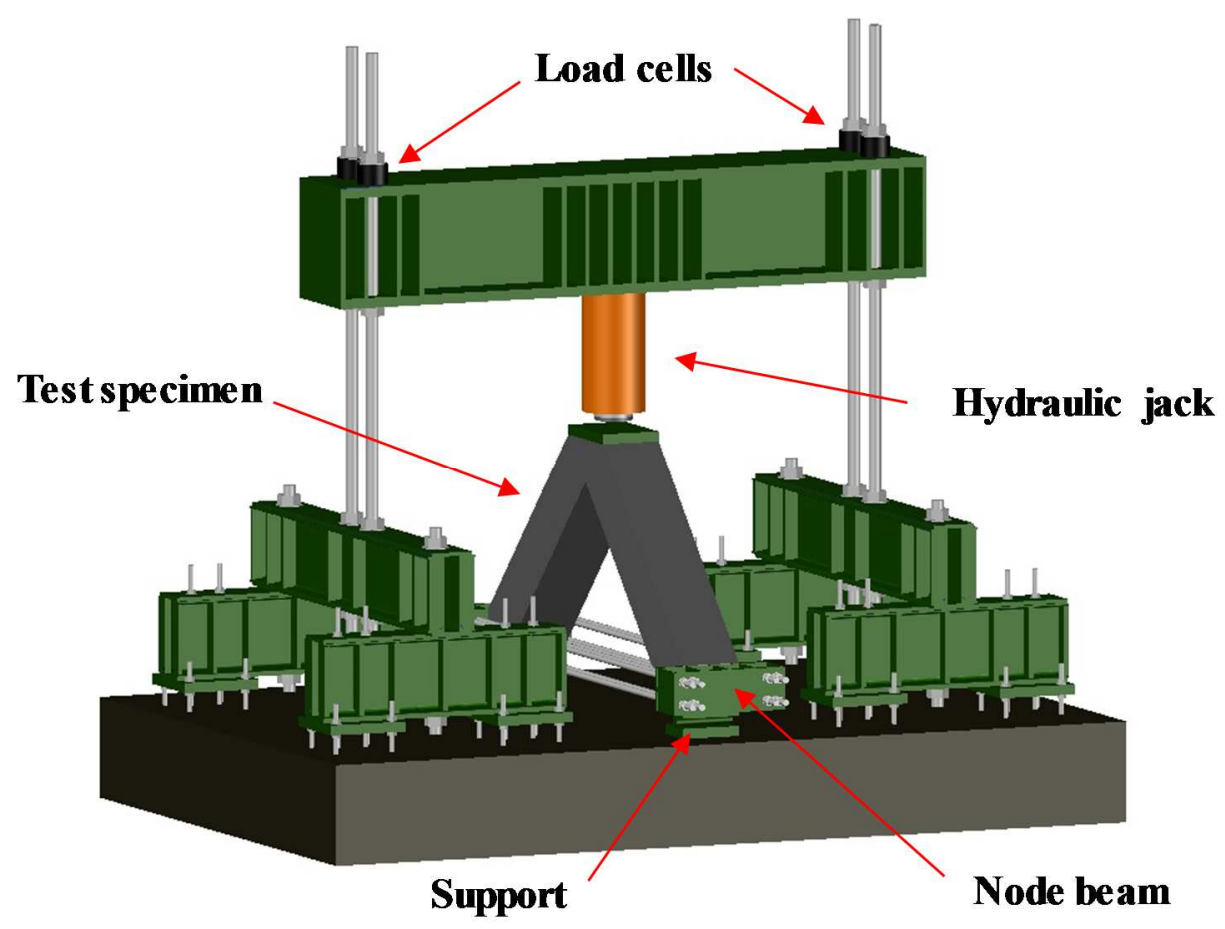

Figure 4-4: Schematic of test setup

\subsubsection{Loading Protocol}

The beams were loaded monotonically in increments of approximately 10 to 25 kips (44.5 to $111 \mathrm{kN}$ ) prior to cracking. After each load increment the beams were inspected to see if the first crack had developed. After cracking, load increments were increased to approximately 50 kips $(222 \mathrm{kN})$. Between each load increment, the beams were inspected to measure crack widths and mark crack progression. Photographs of cracking were also taken after each load increment. The estimated capacity of each specimen was obtained 
from finite element analyses and STM prior to testing. The specimens were not approached, and load was applied continuously to failure, after the load on the specimens was greater than approximately half of the estimated capacity. The approximate loading speed for all of the tests was approximately $2 \mathrm{kips} / \mathrm{s}(8.9 \mathrm{kN} / \mathrm{s})$.

\subsubsection{Instrumentation}

Data was collected during testing at a rate of $1 \mathrm{~Hz}$ using calibrated load cells, vibrating wire (VW) gages, string potentiometers, linear potentiometers, and pressure transducers. Load cells with a capacity of 250 kips $(1,112 \mathrm{kN})$ were placed between the top beam and the reaction nuts at each rod location, as shown in Figure 4-4. Two linear potentiometers were located at the centerline of the beam on each side, 7.5 inches $(191 \mathrm{~mm})$ below the loading plate in all the tests. The linear potentiometers were placed at this location so deflections could be measured at the same location for both the rectangular and truss-like specimens. These results were recorded by a datalogger using a custom code written for the testing series. The location of the linear potentiometers and VW strain gages is shown in Figure 4-5.

Sensors were labeled based on their location on the sample: "T" for top, "M" for middle and "B" for bottom of strut. Since sensors are in different directions, local Cartesian coordinates are defined for each strut: " $\mathrm{X}$ " signifies strains measured in the direction of the strut and "Y" strains measured perpendicular to the strut axis. 


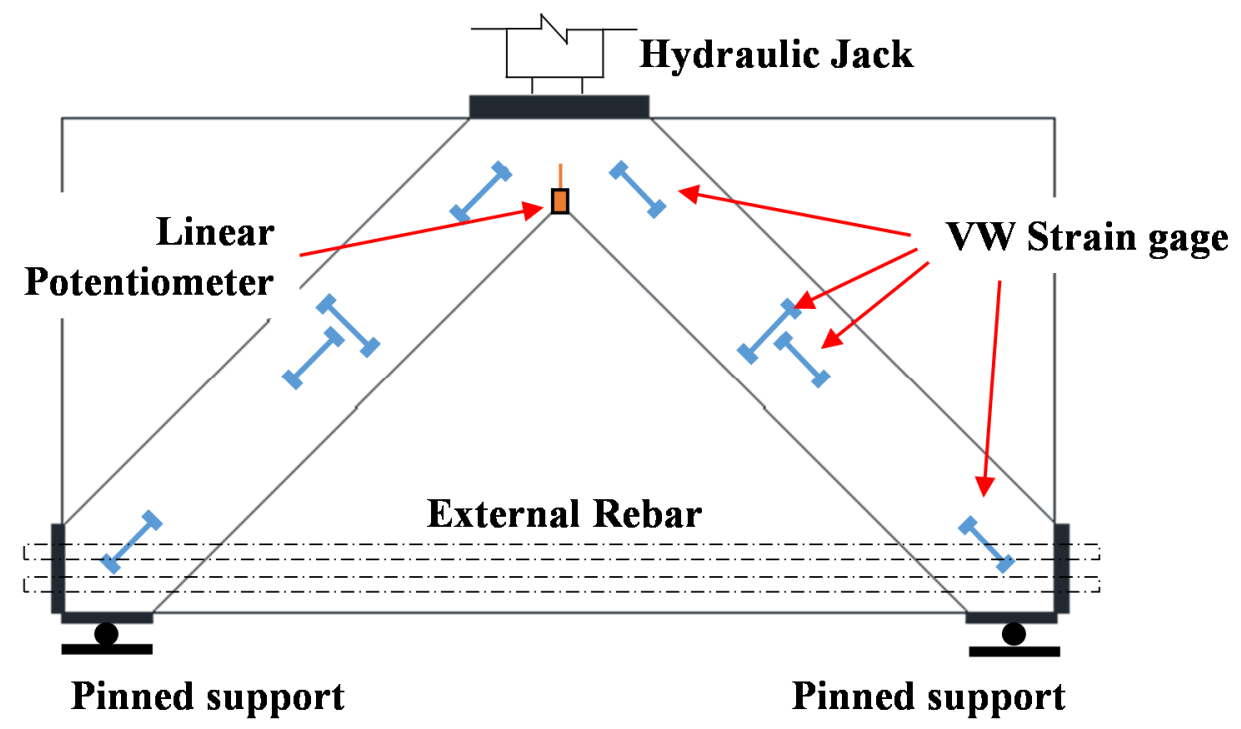

Figure 4-5: Location of instrumentation

\subsection{Experimental Results and Discussion}

The results from the full-scale experimental testing program will be discussed in this section including the crack patterns, observed failure modes, strains parallel and perpendicular to the strut axis, and failure loads.

\subsubsection{Crack Patterns}

The crack patterns for two of the rectangular specimens (bonded and unbonded) are shown in Figure 4-6. In both specimens, a vertical flexure crack started to form at midspan and progress up toward the loading point. For the rectangular beams with unbonded external reinforcement (Re-30-Ex and Re-45-Ex), a single flexure crack formed, progressed toward the load point, and widened under additional load, as shown in Figure 4-6 (a). No shear cracking formed in these beam prior to failure. For the rectangular specimen with internal bonded reinforcement (Re-45-In), cracking started at midspan like the unbonded specimens, as shown in Figure 4-6 (b). Additional cracks then formed along the bottom of 
the beam and some of the flexure cracks located in the shear span turned into shear cracks. As distinguished in Figure 4-6 (b) the cracks observed in 35\% $\mathrm{P}_{\max }$ were similar to cracks observed in $50 \% \mathrm{P}_{\max }$. The failure plane of the specimen with the internal bonded reinforcement was at a similar angle to the shear cracks that had developed. The first cracking loads for all the specimens are shown in Table 4-3.

The truss-like specimens did not have any significant cracking prior to failure. First cracking in these specimens was typically a small crack developing under the load point at the bottom of the load point node. One of these specimens also experienced some spalling of the concrete off the side of the strut close to the failure load. No other cracking was observed prior to failure in the strut or in the support node.
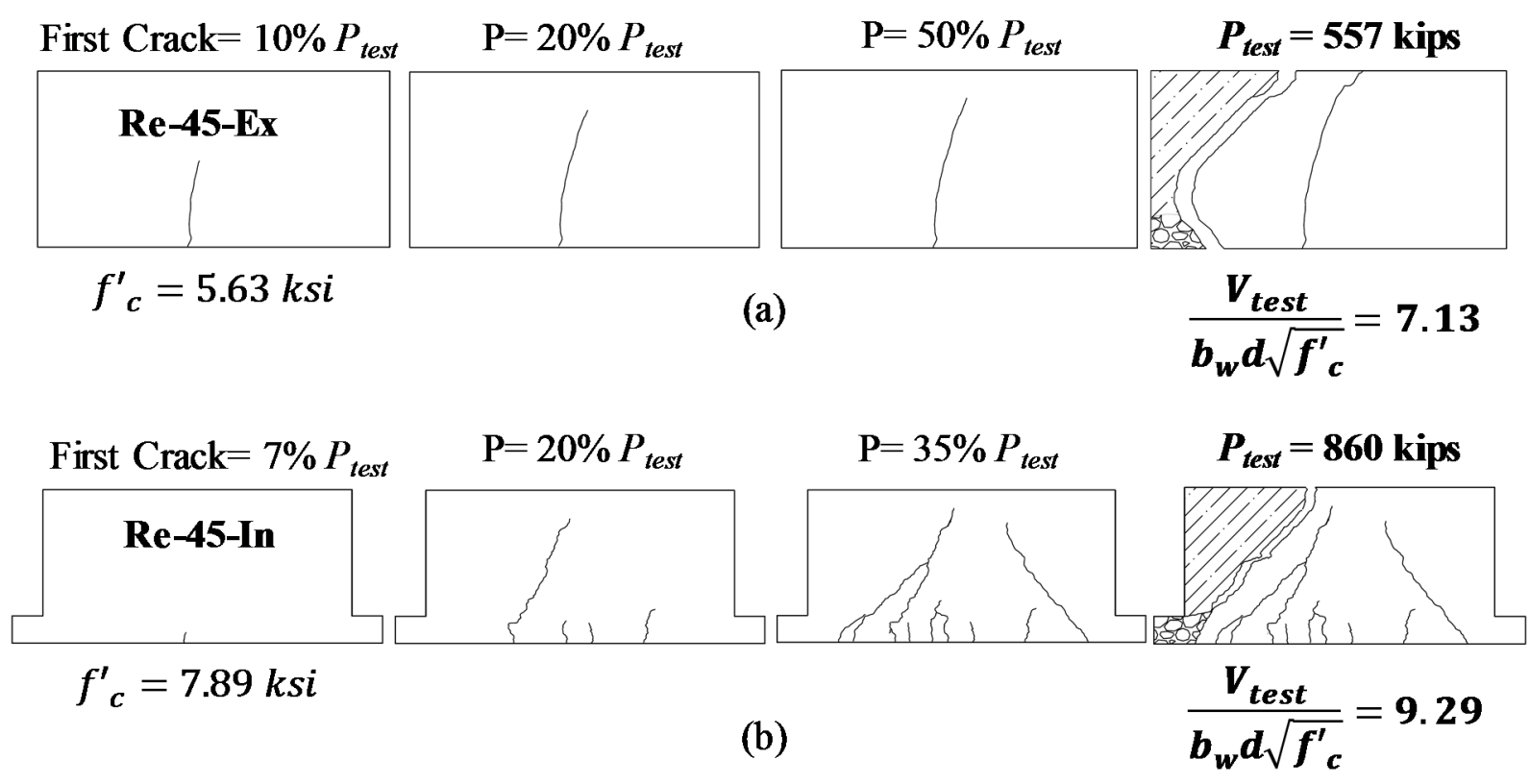

Figure 4-6: Crack pattern for (a) unbonded (Re-45-Ex) and (b) bonded (Re-45-In) specimens

\subsubsection{Observed Failure Modes}

A photo of all the specimens before, during and immediately following failure is shown in 
Figure 4-7. Slow motion analysis of the videos during failure allowed the researchers to identify the specific component of each beam that failed first.

The two rectangular specimens with external unbonded reinforcement (Re-30-Ex and Re45-Ex) both had similar failure mechanisms, as shown in Figure 4-7 (a) to (c) and (g) to (i). In both, failure occurred when the top corner of the rectangular beam broke off after development of a diagonal crack. The bearing region broke up as the top corner rotated away. The corner of each rectangular beam broke off close to the line between the edge of the load plate and the top edge of the back-face support plate; this line is highlighted in Figure 4-7 (a) and (g) for the near span. From slow motion analysis of the failure videos, it could be seen that the top corner of these beams began to break off just before the crushing of the support node.

The rectangular specimen with internal bonded reinforcement (Re-45-In) failed in a similar manner to the rectangular beams with external unbonded reinforcement. This specimen also appeared to have the failure of by a diagonal crack and loss of the beam corner.

The truss-like specimens with external unbonded reinforcement (Tr-30-Ex and Tr-45-Ex) both had similar failure mechanisms, as shown in Figure 4-7 (d) to (f) and (j) to (l). Both specimens had little to no cracking prior to failure. There was some spalling that occurred on the side of the struts, highlighted in Figure 4-7 (j). The failure of these specimens was caused by crushing of the concrete in the node under the load. 


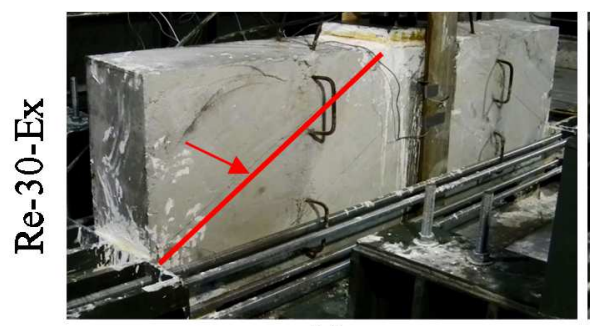

(a)

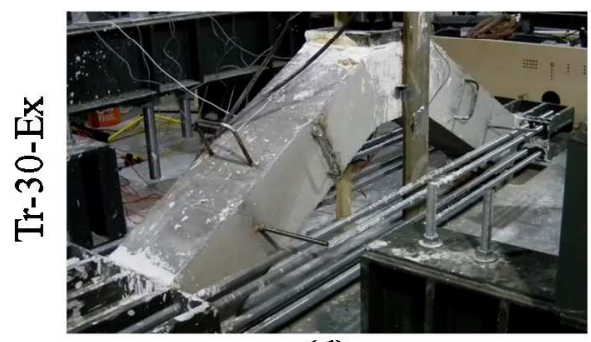

(d)

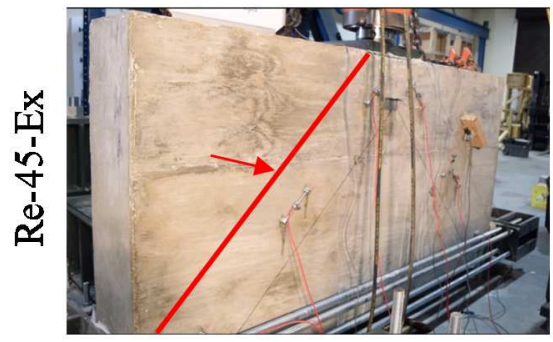

(g)

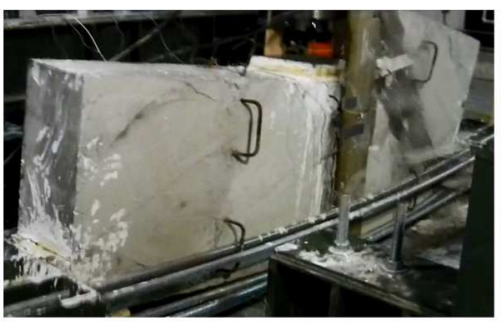

(b)

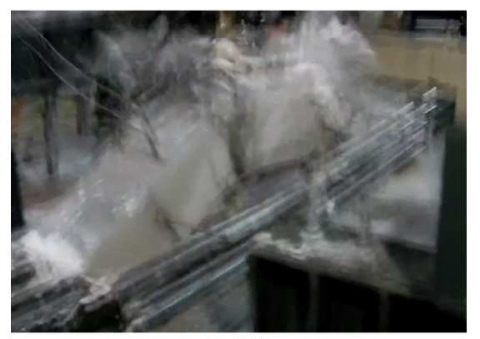

(e)

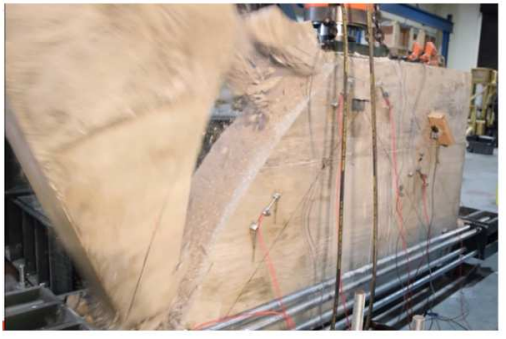

(h)

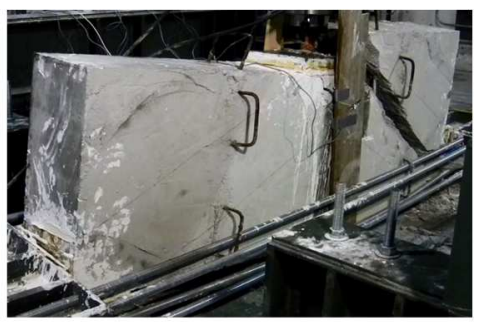

(c)

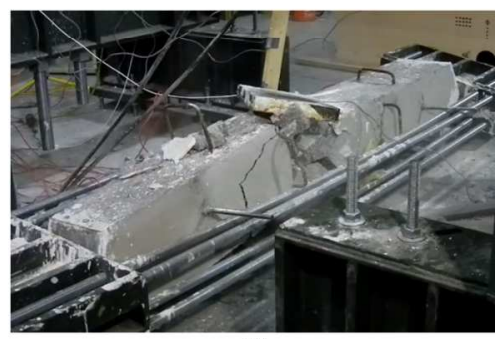

(f)

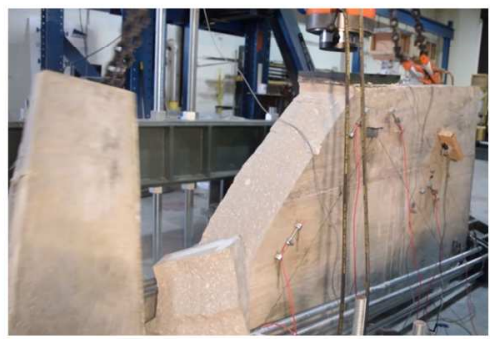

(i)

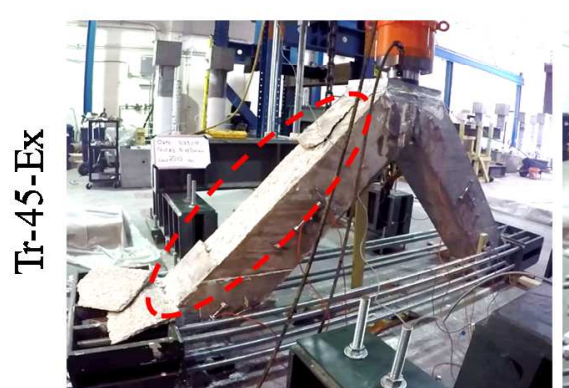

(j)

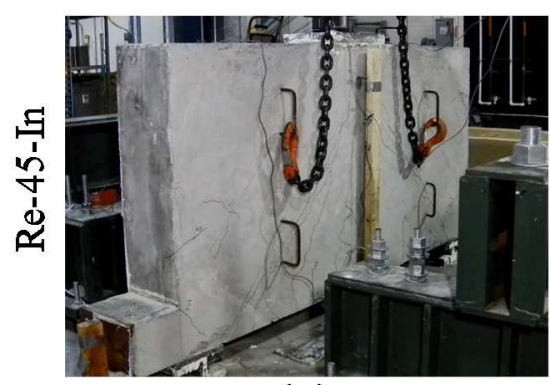

(m)

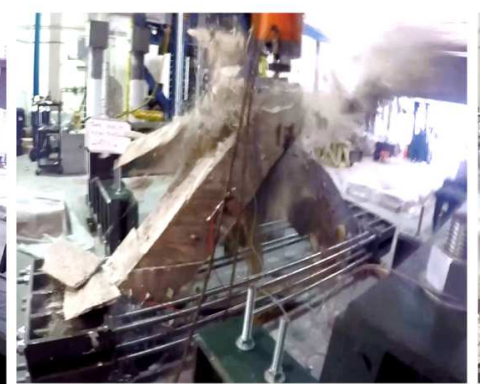

(k)

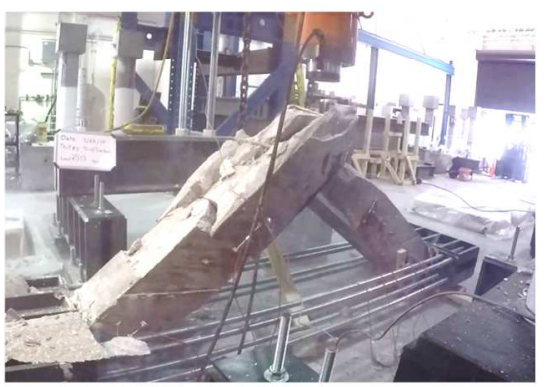

(l)

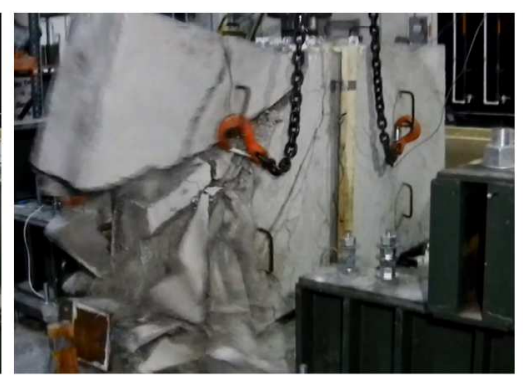

(n)

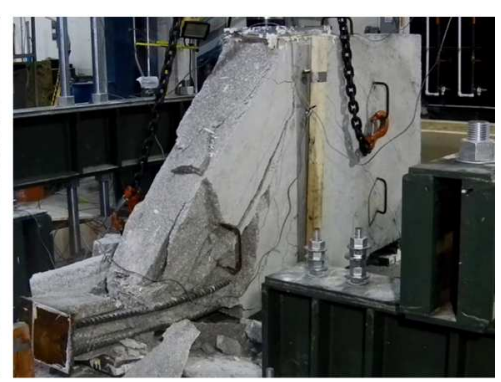

(o)

Figure 4-7: Before, during, and after failure for five tests 


\subsubsection{Low-Cycle Fatigue of Internally Reinforced Rectangular Specimen}

The actual strength of the concrete for specimens cast during the second day of casting was significantly higher than the specified strength. This resulted in one of the specimens included in this paper to have a higher capacity than that of the test setup. Finite element analysis was used to estimate the failure load, which was not substantially higher than the capacity of the test setup (890-kip $[3,960-\mathrm{kN}]$ estimated capacity versus 800 -kip $[3,560-$ $\mathrm{kN}$ ] capacity test setup). This specimen was then tested to failure through low-cycle fatigue.

This specimen was loaded to 800 kips $(3,560 \mathrm{kN})$ and then unloaded until failure. The load versus deflection curve for all the cycles is shown in Figure 4-8 (a). The specimen failed after the seventh cycle. The seven-cycle failure was used with knowledge from previous low-cycle fatigue testing of unreinforced concrete members (ACI 215 [49], and Paskova and Meyer [50]) to determine the one-cycle failure load, as shown in Figure 4-8 (b). The cycled load (800 kips [3,560 kN]) was found to be about 93 percent of the one-cycle failure load, which could then be estimated as 860 kips $(3,825 \mathrm{kN})$. The one-cycle failure load is used in the below discussions. 


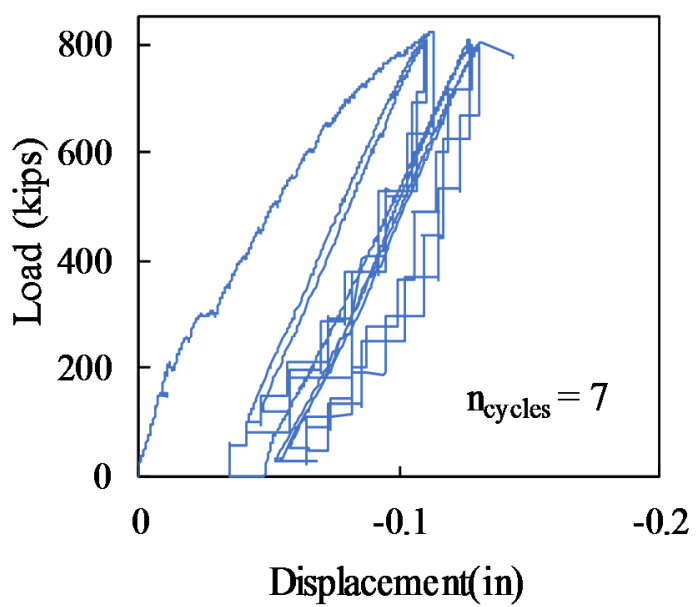

(a)

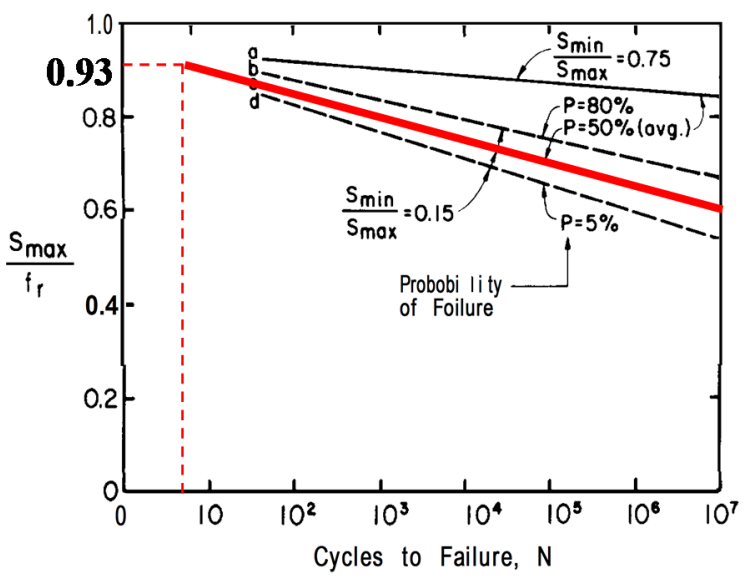

(b)

Figure 4-8: (a) Load-displacement curve for bonded specimen and (b) curve relating number of cycles to failure to ultimate strength $(\mathrm{ACI} 215,1992)(1 \mathrm{kip}=4.44 \mathrm{kN}),(1 \mathrm{in}=25.4 \mathrm{~mm})$

\subsubsection{Analysis of Test Results and Discussion}

The load versus displacement curves for all the beams with external unbonded reinforcement are shown in Figure 4-9. All the unbonded externally reinforced beams had linear elastic responses until the failure load was reached. This can be compared to the nonlinear response of the bonded internally reinforced beam (Re-45-In) shown in Figure 4-8 (a). All the specimens failed in a brittle manner, so no specimens showed any postultimate load ductility. 


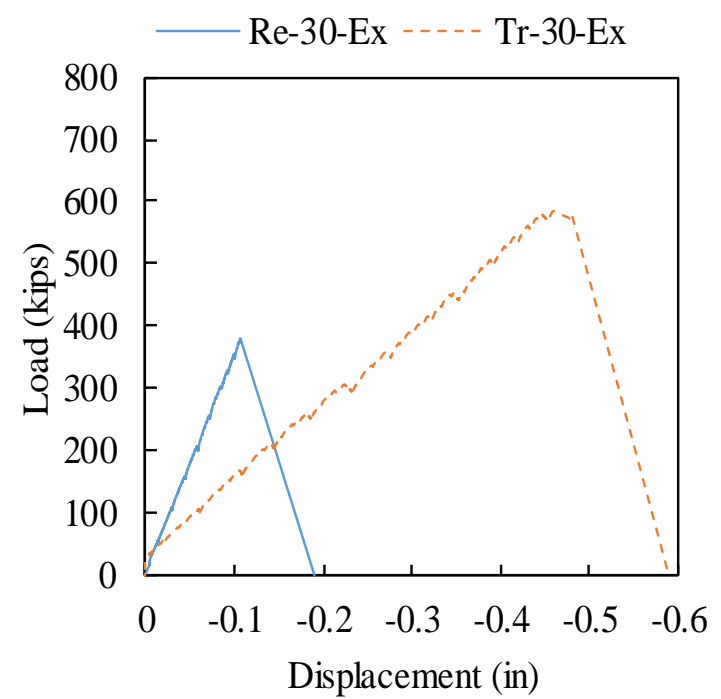

(a)

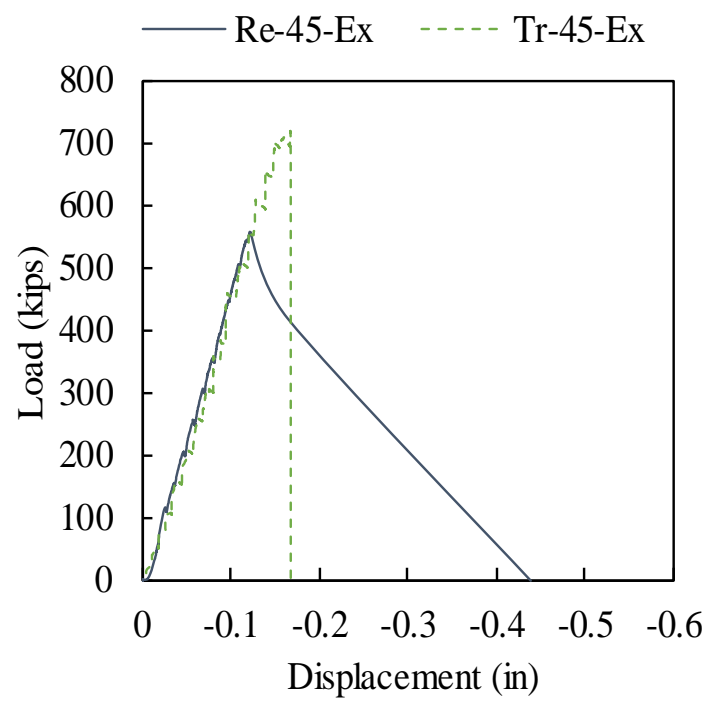

(b)

Figure 4-9: Load versus displacement curve for unbonded specimens with (a) 30-degree and (b) 45 -degree strut angles $(1 \mathrm{kip}=4.44 \mathrm{kN}),(1 \mathrm{in}=25.4 \mathrm{~mm})$

The normalized failure loads for all the specimens are shown in Figure 4-10. These loads are normalized in two different ways to account for the varied behavior between crushing of the compression struts and failure induced by diagonal tension. The first normalization is based on the stress at the strut-to-node interface and the compressive strength of concrete $\left(f^{\prime} c\right)$, as shown in Equation 4-1. Normalizing the strut stress by the compressive strength is appropriate since strut crushing is controlled by the compressive strength. The second normalization is based on the shear stress and the square root of the compressive strength, as shown in Equation 4-2.

$$
\begin{gathered}
N_{\text {strut stress }}=\frac{V_{\text {test }}}{f^{\prime}{ }_{c} A_{\text {strut }} \sin \theta_{\text {strut }}} \\
N_{\text {shear stress }}=\frac{V_{\text {test }}}{b_{w} d \sqrt{f^{\prime}{ }_{c}}}
\end{gathered}
$$

For these specimens, the normalized strut stress is most appropriate for the truss-like 
specimens and the normalized shear stress for the rectangular specimens. This is because the truss-like specimens clearly failed due to crushing of the strut under the support while the rectangular specimen all were influenced by the diagonal tension developing in the strut.

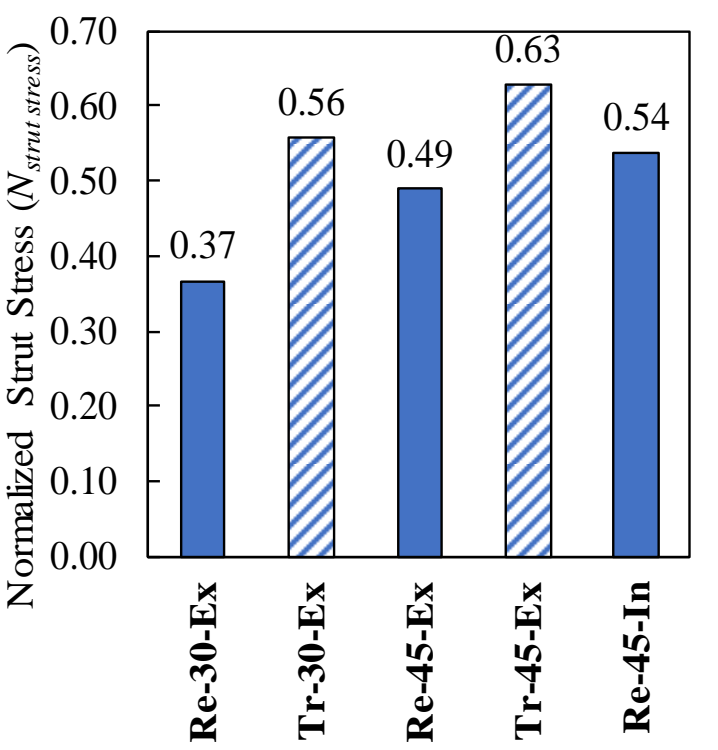

(a)

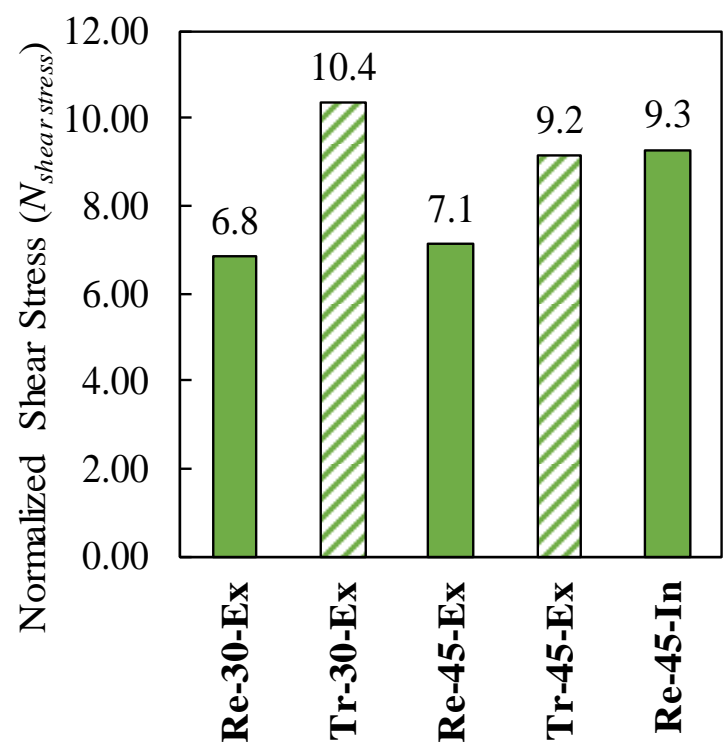

(b)

Figure 4-10: Summary of the experimental failure loads (a) normalized based on strut stress and (b) normalized based on shear stress

There is a clear difference in strength between the rectangular and truss-like specimens. The normalized strength of the truss-like specimens was 41 percent greater than the rectangular specimen for 30-degrees and 25 percent greater for 45 -degree. The failure mechanisms for these beams is also shown in Figure 4-11. Failure in the rectangular beams was triggered by loss of the top corner followed by crushing of the concrete in the support node. The loss of the corner of these beams shows the presence of diagonal tension in these beams. Failure in the truss-like beams was caused by the crushing of the concrete in the node under the support. The difference in strength between the rectangular and truss-like 
specimens was greater in the 30-degree specimens suggesting that diagonal tension becomes more significant as strut angle decreases.

The rectangular beam with external reinforcement (Re-45-Ex) had a normalized shear stress 26-percent less than the beam with internally bonded reinforcement (Re-45-In). This was unexpected as it was anticipated that the additional tensile stresses in the concrete developed from the bonded steel would decrease the capacity of the strut and support node. The difference in serviceability performance between these two specimens is presented above and shown in Figure 4-6.

Evaluation of the effect of strut angle depends on how the data is normalized. As previously mentioned, the failure loads of the truss-like specimens are most appropriately normalized by the strut area and concrete compressive strength, shown in Figure 4-10 (a) and Equation 4-1. Using this normalizing, the 45-degree truss specimen was 12 percent stronger than the 30-degree specimen. The failure loads of the rectangular specimens are most appropriately normalized by shear stress, as shown in Figure 4-10 (b) and Equation 4-2. The 45-degree rectangular specimen was about 4 percent stronger than the 30-degree specimen using this normalization technique. 


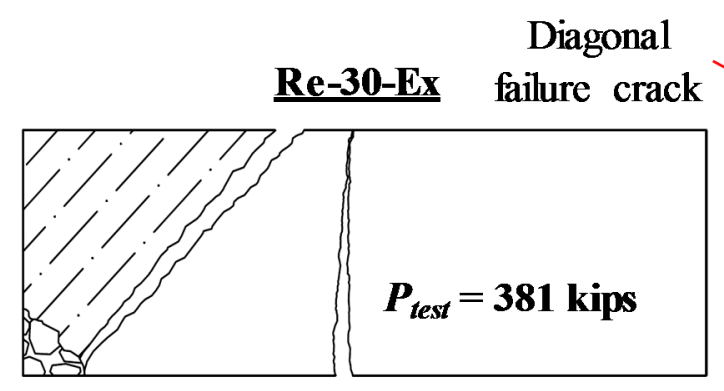

(a)

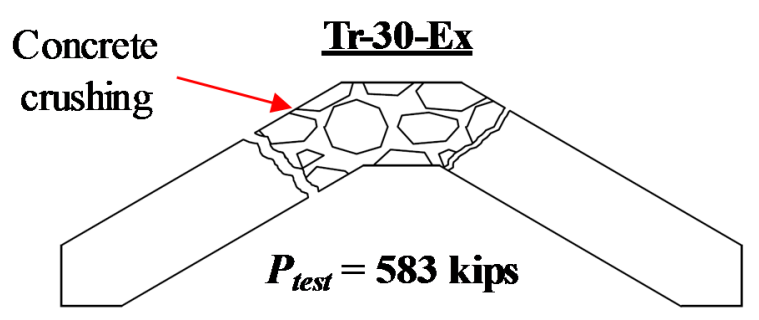

(c)
$\underline{\mathrm{Re}-45-\mathbf{E x}}$

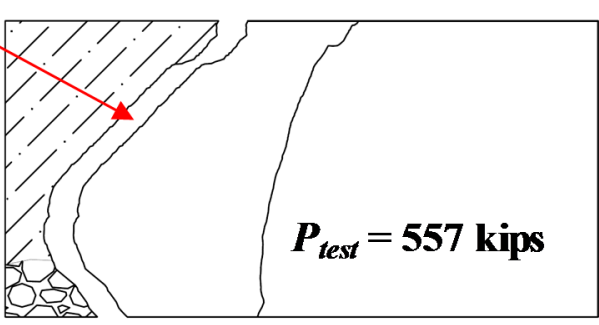

(b)

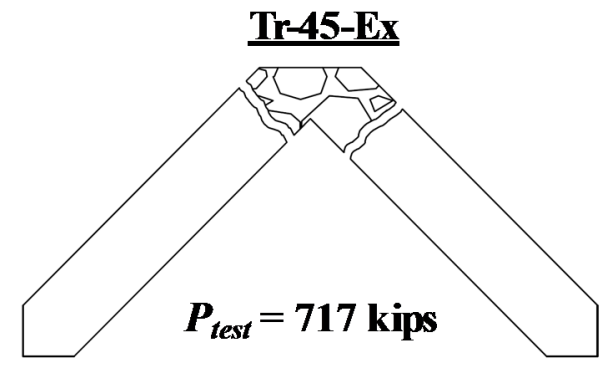

(d)

Figure 4-11: Failure modes of rectangular versus truss specimens

The longitudinal strains along the axis of the struts are plotted against the applied load in Figure 4-12 (a) and (c) and against location in Figure 4-12 (b) and (d) for the rectangular and truss-like specimens, respectively. The presented results are for the 45-degree strut specimens, but similar results were also observed in the 30 -degree specimens. The strain in the middle gage (at mid-length of the strut) was lower than the strain at the ends of the strut for the rectangular specimen. These strains would be consistent with diagonal tension and spread of stresses in the rectangular beams. The longitudinal strains in the truss-like specimens were similar in the lower and middle portions of the strut and then increased at the top of the strut. The failure occurred at the top of the strut in these specimens, which would explain the reason for the increased strain at that location. 


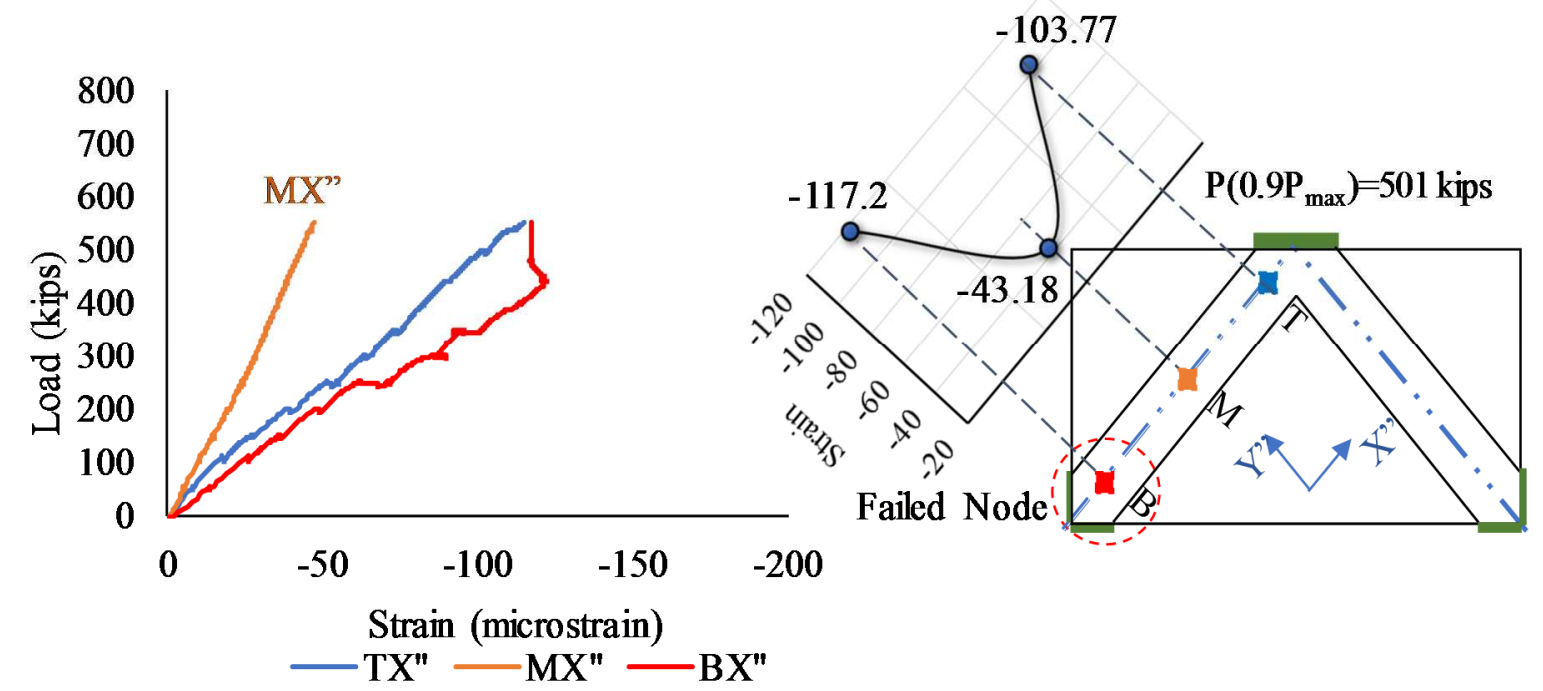

(a)

(b)

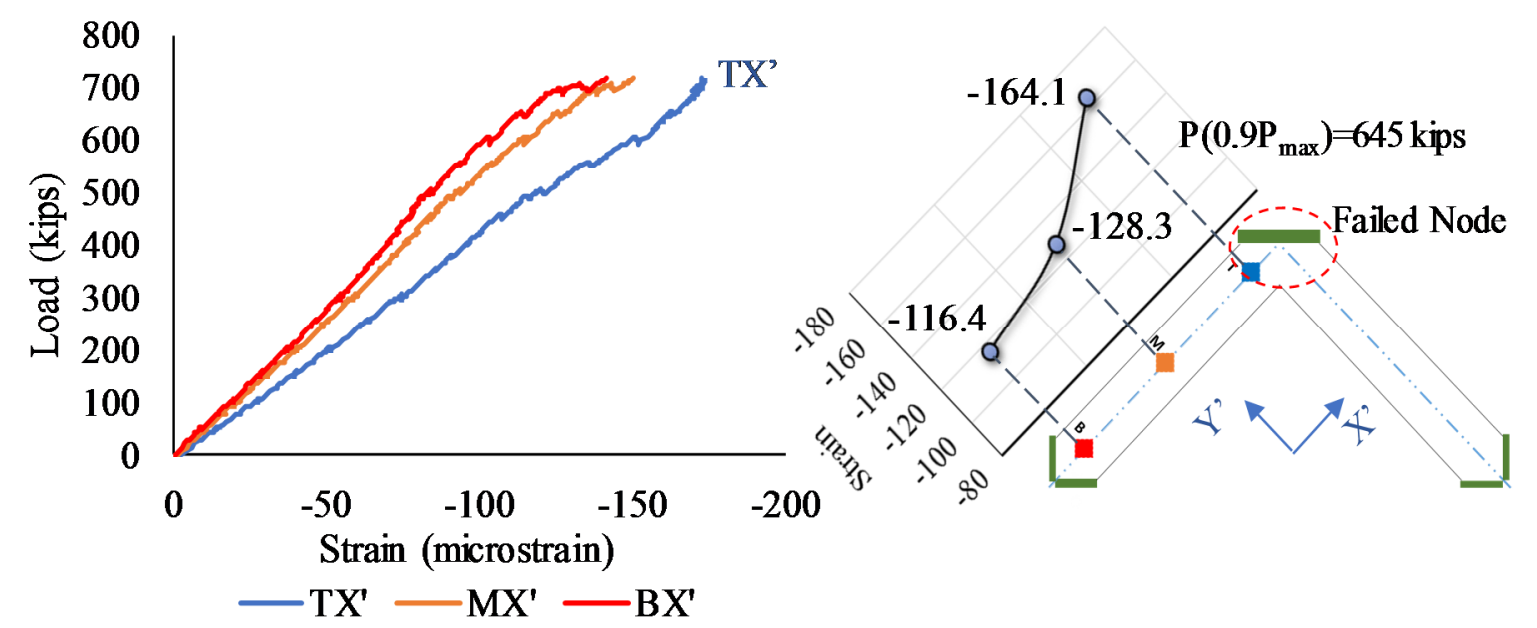

(c)

(d)

Figure 4-12: (a) Load versus longitudinal strain curve and (b) strain versus distance curve at 0.9Pmax for Re-45-Ex and (c) Load versus strain curve and (d) strain versus distance curve at 0.9Pmax for Tr-45-Ex $(1 \mathrm{kip}=4.44 \mathrm{kN})$.

Strain was also measured perpendicular to the strut axis at the mid-length of the strut. These perpendicular strains are plotted versus the load for the 30-degree strut angle rectangular and truss-like specimens (Re-30-Ex and Tr-30-Ex, respectively) in Figure 4-13. Similar results were obtained from the 45 -degree specimens. Transverse strains developed in both 
the rectangular and truss-like specimens. It was expected that there would be larger transverse strains developing in the rectangular specimens than the truss-like specimens, but comparable strains developed in each. The perpendicular strain in the truss-like specimen at the failure load of the rectangular specimen is highlighted in Figure 4-13 (b). The transverse strain of the rectangular specimen was about 16 percent greater than the truss-like one in exactly the middle of the strut.

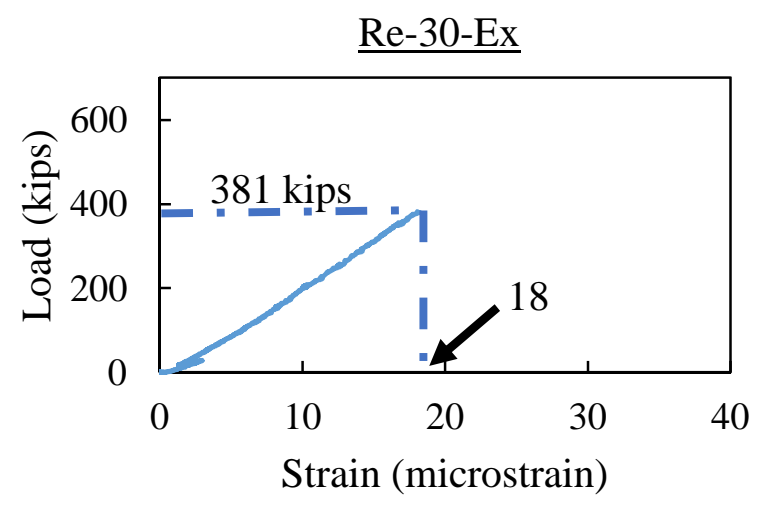

(a)

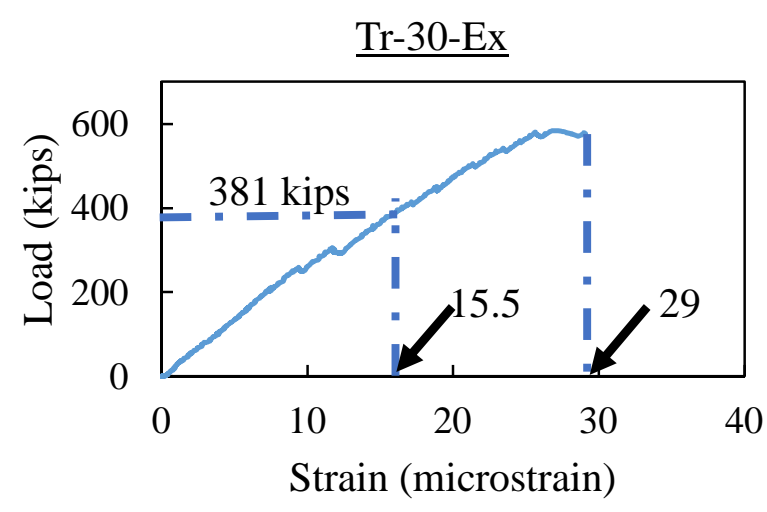

(b)

Figure 4-13: Load versus perpendicular strut strain for (a) Re-30-Ex and (b) Tr-30-Ex (1 kip = $4.44 \mathrm{kN})$.

\subsection{Comparison with Current STM Estimates}

A comparison between the actual test capacity and estimated capacity of the beams using ACI 318-14 [3], the 2016 AASHTO LRFD Bridge Design Specification [19] will be presented in this section. A summary of the actual capacity of each specimen alongside the estimated capacity using both ACI 318-14 [3] and AASHTO LRFD [19] is presented in Table 4-3. Note that the estimated capacities do not include the strength reduction factors $(\phi)$. The measured strength normalized by the estimated capacity is shown in Figure 4-14; note that a measured over estimated capacity ratio (M/E) less than 1.0 is unconservative. 
The AASHTO LRFD [19] provisions conservatively estimated the failure load for all the specimens. The ACI 318-14 provisions conservatively estimated the capacity of two of the five specimens (Tr-45-Ex and Re-45-In). The other three specimens were unconservatively estimated using the ACI 318-14 provisions: Re-30-Ex had an M/E of 0.74, Tr-30-Ex was 0.81, and Re-45-Ex was 0.98 .

Table 4-3: Measured and Estimated Failure Loads

\begin{tabular}{|c|c|c|c|c|c|}
\hline No. & $\begin{array}{c}\text { Specimen } \\
\text { Name }\end{array}$ & $\begin{array}{c}\boldsymbol{P}_{\text {crack }}, \mathbf{k i p s} \\
(\mathbf{k N})\end{array}$ & $\begin{array}{c}\boldsymbol{P}_{\text {test }}, \mathbf{k i p s} \\
(\mathbf{k N})\end{array}$ & $\begin{array}{c}\boldsymbol{P}_{\text {ACI }}, \mathbf{k i p s} \\
(\mathbf{k N})\end{array}$ & $\begin{array}{c}\boldsymbol{P}_{\text {AASHTo, }}, \\
\mathbf{k i p s}(\mathbf{k N})\end{array}$ \\
\hline 1 & $\operatorname{Re}-30-E x$ & $25(111)$ & $381(1690)$ & $512(2277)$ & $380(1690)$ \\
\hline 2 & $T r-30-E x$ & $100(445)$ & $583(2590)$ & $709(3153)$ & $375(1668)$ \\
\hline 3 & $\operatorname{Re}-45-E x$ & $60(267)$ & $557(2480)$ & $568(2526)$ & $488(2170)$ \\
\hline 4 & $T r-45-E x$ & $382(1700)$ & $717(3190)$ & $691(3073)$ & $517(2299)$ \\
\hline 5 & $\operatorname{Re}-45-I n$ & $60(267)$ & $860(3830)$ & $669(2975)$ & $501(2228)$ \\
\hline
\end{tabular}




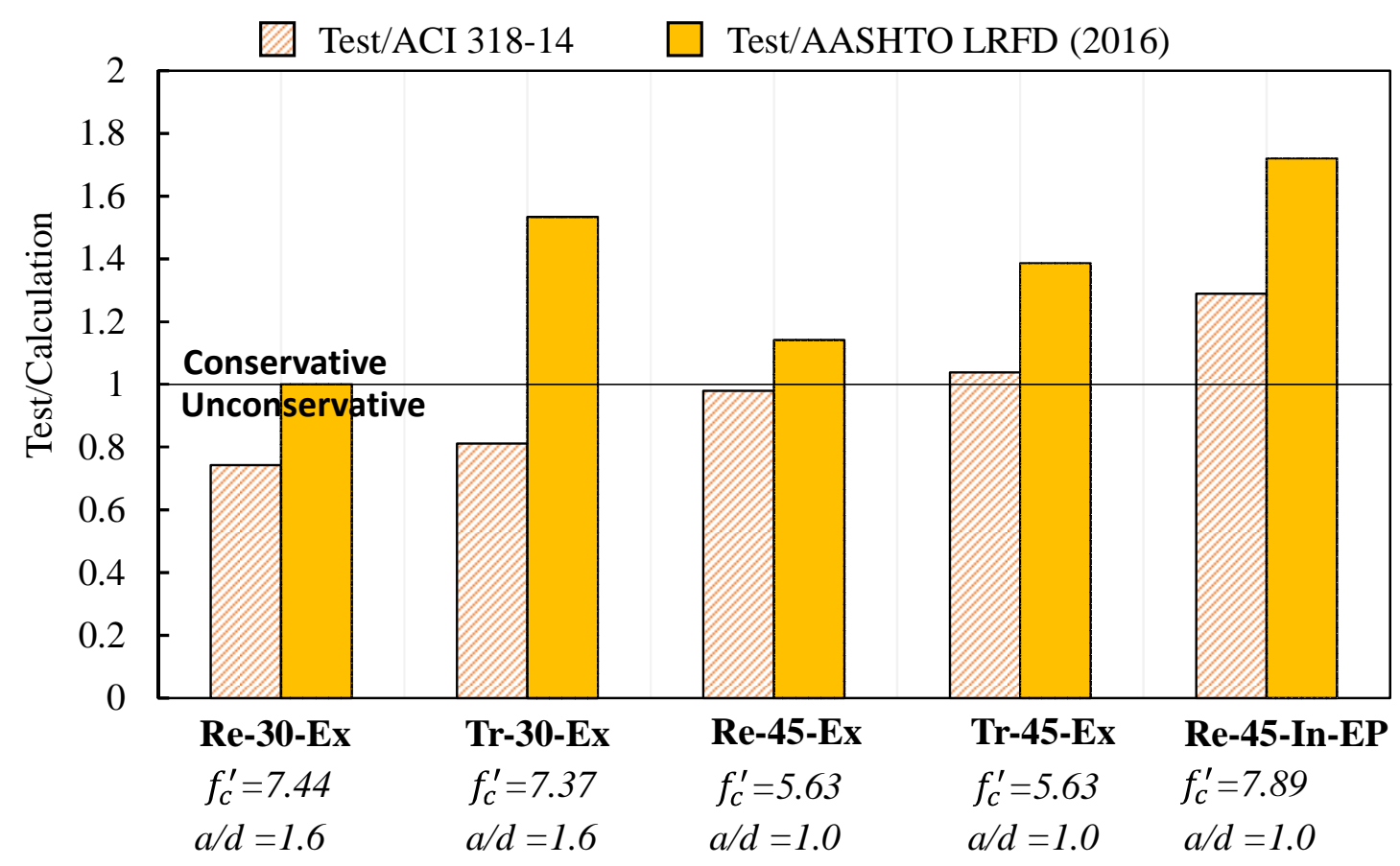

Figure 4-14: Measured strength divided by estimated strength using ACI 318-14 [3] and AASHTO LRFD [19].

The predicted failure modes compared with observed failure modes are shown in Table 4-4. Generally, the predicted failure node using ACI 318-14 [3] was similar to the predicted failure node using AASHTO LRFD [19], although the controlling face of the failure node was different for some members. These predicted failures were similar to the observed failure mode for most of the members. The only significant difference was the prediction of the failure location for Re-45-In, which had internally bonded reinforcement with welded plates at the end. An in-depth discussion of this specimen can be found in Rezaei et al. [11]. 
Table 4-4: Predicted versus observed failure modes

\begin{tabular}{|c|c|c|c|}
\hline Specimen & ACI Predicted & AASHTO Predicted & Observed \\
\hline Re-30-Ex & $\begin{array}{c}\text { Strut-to-Node } \\
\text { Interface (Support } \\
\text { Nodes) }\end{array}$ & $\begin{array}{c}\text { Back Face } \\
\text { (Support Nodes) }\end{array}$ & $\begin{array}{l}\text { Diagonal Tension } \\
\text { Support Nodes }\end{array}$ \\
\hline $\operatorname{Tr}-30-E x$ & $\begin{array}{c}\text { Back Face } \\
\text { (Support Nodes) }\end{array}$ & $\begin{array}{c}\text { Back Face } \\
\text { (Load and Support } \\
\text { Nodes) }\end{array}$ & Load Node \\
\hline Re-45-Ex & $\begin{array}{c}\text { Strut-to-Node } \\
\text { Interface (Support } \\
\text { Nodes) }\end{array}$ & $\begin{array}{c}\text { Back Face } \\
\text { (Support Nodes) }\end{array}$ & $\begin{array}{l}\text { Diagonal Tension } \\
\text { Support Nodes }\end{array}$ \\
\hline $\operatorname{Tr}-45-\mathrm{Ex}$ & $\begin{array}{l}\text { Back Face } \\
\text { (Load Node) }\end{array}$ & $\begin{array}{l}\text { All Faces (Load and } \\
\text { Support Nodes) }\end{array}$ & Load Node \\
\hline Re-45-In & $\begin{array}{l}\text { Strut-to-Node } \\
\text { Interface } \\
\text { (Load Node) }\end{array}$ & $\begin{array}{l}\text { Back Face } \\
\text { (Load Node) }\end{array}$ & $\begin{array}{l}\text { Diagonal Tension } \\
\text { Support Nodes }\end{array}$ \\
\hline
\end{tabular}

\subsection{Summary and Conclusions}

The work of this project was to explore the difference in behavior between rectangular and truss-like beams without shear reinforcement. The experimental work consisted of testing five large-scale beams with different geometries (rectangular and truss-like), different strut angles (30 and 45 degrees), and different longitudinal reinforcement (external unbonded and internal bonded). The specimens were tested to failure and loads, deflections, and strains along the strut length perpendicular and parallel to the strut axis were measured. The behavior of the specimens and struts during testing was monitored, and the experimental capacity was compared to the estimated capacity using ACI 318-14 [3] and AASHTO LRFD [19].

Several observations and conclusions can be made based on the results of this study: 
- Geometry: Truss-like specimens failed at higher loads than rectangular specimens (with the same angle). The truss-like specimens clearly failed due to crushing of the concrete in the node under the load point. Failure of the rectangular specimens was clearly triggered by the top corner of the specimens breaking off followed by failure of the support node. Pujol et al. [8] had previously found that strut geometry in vertically oriented struts did not influence the strut strength. The results from Pujol et al. [8] coupled with the observation from the failure of the rectangular specimens would suggest that there are diagonal tensile stresses that develop in these rectangular beam elements that influence the behavior of the member.

- Type of Reinforcement: The rectangular beam with external reinforcement had a normalized shear stress 26 percent less than the beam with internally bonded reinforcement. This was unexpected, since it was thought that the internal bonded reinforcement would increase the tensile stresses in the strut. Additional research is currently being done to further investigate this effect.

- Strut Angle: The 45-degree truss specimen was 12 percent stronger than the 30degree truss specimen. The 45 -degree rectangular specimen was about 4 percent stronger than the 30-degree specimen. These results would suggest that strut angle does influence the strength of struts. Further testing should be done with struts at additional angles to identify the exact relationship.

The current ACI 318 [3] STM provisions do not estimate the failure load of all the specimens conservatively. Design recommendations have been made by Klein et al. [12] to capture the influence of diagonal tension in these members. 


\subsection{Acknowledgements}

The authors would like to thank Florida International University (FIU) for supporting this research. The authors would also like to thank the several undergraduate and graduate research assistants who helped on the project: Lamar Case, Manuel Matus, Francisco Chitty, and Dewan Hossain.

\subsection{Appendix}

The following symbols are used in the paper:

a/d $\quad=$ shear span-to-depth ratio

$A_{\text {strut }}=$ area of strut-to-node interface, in. $^{2}$

$b_{w} \quad=$ web width, wall thickness, or diameter of circular section, in.

$d \quad=$ distance from extreme compression fiber to centroid of longitudinal tension reinforcement, in.

$f_{c}{ }^{\prime} \quad=$ specified compressive strength of concrete, psi.

$L \quad=$ length of specimens, in.

$N_{\text {shear stress }}=$ stress at strut-to-node interface normalized by concrete compression strength

$N_{\text {strut stress }} \quad=$ shear stress normalized by square root of concrete compression strength $P_{\text {crack }}=$ applied load at first cracking, kips

$P_{\text {test }} \quad=$ applied load at failure, kips

$P_{A C I}=$ estimated applied load at failure using ACI 318, kips

$P_{\text {AASHTO }}=$ estimated applied load at failure using AASHTO LRFD, kips

$V_{\text {test }} \quad=$ shear force at beam failure, kips 
$Z \quad=$ beam height of test specimens, in.

$\theta_{\text {strut }}=$ angle of strut, rad. 


\title{
Chapter 5: Effect of Development and Beam Geometry on Behavior of Concrete
}

\section{Deep Beams ${ }^{\text {a }}$}

\author{
*Nazanin Rezaei ${ }^{\mathrm{b}}$, Gary Klein ${ }^{\mathrm{c}}$, and David Garber ${ }^{\mathrm{d}}$
}

\subsection{Abstract}

The effect of development type and length and beam geometry on the behavior of discontinuity regions in concrete deep beams was investigated through experimental testing and numerical study. Observations of cracking patterns and measurements of load and displacement at midspan of four large-scale concrete deep beams tested under a threepoint load setup were used to calibrate numerical models. Thirty-five specimens were then modeled in a nonlinear finite element software to evaluate the strength of deep beams with different development lengths, development types, strut angles, and beam geometries. Development length and type of development was found to impact the presence of tensile stress in the support nodes. A rectangular beam geometry was found to cause diagonal tension stresses in the struts, not present in truss-like specimens. The tensile stresses from reinforcement development and diagonal tension were found to not be additive in these rectangular beams.

Keywords: Strut-and-tie, Finite element, Deep beam, Development, Failure mechanism

a Submitted to ACI Structural Journal

b Corresponding Author. PhD candidate, Civil and Environmental Engineering, Florida International University, Miami, Fl, USA. E-mail: nreza002@ fiu.edu.

c Executive Vice President and Senior Principal, WJE (Wiss, Janney, Elstner) Associates, Northbrook, Illinois, USA. E-mail: gklein@wje.com.

d Assistant Professor, Civil and Environmental Engineering, Florida International University, Miami, Fl, USA. E-mail: dgarber@ fiu.edu. 


\section{$5.2 \quad$ Introduction}

The strut-and-tie method (STM) is a simple and reliable tool for designing reinforced concrete deep beam members and discontinuity regions. STM relies on modeling the stress flow in a member with a theoretical truss or kinematic model composed of compression elements (struts), tension elements (ties), and the intersection of these elements (nodes). Nodal zones are the critical regions of the strut-and-tie model and can be defined based on the types of elements intersecting the node; they can be bounded by three or more struts (CCC), two or more struts and a tie (CCT), or a strut or struts and ties in two or more directions (CTT). According to Yun [51], the strength of nodal zones in the structure depends on:

- Supports, struts, anchorage plates, and reinforcement, which can introduce confinement in the nodal zones,

- Ties which are anchored in, or across, a nodal zone, which affect strain distribution in nodal zones and can cause splitting stresses.

Other researchers have also confirmed the effects of confinement through experimental testing of beams with different bearing areas [52] and the effects of tension reinforcement [53]. These effects lead to nodes in the presence of tension (CCT and CTT) having lower capacities than nodes under only compression (CCC), which may also experience benefits from confinement.

The strength of a member using STM is also dependent on the development of the reinforcement required to provide sufficient strength in ties. Development of reinforcement can be achieved by providing a sufficient embedment length of straight reinforcement. Hooked and headed bars can be used to decrease the required development length, but can 
lead to congestion, which can cause constructability issues and poor concrete consolidation. Alternatively, tie reinforcement can be welded to anchorage plates that develop the tie force at the weld. Whether straight, hooked, or headed bars or some other means for bar development are used, the general requirement for STM is that the tie force be developed at the point where the centroid of the tie leaves the extended nodal zone [3]. However, it is considered good practice to develop the yield strength of the tie at the face of the support or reaction due to the likelihood of cracks at these locations. Ties can fail due to yielding of the tie reinforcement (which results in a desirable ductile failure), rupture or failure of the hook, headed bar, or mechanical device, or development failure of reinforcement [54].

There has been some research done on the impact of headed reinforcement on the behavior of CCT nodes [54]-[57]. Thompson et al. [54] investigated the effect of headed bars on CCT node behavior through large-scale experimental testing. In their study, sixty-four CCT node specimens with 30,45 , and 55-degree strut angles were tested to failure. The researchers found that using small headed bars can increase the strength of the CCT nodes by up to 44 percent as compared to the non-headed bar case. They also found that bars required smaller head sizes as strut angle decreased, due to the increased available development length in the extended nodal zone.

These nodal zones are only one component of a complete strut-and-tie model. A strut-andtie model is composed of struts, ties, and nodal zones, as shown in Figure 5-1 for a simplysupported four-point loaded deep beam. During design, each of these elements must be designed and checked individually to resist the corresponding forces in the truss modeling the force flow through the beam. Current design provisions [3] base the strength of strut 
elements on the strut type. Bottle-shaped struts are thought to be struts where stress can spread throughout the length of the strut. Prismatic struts are struts where compressive stresses are not able to spread. Bottle-shaped struts can be idealized as prismatic struts, but current ACI definitions would suggest this does not eliminate development of transverse tension. Recent work [8], [10], [12] has brought into question whether this is the actual behavior of these elements.

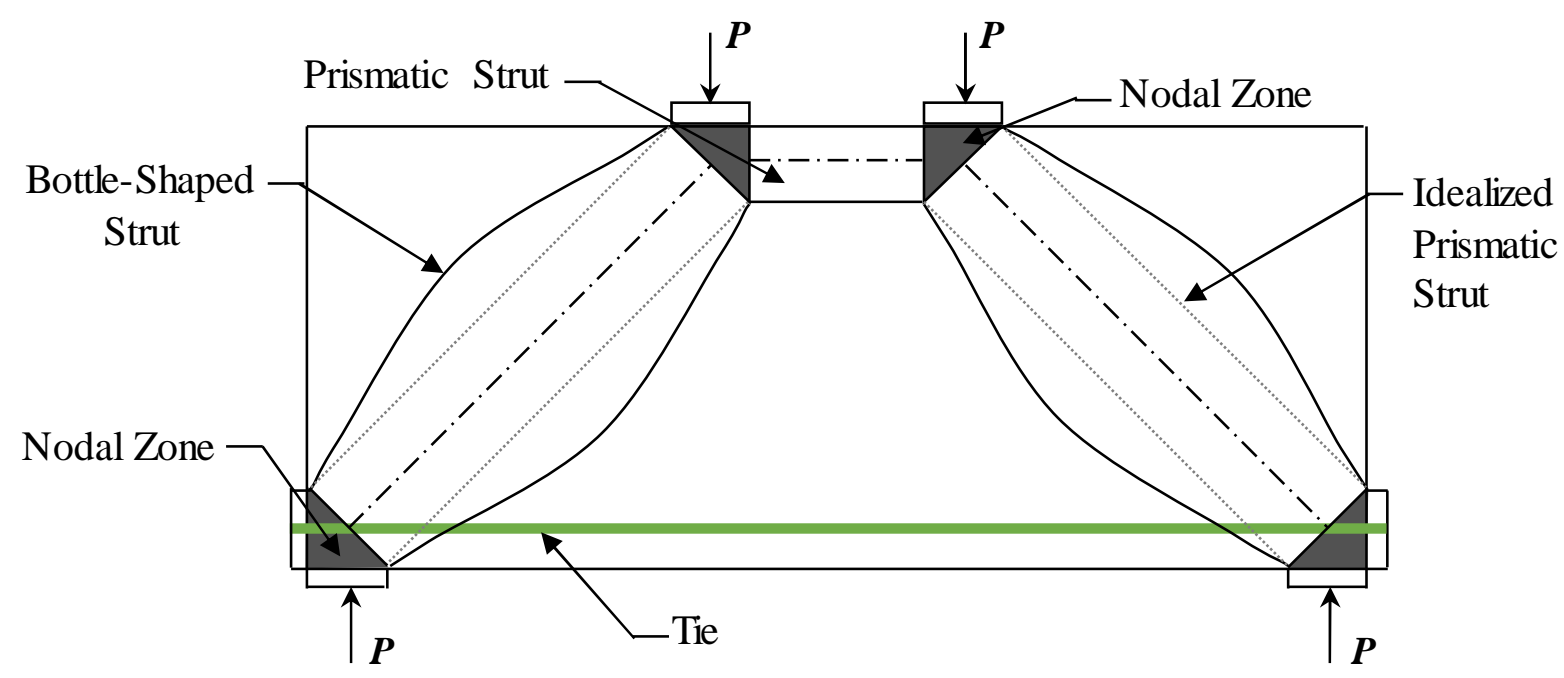

Figure 5-1: Description of strut-and-tie model with ACI 318-14 [3] strut definitions

The primary purpose of this study is to continue to investigate the influence of tension on the overall behavior of deep beam members through connecting the influence of development length to reinforcement type and specimen geometry.

\subsection{Research Significance}

There is a gap in understanding of how various factors affect the behavior of nodal zones and disturbed regions in deep beam members. This research investigated four independent parameters, including: overhang length (ranging from no development length provided past 
the end of the bearing to full development provided for the specific development type), rebar development type (straight, hooked, internally bonded and externally unbonded reinforcement attached to the external plates), beam type (rectangular and truss-like), and strut angle $(30,45$, and 60 degrees). The goal of the research was to determine the impact of these parameters on the development of tension in nodal zones and diagonal struts and to determine if the effects were additive or independent of one another.

\subsection{Experimental Program}

\subsubsection{Specimen Geometry and Design}

The experimental program conducted at Florida International University (FIU) included the experimental testing of several concrete deep beams [10]. The results for four of these specimens are presented in this paper to validate the numerical analysis provided later. The details for the four specimens tested experimentally are shown in Table 5-1 and in Figure 5-2 (with the appropriate overhang length $\left[\ell_{2}\right]$ and reinforcement type). The specimens all had the same span length (span length 96 inches [2.44 m]), height (48 inches [1.22 m]), and width (12 inches [0.305 m]).

The naming convention for all the specimens is based on the following experiment variables:

- Specimen Type: "Re" for rectangular and "Tr" for truss-like

- Reinforcement Type: "ExU" for externally unbonded; "S" for internal straight bonded; " $\mathrm{H}$ " for internal hooked bonded; and "EP" for internal bonded welded to steel plate 
- Overhang Length $\left(\ell_{2}\right)$ : distance from outside of support bearing to end of development length

Note that the results from three of the four specimens (all but $\operatorname{Re}_{(E)}-\mathrm{H}-0$ ) have been previously presented in Rezaei et al. [10].

Table 5-1: Details of experimental test specimens (“(E)” subscript identifies experimental tests)

\begin{tabular}{|c|c|c|c|c|c|}
\hline No. & $\begin{array}{c}\text { Specimen } \\
\text { Name }\end{array}$ & $\begin{array}{c}\text { Specimen } \\
\text { Type }\end{array}$ & Reinforcement Type & $\begin{array}{c}\boldsymbol{\ell}_{2, \mathbf{i n} .} \\
(\mathbf{m m})\end{array}$ & $\begin{array}{c}\boldsymbol{f}^{\prime}{ }^{\prime}, \mathbf{k s i} \\
(\mathbf{M P a})\end{array}$ \\
\hline \hline 1 & $\operatorname{Re}_{(\mathrm{E})-\mathrm{H}-0}$ & Rectangle & Internal-Hooked & $0(0)$ & $7.86(54)$ \\
\hline 2 & $\operatorname{Re}_{(\mathrm{E})-\mathrm{EP}-9.5}$ & Rectangle & Internal-Extended Plate & $\begin{array}{c}9.5 \\
(241)\end{array}$ & $7.89(54)$ \\
\hline 3 & $\operatorname{Re}_{(\mathrm{E})}-\mathrm{ExU}-0$ & Rectangle & External Unbonded & $0(0)$ & $5.63(38)$ \\
\hline 4 & $\operatorname{Tr}_{(\mathrm{E})-\mathrm{ExU}-0}$ & Truss & External Unbonded & $0(0)$ & $5.63(38)$ \\
\hline
\end{tabular}

An external plate was welded onto the internally bonded longitudinal reinforcement in one of the experimental specimens $\left(\operatorname{Re}_{(\mathrm{E})}-\mathrm{EP}-9.5\right)$, shown in Figure 5-2 (b). CCT and CTT nodes have generally lower strength capacity than CCC nodes. According to previous studies, using steel cage and anchorage plates on top of the support plates may change the formation of the CCT node [51], [58]. In the case of developing a \#11 reinforcement properly, the required head on a headed bar would create congestion of the plates at the end [56]. For this reason, all the bars were welded to one plate at each end. 


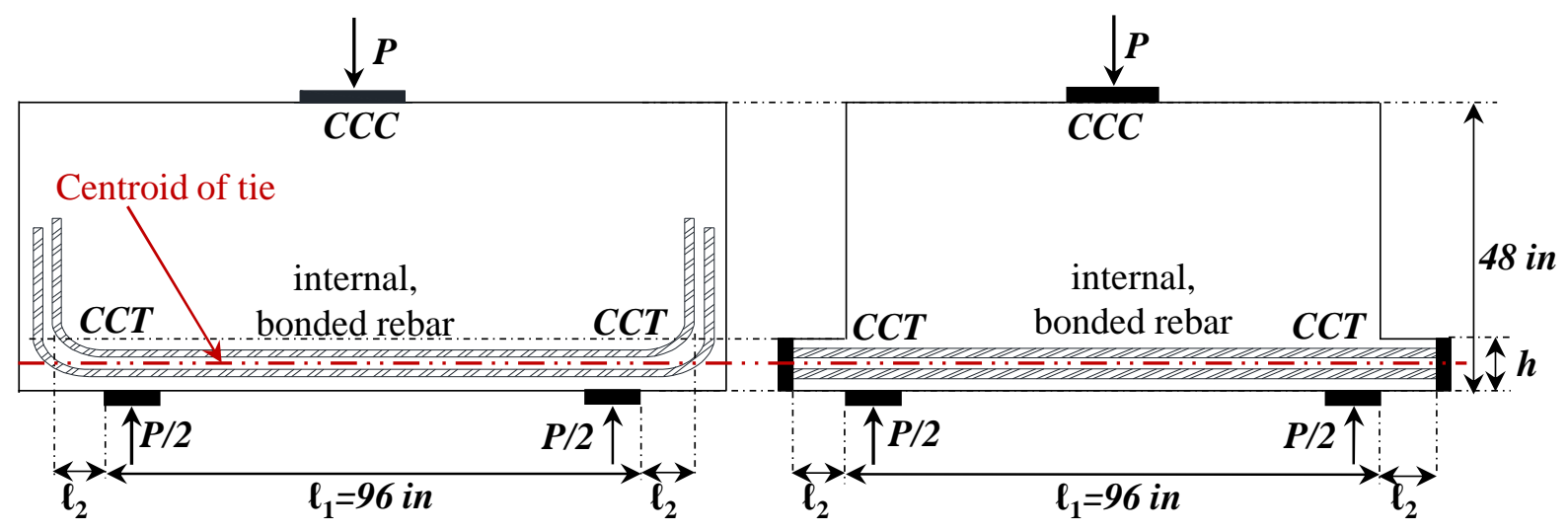

(a)

(b)

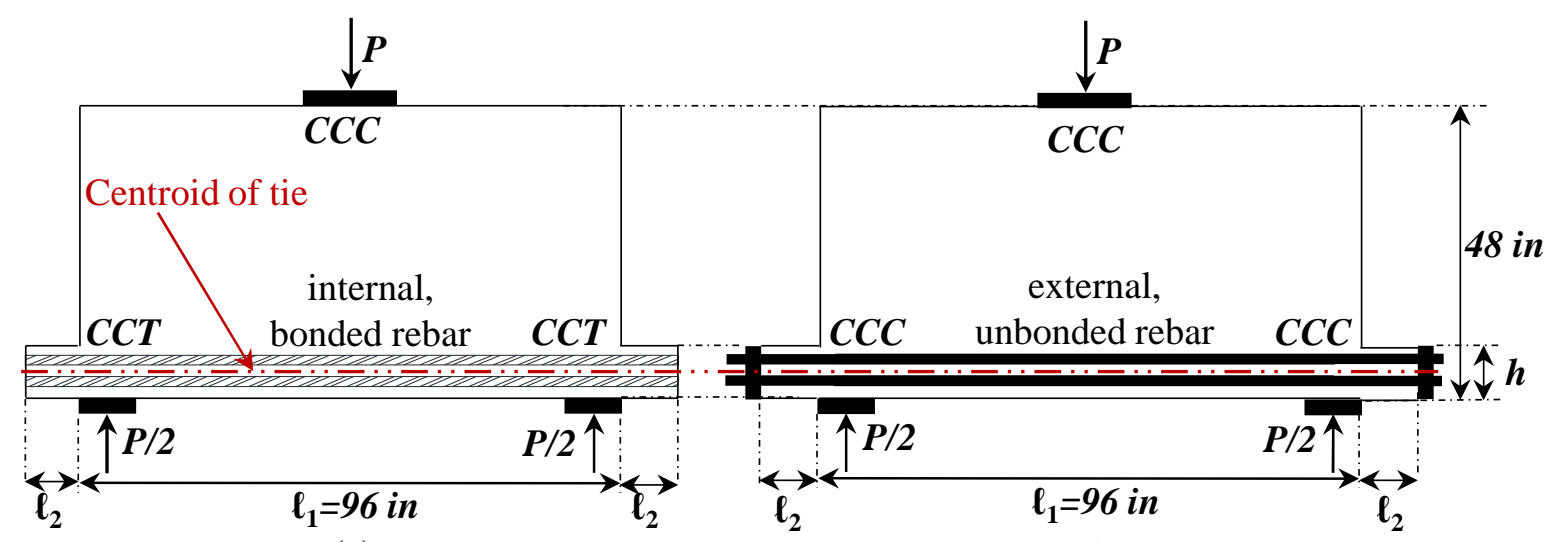

(c)

(d)

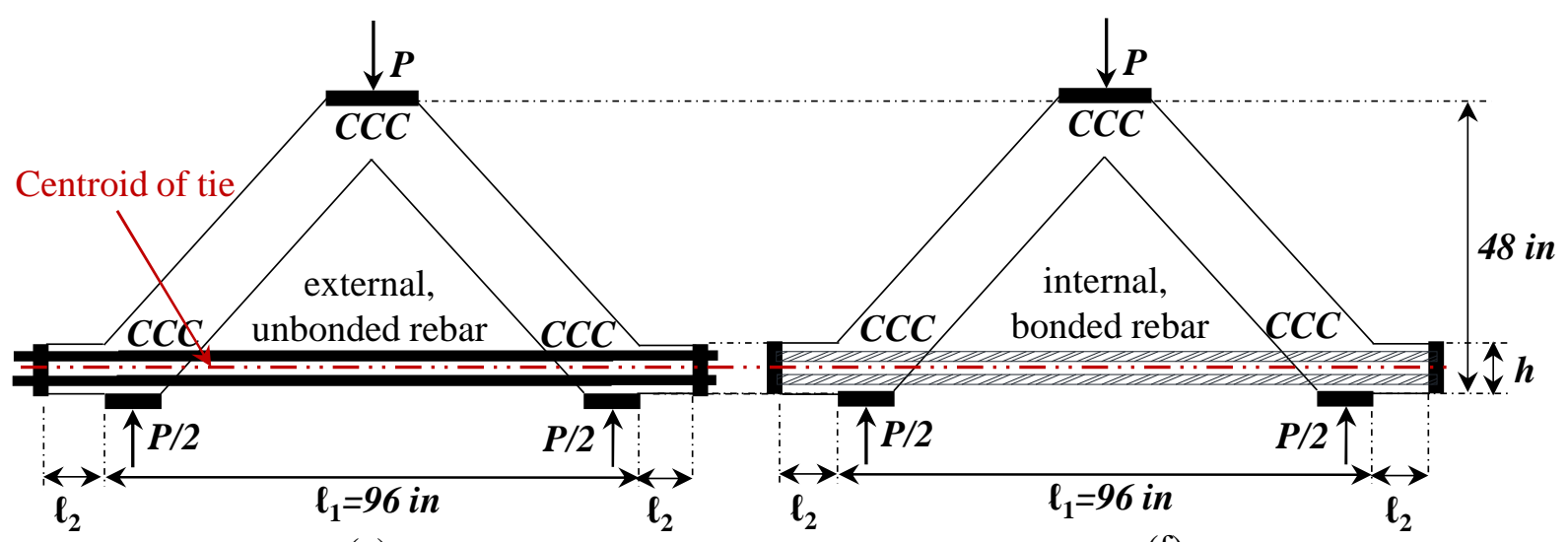

(e)

(f)

Figure 5-2: Typical specimens geometry for beam series (a) Re-H, (b) Re-EP, (c) Re-S, (d) ReExU, (e) Tr-ExU, (f) Re-EP, where $\ell_{2}$ is overhang length and $\mathrm{h}$ is 8.5 inches $(215 \mathrm{~mm}$ )

The full experimental matrix for the numerical investigation is presented in later sections, but uses the same nomenclature described above. 


\subsubsection{Material}

The externally unbonded reinforced specimens $\left(\operatorname{Re}_{(\mathrm{E})}-\mathrm{Ex} U-0\right.$ and $\left.\operatorname{Tr}_{(\mathrm{E})}-\mathrm{Ex} U-0\right)$ were cast at the same time using the concrete mixture shown in Table 5-2. The internally reinforced cases $\left(\operatorname{Re}_{(\mathrm{E})}-\mathrm{H}-0\right.$ and $\left.\operatorname{Re}_{(\mathrm{E})}-\mathrm{EP}-9.5\right)$ were cast at the same time on another day using the same design mixture as the first cast. The maximum size of the aggregates in this mixture was 0.5 inches $(12.7 \mathrm{~mm})$. A 0.48 water-to-cement ratio was used in both casts. The compressive strength measured on the test days are shown in Table 5-2. The ties were overdesigned to not govern the failure. The specified yield strength for external and internal tie reinforcement was $100 \mathrm{ksi}(690 \mathrm{MPa})$ and $60 \mathrm{ksi}(413 \mathrm{MPa})$, respectively.

Table 5-2: Concrete mix design

\begin{tabular}{|c|c|c|c|c|c|c|c|}
\hline & $\begin{array}{l}\text { Cement } \\
\text { lb (kg) }\end{array}$ & $\begin{array}{l}\text { Water } \\
\text { lb (kg) }\end{array}$ & $\begin{array}{c}\text { Fine } \\
\text { agg. } \\
\text { lb (kg) }\end{array}$ & $\begin{array}{c}\text { Coarse } \\
\text { agg. } \\
\text { lb (kg) }\end{array}$ & $\begin{array}{c}\text { Admix. } \\
\text { oz/yd } \\
(\mathrm{kg} / \mathrm{m})\end{array}$ & $\begin{array}{l}\text { Specified } \\
\text { slump } \\
\text { in. }(\mathrm{mm})\end{array}$ & air \\
\hline Quantities & $\begin{array}{c}690 \\
(312)\end{array}$ & $\begin{array}{c}333 \\
(151)\end{array}$ & $\begin{array}{l}1,808 \\
(820)\end{array}$ & $\begin{array}{c}920 \\
(417)\end{array}$ & $\begin{array}{c}38 \\
(1.18)\end{array}$ & $\begin{array}{c}5-7 \\
(127-178)\end{array}$ & $\begin{array}{c}1.5- \\
4.5 \%\end{array}$ \\
\hline
\end{tabular}

\subsubsection{Loading Setup}

An 800-kip $(3,558-\mathrm{kN})$ load frame was designed for the experimental testing, shown in Figure 5-3. The load frame consisted of an 800-kip (3,558 kN) hydraulic jack, four 250kip $(1,112 \mathrm{kN})$ calibrated load cells to measure the load, pin supports at the beam ends, a node beam to provide the necessary longitudinal restraint in the externally reinforced beams, and linear potentiometers to measure vertical and horizontal deflection. The node beam was not used for the internally reinforced specimens. High strength gypsum cement mortar was used at the supports and load points to level the test specimens and ensure the load was applied evenly on the specimens. 


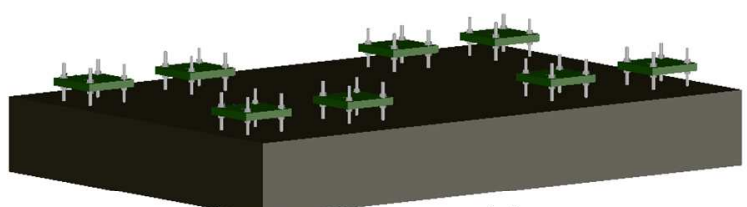

(a)

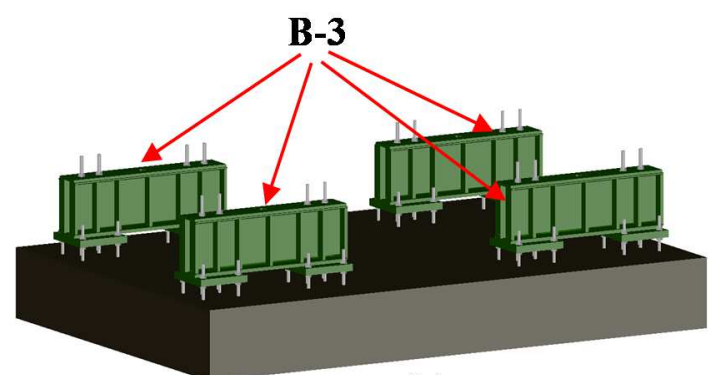

(b)

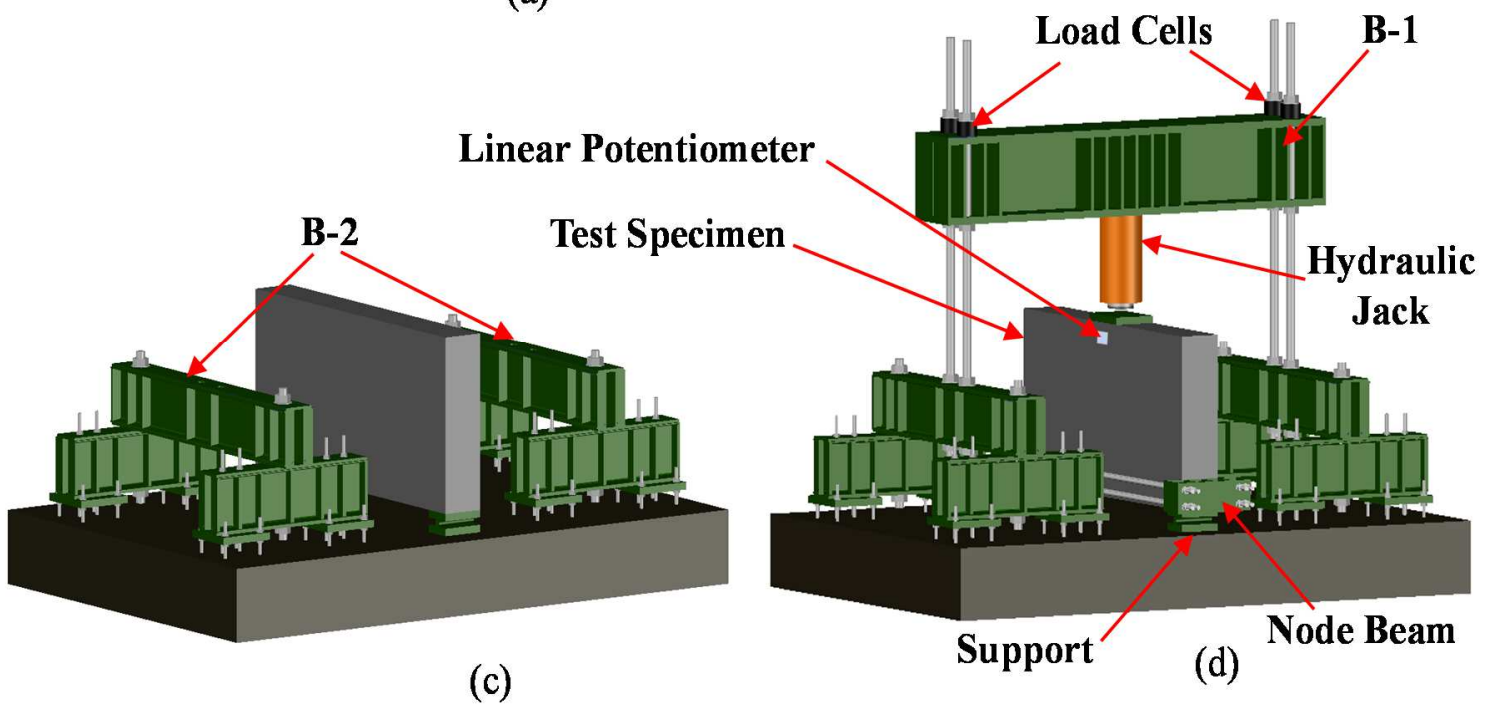

Figure 5-3: The steps of loading setup and specimen installation

\subsubsection{Loading Protocol}

The load was initially applied monotonically in increments of approximately 10 to $25 \mathrm{kips}$ (44.5 to $111 \mathrm{kN}$ ) on top of the specimens until the formation of the first crack. After the first crack was observed, additional load was applied in increments of approximately 50 kips $(222 \mathrm{kN})$. After each increment, the loading process was paused to measure crack widths, mark crack progression, and take photos of cracks. The load was applied continuously to failure and the specimens were not approached, after the load on the specimens was greater than approximately half of the estimated capacity. Photographs of $\operatorname{Re}_{(\mathrm{E})}-\mathrm{H}-0$ before failure, during, and after failure are shown in Figure 5-4. 


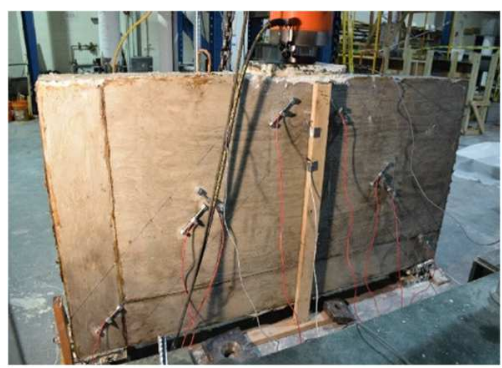

(a)

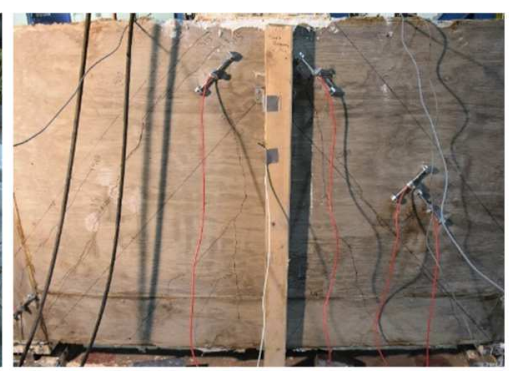

(b)

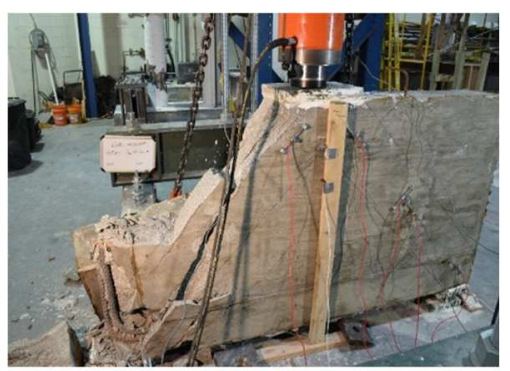

(c)

Figure 5-4: $\operatorname{Re}_{(\mathrm{E})}-\mathrm{H}-0$ (a) before loading, (b) during loading, (c) after failure

\subsubsection{Instrumentation}

Load and deflection were measured during testing using calibrated load cells and linear potentiometers, respectively. Load cells with a capacity of $250 \mathrm{kips}(1,112 \mathrm{kN})$ were placed between B-1 and the reaction nuts at each rod location, as shown in Figure 5-3 (d). Two linear potentiometers were located at the centerline of the beam on each side, 7.5 inches $(191 \mathrm{~mm})$ below the loading plate in all the tests. The linear potentiometers were placed at this location so deflections could be measured at the same location for all the specimens.

\subsection{Numerical Program}

An overview of the numerical investigation will be given in this section, including the validation of the numerical models based on the experimental results.

\subsubsection{Modeling Parameters}

The finite element analysis was completed using ATENA GiD 13.0.3. The geometry of the specimens was built in the pre-processor and the material properties were assigned to each element of the specimen. As material properties play a significant role in numerical modeling, it is important to have models that accurately estimate actual material behavior 
for valid results. The concrete was modeled by a 3D solid brick element with CC3DNonLinCementitious2 material prototype, which is fully incremental with eight to 20 nodes [59]. Plastic deformation, cracking, and crushing can be modeled with this element and material, and it has three degrees of freedom (X, Y, and Z) at each node. Cracking is predicted using a fictitious crack model [60]. This model is defined based on crack-opening law and fracture energy to model crack propagation in reinforced concrete structures. Three crack opening stages were defined during crack formation, as shown in Figure 5-5 (a). The concrete remains uncracked at applied tensile stresses $\left(\sigma_{c l}\right)$ less than the effective tensile strength $\left(f^{\prime}{ }^{e}{ }^{e f}\right)$. After cracking, a crack will increase in width based on the fracture energy $\left(G_{F}\right)$ of the crack until the full crack width $\left(w_{c}\right)$ is reached. After a crack has reached $w_{c}$, the crack as compatibility requires without the need for additional fracture energy.

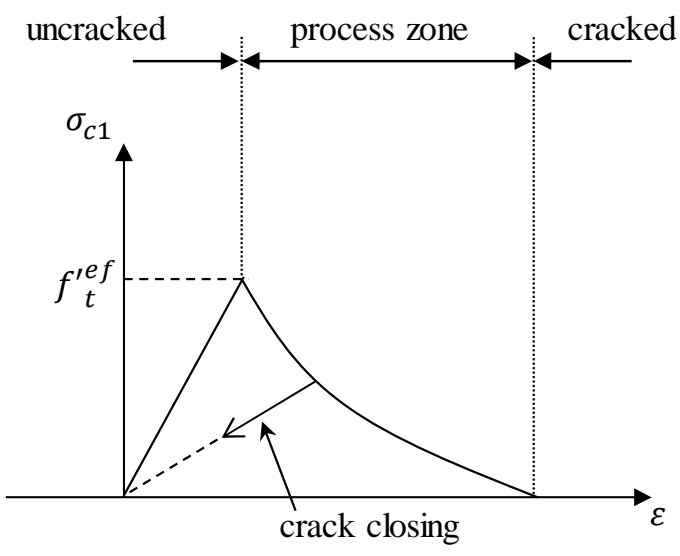

(a)

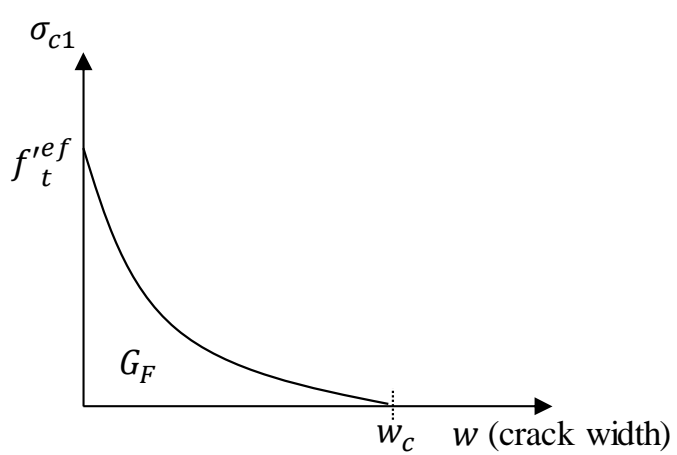

(b)

Figure 5-5: (a) Tensile stress-strain curve for concrete with stages of crack opening, and (b) exponential crack opening law, adapted from [60]

The summary of the concrete material model is shown in Table 5-3. A non-linear elasticplastic behavior was considered for the concrete. This behavior suggests linear relations in 
the stress-strain field before cracking (Hooke's Law), and after cracking the DruckerPrager and Rankine criteria are used to determine the behavior of specimens in compression and tension, respectively. Plastic strain and tension stiffening effects are also considered in the software.

Table 5-3: Summary of Concrete Material Properties

\begin{tabular}{|c|c|}
\hline \multicolumn{2}{|c|}{ Concrete Material Properties } \\
\hline Base Material Prototype & CC3DNonLinCementitious2 \\
\hline Cylinder Compressive Strength & $7.89 \mathrm{ksi}(54 \mathrm{MPa})$ \\
\hline Initial Elastic Modulus & $4,350 \mathrm{ksi}(29,992 \mathrm{MPa})$ \\
\hline Poisson's Ratio & 0.2 \\
\hline Tensile Strength & $0.52 \mathrm{ksi}(3 \mathrm{MPa})$ \\
\hline
\end{tabular}

Reinforcement was modeled using 1D bar elements which are a uniaxial tensioncompression element and CCReinforcement was chosen as a material prototype. All the unbonded and bonded reinforcement were modeled as typical Grade 100 and 60 reinforcement, respectively. The unbonded reinforcement for the experimental specimens was high-strength (Grade 100) threaded rods. Normal bond characteristics between the concrete and reinforcement were used for the bonded specimens; this is an assumption that there were no issues with the bond at the time of casting. An elastic-plastic behavior was used to model the ties because they were designed to hold the stress before their yielding point. The steel yielding criterion was based on the von Mises definitions.

Steel plates were used to simulate supports and loading plates using the 3Delasticisotropic material type. Steel plates were used to best impersonate support and load conditions of the experimental specimens. An elastic-isotropic material was assumed for the steel plates of the supports and loading area. 
The size of the mesh for this study varied between 2 and 3 inches (50 and $76 \mathrm{~mm}$ ). A tetrahedral mesh was adopted for the truss-like specimens. A hexahedron mesh was used for the rectangular specimens. The mesh size was refined using the results from the experimental testing and then used for all numerical models.

Pin and roller support conditions were modeled at the centerline of the support plates. A displacement-controlled, distributed load was applied at the centerline of the load plate monotonically in 50 increments until failure. Results were obtained for each load step, including: the load-deflection curve, the ultimate load, the ultimate deflection, stress strain values, and cracking behavior at each step.

\subsubsection{Model Validation}

The FE analysis was validated based on the load-displacement curves for four of the experimental specimens, as shown in Figure 5-6. The slopes of the experimental curves are similar to those of the numerical curves. Additionally, the failure loads from the numerical models were between 0 and 7-percent of the failure load measured through the experimental testing. These results suggest good agreement between the experimental and numerical results. 


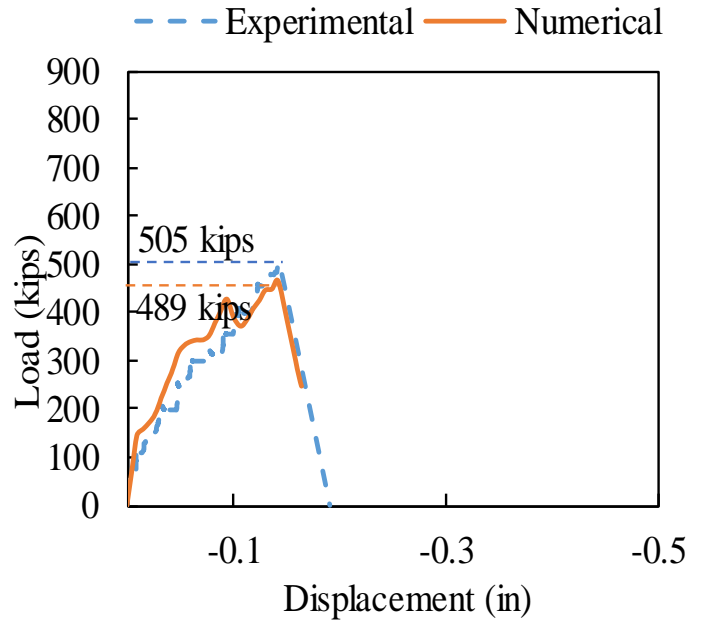

(a)

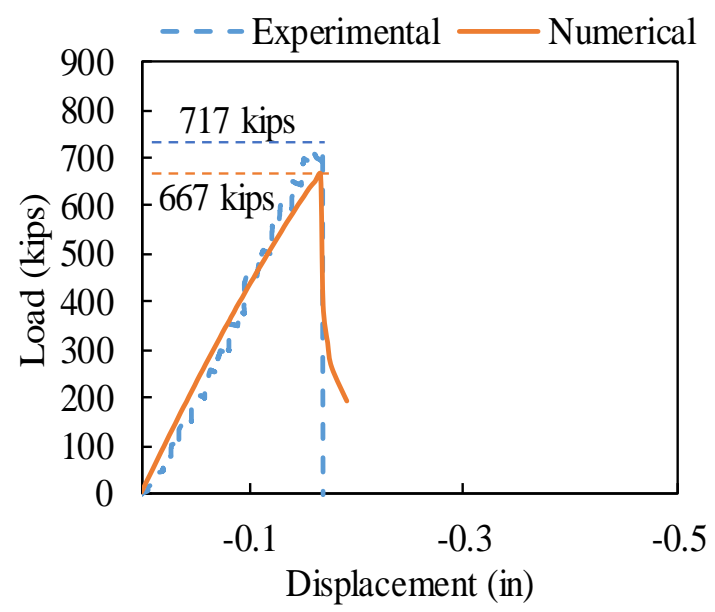

(c)

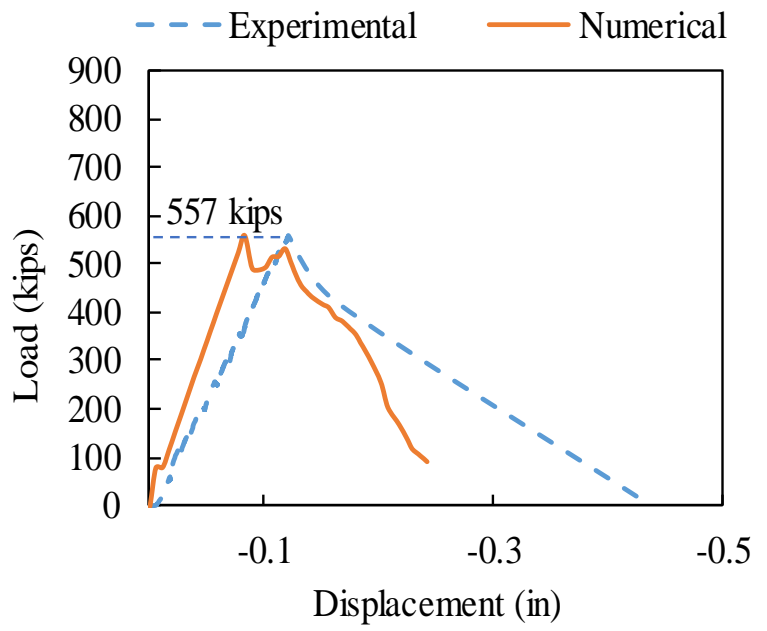

(b)

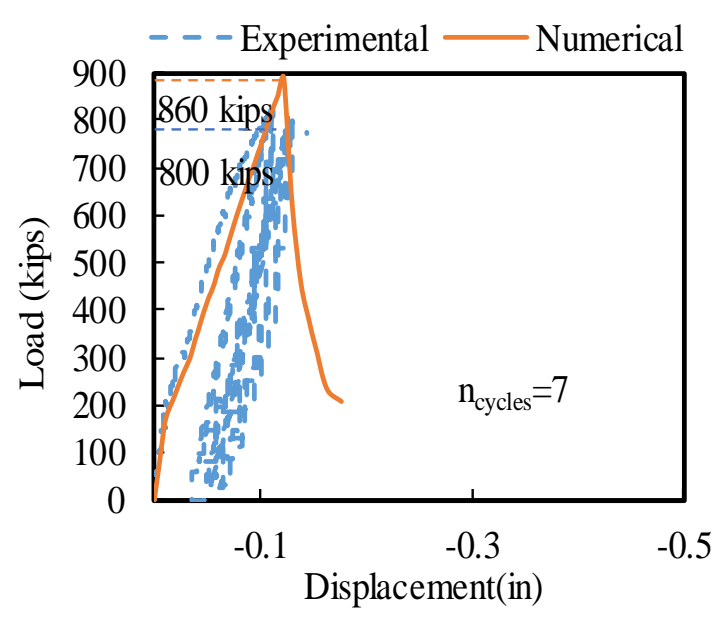

(d)

Figure 5-6: Comparing load-displacement results from experimental and numerical outputs (a) Re-H-0, (b) Re-ExU-0, (c) Tr-ExU-0, and (d) Re-EP-9.5

The crack pattern was obtained at different stages of loading using the FE software. The crack pattern from the software could then be compared to the observed crack pattern from the experimental testing. The distribution of the observed cracks from the experimental test for Re-H-0 compared to the cracking from the numerical study is shown in Figure 5-7. First cracking occurred in both the experimental test and numerical model at about 10-percent 
of the failure load and propagated from the mid-span upward to the load plate, as shown in Figure 5-7 (a) and (b). Because the reinforcement was bonded, additional flexure cracking and shear cracking formed, as shown in Figure 5-7 (c) and (d). The failure initiated by a development failure of the hook and diagonal failure was then seen in both experimental and numerical results. The crack patterns and service behavior in actual tests and FE analysis were consistent, further validating the results.

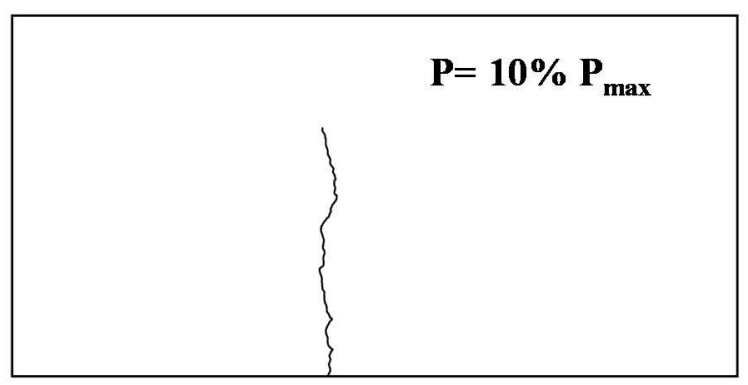

(a)

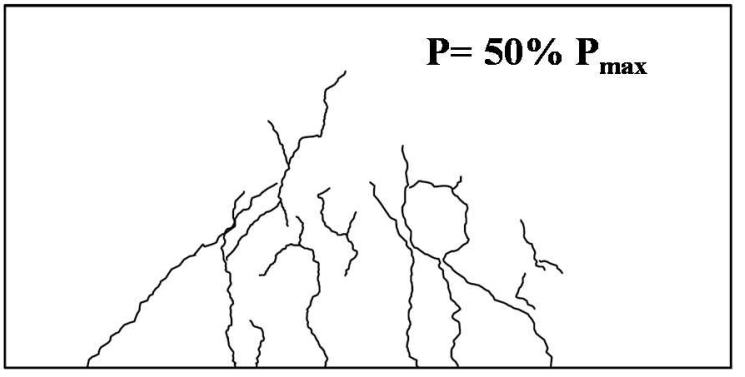

(c)

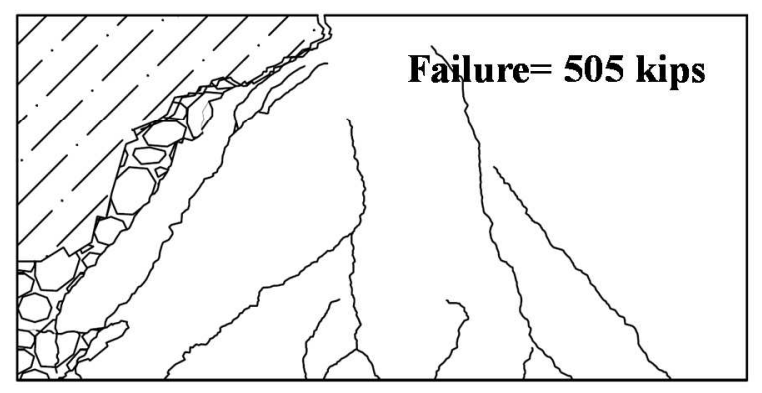

(e)

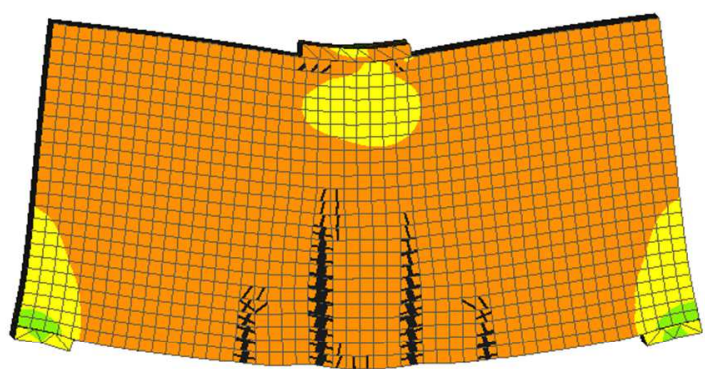

(b)

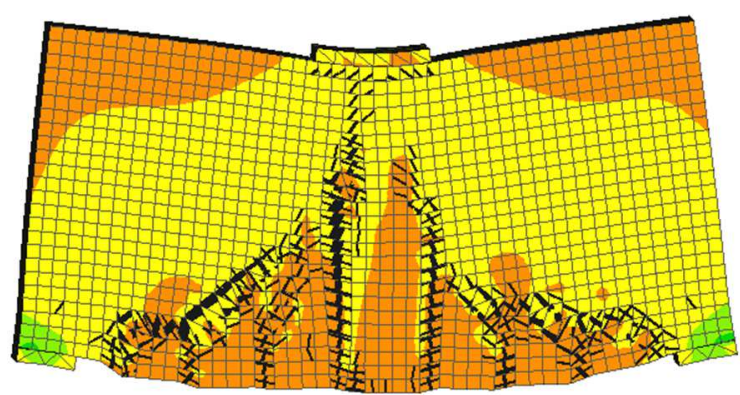

(d)

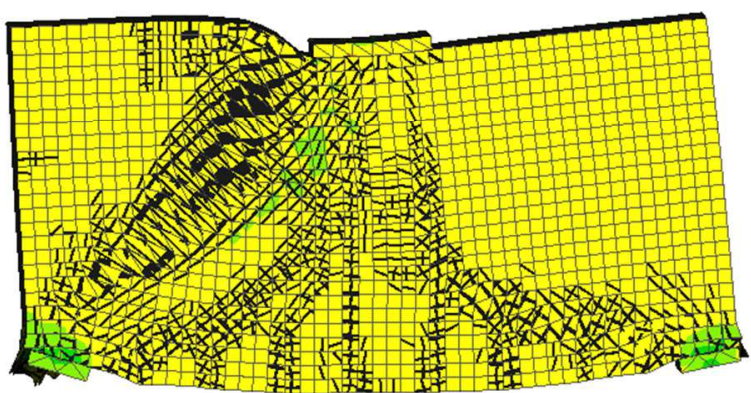

(f)

Figure 5-7: Actual and predicted crack patterns in Re-H-0 


\subsubsection{Numerical Specimen Details}

The primary experimental variables for this numerical study were:

- Specimen type: rectangular and truss-like

- Reinforcement and development type: internal-straight, internal-hooked, internal with a plate welded on end, and external with a plate bolted on end

- Overhang length: ranging from no development length provided past the end of the bearing to full development provided for the specific development type

- Strut angle: 45-degrees was chosen as the primary value for strut angle, but 30and 60-degree were also investigated for the specimens with bonded and unbonded external reinforcement with plates attached on the ends

From these experimental variables, six primary series of specimens (shown in Figure 5-2) were modeled in the FE software with different geometry and overhang length. All the specimens with 45-degree strut angles modeled in the FE software are shown in Table 5-4.

Table 5-4: Summary of the numerical specimen details and results

\begin{tabular}{|c|c|l|c|c|c|c|}
\hline No. & $\begin{array}{c}\text { Specimen } \\
\text { Name }\end{array}$ & $\begin{array}{c}\text { Specimen } \\
\text { Type }\end{array}$ & $\begin{array}{c}\text { Reinf. } \\
\text { Type }\end{array}$ & $\begin{array}{c}\text { Overhang } \\
\text { length,in. } \\
(\mathbf{m m})\end{array}$ & $\begin{array}{c}\text { Failure } \\
\text { Load,kips } \\
(\mathbf{k N})\end{array}$ & $\begin{array}{c}\text { Failure } \\
\text { Location }\end{array}$ \\
\hline 1 & Re-S-0 & Rectangle & $\begin{array}{c}\text { Internal- } \\
\text { Straight }\end{array}$ & $0(0)$ & $\begin{array}{c}484.7 \\
(2,156)\end{array}$ & $\begin{array}{c}\text { Support } \\
\text { Nodes }\end{array}$ \\
\hline 2 & Re-S-9.5 & Rectangle & $\begin{array}{c}\text { Internal- } \\
\text { Straight }\end{array}$ & $9.5(241)$ & $\begin{array}{c}639.5 \\
(2,844)\end{array}$ & $\begin{array}{c}\text { Support } \\
\text { Nodes }\end{array}$ \\
\hline 3 & Re-S-18 & Rectangle & $\begin{array}{c}\text { Internal- } \\
\text { Straight }\end{array}$ & $18(457)$ & $\begin{array}{c}742.6 \\
(3,303)\end{array}$ & $\begin{array}{c}\text { Support } \\
\text { Nodes }\end{array}$ \\
\hline 4 & Re-S-30 & Rectangle & $\begin{array}{c}\text { Internal- } \\
\text { Straight }\end{array}$ & $30(762)$ & $\begin{array}{c}775.7 \\
(3450)\end{array}$ & $\begin{array}{c}\text { Support } \\
\text { Nodes }\end{array}$ \\
\hline 5 & Re-S-35 & Rectangle & $\begin{array}{c}\text { Internal- } \\
\text { Straight }\end{array}$ & $35(889)$ & $\begin{array}{c}786.39 \\
(3,498)\end{array}$ & $\begin{array}{c}\text { Support } \\
\text { Nodes }\end{array}$ \\
\hline 6 & Re-S-40 & Rectangle & $\begin{array}{c}\text { Internal- } \\
\text { Straight }\end{array}$ & $40(1,016)$ & $\begin{array}{c}811.4 \\
(3,609)\end{array}$ & $\begin{array}{c}\text { Support } \\
\text { nodes }\end{array}$ \\
\hline
\end{tabular}




\begin{tabular}{|c|c|c|c|c|c|c|}
\hline No. & $\begin{array}{l}\text { Specimen } \\
\text { Name }\end{array}$ & $\begin{array}{c}\text { Specimen } \\
\text { Type }\end{array}$ & $\begin{array}{l}\text { Reinf. } \\
\text { Type }\end{array}$ & $\begin{array}{l}\text { Overhang } \\
\text { length,in. } \\
\text { (mm) }\end{array}$ & $\begin{array}{c}\text { Failure } \\
\text { Load,kips } \\
(\mathbf{k N})\end{array}$ & $\begin{array}{c}\text { Failure } \\
\text { Location }\end{array}$ \\
\hline 7 & $\mathrm{Re}-\mathrm{H}-0$ & Rectangle & $\begin{array}{l}\text { Internal- } \\
\text { Hooked }\end{array}$ & $0(0)$ & $\begin{array}{c}496.7 \\
(2,209)\end{array}$ & $\begin{array}{l}\text { Support } \\
\text { Nodes }\end{array}$ \\
\hline 8 & Re-H-9.5 & Rectangle & $\begin{array}{l}\text { Internal- } \\
\text { Hooked }\end{array}$ & $9.5(241)$ & $\begin{array}{c}751.2 \\
(3,341)\end{array}$ & $\begin{array}{c}\text { Support } \\
\text { Nodes }\end{array}$ \\
\hline 9 & Re-H-18 & Rectangle & $\begin{array}{l}\text { Internal- } \\
\text { Hooked }\end{array}$ & $18(457)$ & $\begin{array}{c}915.4 \\
(4,071) \\
\end{array}$ & $\begin{array}{c}\text { Support } \\
\text { Nodes }\end{array}$ \\
\hline 10 & Re-H-30 & Rectangle & $\begin{array}{l}\text { Internal- } \\
\text { Hooked }\end{array}$ & $30(762)$ & $\begin{array}{c}891.3 \\
(3,964)\end{array}$ & $\begin{array}{l}\text { Support } \\
\text { Nodes }\end{array}$ \\
\hline 11 & Re-H-40 & Rectangle & $\begin{array}{l}\text { Internal- } \\
\text { Hooked }\end{array}$ & $40(1,016)$ & $\begin{array}{c}853.6 \\
(3,797)\end{array}$ & $\begin{array}{c}\text { Support } \\
\text { Nodes }\end{array}$ \\
\hline 12 & Re-EP-0 & Rectangle & $\begin{array}{c}\text { Internal- } \\
\text { External } \\
\text { Plate }\end{array}$ & $0(0)$ & $\begin{array}{c}809.7 \\
(3601)\end{array}$ & $\begin{array}{c}\text { Support } \\
\text { Nodes }\end{array}$ \\
\hline 13 & Re-EP-9.5 & Rectangle & $\begin{array}{c}\text { Internal- } \\
\text { External } \\
\text { Plate }\end{array}$ & $9.5(241)$ & $\begin{array}{c}889.5 \\
(2,156)\end{array}$ & $\begin{array}{c}\text { Support } \\
\text { Nodes }\end{array}$ \\
\hline 14 & Re-EP-18 & Rectangle & $\begin{array}{c}\text { Internal- } \\
\text { External } \\
\text { Plate }\end{array}$ & $18(457)$ & $\begin{array}{c}865.7 \\
(3,850)\end{array}$ & $\begin{array}{c}\text { Support } \\
\text { Nodes }\end{array}$ \\
\hline 15 & Re-EP-40 & Rectangle & $\begin{array}{c}\text { Internal- } \\
\text { External } \\
\text { Plate }\end{array}$ & $40(1,016)$ & $\begin{array}{c}833.7 \\
(3,708)\end{array}$ & $\begin{array}{c}\text { Support } \\
\text { Nodes }\end{array}$ \\
\hline 16 & Re-ExU-0 & Rectangle & $\begin{array}{c}\text { External- } \\
\text { Unbonded }\end{array}$ & $0(0)$ & $\begin{array}{c}911.7 \\
(4,055)\end{array}$ & $\begin{array}{c}\text { Support } \\
\text { Nodes }\end{array}$ \\
\hline 17 & $\begin{array}{c}\text { Re-ExU- } \\
9.5\end{array}$ & Rectangle & $\begin{array}{c}\text { External- } \\
\text { Unbonded }\end{array}$ & $9.5(241)$ & $\begin{array}{c}942.7 \\
(4,193) \\
\end{array}$ & $\begin{array}{c}\begin{array}{c}\text { Support } \\
\text { Nodes }\end{array} \\
\end{array}$ \\
\hline 18 & $\begin{array}{c}\text { Re-ExU- } \\
18\end{array}$ & Rectangle & $\begin{array}{c}\text { External- } \\
\text { Unbonded }\end{array}$ & $18(457)$ & $\begin{array}{c}881.7 \\
(3,922)\end{array}$ & $\begin{array}{c}\text { Support } \\
\text { Nodes }\end{array}$ \\
\hline 19 & $\begin{array}{c}\text { Re-ExU- } \\
40\end{array}$ & Rectangle & $\begin{array}{c}\text { External- } \\
\text { Unbonded }\end{array}$ & $40(1,016)$ & $\begin{array}{c}880.9 \\
(3,918)\end{array}$ & $\begin{array}{c}\text { Support } \\
\text { Nodes }\end{array}$ \\
\hline 20 & Tr-EP-0 & Truss & $\begin{array}{c}\text { Internal- } \\
\text { External } \\
\text { Plate } \\
\end{array}$ & $0(0)$ & $\begin{array}{c}884.6 \\
(3,934)\end{array}$ & $\begin{array}{c}\text { Support } \\
\text { Nodes }\end{array}$ \\
\hline 21 & Tr-EP-9.5 & Truss & $\begin{array}{c}\text { Internal- } \\
\text { External } \\
\text { Plate } \\
\end{array}$ & $9.5(241)$ & $\begin{array}{c}989.4 \\
(4,401)\end{array}$ & $\begin{array}{c}\text { Support } \\
\text { Nodes }\end{array}$ \\
\hline 22 & Tr-EP-18 & Truss & $\begin{array}{c}\text { Internal- } \\
\text { External } \\
\text { Plate }\end{array}$ & $18(457)$ & $\begin{array}{c}1011 \\
(4,497)\end{array}$ & $\begin{array}{c}\text { Support } \\
\text { Nodes }\end{array}$ \\
\hline
\end{tabular}




\begin{tabular}{|c|c|c|c|c|c|c|}
\hline No. & $\begin{array}{c}\text { Specimen } \\
\text { Name }\end{array}$ & $\begin{array}{c}\text { Specimen } \\
\text { Type }\end{array}$ & $\begin{array}{c}\text { Reinf. } \\
\text { Type }\end{array}$ & $\begin{array}{c}\text { Overhang } \\
\text { length,in. } \\
(\mathbf{m m})\end{array}$ & $\begin{array}{c}\text { Failure } \\
\text { Load,kips } \\
(\mathbf{k N})\end{array}$ & $\begin{array}{c}\text { Failure } \\
\text { Location }\end{array}$ \\
\hline 23 & Tr-EP-40 & Truss & $\begin{array}{c}\text { Internal- } \\
\text { External } \\
\text { Plate }\end{array}$ & $40(1,016)$ & $\begin{array}{c}1003.6 \\
(4,464)\end{array}$ & $\begin{array}{c}\text { Support } \\
\text { Nodes }\end{array}$ \\
\hline 24 & Tr-ExU-0 & Truss & $\begin{array}{c}\text { External- } \\
\text { Unbonded }\end{array}$ & $0(0)$ & $\begin{array}{c}1194.5 \\
(5,313)\end{array}$ & $\begin{array}{c}\text { Load } \\
\text { Nodes }\end{array}$ \\
\hline 25 & $\begin{array}{c}\text { Tr-ExU- } \\
9.5\end{array}$ & Truss & $\begin{array}{c}\text { External- } \\
\text { Unbonded }\end{array}$ & $9.5(241)$ & $\begin{array}{c}1136.6 \\
(5,055)\end{array}$ & $\begin{array}{c}\text { Load } \\
\text { Nodes }\end{array}$ \\
\hline 26 & $\begin{array}{c}\text { Tr-ExU- } \\
18\end{array}$ & Truss & $\begin{array}{c}\text { External- } \\
\text { Unbonded }\end{array}$ & $18(457)$ & $\begin{array}{c}1090.6 \\
(4,851)\end{array}$ & $\begin{array}{c}\text { Load } \\
\text { Nodes }\end{array}$ \\
\hline 27 & $\begin{array}{c}\text { Tr-ExU- } \\
40\end{array}$ & Truss & $\begin{array}{c}\text { External- } \\
\text { Unbonded }\end{array}$ & $40(1,016)$ & $\begin{array}{c}1051.9 \\
(4,679)\end{array}$ & $\begin{array}{c}\text { Load } \\
\text { Nodes }\end{array}$ \\
\hline
\end{tabular}

The development lengths were calculated according to Section 25.4.2.3 and 25.4.3.1 of ACI 318-14 and found to be 40 inches $(1,016 \mathrm{~mm})$ for straight bars and 18 inches (457 $\mathrm{mm})$ for hooked bars. An additional overhang length of 9.5 inches $(241 \mathrm{~mm})$ was chosen to have a length between 0 inches and 18 inches $(0$ and $457 \mathrm{~mm})$ and to be able to compare the results with one of the experimental tests, $\operatorname{Re}_{(\mathrm{E})}-\mathrm{EP}-9.5$.

Additional specimens with 30- and 60-degree angles are provided in Table 5-5. These specimens only included Re-EP, Tr-EP, Re-ExU, and Tr-ExU series. Additionally, an overhang length beyond the edge of the bearing pad of 0 inches $(0 \mathrm{~mm})$ was used for all these specimens. 
Table 5-5: Summary of the numerical specimen details and results for different strut angle and 0 in. $(0 \mathrm{~mm})$ overhang length

\begin{tabular}{|c|c|c|c|c|c|c|}
\hline No. & $\begin{array}{l}\text { Specimen } \\
\text { Name }\end{array}$ & $\begin{array}{c}\text { Specimen } \\
\text { Type }\end{array}$ & $\begin{array}{c}\text { Reinf. } \\
\text { Type }\end{array}$ & $\begin{array}{c}\text { Strut } \\
\text { angle } \\
\text { (degree) }\end{array}$ & $\begin{array}{c}\text { Failure } \\
\text { Load,kips } \\
(\mathbf{k N})\end{array}$ & $\begin{array}{c}\text { Failure } \\
\text { Location }\end{array}$ \\
\hline 1 & Re-EP-30 & Rectangle & $\begin{array}{c}\text { Internal- } \\
\text { External } \\
\text { Plate } \\
\end{array}$ & 30 & $\begin{array}{c}392.8 \\
(1,747)\end{array}$ & $\begin{array}{l}\text { Support } \\
\text { Nodes }\end{array}$ \\
\hline 2 & Re-EP-45 & Rectangle & $\begin{array}{c}\text { Internal- } \\
\text { External } \\
\text { Plate }\end{array}$ & 45 & $\begin{array}{c}809 \\
(3,598)\end{array}$ & $\begin{array}{l}\text { Support } \\
\text { Nodes }\end{array}$ \\
\hline 3 & Re-EP-60 & Rectangle & $\begin{array}{c}\text { Internal- } \\
\text { External } \\
\text { Plate }\end{array}$ & 60 & $\begin{array}{l}1404.3 \\
(6,246)\end{array}$ & $\begin{array}{l}\text { Support } \\
\text { Nodes }\end{array}$ \\
\hline 4 & Tr-EP-30 & Truss & $\begin{array}{c}\text { Internal- } \\
\text { External } \\
\text { Plate }\end{array}$ & 30 & $\begin{array}{c}362.8 \\
(1,613)\end{array}$ & $\begin{array}{c}\text { Load } \\
\text { Nodes }\end{array}$ \\
\hline 5 & Tr-EP-45 & Truss & $\begin{array}{c}\text { Internal- } \\
\text { External } \\
\text { Plate }\end{array}$ & 45 & $\begin{array}{c}885 \\
(3,936)\end{array}$ & $\begin{array}{l}\text { Load } \\
\text { Nodes }\end{array}$ \\
\hline 6 & Tr-EP-60 & Truss & $\begin{array}{c}\text { Internal- } \\
\text { External } \\
\text { Plate }\end{array}$ & 60 & $\begin{array}{c}954 \\
(4,243)\end{array}$ & Load nodes \\
\hline 7 & Re-ExU-30 & Rectangle & $\begin{array}{l}\text { External- } \\
\text { Unbonded }\end{array}$ & 30 & $\begin{array}{c}593.2 \\
(2,638)\end{array}$ & $\begin{array}{c}\text { Support } \\
\text { Nodes }\end{array}$ \\
\hline 8 & Re-ExU-45 & Rectangle & $\begin{array}{l}\text { External- } \\
\text { Unbonded }\end{array}$ & 45 & $\begin{array}{c}912 \\
(4056)\end{array}$ & $\begin{array}{l}\text { Support } \\
\text { Nodes }\end{array}$ \\
\hline 9 & Re-ExU-60 & Rectangle & $\begin{array}{l}\text { External- } \\
\text { Unbonded }\end{array}$ & 60 & $\begin{array}{l}1351.6 \\
(6,012)\end{array}$ & $\begin{array}{c}\text { Support } \\
\text { Nodes }\end{array}$ \\
\hline 10 & Tr-ExU-30 & Truss & $\begin{array}{l}\text { External- } \\
\text { Unbonded }\end{array}$ & 30 & $\begin{array}{c}746.4 \\
(3,320)\end{array}$ & $\begin{array}{l}\text { Load } \\
\text { Nodes }\end{array}$ \\
\hline 11 & Tr-ExU-45 & Truss & $\begin{array}{l}\text { External- } \\
\text { Unbonded }\end{array}$ & 45 & $\begin{array}{c}1195 \\
(5,315)\end{array}$ & $\begin{array}{c}\text { Load } \\
\text { Nodes }\end{array}$ \\
\hline 12 & Tr-ExU-60 & Truss & $\begin{array}{l}\text { External- } \\
\text { Unbonded }\end{array}$ & 60 & $\begin{array}{l}1367.2 \\
(6,081)\end{array}$ & Load nodes \\
\hline
\end{tabular}




\subsection{Results and Discussion}

The results from the FE analyses are presented in this section. An overall summary of the results is first presented followed by a breakdown of results by comparison:

- Effect of development length,

- Effect of type of development,

- Effect of beam type,

- Effect of internal bonded versus external unbonded reinforcement, and

- Effect of strut angle.

\subsubsection{Summary of Results}

As mentioned, there were six primary series of beams that were modeled based on the beam geometry and tie reinforcement. The failure loads for all these beams at the various overhang lengths are summarized in Table 5-6. The failure load for beams with theoretically fully developed reinforcement is highlighted. These results are all for 45degree beams; results from the 30- and 60-degree beams will be discussed in more detail in later sections. 
Table 5-6: Summary of failure loads for all beams with 45-degree strut angle in numerical investigation (underlined* number indicates sufficient development length estimated using ACI

318-14)

\begin{tabular}{|c|c|c|c|c|c|c|}
\hline \multirow{2}{*}{$\begin{array}{c}\ell_{2}, \\
\text { in. }(\mathbf{m m})\end{array}$} & \multicolumn{6}{|c|}{ Failure Loads (organized by series), kips $(k N)$} \\
\hline & $\operatorname{Re}-S$ & $R e-H$ & $R e-E P$ & $\operatorname{Re}-\boldsymbol{E x} U$ & $T r-E P$ & $\boldsymbol{T r}-\boldsymbol{E x} U$ \\
\hline $0(0)$ & $\begin{array}{c}485 \\
(2157)\end{array}$ & $\begin{array}{c}497 \\
(2209)\end{array}$ & $\frac{809.7 *}{(3601)}$ & $\frac{912 *}{(4056)}$ & $\underline{885 *}$ & $\frac{1195^{*}}{(5315)}$ \\
\hline $9.5(241)$ & $\begin{array}{c}640 \\
(2846)\end{array}$ & $\begin{array}{c}751 \\
(3340)\end{array}$ & $\frac{890}{(3958)}$ & $\begin{array}{l}942.7 \\
(4193)\end{array}$ & $\begin{array}{c}989 \\
(4399)\end{array}$ & $\begin{array}{c}1137 \\
(5057)\end{array}$ \\
\hline $18(457)$ & $\begin{array}{c}743 \\
(3305)\end{array}$ & $\frac{915 *}{(4070)}$ & $\begin{array}{c}866 \\
(3852)\end{array}$ & $\begin{array}{c}881.7 \\
(3741)\end{array}$ & $\begin{array}{c}1011 \\
(4497)\end{array}$ & $\begin{array}{c}1091 \\
(4853)\end{array}$ \\
\hline $30(762)$ & $\begin{array}{c}776 \\
(3451)\end{array}$ & $\begin{array}{c}891.3 \\
(3964)\end{array}$ & - & - & - & - \\
\hline 35 (889) & $\begin{array}{c}786 \\
(3496)\end{array}$ & - & - & - & - & - \\
\hline 40 (1016) & $\frac{811 *}{(3607)}$ & $\begin{array}{c}853.6 \\
(3797)\end{array}$ & $\begin{array}{c}834 \\
(3709)\end{array}$ & $\begin{array}{l}880.9 \\
(3700)\end{array}$ & $\begin{array}{c}1004 \\
(4466)\end{array}$ & $\begin{array}{c}1052 \\
(4679)\end{array}$ \\
\hline
\end{tabular}

\subsubsection{Effect of Development Length}

The available development length provided did affect the behavior of the beams for all the different development and beam types. The failure loads for all the beams versus overhang length are shown in Figure 5-8. 


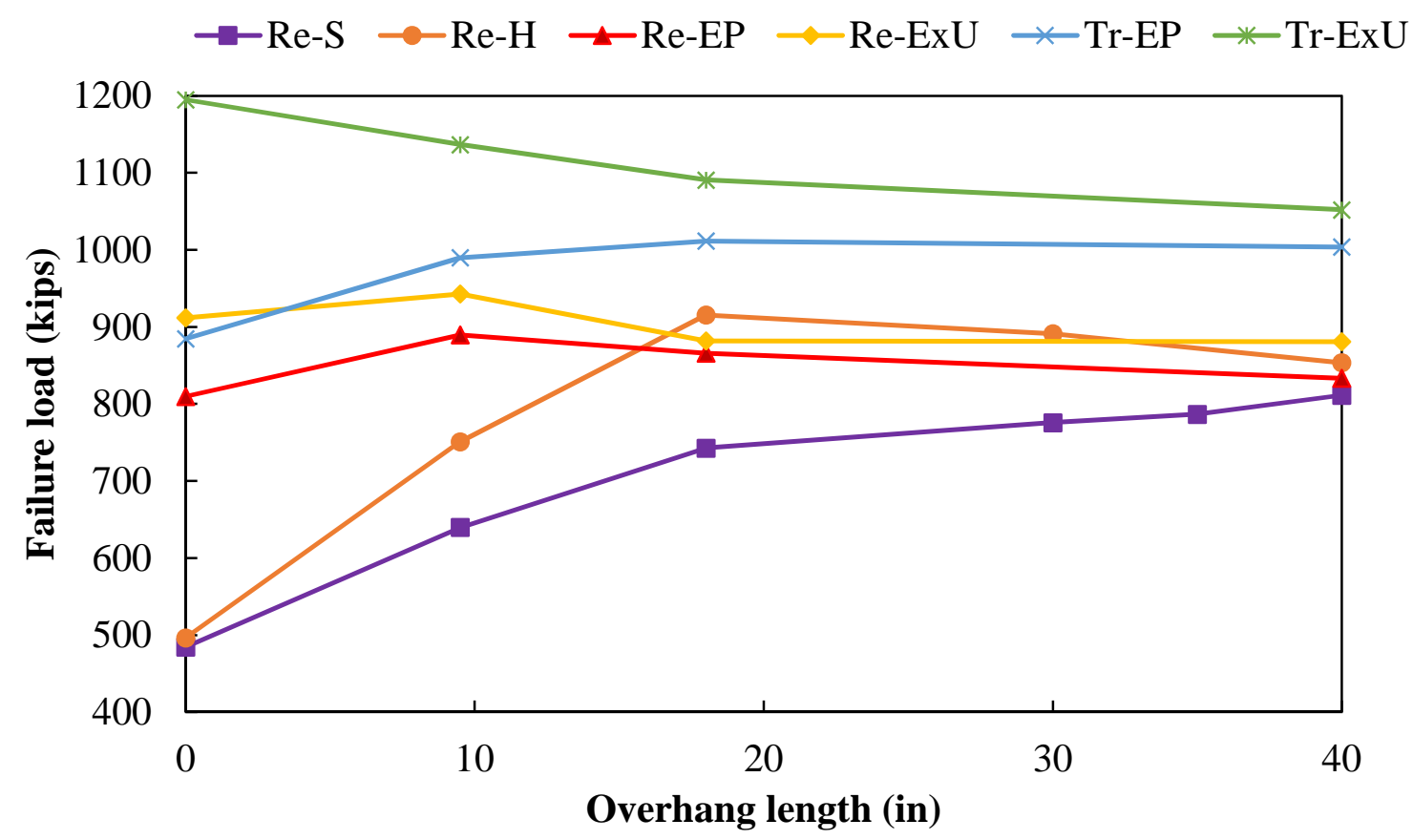

Figure 5-8: Failure load versus overhang length

The two types of development reliant on the internal development of the reinforcement (Re-S and Re-H) increase in capacity as they approach their estimated development lengths: 18 inches $(457 \mathrm{~mm})$ for hooked bar and 40 inches $(1016 \mathrm{~mm})$ for straight bars. The maximum capacity for these beams came when the overhang length provided exactly the needed development. The capacity decreased slightly in the hooked beam at longer overhang lengths. This was thought to have occurred due to the self-weight of the cantilevered overhang introducing additional tensile stress in the node.

The rectangular beams with internal reinforcement welded to external plates (Re-EP) did not see a substantial change in capacity as the overhang length was varied. There was a slight increase in capacity when going from an overhang length of 0 inches $(0 \mathrm{~mm})$ to 9.5 inches $(241 \mathrm{~mm})$. This was likely a result of the 9.5-inch $(241-\mathrm{mm})$ overhang length moving some of the tensile stresses from development outside of the nodal zone. 
The truss-like beams (Tr-EP and Tr-ExU) both experienced a dramatic change in capacity based on the overhang length. A proposed reason for the truss-like beams being more affected by overhang length than the rectangular beams is discussed in detail in a later section. The beams with internal, bonded reinforcement (Tr-EP) had an increased capacity as the overhang length was increased. Like Re-EP, this is likely a result of larger overhang lengths moving tensile stresses associated with bar development outside of the nodal zone. The truss-like beams with the external, unbonded reinforcement (Tr-ExU) had a decreased capacity with longer overhang lengths. This is likely a result of smaller overhang lengths allowing for increased benefits due to the confinement of the external plate.

\subsubsection{Effect of Type of Development}

The type of development used to develop the reinforcement did not have a significant impact on the ultimate capacity of the rectangular beams; the failure loads for beams with sufficient overhang length (highlighted in Table 5-6) were within about 10-percent of each

other. The load versus deflection curves for these beams are shown in Figure 5-9. All the beams had the same stiffness prior to first cracking. After cracking, the stiffness varied in the beams with: Re-S-40 having the softest response, Re-H-18 and Re-EP-0 having similar stiffnesses, and Re-ExU-0 having the stiffest response. 


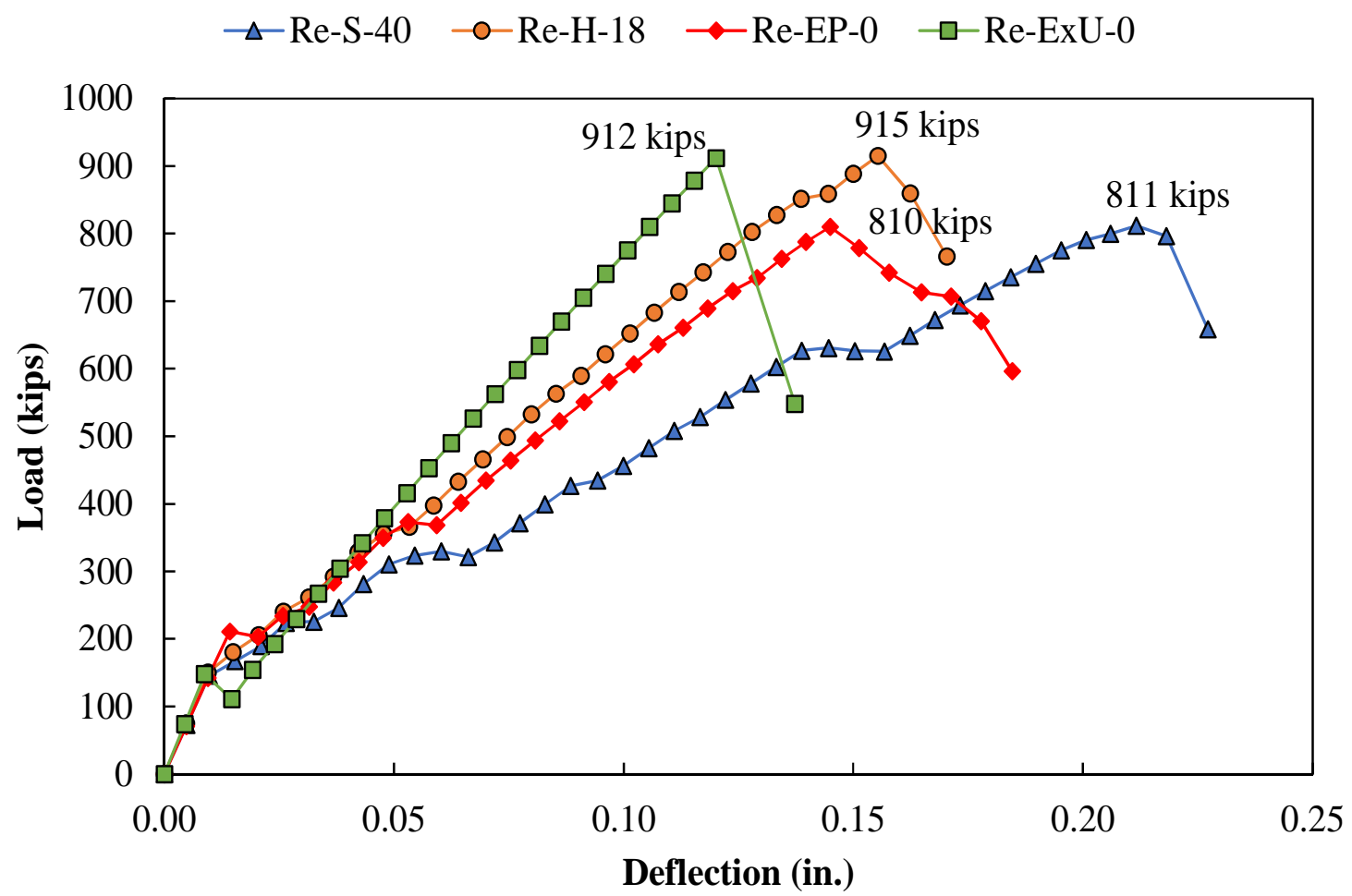

Figure 5-9: Load versus deflection curves for rectangular beams with fully developed longitudinal reinforcement

As discussed above, the presence of bonded reinforcement introduces tensile stresses in the support node region as the reinforcing bars develop. The location and effect of these tensile stresses can be most clearly seen in the truss-like beams. The vertical stresses and crack pattern for truss-like beams with internal bonded and external unbonded reinforcement ( $\mathrm{Tr}$ EP-0 and Tr-ExU-0, respectively) at 20-percent of the failure load, 50-percent of the failure load, and at the failure load are shown in Figure 5-10. The tensile stress introduced by the bonded reinforcement causes cracking in the leg of the truss-like beam, shown in Figure 5-10 (c) compared with the compression stress of Figure 5-10 (d) with external unbonded reinforcement. Note that the tensile stresses introduced by reinforcing bar development are at a different location in these beams than diagonal tension introduced by beam bending, 
so the effects are not additive. This supports the idea presented elsewhere [12] that there can be a separate diagonal tension stress check separate from STM nodal stress checks.

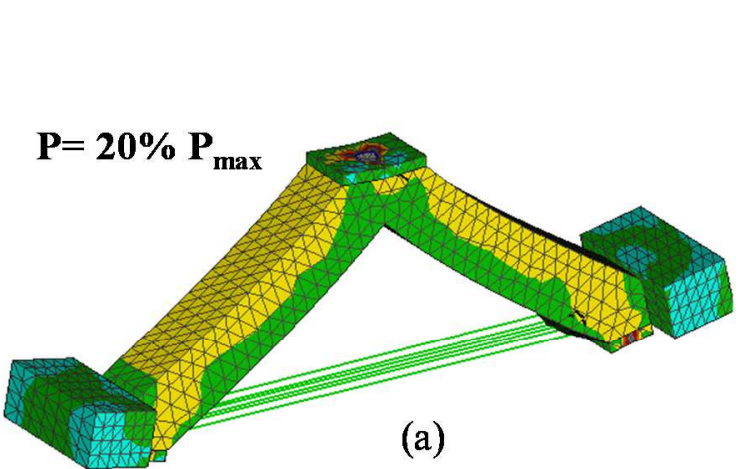

(a)

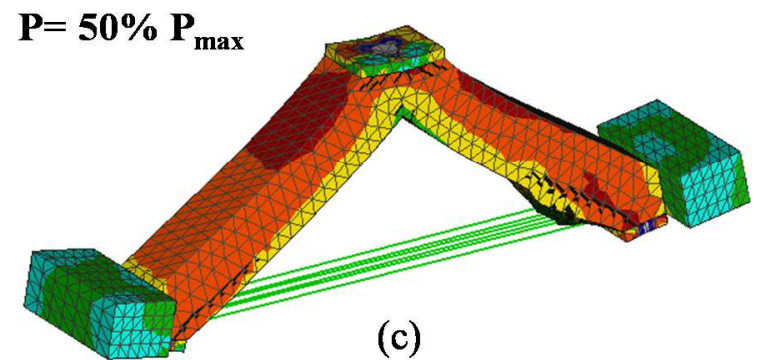

(c)

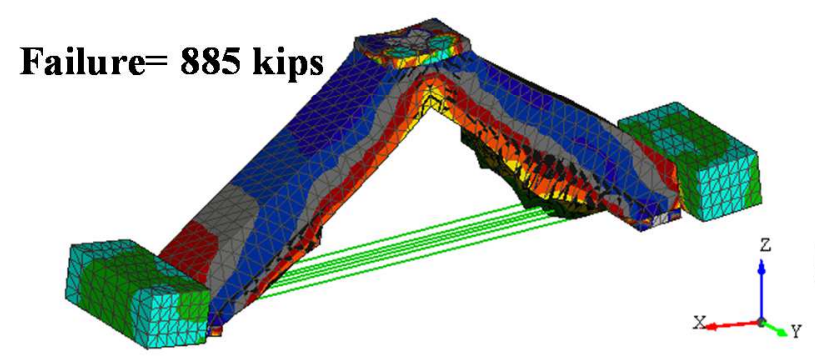

(e)

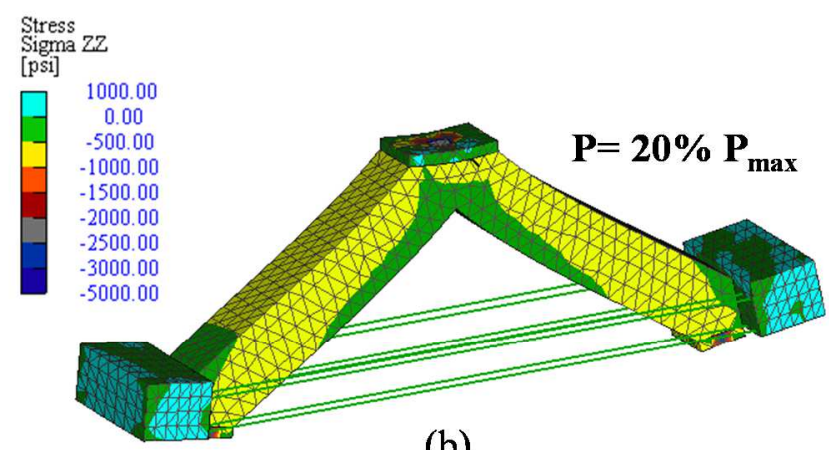

(b)

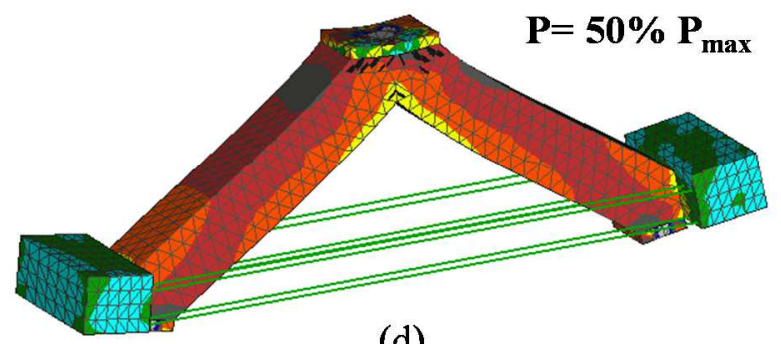

(d)

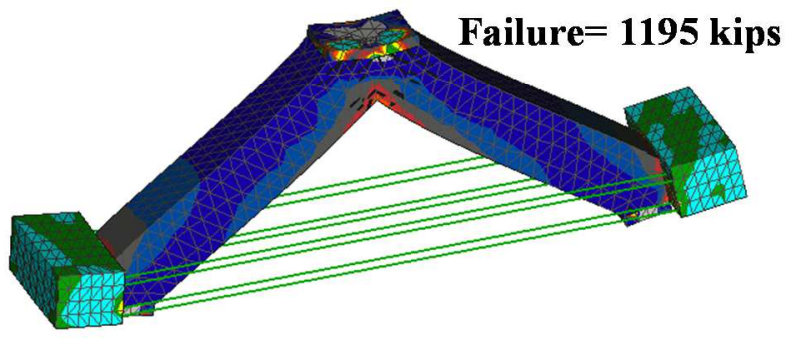

(f)

Figure 5-10: FE model for (a) Tr-EP-0 at 20 percent of $\mathrm{P}_{\max }$, (b) Tr-ExU-0 at 20 percent of $\mathrm{P}_{\max }$ (c) Tr-EP-0 at 50 percent of $\mathrm{P}_{\max }$, (d) Tr-ExU-0 at 50 percent of $\mathrm{P}_{\max }$, (e) Tr-EP-0 after failure and (f) Tr-ExU-0 after failure

\subsubsection{Effect of Beam Type}

Rectangular and truss-like beams were modeled to better understand the effect of the beam type on behavior and strength. Beam type has a large effect on the general beam behavior and on the way development length and type of development impacts the behavior. 
The failure loads for rectangular and truss-like beams with no overhang and an external plate welded to either internal or external reinforcement are shown in Figure 5-11. The failure loads for the truss-like beam with external, unbonded reinforcement (Tr-ExU-0) was about 40-percent higher than the rectangular beams. The truss-like beam with internal, bonded reinforcement welded to the steel plate (Tr-EP-0) had a similar capacity to the rectangular beams. This shows how the tensile stresses caused by the bonded reinforcement developing in the nodal zone can decrease the strength.

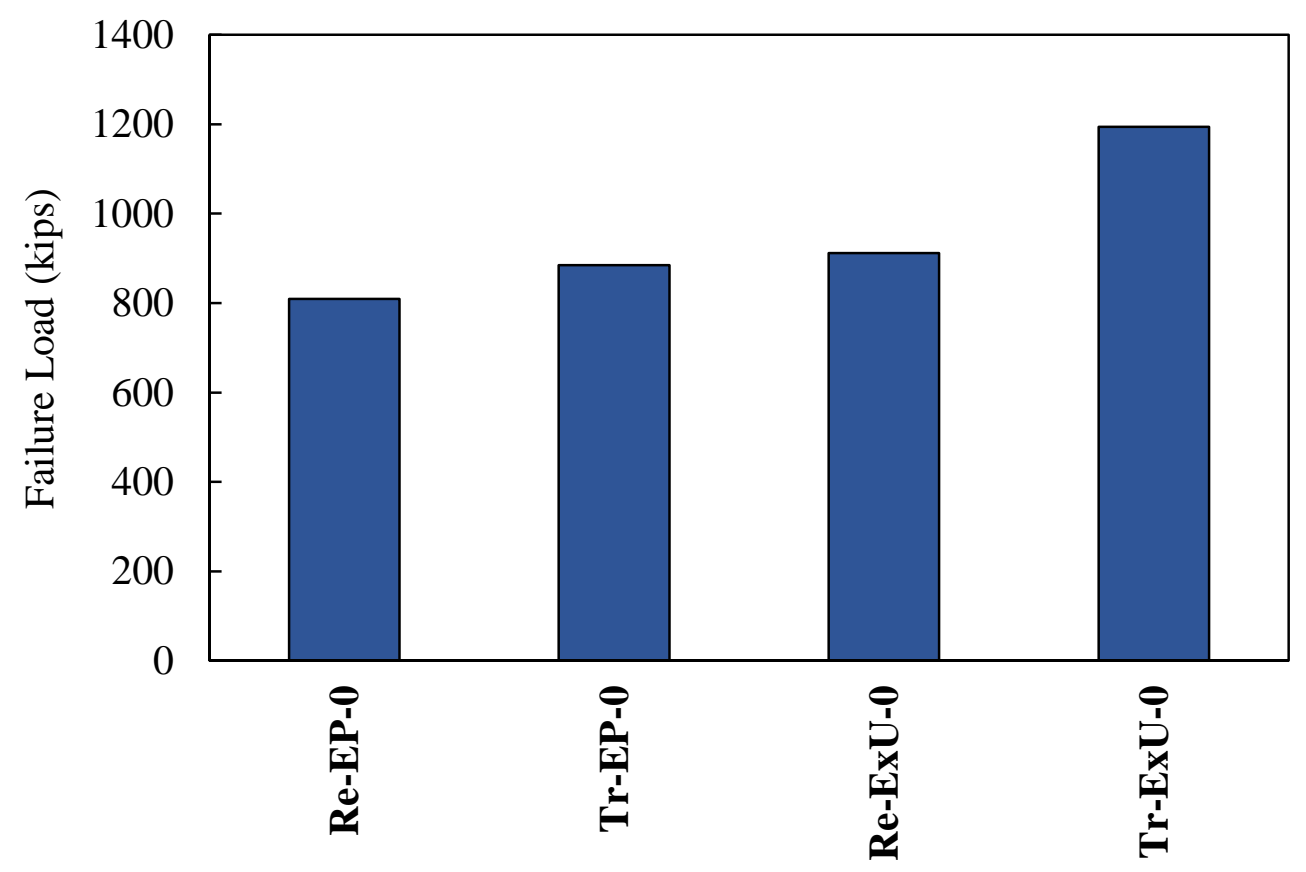

Figure 5-11: Summary of the numerical failure loads versus specimens

As previously introduced, the beam type will also impact the way that available development length and development type impact the behavior and ultimate strength. The rectangular beam already had diagonal tensile stress introduced by beam bending that will decrease the capacity. Additional tensile stress introduced by development in the nodal zone did not change the behavior. This would suggest that the diagonal tensile stress from 
beam bending is impacting the beam at a different location than the tensile stress from development in the support node. This is consistent with previous observations on the failure of similar beams through experimental testing [10]. Because there are no diagonal tensile stresses impacting the behavior of the truss-like beams, introducing tensile stress in the support nodes does impact the behavior of the truss-like beams. Having external, unbonded reinforcement with a plate welded on the end allowed for the node to have compression on three faces and gain confinement benefits. Internal, bonded reinforcement introduced tension in the support node and decreased capacity. This is described in more detail in the following section.

\subsubsection{Effect of Strut Angle}

The effect of strut angle was investigated for the rectangular and truss-like specimens with plates welded to the reinforcement. The normalized strut stress at failure for these specimens are shown in Figure 5-12 organized by beam type. A discussion on normalization can be found in Rezaei et al. [10].

The strut angle had the most dramatic effect for the rectangular beams (Re-EP and ReExU), where a smaller strut angle corresponds to lower capacities. The truss-like beam with bonded reinforcement and a 30-degree strut angle had a lower capacity than steeper angles, due to the reinforcement having more contact with the concrete than specimens with steeper angles. Strut angle did not have a significant impact on the truss-like beam with external, unbonded reinforcement (Tr-ExU). The failure in these beams was in the node under the loading plate, which may be the reason why they were not as affected by varying strut angles. 


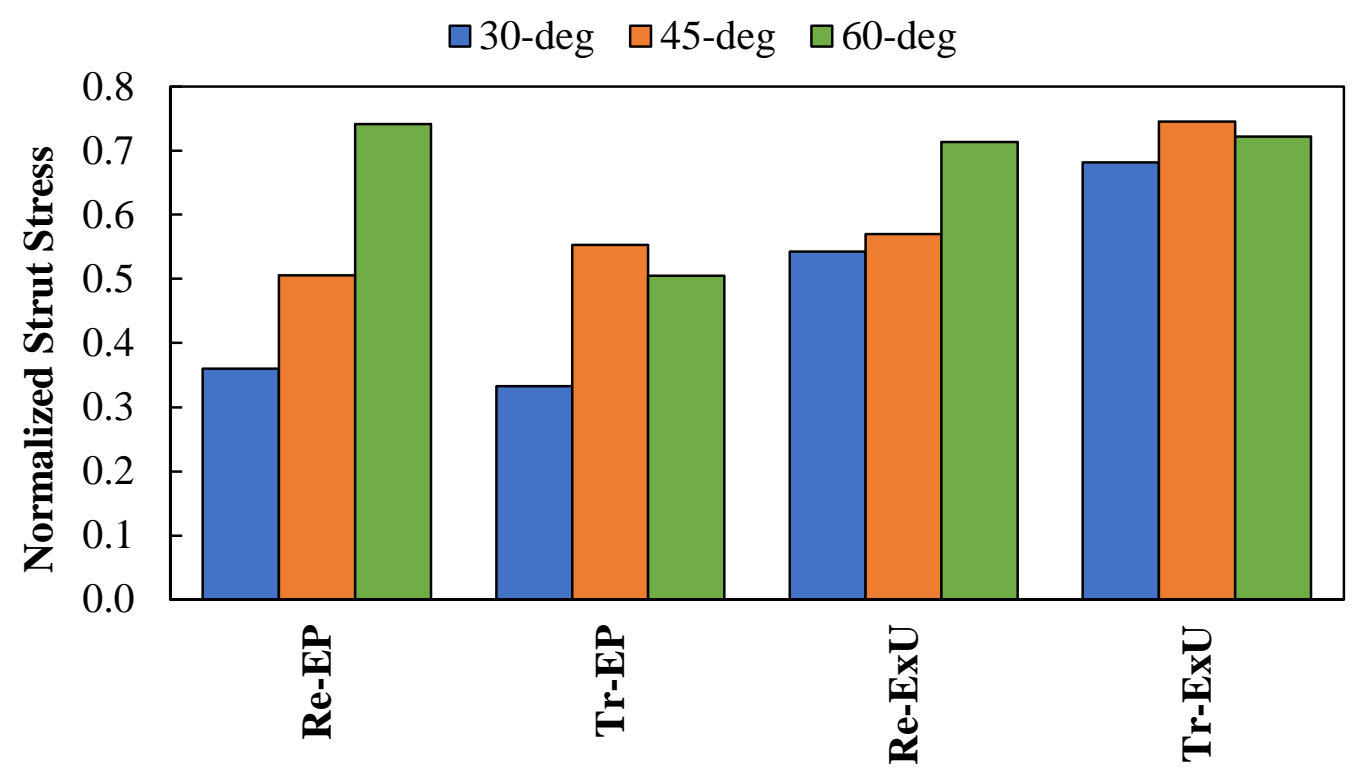

Figure 5-12: Normalized strut stress versus series

\subsection{Summary and Conclusions}

This paper investigated the effect of specimen shape (rectangular and truss-like), development type (straight, hooked, external unbonded, and internal bonded bars), overhang length $(0$ inches $[0 \mathrm{~mm}]$ and 9.5 inches [241 mm], 18 inches [457 mm], and 40 inches $[1,016 \mathrm{~mm}])$, and strut angle $(30,45$, and 60 degrees) on the behavior of concrete deep beams. Crack patterns, load-deflection behavior, and ultimate loads from large-scale experimental tests were used to validate the results from numerical analysis. Then numerical models were developed and analyzed to investigate the abovementioned parameters. Several observations and conclusions can be made based on the results from the numerical study:

- Overhang length: Insufficient available development length led to development failure and lower ultimate capacities, as would be expected. 
Additionally, beams had a higher capacity when the region where internal, bonded reinforcement was developing was shifted away from the support nodes, i.e. with longer overhang lengths. This shows how tension stresses caused by reinforcement development can decrease the strength of nodes (as is handled by difference in node type in most design codes) and how this effect can be mitigated by moving the region of development away from the nodal zone.

- Development type (rectangular beams): The type of development used to develop the reinforcement did not have a significant impact on the ultimate capacity of the rectangular beams; the failure loads for beams with sufficient overhang were within about 10-percent of each other. The type of development did impact the member stiffness, with unbonded reinforcement resulting in a stiffer post-cracking response of the specimens.

- Development type (truss-like beams): The type of reinforcement development (internal bonded versus external unbonded) did significantly impact the ultimate capacity of the truss-like beams, with the internally bonded specimens having a 26-percent lower capacity than externally unbonded.

- Strut type: The strength of the truss-like specimen with external, unbonded reinforcement with zero for overhang length (Tr-ExU-0) was about 40-percent higher than the rectangular beams (bonded and 
unbonded reinforcement). This point also discussed in more detail elsewhere [10].

- Strut angle: The strut angle had a large effect on the strength of rectangular beams, with larger strut angles having higher capacity. The strut angle did not have consistent affect on the truss-like specimens though.

\subsection{Acknowledgments}

The authors would like to thank Florida International University (FIU) for supporting this research.

\subsection{Appendix A}

The following symbols are used in the paper:

$f_{c}^{\prime}=$ specified compressive strength of concrete, psi.

$\ell_{1}=$ span length, in.

$\ell_{2}=$ overhang length, in.

$\mathrm{h}=$ back face height, in. 


\title{
Chapter 6: Shear in Discontinuity Regions ${ }^{\mathrm{a}}$
}

\author{
*Gary J. Klein ${ }^{\mathrm{b}}$, Nazanin Rezaei ${ }^{\mathrm{c}}$, David Garber ${ }^{\mathrm{d}}$, and A. Koray Tureyen ${ }^{\mathrm{e}}$
}

\subsection{Abstract}

Since its introduction into the ACI 318 code in 2002 [2], the strut-and-tie method has been based on the premise that strength is sufficient if the idealized truss model is in equilibrium with the applied load without exceeding the capacity of struts, ties, and nodes. However, in spite of low strut efficiency factors for so-called bottle-shaped struts, the strut-and-tie method can be unconservative. Struts are not weaker because they are bottle-shaped; rather, the apparent weakness is due to shear failure where struts cross a diagonal tension field. Accordingly, discontinuity regions designed using the strut-and-tie method should be separately checked for shear strength as dictated by the strength of the diagonal tension field. This paper describes the development of design equations for shear strength of discontinuity regions. The design equations consider the effect on strength of shear span, depth, and lightweight concrete. This design procedure is under consideration for adoption in ACI 318-19.

a Submitted to Concrete International (ACI Publication)

${ }^{\mathrm{b}}$ Corresponding Author. Executive Vice President and Senior Principal, WJE (Wiss, Janney, Elstner) Associates, Northbrook, Illinois, USA. E-mail: gklein@wje.com.

${ }^{c} \mathrm{PhD}$ candidate, Civil and Environmental Engineering, Florida International University, Miami, Fl, USA.E-mail: nreza002@fiu.edu.

d Assistant Professor, Civil and Environmental Engineering, Florida International University, Miami, Fl, USA. E-mail: dgarber@ fiu.edu.

${ }^{\text {e }}$ Senior Associate, WJE (Wiss, Janney, Elstner) Associates, Northbrook, Illinois, USA. E-mail: atureyen@wje.com. 
Keywords: Shear, discontinuity region, diagonal tension, strut-and-tie method, strut

\subsection{Introduction}

The strut-and-tie method was introduced into Building Code Requirements for Structural Concrete (ACI 318) in 2002, although its origins date to the end of the 19th century [2].

The ACI 318-02 version of the strut-and-tie method is largely based on a 1987 report by Schlaich et al. [14], which describes procedures for designing structural elements using a system of struts and ties connected at nodes. The method is primarily intended for regions of the structure where the stress flow is influenced by concentrated loads, corners, openings, or other discontinuities. Such regions are referred to as discontinuity regions or D-regions. Strain distribution in D-regions is highly nonlinear, and the assumption of plane sections remaining plane does not apply. The strut-and-tie method is especially useful in D-regions because it allows for designing and detailing of the concrete section and reinforcement in accordance with a clearly visualized force field that is in static equilibrium, rather than relying on past practices or restrictive empirical guidelines.

However, as will be explained in this paper, there are several concerns and inconsistencies in the current Code (ACI 318-14 [3]) related to shear strength in D-regions:

- Interior struts (struts not located along an outer edge of a D-region) are not weaker than edge struts because they are "bottle-shaped;" rather, the apparent weakness arises because interior struts cross a diagonal tension field.

- The strut efficiency factor, $\beta_{s}$, for interior struts is unconservative because Dregions can fail in shear, which is not considered in the strut-and-tie method. 
- The shear stress in deep beams is limited to $10 \sqrt{f_{c}^{\prime}} \cdot(\sqrt{p s i}$ units are used herein; $1 \sqrt{p s i}=0.083 \sqrt{M P a}$ ). This limit does not apply to members or D-regions that do not "qualify" as deep beams, which is inconsistent at best. Furthermore, this limit is unnecessarily restrictive for D-regions with steeply inclined interior struts.

- Size effect, $\lambda_{s}$, is not considered.

- The lightweight concrete factor, $\lambda$, is used as a multiplier on $f_{c}^{\prime}$ rather than on $\sqrt{f_{c}^{\prime}}$, as it is elsewhere in the Code.

This paper addresses these concerns and inconsistencies based on review of relevant literature, analysis of published test data, and an experimental program evaluating the influence of diagonal tension on the strength of struts. Code changes are proposed for ACI 318-19 that require an independent check of shear strength based on the ratio of shear span to effective depth, $a_{v} / d$. For purposes of this paper, "shear strength" and "shear failure" relate to failures initiated by diagonal cracking and not strut compression or bearing failure. The proposed changes are compatible with proposals for new one-way shear equations [61] . Size effect and the lightweight concrete factor are incorporated in the proposed changes.

\subsection{Strength of Struts}

\subsubsection{Bottle-shaped Struts}

ACI 318-14 specifies a strut efficiency factor, $\beta_{s}$, of 0.6 for unreinforced bottle-shaped struts and 0.75 for reinforced bottle-shaped struts. Bottle-shaped struts are located in a region where the width of the compressed concrete at mid-length of the strut can spread laterally. However, research and testing by Laughery and Pujol [9] shows that bottle- 
shaped struts are no weaker than prismatic struts. Referring to Figure 1, prismatic (a) and two-dimensional bottle-shaped struts (b) exhibited approximately equal strength, both averaging about $0.85 f_{c}^{\prime}$, which is equivalent to a $\beta_{s}$ of 1.0. Prismatic and two-dimensional bottle-shaped struts were less than half as strong as three-dimensional bottle-shaped struts (Figure 6-1(c)).

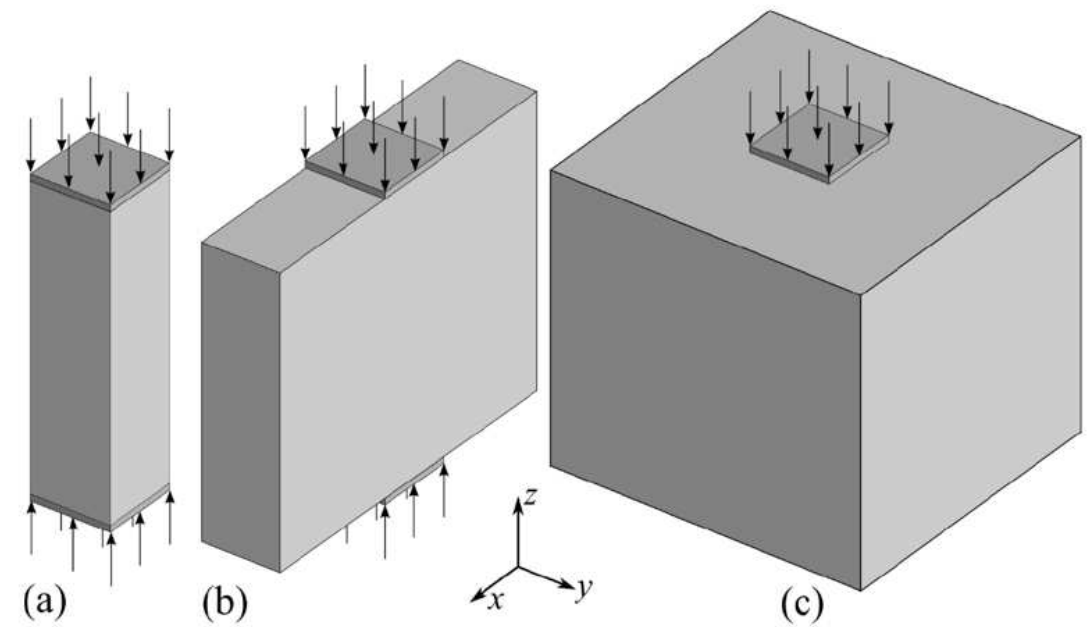

Figure 6-1: Illustrations of (a) rectangular prismatic strut, (b) 2-D rectangular bottle strut, and (c) 3-D rectangular bottle strut. After Laughery and Pujol

In an element like that shown in Figure 6-1(b), stresses spread laterally between the concentrated load or reaction areas and mid-length of the strut without the presence of a diagonal tension field. However, in deep beams and other D-regions, the stress flow is much more complex, as illustrated in Figure 6-2. Struts between the load and reaction cross through a field of diagonal tension and the stress flow is not bottle-shaped. 


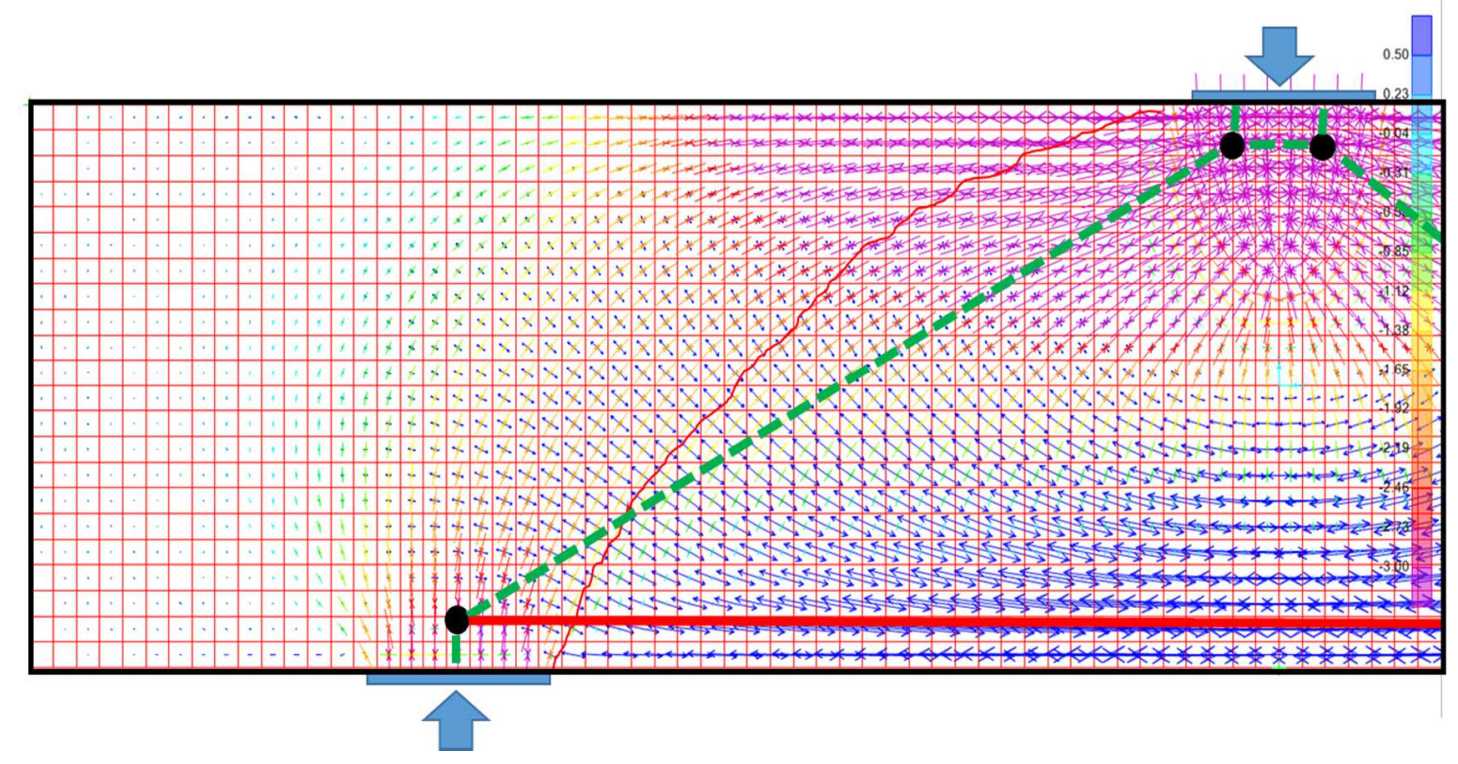

Figure 6-2: Example of stress flow in a deep beam

These observations suggest that strength of deep beams and other D-regions is most often limited by diagonal tension rather than strut crushing. ACI 318-14 and the associated commentary are misleading in that they incorrectly attribute lower $\beta_{s}$ values to bottleshaped stress flow. For this reason, struts that extend diagonally through the interior of Dregions are referred to herein as interior struts rather than bottle-shaped struts. Struts that carry compressive force along an edge of D-region are referred to as $e$ dge struts.

\subsubsection{Strut Strength Coefficients}

Reineck and Todisco [62] evaluated the strut strength coefficients, $\beta_{s}$, in ACI 318-14 relative to test data in the ACI-DAfStb Database [63] for members without transverse reinforcement. Tested shear strength, $V_{\text {test }}$, was compared to the strength calculated in accordance with the strut-and-tie method in ACI 318-14, $V_{\text {calc }}$. Several test values were much less than predicted by ACI 318-14 methods throughout the full range of $a_{v} / d$ considered. Based on these findings, Reineck and Todisco recommended that $\beta_{s}$ be 
reduced from 0.6 to 0.42 .

The findings are shown in Figure 6-3 as a plot of $V_{\text {test }} / V_{\text {calc }}$ versus $f_{c}^{\prime}$. In this plot, the calculated shear strength was based on Reineck and Todisco Alternative 3 in which the depth of the compression zone, $c$, was calculated for the load at shear failure. The trendline indicates that $V_{\text {test }} / V_{\text {calc }}$ decreases with increasing $f_{c}^{\prime}$. For the higher concrete strengths, the trendline closely follows $100 \sqrt{f_{c}^{\prime}} / f_{c}^{\prime}$ (the solid grey line), which is the expected trendline for failures that are proportional to $\sqrt{f_{c}^{\prime}}$ rather than $f_{c}^{\prime}$.

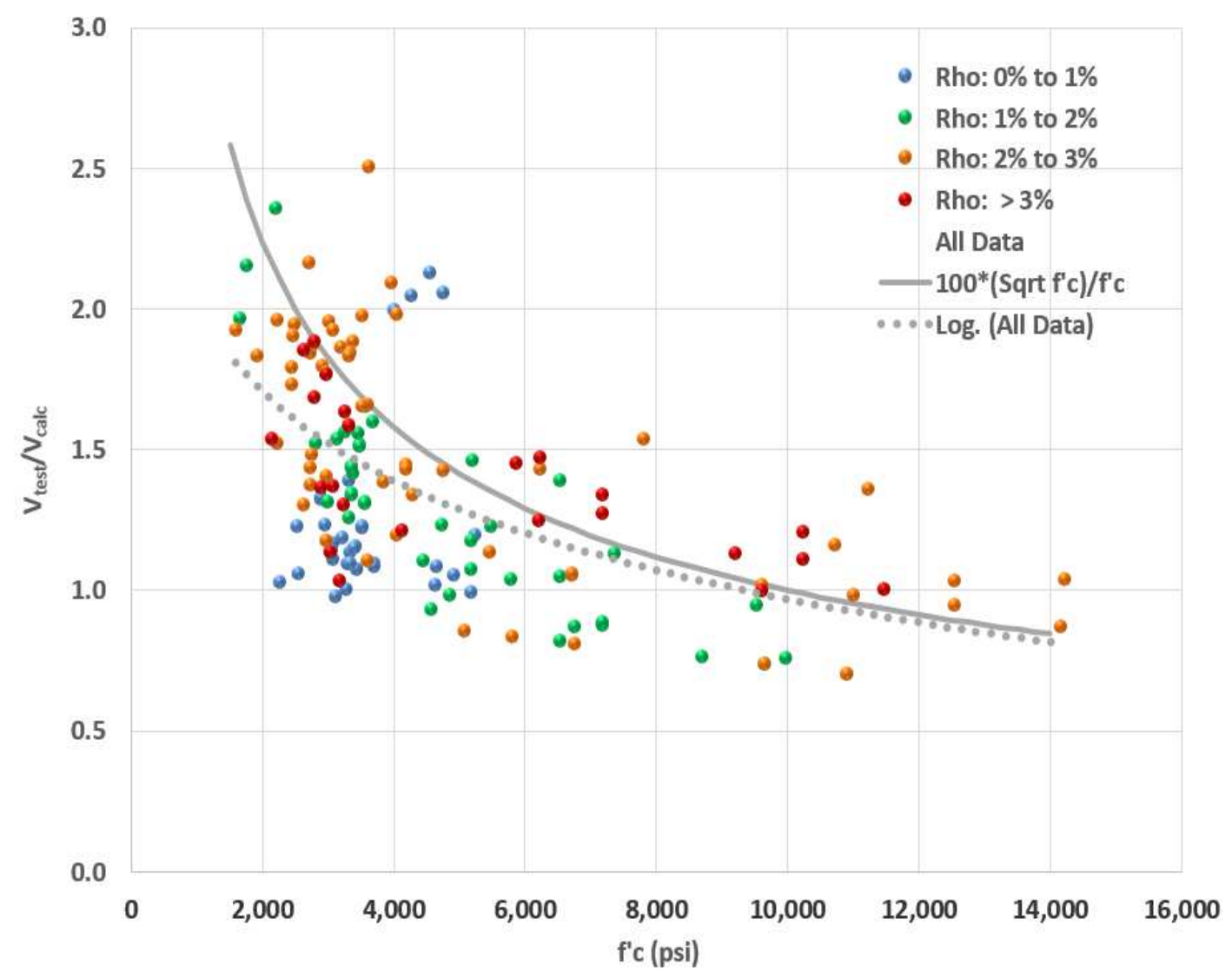

Figure 6-3: $V_{\text {test }} / V_{\text {calc }}$ versus $f^{\prime}{ }_{c}\left(V_{\text {calc }}\right.$ in accordance with the strut-and-tie method in ACI 31814)

This observation strongly indicates that most failures in the Joint ACI-DAfStb database are 
due to diagonal tension (which varies with $\sqrt{f_{c}^{\prime}}$ ) rather than strut crushing. This finding is consistent with the failure descriptions in the database and research papers from which the database was developed.

\subsubsection{Experimental Study}

An experimental study was conducted at Florida International University (FIU) to investigate the behavior of struts in deep beams. The full experimental study involved the testing of ten full-scale specimens; the results from four of these specimens are discussed here. Two pairs of rectangular and truss-like specimens were tested using the set-up shown in Figure 6-4. The details of the four specimens are provided in Table 6-1.

Table 6-1: Specimen details and test results

\begin{tabular}{|c|c|c|c|c|c|c|c|c|c|}
\hline \multirow{3}{*}{$\begin{array}{c}\text { Specimen } \\
\text { Name }\end{array}$} & \multirow{3}{*}{ Type } & \multicolumn{3}{|c|}{ Dimensions } & \multirow{3}{*}{$\begin{array}{l}\text { Strut } \\
\text { Angle } \\
\text { deg. }\end{array}$} & \multirow{3}{*}{$\begin{array}{c}\mathbf{f}_{\mathbf{c}}^{\prime} \\
\mathbf{k s i} \\
(\mathbf{M P a})\end{array}$} & \multirow{3}{*}{$\begin{array}{c}\text { Failure } \\
\text { Load kips } \\
\text { (kN) }\end{array}$} & \multirow{3}{*}{$\boldsymbol{\beta}_{\mathrm{s}}$} & \multirow{3}{*}{$\begin{array}{l}\text { Truss } \\
\text { Rect. }\end{array}$} \\
\hline & & \multicolumn{3}{|c|}{ in./(mm) } & & & & & \\
\hline & & Ht. & Length & Thick. & & & & & \\
\hline Re-30-Ex & Rect. & $\begin{array}{l}31.3 \\
(795)\end{array}$ & $\begin{array}{c}96 \\
(2438)\end{array}$ & $\begin{array}{c}12 \\
(305)\end{array}$ & 30 & $\begin{array}{r}7.44 \\
(51.3)\end{array}$ & $\begin{array}{c}380 \\
(1960)\end{array}$ & 0.43 & \\
\hline Tr-30-Ex & Truss & $\begin{array}{l}31.3 \\
(795)\end{array}$ & $\begin{array}{c}96 \\
(2438)\end{array}$ & $\begin{array}{c}12 \\
(305)\end{array}$ & 30 & $\begin{array}{c}7.37 \\
(50.8)\end{array}$ & $\begin{array}{c}575 \\
(2558)\end{array}$ & 0.66 & \\
\hline Re-45-Ex & Rect. & $\begin{array}{c}48 \\
(1219)\end{array}$ & $\begin{array}{c}96 \\
(2438)\end{array}$ & $\begin{array}{c}12 \\
(305)\end{array}$ & 45 & $\begin{array}{r}5.63 \\
(38.8)\end{array}$ & $\begin{array}{c}557 \\
(2478)\end{array}$ & 0.58 & \\
\hline $\operatorname{Tr}-45-E x$ & Truss & $\begin{array}{c}48 \\
(1219)\end{array}$ & $\begin{array}{c}96 \\
(2438)\end{array}$ & $\begin{array}{c}12 \\
(305)\end{array}$ & 45 & $\begin{array}{c}5.63 \\
(38.8)\end{array}$ & $\begin{array}{c}717 \\
(3189)\end{array}$ & 0.74 & \\
\hline
\end{tabular}


All four specimens were 96 inches $(2438 \mathrm{~mm})$ long and 12 inches $(304 \mathrm{~mm})$ thick. Specimens were simply supported and flexurally reinforced with external high-strength threaded rods. The length and height of the bearings at each end was 8.5 inches $(216 \mathrm{~mm})$. External reinforcement was used to avoid disruption of the bottom nodal region due to reinforcement development.

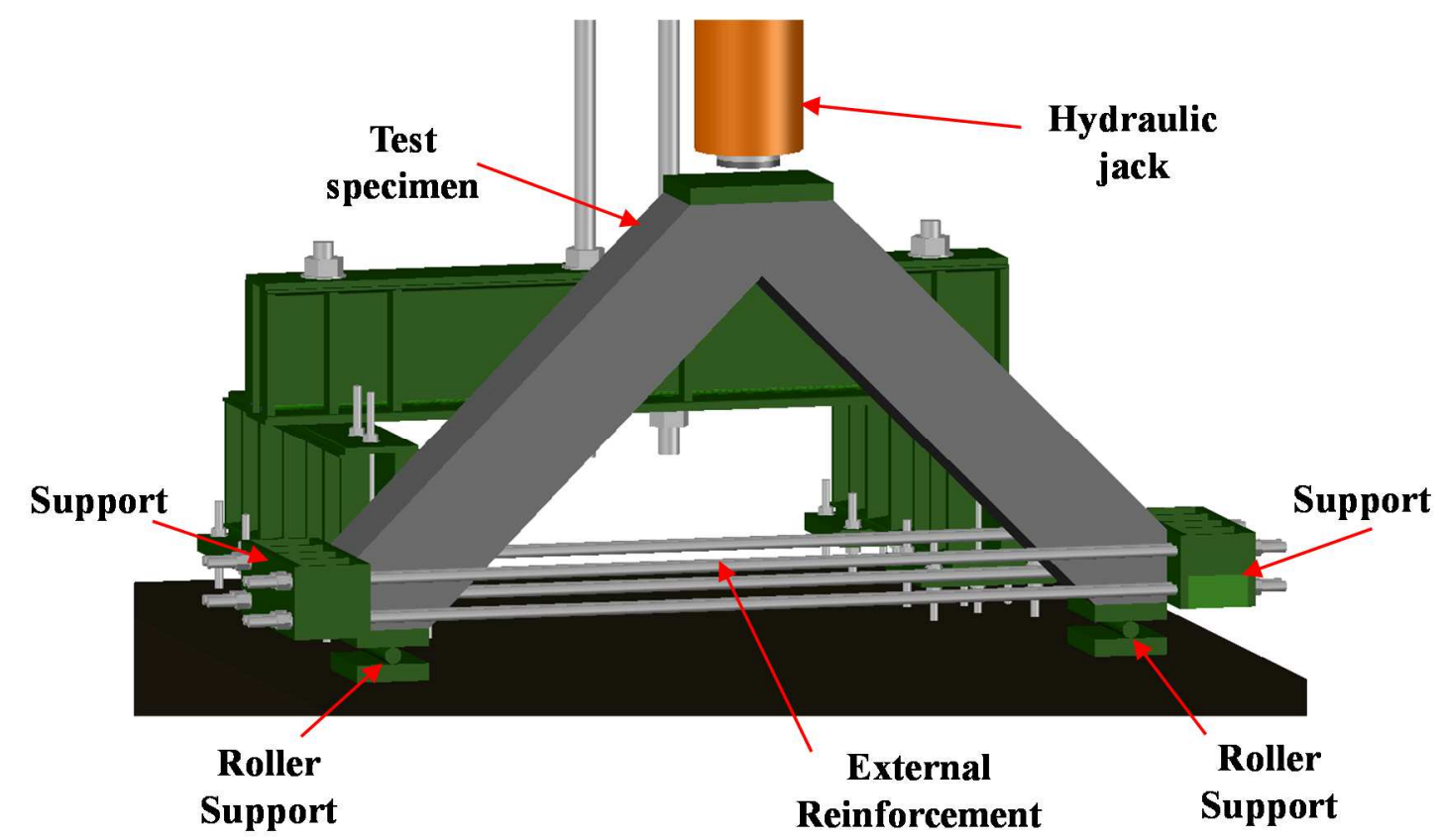

Figure 6-4: Schematic of test setup and specimen with supports (truss-like specimen shown)

The first pair consisted of a rectangular and truss-like specimen with identical overall dimensions and concrete compressive strengths of approximately $7.4 \mathrm{ksi}(51 \mathrm{MPa})$. The 31.3-inch (795-mm) height of the specimens was selected such that the strut angle was 30 degrees from horizontal. The shape of the truss-like specimens (see Figure 6-4) precludes development of diagonal tension across the strut. As such, comparison of the truss-like specimens to their rectangular counterparts allows for evaluation of the effect of diagonal tension on strut strength. The second pair differed from the first pair in two respects: 1) the 
height was increased to 48 inches $(1219 \mathrm{~mm})$ such that the strut angle was 45 degrees, and 2) the concrete compressive strength was $5.6 \mathrm{ksi}(39 \mathrm{MPa})$.

Loads were measured using calibrated load cells, vertical displacement at midspan and horizontal displacement at supports were measured using linear potentiometers, and strain parallel and perpendicular to the strut axis was measured using surface-mounted vibrating wire gages.

The specimens were tested to failure. The rectangular specimens failed in diagonal tension, while the truss-like specimens failed primarily by crushing of the concrete. All specimens failed suddenly and violently. The cracking pattern for specimen Re-45-Ex is shown in Figure 6-5. At approximately 10 percent of the failure load, a flexural crack developed near midspan (dashed gray line). This crack grew in width and progressed toward the compression block as additional load was applied. The instant of failure captured from slow-motion video is shown in the inset image. The primary failure crack (red line) appears to initiate at the curved green arrow. Additional secondary cracks developed due to restraint at the load and reaction areas as the upper corner of the specimen rotated away about the support. The estimated pattern of secondary cracks is illustrated in gray lines in Figure 6-5. The other rectangular beam specimen, Re-30-Ex, failed in a similar fashion. 


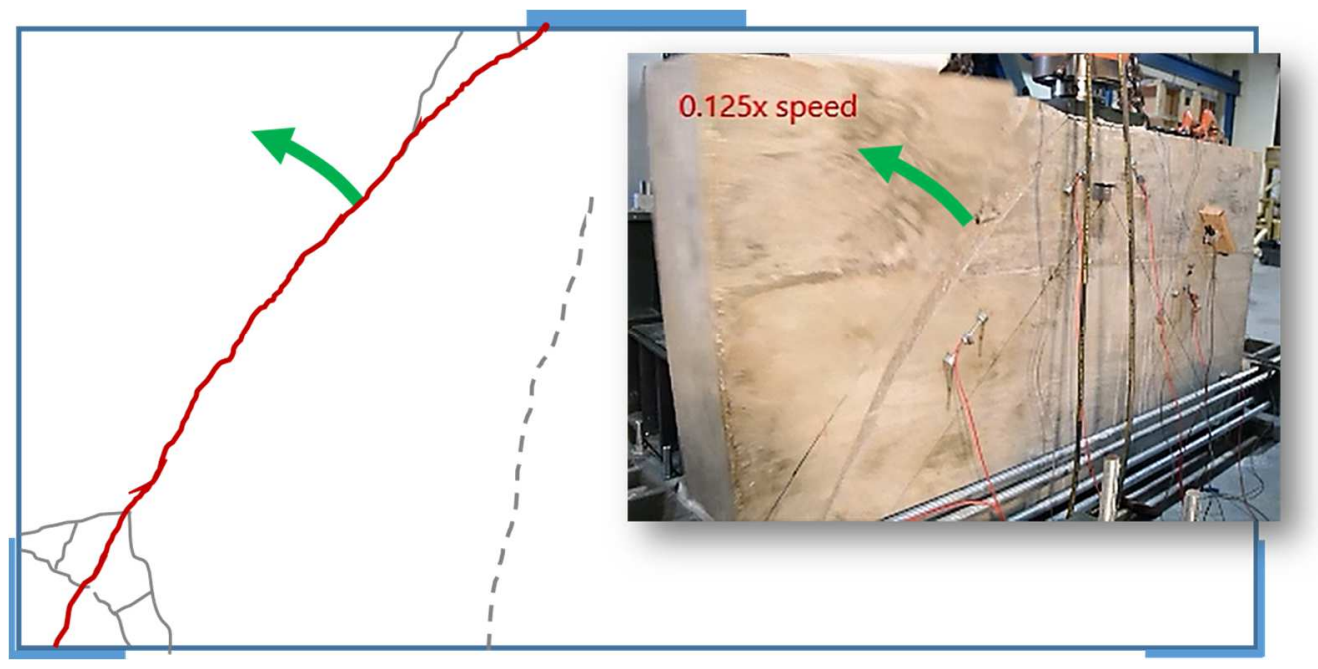

Figure 6-5: Failure crack pattern and image of instant of failure: Specimen Re-45-Ex

The truss-like specimens failed primarily by crushing of the concrete just below the load area. As load was applied, the struts shortened and the reaction points separated, adding bending stress to the strut compressive stress. Therefore, the strut strength factors, $\beta_{s}$, for the truss-like specimens were less than 1.0 by approximately 25 percent.

The truss-like specimens for the 30 degree and 45 degree strut angle were approximately 50 and 30 percent stronger than their rectangular counterparts, respectively. As discussed by Van den Hoogen [28], Beeby observed a similar difference between a rectangular specimen and an identical specimen except for a triangular cut-out at the bottom of the specimen. In light of the Laughery and Pujol [9] findings previously discussed, the reduced strength of rectangular specimens appears to be due to diagonal tension rather than a bottleshaped stress field.

\subsection{Shear Strength of D-Regions}

The research described above indicates D-regions can fail in shear before the strut crushes. This section explores the factors that influence shear strength of D-regions. 


\subsubsection{Shear Span}

Consider the full-story transfer girder illustrated in Figure 6-6 and the shear stresses along line $\boldsymbol{a}$ - $\boldsymbol{a}$. Such a girder might be used at an offset in the column grid. The shear force is carried by a direct strut between the bottom of the top column and top of the bottom column. In taller buildings, shear stresses can substantially exceed the $10 \sqrt{f_{c}^{\prime}}$ limit in ACI $318-14$.

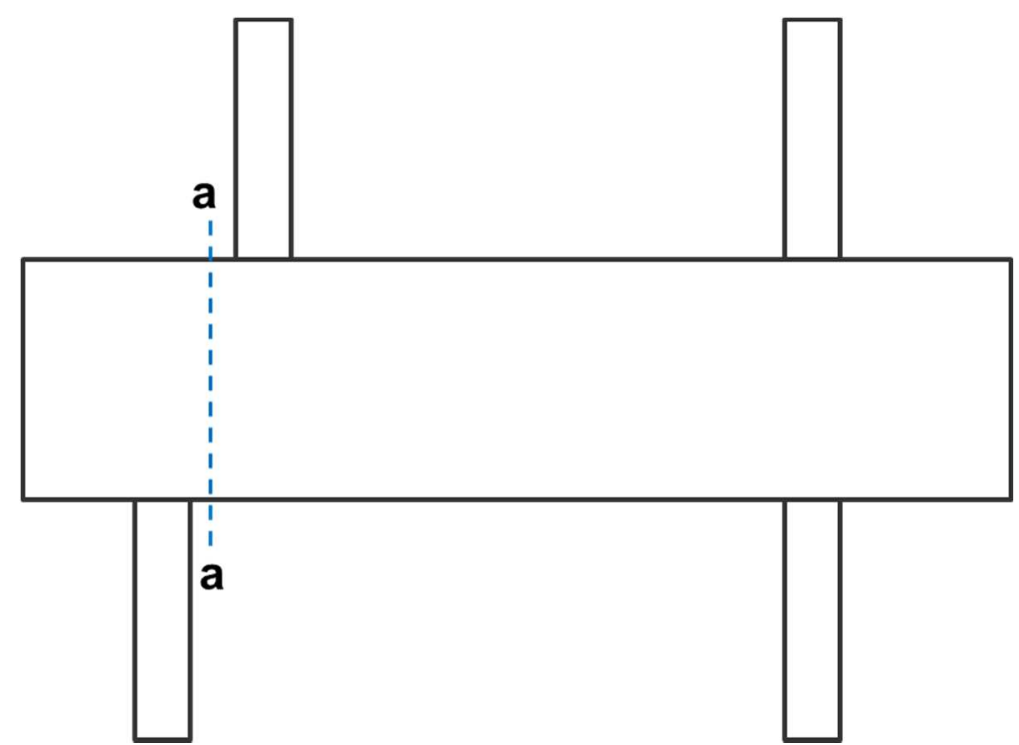

Figure 6-6: Transfer girder at an offset in the column grid

Zsutty [64] reported on the inverse relationship between shear strength and $a_{v} / d$ ratio. $\mathrm{He}$ recommended a multiplier of $2.5 /\left(a_{v} / d\right)$ to account for the effect of shear span. This expression times $2 \sqrt{f_{c}^{\prime}} b_{w} d$ gives the following expression for shear strength of D-regions:

$$
V_{c}=\frac{5 \sqrt{f_{c}^{\prime}} b_{w} d}{\left(a_{v} / d\right)} \quad \text { Equation 6-1 }
$$

Figure 6-7 is a plot of shear stress at failure vs $a_{v} / d$. The data are from the Joint ACIDAfStb Database $\left[63\right.$, p.] for members without transverse reinforcement $a_{v} / d$ ratios of 2.0 
or less. At very low $a_{v} / d$ ratios, the shear strength substantially exceeds the current 10 $\sqrt{f_{c}^{\prime}}$ limit. The shallowest allowable strut angle of 25 degrees corresponds to an $a_{v} / d$ ratio of about 2 and a shear stress limit of $2.5 \sqrt{f_{c}^{\prime}}$. The gray line shows the shear stress given by expressed in terms of $\sqrt{f_{c}^{\prime}}$. All data points are near or above the line, indicating that Equation 6-1 provides a conservative lower bound to the shear strength of D-regions in the Joint ACI-DAfStb database, even if strut crushing controlled.

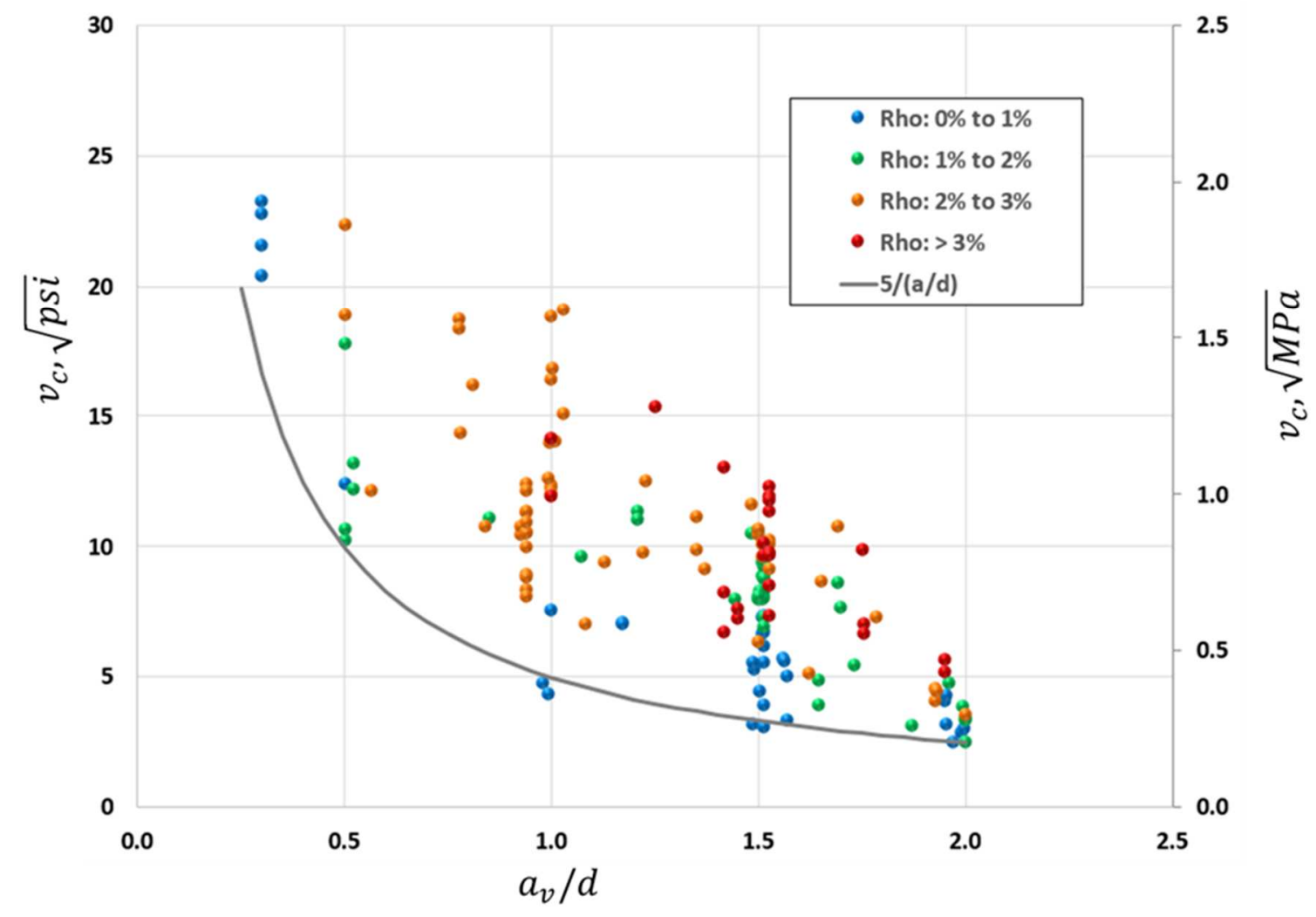

Figure 6-7: Shear stress $v_{c}$ vs ratio of shear span to effective depth, $a_{v} / d$

\subsubsection{Size Effect and Lightweight Concrete Factors}

Equation 6-1 does not consider reductions in shear strength due to size effect or reduced mechanical properties of lightweight concrete, although both of these factors would be 
expected to reduce shear strength as governed by diagonal tension. However, these factors are not especially important for the comparison shown in Figure 6-7 because the Joint ACIDAfStb Database primarily includes relatively small specimens fabricated with normalweight concrete.

For more than a decade, Joint ACI-ASCE Committee 445 and ACI Subcommittee 318-E have recognized that size effect can significantly reduce the shear strength of deep members without transverse reinforcement, such as footings and thick one-way slabs. The sectional design equations for both one-way and two-way shear strength will include a size effect factor in 318-19. The size effect factor, $\lambda_{s}$, under consideration at the time of writing is as follows:

$$
\lambda_{s}=1.4 / \sqrt{1+d / 10} \leq 1.0
$$

where $d$ is in inches (the metric equivalent is $1.4 / \sqrt{1+d / 254}$, where $d$ is in mm).

Also, because the basis of the proposed design equation is diagonal tension, the lightweight concrete factor, $\lambda$, should be considered to account for the lower tensile-to-compressive strength ratio of lightweight concrete compared with normal-weight concrete.

Including size effect and the reduced tensile-to-compressive strength properties of lightweight concrete, Equation 6-1 becomes:

$$
V_{c}=\frac{5 \lambda \lambda_{s} \sqrt{f_{c}^{\prime}} b_{w} d}{\left(a_{v} / d\right)}
$$

Equation 6-2

\subsubsection{Reinforcement Ratio}

The data in Figure 6-7 are sorted by ranges of reinforcement ratio. As can be seen, for a given $a_{v} / d$ ratio, shear stress at failure generally increases with increasing reinforcement 
ratio. At the time of writing, the one-way shear design proposal being considered for ACI 318-19 recognizes the relationship between reinforcement ratio and shear strength, as well as size effect and the lightweight concrete factor. For members without axial force, the following design equation is under consideration:

$$
V_{c}=8 \lambda \lambda_{s}\left(\rho_{w}\right)^{1 / 3} \sqrt{f_{c}^{\prime}} b_{w} d
$$

Equation 6-3

where $\rho_{w}=$ ratio of flexural tension reinforcement area to $b_{w} d$, and $f_{c}^{\prime}$ is the concrete compressive strength in psi.

Combining Equation 6-3 with the 2.5/( $\left.a_{v} / d\right)$ shear span modification factor recommended by Zsutty gives the following equation for shear strength of D-regions:

$$
V_{c}=\frac{20 \lambda \lambda_{s}\left(\rho_{w}\right)^{1 / 3} \sqrt{f_{c}^{\prime}} b_{w} d}{(a / d)}
$$

Equation 6-4

Tested shear strength for members without transverse reinforcement and $a_{v} / d$ less than 2.0 was compared to the shear strength calculated in accordance with Eq. 4. The tested shear strength exceeds the shear strength predicted by Equation 6-4 for all data, and Equation 6-4 appears to capture trends related to reinforcement ratio and $a_{v} / d$ ratio.

\subsection{Conclusions and Recommendations}

\subsubsection{Conclusions}

In conclusion, the research, data analysis, and experimental program described above have confirmed that interior struts are not weaker than edge struts because they are "bottleshaped." Rather, where interior struts cross a diagonal tension field, the member generally fails by the development of a diagonal tension crack in the shear span rather than crushing 
of the strut. This study also shows that shear strength of D-regions mainly depends on the $a_{v} / d$ ratio.

\subsubsection{Recommendations}

Based on these findings, several changes to the ACI code are recommended. The primary change is to require a separate check of shear strength in D-regions using Equation 6-2, which considers $a_{v} / d$ ratio as well as size effect and the lightweight concrete factor. Alternatively, shear strength can be based on Equation 6-4, which considers reinforcement ratio in addition to the factors considered by Equation 6-2. Both equations provide a conservative lower bound to the diagonal tension strength of the section while allowing shear stresses that exceed the current limit of $10 \sqrt{f_{c}^{\prime}}$ for members with very low $a_{v} / d$ ratios, like the transfer girder shown in Figure 6-6.

If the shear force in the discontinuity region is resisted by transverse reinforcement, $a_{v} / d$ in Equation 6-2 or Equation 6-4 can be replaced with $\cot \theta$, where $\theta$ is the angle between the strut and longitudinal tie. Because the ACI 318 requires the angle between the axes of any strut and tie (the transverse reinforcement in this case) be at least 25 degrees, $\theta$ cannot exceed 65 degrees and the allowable shear stress in D-regions with transverse reinforcement is in effect limited to about $10 \lambda \lambda_{s} \sqrt{f_{c}^{\prime}}$.

Although Equation 6-2 and Equation 6-4 are conservative relative to the Joint ACI-DAfStb Database, strut strength should be evaluated to avoid compression failures in areas of concentrated loads and reactions. However, a strut strength factor, $\beta_{s}$, of 0.75 (the current value for reinforced struts) can be used for typical interior struts. Equation 6-2 or Equation 6-4 account for the effects of a tension stress field across interior struts; therefore, the 0.6 
$\beta_{s}$ limit for bottle-shaped struts need not be used. Additionally, the strut-and-tie method should still be used to check tie strength and development.

These design recommendations resolve the issues listed in the introduction. Additionally, the recommendations should lead to more economical design of deep footings and thick slabs because the beneficial effect of low $a_{v} / d$ ratios counteracts size effect. The sectional design provisions of ACI 318-19 will require consideration of size effect in deep members without transverse reinforcement. These recommendations do not apply to shear stress limits for beam-column joints, which are addressed separately in Chapter 18 of ACI 318. At the time of writing, these changes have been approved by ACI Subcommittee 318-E and are being considered by the full committee.

\subsection{Acknowledgements}

The experimental study described herein was funded by Florida International University. The authors wish to express their sincere gratitude for the University's support. The authors also gratefully acknowledge technical assistance and guidance from ACI Subcommittees 445-A and 318-E as well as numerous ACI colleagues including Jeff Rautenberg, Santiago Pujol, Mete Sozen, David Sanders, Dan Kuchma, Karl-Heinz Reineck, and Evan Benz. 


\section{Chapter 7: Summary, Conclusions, and Recommendations}

This chapter includes a summary of the main conclusions of this dissertation and recommendations for future work.

\subsection{Summary and Conclusions}

The overall goal of the work presented in this dissertation was to investigate the behavior of struts and nodes in the strut-and-tie method (STM). The thought of current code provisions is that there are two types of struts (bottle-shaped and prismatic), and that these types of struts behave differently. Recent research has shown that there is no difference in the behavior of these types of struts when they are vertically oriented. There is an apparent difference in strength when the struts are placed at an angle, and the angle of the strut does affect the strength.

This research aimed at better understanding the reason vertically oriented struts behave differently than inclined struts. The primary work consisted of three main components: (1) experimental testing, (2) numerical study, and (3) design recommendations.

\subsubsection{Experimental Testing}

The experimental phase included six full-scale concrete deep beams with different geometries (rectangular and truss-like), strut angle $\left(30^{\circ}\right.$ and $\left.45^{\circ}\right)$, and reinforcement (externally unbonded bars, internally bonded hooked bars, and internally bonded bars with welded external plates). The specimens were loaded under a three-point load setup and supported with pin-pin supports, vertically. Failure load, deflection, and strains were measured, and failure modes were observed and documented during testing. The capacity of the specimens was calculated based on ACI 318-14 [3] and AASHTO LRFD [19] and 
compared to the experimental capacity. Several conclusions can be made based on the results of the experimental testing:

\section{Truss-like specimens failed at higher loads than rectangular specimens (with} similar angles): The truss-like specimens clearly failed due to crushing of the concrete in the node under the load point. Failure of the rectangular specimens was clearly triggered by the top corner of the specimens breaking off (caused by diagonal tension from bending) followed by failure of the support node.

2. Strut with shallower angle was weaker than steeper angle: The 45-degree truss specimen was 12-percent stronger than the 30-degree truss specimen. The 45degree rectangular specimen was 4-percent stronger than the 30-degree specimen. This was confirmed in the rectangular beams in the numerical study. The experimental results were then used to calibrate the numerical models.

\subsubsection{Numerical Study}

The second phase consisted of a numerical study of concrete deep beams using a non-linear finite element software to investigate the capacity and behavior of a larger variety of specimens. After validating numerical models with experimental results, 35 specimens were numerically modeled to expand the study of the behavior of struts. Specimen shape (rectangular and truss-like), reinforcement development type (straight, hooked, external unbonded, and internal bonded bars), overhang length (0 inches [0 mm] and 9.5 inches [241 mm], 18 inches [457 mm], and 40 inches [1,016 mm]), and strut angle (30, 45, and

60 degrees) were the primary variables in the specimens. Several additional conclusions can be made based on the results of the numerical study: 


\section{Shifting reinforcement development away from node can increase capacity:}

Development of bonded reinforcement causes tension stresses to develop in the surrounding concrete. Developing reinforcement in the nodal zones was found to decrease the strength of the node.

\section{Internal, bonded reinforcement decreased strength of truss-like beams but not} rectangular beam: Truss-like beams with internally bonded reinforcement had 26-percent lower capacity than externally unbonded beams. The strength of the rectangular beams was not heavily impacted by the type of reinforcement. This shows that the bonded reinforcement does introduce tension in the nodal zone (decreasing the strength of the truss-like beams), but that the diagonal tension caused by bending in the rectangular beams still controls failure. These results suggest that the tension effect from development and diagonal tension from bending are not additive and separate design checks are appropriate (as were proposed in this work).

\subsubsection{Design Recommendations}

Based on the experimental investigation in this research and previous works, several changes were recommended to the ACI 318 Building Code. These changes are based on the following conclusions:

5. Diagonal tension decreases strength of rectangular beams: The observations from this research and previous studies confirm that rectangular beams fail at lower loads than truss-like beams not because bottle-shaped struts are weaker than prismatic struts, but because beam bending causes diagonal tension in the 
rectangular beams. Because this tension occurs outside of nodal zones, a separate check (apart from typical node stress checks) is appropriate.

6. Shear span-to-depth ratio has a significant effect on shear strength: The shearspan-to-depth ratio $(a / d)$ impacts the strut angle, which changes the influence the diagonal tension has on the strut behavior. This factor was included in the recommended equation.

The following equation (Equation 7-1), is recommended to limit the shear strength of the member. This equation is an additional check to ensure the diagonal tension in a member does not control. This equation depends on the shear span-to-depth ratio, size effect, and the light weight concrete factor.

$$
V_{c}=\frac{5 \lambda \lambda_{s} \sqrt{f_{c}^{\prime}} b_{w} d}{\left(a_{v} / d\right)} \quad \text { Equation 7-1 }
$$

where (defined in ACI 318-14 [3]):

$$
\begin{aligned}
& a_{v}=\text { shear span, equal to distance from center of concentrated load to either: (a) } \\
& \text { face of support for continuous or cantilevered members, or (b) center of } \\
& \text { support for simply supported members. } \\
& b_{w}=\text { web width or diameter of a circular member } \\
& d=\text { distance from extreme compression fiber to centroid of longitudinal tension } \\
& \text { reinforcement } \\
& f^{\prime}{ }_{c}=\text { specified compressive strength of concrete } \\
& \lambda=\text { modification factor to reflect the reduced mechanical properties of } \\
& \text { lightweight concrete relative to normalweight concrete of the same } \\
& \text { compressive strength }
\end{aligned}
$$


and where:

$$
\begin{array}{rlrl}
\lambda_{s}= & \text { size effect factor } & & \\
\text { For } d \text { in inches: } & \lambda_{s}=1.4 / \sqrt{1+d / 10} \leq 1.0 & \text { Equation 7-2 } \\
& \text { For } d \text { in } \mathrm{mm}: & \lambda_{s}=1.4 / \sqrt{1+d / 254} \leq 1.0 & \text { Equation 7-3 }
\end{array}
$$

An alternate equation (Equation 7-4) is also proposed to also consider the impact of reinforcement ratio on the shear strength.

$$
V_{c}=\frac{20 \lambda \lambda_{s}\left(\rho_{w}\right)^{1 / 3} \sqrt{f_{c}^{\prime}} b_{w} d}{\left(a_{v} / d\right)} \quad \text { Equation 7-4 }
$$

\subsection{Recommendations for Future Work}

The following items should be considered for future work:

- Additional experimental tests should be done with additional strut angles to investigate the exact relationship of strut angle and ultimate capacity of the specimens.

- All the specimens in this program did not have shear reinforcement. The impact of the presence of minimum shear reinforcement on the above observations should also be investigated.

- Additional experimental testing should be done with different bonded and unbonded reinforcement to confirm the findings from the numerical efforts of this research. 


\section{References}

[1] L. AASHTO, "Specification for Highway Bridge Design," Am. Assoc. State Highw. Transp. Off. Wash. DC, 1994.

[2] ACI Committee 318, "Building Code Requirements for Structural Concrete (ACI 318-02) and Commentary (ACI 318R-02)." American Concrete Institute, Farmington Hills, 443 pp-2002.

[3] ACI Committee 318, "Building Code Requirements for Structural Concrete and Commentary (ACI 318-14)." American Concrete Institute,Farmington Hills,MI, 2014.

[4] D. Birrcher, R. Tuchscherer, M. Huizinga, O. Bayrak, S. L. Wood, and J. O. Jirsa, "Strength and Serviceability Design of Reinforced Concrete Deep Beams," Apr. 2009.

[5] M. D. Brown, C. L. Sankovich, O. Bayrak, and J. O. Jirsa, "Behavior and efficiency of bottle-shaped struts," ACI Struct. J., vol. 103, no. 3, p. 348, 2006.

[6] J. Schlaich and K. Schafer, "Design and detailing of structural concrete using strutand-tie models," Struct. Eng., vol. 69, no. 6, pp. 113-125, 1991.

[7] D. K. Sahoo, B. Singh, and P. Bhargava, "An appraisal of the ACI strut efficiency factors," Mag. Concr. Res., vol. 61, no. 6, pp. 445-456, 2009.

[8] S. Pujol, J. M. Rautenberg, and M. A. Sozen, "Compressive Strength of Concrete in Nonprismatic Elements," Concr. Int., vol. 33, no. 9, pp. 42-49, Sep. 2011.

[9] L. Laughery and S. Pujol, "Compressive strength of unreinforced struts," ACI Struct. J., vol. 112, no. 5, p. 617, 2015.

[10] Nazanin Rezaei, Gary Klein, and David Garber, "STRUT STRENGTH AND FAILURE IN FULL-SCALE CONCRETE DEEP BEAMS,” ACI Struct. J., 2018. 
[11] Nazanin Rezaei,Gary Klein, David Garber, "Effect of Development and Beam Geometry on Behavior of Concrete Deep Beams," 2018.

[12] Gary J. Klein, Nazanin Rezaei, David Garber, and A. Koray Tureyen, "SHEAR IN DISCONTINUITY REGIONS," Concr. Int., no. in press, 2018.

[13] A. J. C. Barr de Saint-Venant, "Memoire sur la torsion des prismes," CR Acad Sci, vol. 37,1853 .

[14] J. Schlaich, K. Schäfer, and M. Jennewein, "Toward a consistent design of structural concrete," PCI J., vol. 32, no. 3, pp. 74-150, 1987.

[15] D. B. Garber, J. M. Gallardo, G. D. Huaco, V. A. Samaras, and J. E. Breen, "Experimental evaluation of strut-and-tie model of indeterminate deep beam," ACI Struct. J., vol. 111, no. 4, p. 873, 2014.

[16] S. ACI, "208 (2002): Examples for the Design of Structural Concrete with Strut-andTie Models. Reineck, K," H Ed. ACI SP-208 ACI Farmington Hills MI.

[17] K.-H. Reineck and L. C. Novak, "Further Examples for the Design of Structural Concrete with Strut-and-Tie Models," ACI SP-273 2010 ACI Farmington Hills MI, 2010.

[18] ACI Committee 318, "Building Code Requirements for Structural Concrete and Commentary (ACI 318-05).” American Concrete Institute, Farmington Hills, 2005.

[19] AASHTO, "Specification for Highway Bridge Design." American Association of State Highway and Transportation Officials, Washington, DC, 2016.

[20] O. Bayrak and M. Brown, "Minimum Transverse Reinforcement for Bottle-Shaped Struts," Struct. J., vol. 103, no. 6, pp. 813-822, Nov. 2006.

[21] D. K. Sahoo, B. Singh, and P. Bhargava, "Investigation of Dispersion of Compression in Bottle-Shaped Struts," Struct. J., vol. 106, no. 2, pp. 178-186, Mar. 2009. 
[22] A. H. Ghanei and R. Aghayari, "Experimental Investigation on Effect of Aspect Ratio on Behavior of Isolated Reinforced Concrete Struts," Struct. J., vol. 113, no. 4, pp. 643-654, Jul. 2016.

[23] C. G. Quintero-Febres, G. Parra-Montesinos, and J. K. Wight, "Strength of Struts in Deep Concrete Members Designed Using Strut-and-Tie Method," Struct. J., vol. 103, no. 4, pp. 577-586, Jul. 2006.

[24] A. Arabzadeh, R. Aghayari, and A. R. Rahai, "Investigation of experimental and analytical shear strength of reinforced concrete deep beams," Int. J. Civ. Eng., vol. 9, no. 3, pp. 207-214, Sep. 2011.

[25] G. Campione and G. Minafo, "Experimental Investigation on Compressive Behavior of Bottle-Shaped Struts," Struct. J., vol. 108, no. 3, pp. 294-303, May 2011.

[26] P. Adebar and Z. Zhou, "Bearing Strength of Compressive Struts Confined by Plain Concrete," Struct. J., vol. 90, no. 5, pp. 534-541, Sep. 1993.

[27] F. E. Richart and R. L. Brown, "An Investigation of reinforced concrete columns ; a report of an investigation conducted by the Engineering Experiment Station, University of Illinois in coöperation with the American Concrete Institute," 1934.

[28] M. G. M. Van den Hoogen, "Beam or truss mechanism for shear in concrete: Problems converting a beam into a truss," 2013.

[29] Beeby, A.W., "The behaviour of reinforced concrete beams without shear reinforcement in shear," Univ. Leeds U. K. Unpubl., p. 2000.

[30] P. Lampert and B. Thürlimann, "Ultimate Strength and Design of Reinforced Concrete Beams in Torsion and Bending," in Ultimate Strength and Design of Reinforced Concrete Beams in Torsion and Bending / Résistance et dimensionnement des poutres en béton armé soumises à la torsion et à la flexion / Bruchwiderstand und Bemessung von Stahlbetonbalken unter Torsion und Biegung, Birkhäuser, Basel, 1972, pp. 107-131. 
[31] D. Mitchell and M. P. Collins, "Diagonal Compression Field theory-A Rational Model For Structural Concrete in Pure Torsion," J. Proc., vol. 71, no. 8, pp. 396-408, Aug. 1974.

[32] J. A. Ramirez and J. E. Breen, "PROPOSED DESIGN PROCEDURES FOR SHEAR AND TORSION IN REINFORCED AND PRESTRESSED CONCRETE," Nov. 1983.

[33] A. B. Matamoros and K. H. Wong, "DESIGN OF SIMPLY SUPPORTED DEEP BEAMS USING STRUT-AND-TIE MODELS," ACI Struct. J., vol. 100, no. 6, Nov. 2003.

[34] D. K. Sahoo, B. Singh, and P. Bhargava, "Effect of inclination on the strength of struts," Mag. Concr. Res., vol. 63, no. 2, pp. 111-117, Feb. 2011.

[35] R. K. L. Su and D. T. W. Looi, "Revisiting Unreinforced Strut Efficiency Factor," Struct. J., vol. 113, no. 2, pp. 301-312, Mar. 2016.

[36] C. S. Williams, "Strut-and-tie model design examples for bridge," thesis, 2011.

[37] N. A. Larson, "Design of reinforced concrete inverted-T beams for strength and serviceability," May 2013.

[38] J. K. Wight and G. Parra-Montesinos, "Strut and Tie Model for Deep Beam Design," Concr. Int., vol. 25, no. 5, pp. 63-70, May 2003.

[39] Ritter, W., "Die Bauweise Hennebique," Constr. Tech. Hennebique Schweiz. Bauztg. 337.

[40] E. Mörsch and E. P. Goodrich, Concrete-steel construction: (Der Eisenbetonbau). The Engineering news publishing company, 1909.

[41] W. D. Cook and D. Mitchell, "Studies of Disturbed Regions Near Discontinuities in Reinforced Concrete Members," Struct. J., vol. 85, no. 2, pp. 206-216, Mar. 1988. 
[42] J. E. Breen, O. Burdet, C. Roberts, D. Sanders, and G. Wollmann, "ANCHORAGE ZONE REINFORCEMENT FOR POST-TENSIONED CONCRETE GIRDERS," NCHRP Rep., no. 356, 1994.

[43] "Guidance specification for strength evaluation of existing steel and concrete bridges." American Association of State Highways and Transportation Officials, (AASHTO), Washington, D.C, 1989.

[44] van den Hoogen, M., Hordijk, D., Blom, K., \& Vergoossen, R., "The Increasing Bearing Capacity while Remoivng Concrete from Reinforced Beams," Concr. Innov. Des. Fib Symp. Cph., p. 9, May 2015.

[45] FIP Recommendations, 1999, Practical Design of Structural Concrete. FIPCommission 3.

[46] CEB-FIP, 2010, 'CEP-FIP Model Code,' Comité Euro-International du Béton, International Federation for Structural Concrete (fib), Lausanne, Switzerland.

[47] Concrete Reinforcing Steel Institute, 2008, CRSI Handbook, Chicago, IL. CEN, 2004, 'Eurocode 2: Design of Concrete Structures,' European Committee for Standardization, Brussels, Belgium, 229 pp.

[48] CSA Standard CAN3-A23.3-14, 1994, 'Design of Concrete Structures for Buildings with Explanatory Notes,' Canadian Standards Association, Rexdale, Ontario.

[49] ACI Committee 215, 1992, 'Considerations for design of concrete structures subjected to fatigue loading.' J. Am. Concr. Inst., 71(3), 97-121.

[50] T. Paskova and C. Meyer, "Low-Cycle Fatigue of Plain and Fiber-Reinforced Concrete," Mater. J., vol. 94, no. 4, pp. 273-286, Jul. 1997.

[51] Yun Young Mook, "Strength of Two-Dimensional Nodal Zones in Strut-Tie Models," J. Struct. Eng., vol. 132, no. 11, pp. 1764-1783, Nov. 2006. 
[52] R. Tuchscherer, D. Birrcher, M. Huizinga, and O. Bayrak, "Confinement of Deep Beam Nodal Regions," Struct. J., vol. 107, no. 6, pp. 709-717, Nov. 2010.

[53] R. G. Tuchscherer, D. B. Birrcher, C. S. Williams, D. J. Deschenes, and O. Bayrak, "EVALUATION OF EXISTING STRUT AND TIE METHODS AND RECOMMENDED IMPROVEMENTS," Struct. J., vol. 111, no. 6, pp. 1451-1460, Nov. 2014.

[54] M. K. Thompson, M. J. Ziehl, J. O. Jirsa, and J. E. Breen, "CCT Nodes Anchored by Headed Bars- Part 1: Behavior of Nodes," Struct. J., vol. 102, no. 6, pp. 808-815, Nov. 2005.

[55] M. K. Thompson, J. O. Jirsa, J. E. Breen, and R. E. Klingner, "ANCHORAGE BEHAVIOR OF HEADED REINFORCEMENT: LITERATURE REVIEW," p. 112.

[56] K. Thompson, "The anchorage behavior of headed reinforcement in CCT nodes and lap splices,” Thesis, 2002.

[57] M. K. Thompson, J. O. Jirsa, and J. E. Breen, "Behavior and Capacity of Headed Reinforcement," Struct. J., vol. 103, no. 4, pp. 522-530, Jul. 2006.

[58] Panjehpour M, Chai HK, Voo YL, "Refinement of Strut-and-Tie Model for Reinforced Concrete Deep Beams,” Jun-2015.

[59] N. Cervenka, V., Cervenka, J., Janda, Z. and Pryl, D., "ATENA Program Documentation Part 8. User's Manual of ATENA-GiD.," Prague Cervenka Consult., 2015.

[60] Cervenka.V, Jendele.L, and Cervenka.J, "ATENA Program Documentation Part 1, Theory,” Prague Cervenka Consult., p. 330, Dec. 2016.

[61] A. Belarbi, D. A. Kuchma, and D. H. Sanders, "Proposals for New One-Way Shear Equations for the 318 Building Code," Concr. Int., vol. 39, no. 9, pp. 29-32, Sep. 2017. 
[62] K.-H. Reineck and L. Todisco, "Database of Shear Tests for Non-slender Reinforced Concrete Beams without Stirrups," Struct. J., vol. 111, no. 6, pp. 1363-1372, Nov. 2014.

[63] K.-H. Reineck, E. C. Bentz, B. Fitik, D. A. Kuchma, and O. Bayrak, "ACI-DAfStb Database of Shear Tests on Slender Reinforced Concrete Beams without Stirrups," Struct. J., vol. 110, no. 5, pp. 867-876, Sep. 2013.

[64] T. Zsutty, "Shear Strength Prediction for Separate Catagories of Simple Beam Tests," J. Proc., vol. 68, no. 2, pp. 138-143, Feb. 1971. 
Appendix A: Loading Setup Drawings and Details 

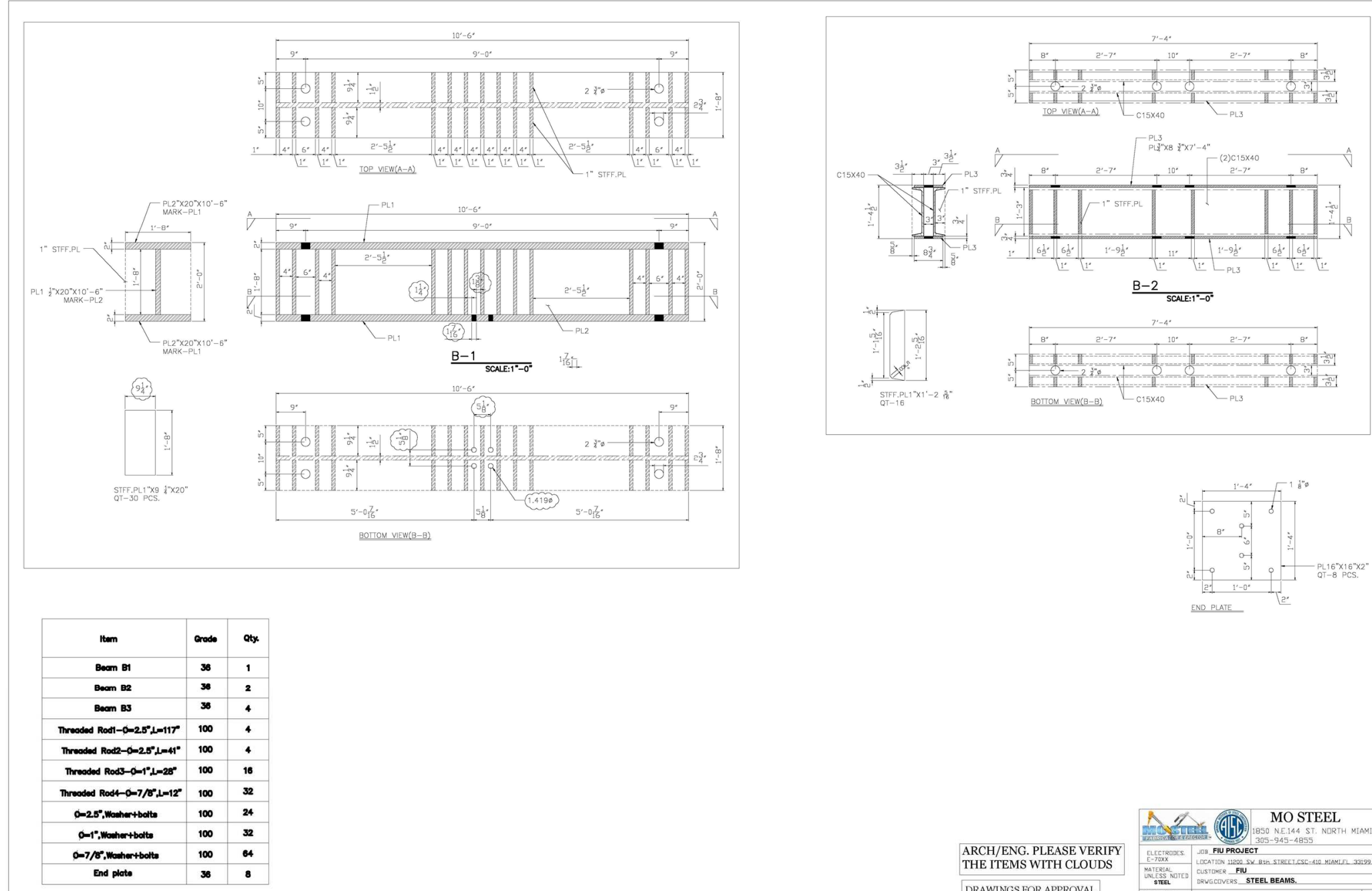

A. A) (117). MO STEEI

ARCH/ENG. PLEASE VERIFY

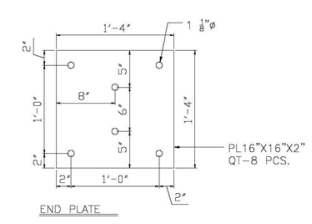

Figure A-1: Construction drawings for beams B-1 and B-2 


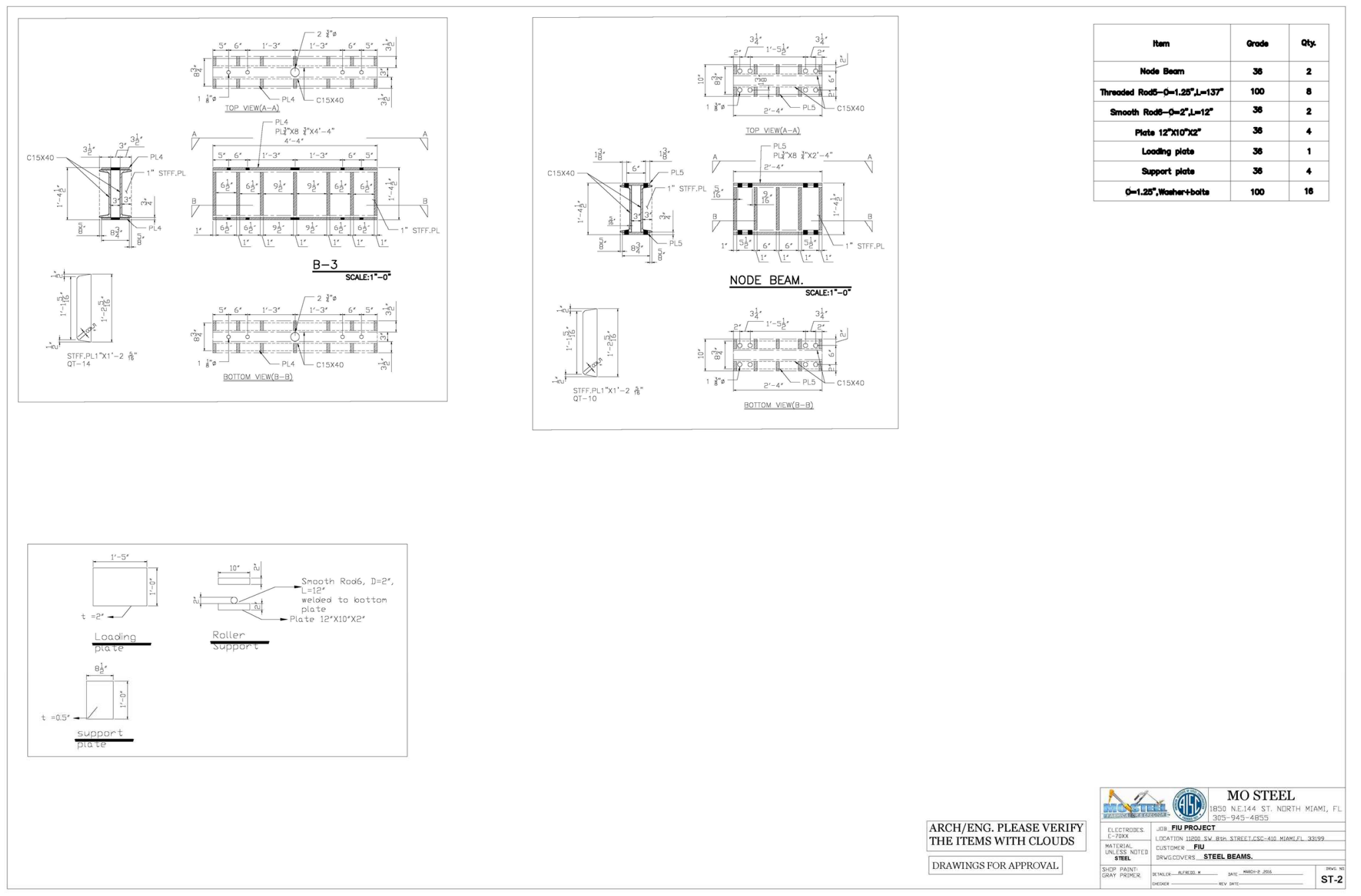

Figure A-2: Construction drawings for B-3, node beams, loading and support plates 
Appendix B: Sample Calculations for Estimating the Specimen Strength using the Strut-and-Tie Method

\section{B.1 Overview}

This appendix provides sample calculations for one of the specimens (Re-45-Ex) tested in the experimental program, shown in Figure B-1. The estimated capacity is calculated using the strut-and-tie method (STM) as specified in ACI 318-14 (2014) and the 2016 AASHTO LRFD Bridge Design Specification (2016).

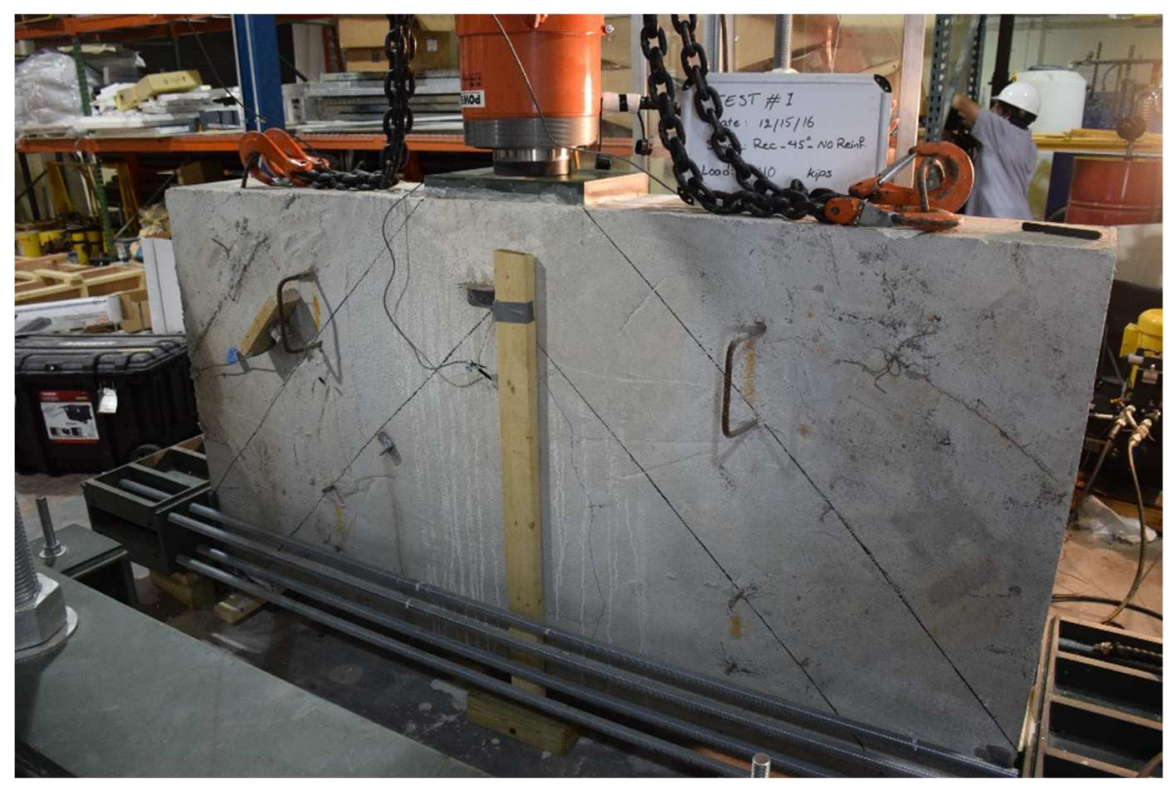

Figure B-1: Re-45-Ex specimen

Beam Re-45-Ex was designed as a companion specimen to Tr-45-Ex to investigate the service and ultimate load behavior of unreinforced deep beams. The dimensions for Re45-Ex and the dimensions of the loading and support bearings are shown in Figure B-2.

The shear-span-to-depth ratio $(a / d)$ was equal to 1.0 , which corresponds to a strut angle $\left(\theta_{s}\right)$ of 45 degrees. The beam was designed to be sufficiently large to adequately represent 
the shear behavior of beams in practice and to have the desired failure mode.

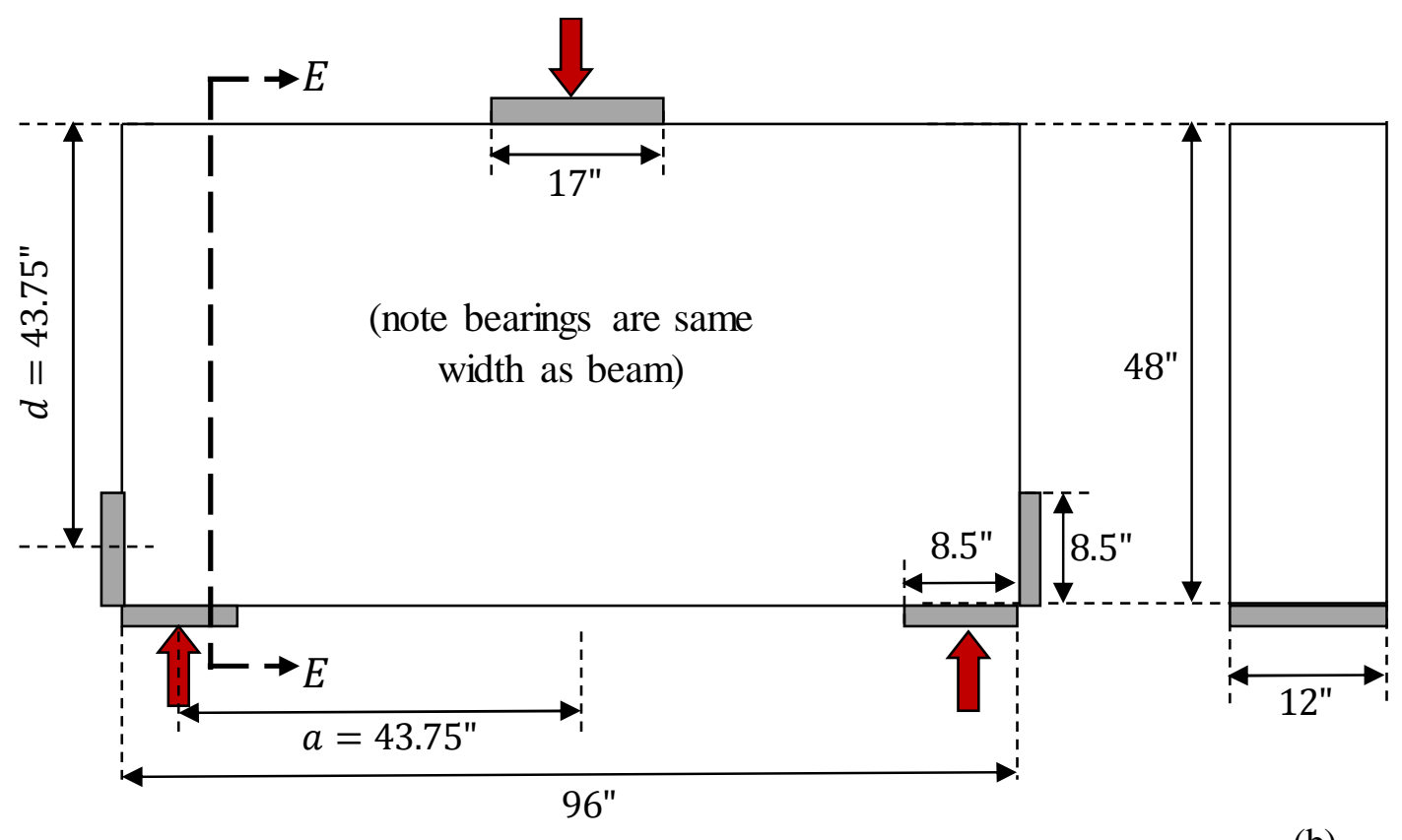

(a)

(b)

Figure B-2: Dimensions for Re-45-Ex: (a) elevation and (b) cross-section

The material properties used to find the estimated capacity are shown in Table B.1. The concrete deep beams were designed with a specific concrete compressive strength $\left(f^{\prime}{ }_{c}\right)$ of $4 \mathrm{ksi}$ and a specified yield strength $\left(f_{y}\right)$ for the unbonded reinforcement $100 \mathrm{ksi}$. The concrete compressive strength measured on the day of testing was used in the calculations.

Table B.1: Material properties used in STM calculations

\begin{tabular}{|c|c|}
\hline Variable & Value used in calculations \\
\hline$f_{c}^{\prime}$ (measured) & $5.63 \mathrm{ksi}$ \\
\hline$f_{y}$ (specified) & $100 \mathrm{ksi}$ \\
\hline
\end{tabular}

The load required to fail different components of a strut-and-tie model can be found using STM. These loads were compared with the actual failure load and failure mode to evaluate 
the conservatism of the design provisions. These comparisons are discussed in more detail in Chapter 4.

\section{B.2 Strut-and-Tie Model}

The first step in STM is to develop a suitable strut-and-tie model. The model for these beams involves a direct strut from load to support and a tension tie equilibrating the forces at the support points, as shown in Figure B-3.

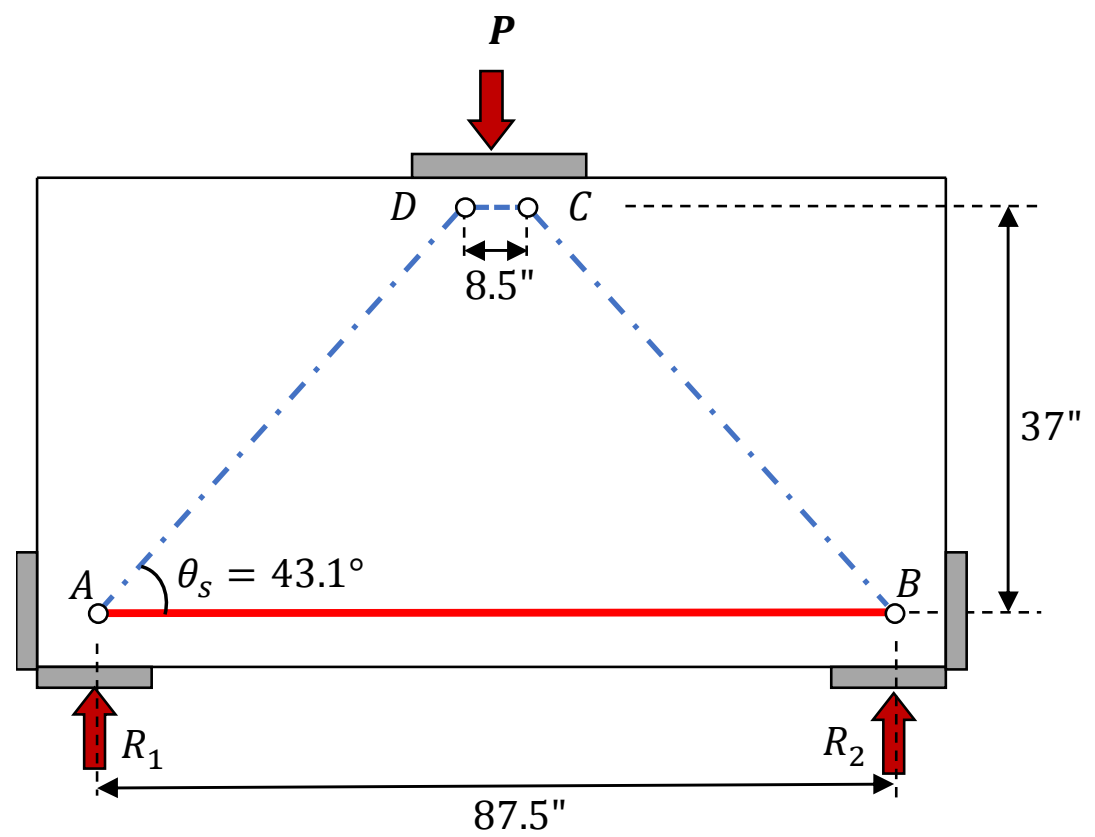

Figure B-3: Strut-and-tie model used for Re-45-Ex

The location of nodes $\mathrm{C}$ and $\mathrm{D}$ was based on the height of the rectangular stress block, shown in Equation B-1. These nodes are assumed to be located at the mid-height of the compression block.

$$
a=\frac{A_{s} f_{y}}{0.85 f^{\prime}{ }_{c} b_{w}}=\frac{\left(7.75 \mathrm{in}^{2}\right)(100 \mathrm{ksi})}{(0.85)(5.63 \mathrm{ksi})\left(12^{\prime \prime}\right)}=13.5^{\prime \prime} \quad \text { Equation B-1 }
$$

The height of nodes $\mathrm{A}$ and $\mathrm{B}$ and the tension tie $\mathrm{AB}$ is located at mid-height of the back support plates. The distance between the top and bottom notes was then found to be: 
Distance between top

and bottom nodes:

$$
h-\frac{a}{2}-\frac{h_{k}}{2}=48^{\prime \prime}-\frac{13.5^{\prime \prime}}{2}-\frac{8.5^{\prime \prime}}{2}=37^{\prime \prime}
$$

The distance between nodes $\mathrm{A}$ and $\mathrm{B}$ is taken as the distance from center to center of the supports:

\section{Distance between}

Node $A$ and Node B:

$$
96^{\prime \prime}-2\left(\frac{8.5^{\prime \prime}}{2}\right)=87.5^{\prime \prime}
$$

The distance between nodes $\mathrm{C}$ and $\mathrm{D}$ is found based on the load distribution of the load plate, as shown in Figure B-4.

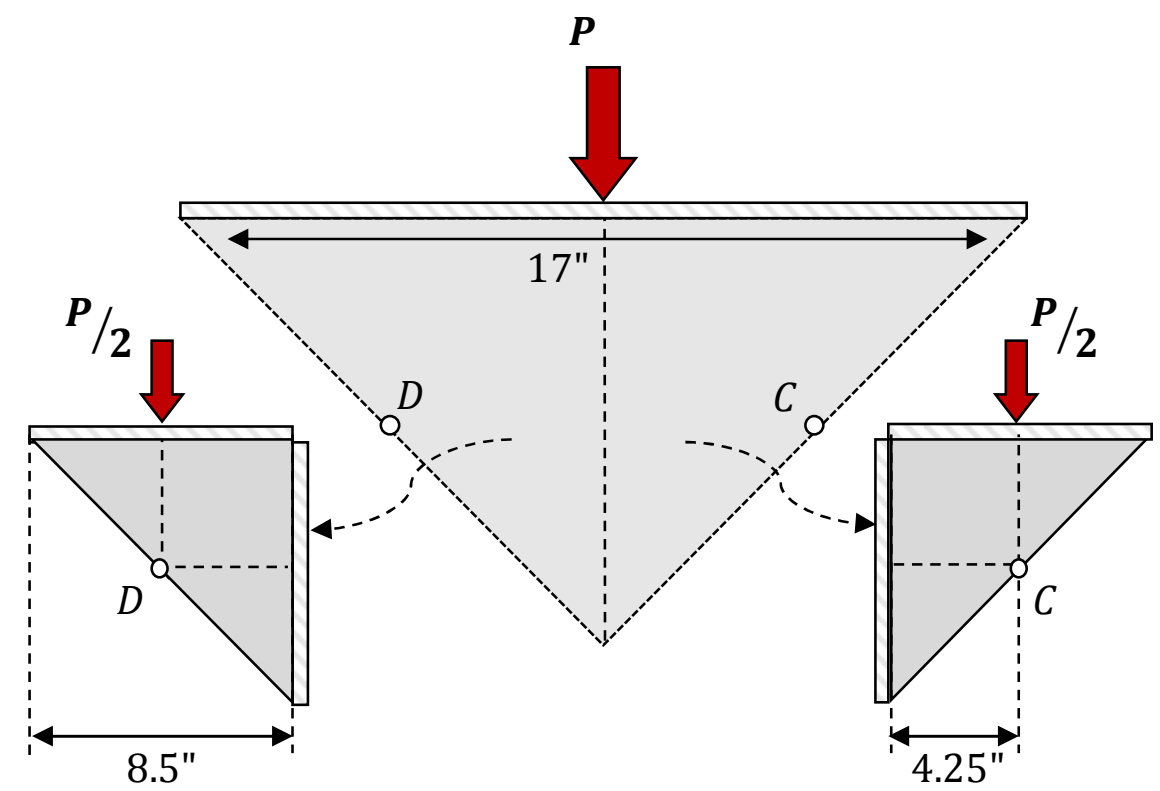

Figure B-4: Distance between nodes C and D for Re-45-Ex

The relationship between the element forces in all the struts and ties and the applied load $(P)$ can be determined from this kinematic model. The forces in each element as a factor of $\mathrm{P}$ are shown in Table B.2. These forces were used to find estimated failure loads required to fail each element in the below calculations. This was used to determine the predicted failure modes in the following sections. 
Table B.2: Element forces for Re-45-Ex

\begin{tabular}{|c|c|}
\hline Element & Element Force \\
\hline Strut $\mathrm{AD}$ & $0.73 P$ \\
\hline Strut $\mathrm{BC}$ & $0.73 P$ \\
\hline Strut $\mathrm{CD}$ & $0.53 P$ \\
\hline Tie $\mathrm{AB}$ & $0.53 P$ \\
\hline Bearing $\mathrm{C}$ and $\mathrm{D}$ & $0.5 P$ \\
\hline Bearing A and $\mathrm{B}$ & $0.5 P$ \\
\hline
\end{tabular}

\section{B.3 Overview of ACI 318-14 Provisions}

The capacity of the section was found using the above strut-and-tie model and the STM provisions from several different design codes and specifications.

The ACI 318-14 Building Code (2014) has separate design checks for the strength of struts, ties, and nodes. The reduced design strength ( $\phi F_{n s}$ for struts, $\phi F_{n n}$ for nodes, and $\phi F_{n t}$ for ties) must be greater than the factored element force $\left(F_{u s}\right.$ for struts, $F_{u n}$ for nodes, and $F_{u t}$ for ties) for struts, ties, and nodes, as shown in Equation B-2 through Equation B-4 from ACI 318-14 §23.3.1.

$$
\begin{array}{llrl}
\phi F_{n s} & \geq F_{u s} & & \text { Equation B-2 } \\
\phi F_{n t} & \geq F_{u t} & & \text { Equation B-3 } \\
\phi F_{n n} & \geq F_{u n} & & \text { Equation B-4 }
\end{array}
$$

The strength of the struts and nodes is dependent on the area of concrete at the interface 
between the struts and nodes ( $A_{c s}$ for struts and $A_{n z}$ for nodes) and the effective concrete strength of the elements $\left(f_{c e}\right)$. Relationships for these design strengths are shown in Equation B-5 through Equation B-8.

$$
\begin{array}{cc}
F_{n s}=f_{c e} A_{c s} & \text { Equation B-5 } \\
f_{c e}=0.85 \beta_{s} f^{\prime}{ }_{c} & \text { Eqn. (23.4.1a) } \\
& \text { Equation B-6 } \\
F_{n n}=f_{c e} A_{n z} & \text { Eqn. (23.4.3) } \\
f_{c e}=0.85 \beta_{n} f^{\prime}{ }_{c} & \text { Equation B-7 } \\
& \text { Eqn. (23.9.1) } \\
& \text { Equation B-8 } \\
& \text { Eqn. (23.9.2) }
\end{array}
$$

The effective concrete strength $\left(f_{c e}\right)$ for struts and nodes is dependent on the strut coefficient $\left(\beta_{s}\right)$ and node coefficient $\left(\beta_{n}\right)$, respectively, and the concrete compressive strength $\left(f^{\prime} c\right)$. The strut coefficient $\left(\beta_{s}\right)$ depends on the geometry and location of a strut. Relevant to this testing, struts with uniform cross-sectional areas along their length have a strut coefficient of 1.0, and struts located in regions where stresses can spread along the strut length without the minimum strut reinforcement have a strut coefficient of $0.6 \lambda$. The truss-like specimens have a uniform area along the length, so the strut coefficient is equal to 1.0. The rectangular specimens allow stress to spread along the strut length, so the strut coefficient is 0.6 (with $\lambda$ equal to 1.0 for normal-weight concrete).

The node coefficient $\left(\beta_{n}\right)$ depends on the number of ties that are anchored into the node. Relevant to this testing, the node coefficient is equal to 1.0 for nodes with no ties and 0.8 for nodal zones anchoring one tie. The specimens with external unbonded reinforcement had no ties anchoring in the nodal zones, so the node coefficient was taken as 1.0. The specimens with internal bonded reinforcement had one tie anchoring in the nodal zone, so 
the node coefficient was taken as 0.8 .

Ties must be designed to have sufficient reinforcement to resist the tension force found in the strut-and-tie model. The strength of non-prestressed ties can be found using Equation B-9, where $A_{t s}$ is the total area of the tie reinforcement. The ties were designed to not control the design of the specimens in this testing.

$$
F_{n t}=A_{t s} f_{y}
$$

Modified Eqn. (23.7.2)

These were some of the factors that were the focus of this testing program. There are several other resources with a more comprehensive explanation of the ACI 318-14 STM procedures [16],[17].

\section{B.4 Calculations for Re-45-Ex Using ACI 318-14}

This section includes the calculations to determine the capacity of each of the components of the strut-and-tie model. The components that were checked include:

1. Node A and B: compression capacity of back face, bearing face, and strut-to-node interface

2. Node C and D: compression capacity of back face, bearing face, and strut-to-node interface

3. Tie AB: sufficient reinforcement provided so tension tie did not control All the nodes in this member were CCC nodes, so the effective concrete strength could be calculated the same for all nodes. The bearing and back faces are only dependent on the node efficiency factor $\left(\beta_{n}\right)$. The strut-to-node interface requires checking the capacity of both the strut and the node. Since the strut will have its minimum area at the strut-to-node 
interface, the strength of both strut and node can be checked by taking the minimum of the node and strut efficiency factors. In this case, the strut efficiency factor $\left(\beta_{s}\right)$ is less than the node efficiency factor. For the truss-like beams, the node efficiency factor will control.

For nodal bounded by struts, bearing areas, or both (i.e. CCC nodes): $\quad \beta_{n}=1.0$

For bearing face: $\quad f_{c e, b}=0.85 \beta_{n} f^{\prime}{ }_{c}=0.85(1.0) f^{\prime}{ }_{c}=0.85 f^{\prime}{ }_{c} \quad(" \mathrm{~b}$ " = bearing $)$

For back face: $\quad f_{c e, k}=0.85 \beta_{n} f^{\prime}{ }_{c}=0.85(1.0) f^{\prime}{ }_{c}=0.85 f^{\prime}{ }_{c} \quad(" \mathrm{k}$ " = back

For struts located in regions of members where the width of strut at midlength is greater than at ends and without minimum reinforcement:

$$
\beta_{s}=0.6 \lambda
$$

For strut-to-node interface:

$$
\begin{aligned}
& f_{c e, s}=\min \left[0.85 \beta_{s}{f^{\prime}}^{\prime}, 0.85 \beta_{n} f^{\prime}{ }_{c}\right] \quad\left({ }^{\prime} \mathrm{s} "=\text { strut-to-node interface }\right) \\
& f_{c e, s}=\min \left[0.85(0.6 \lambda) f^{\prime}{ }_{c}, 0.85(1.0) f^{\prime}{ }_{c}\right]
\end{aligned}
$$

Where $\lambda=1.0$ for normal weight concrete

$$
f_{c e, s}=0.85(0.6) f^{\prime}{ }_{c}=0.51 f^{\prime}{ }_{c}
$$

These effective concrete strengths are used for all the following calculations.

Note that no strength reduction factors were used in this example. The goal was to compare the estimated capacity with the actual capacity. The estimated capacity does not include the strength reduction factor.

\section{B.4.1 Load Node (Nodes C and D)}

The nodes located under the loading plate are both CCC nodes, as shown in Figure B-5. The capacity of nodes C and D are equal since they have the same geometry, materials, and demand. 


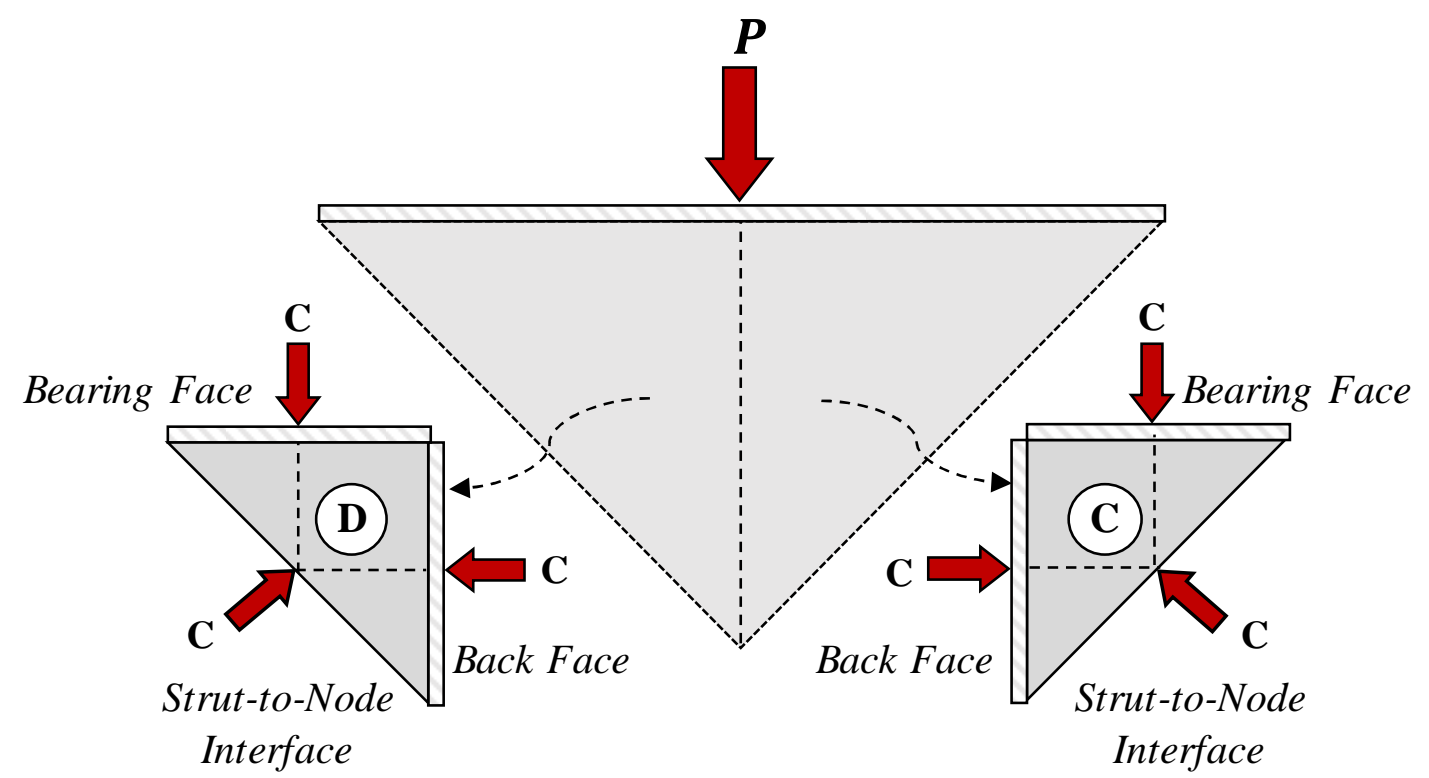

Figure B-5: Nodes under the load plate (Nodes C and D)

Calculations are provided for determining the capacity of the bearing face, back face, and strut-to-node interface for Node D.

\section{B.4.1.1 Bearing Face}

The bearing face of Node D is the surface where the load was applied. Because the load equally distributes to Strut $\mathrm{AD}$ and $\mathrm{BC}$, the length of the bearing face is half of the overall length of the load plate, as shown in Figure B-4.

$$
l_{b}=17 " / 2=8.5 "
$$

The bearing area can then be found by taking this length times the width of the bearing, which in this case was equal to the beam width.

$$
\text { Bearing area: } \quad A_{n z, b}=b_{w} l_{b}=(12 \text { in. })(8.5 \text { in. })=102 \mathrm{in}^{2}
$$

This area can then be used with the effective concrete strength to find the capacity of the bearing face of Node D. 
Effective concrete strength: $\quad f_{c e, b}=0.85 \beta_{n} f^{\prime}{ }_{c}$

$$
\beta_{n}=1.0 \text { for bearing face in CCC node }
$$

Measured compressive strength: $\quad f^{\prime}{ }_{c}=5.63 \mathrm{ksi}$

$$
\begin{gathered}
f_{c e, b}=0.85(1.0)(5.63 \mathrm{ksi})=4.79 \mathrm{ksi} \\
\text { Capacity: } \quad F_{n n, b}=f_{c e, b} A_{n z, b}=(4.79 \mathrm{ksi})\left(102 \mathrm{in}^{2}\right)=488.6 \mathrm{kips}
\end{gathered}
$$

The load required to fail the bearing face of Node D could then be found based on the element forces from Table B.2.

$$
\text { Demand: } \quad F_{\text {un }, b}=0.5 P
$$

The load required to fail the bearing face of Node $\mathrm{D}$ is then found by setting the demand equal to the capacity and solving for $P$.

$$
F_{n n, b}=F_{u n, b}=0.5 P
$$

Load required to fail bearing face of Node D:

$$
P_{n n, b}=\frac{F_{n n, b}}{0.5}=\frac{488.6 k}{0.5}=977.2 \text { kips }
$$

This load will be compared with the loads required to fail the other faces of the other elements to determine which controls the capacity.

\section{B.4.1.2 Back Face}

The back face of Node D is the portion of the node bordering Node C, as shown in Figure B-5. The height of the back face is equal to the depth of the compression block ( $a$ ) found above:

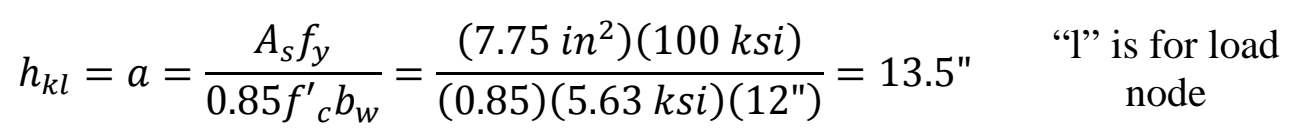


This height is multiplied by the width of the bearing, which in this case is equal to the beam width.

$$
\text { Backface area: } \quad A_{n z, k}=b_{w} h_{k l}=(12 \text { in. })(13.5 \text { in. })=161.9 \mathrm{in}^{2}
$$

The area can then be used with the effective concrete strength to find the capacity of the back face of Node D.

$$
\text { Effective concrete strength: } \quad f_{c e, k}=0.85 \beta_{n} f^{\prime}{ }_{c}
$$

$$
\beta_{n}=1.0 \text { for back face in CCC node }
$$

Measured compressive strength: $\quad \quad^{\prime}{ }_{c}=5.63 \mathrm{ksi}$

$$
\begin{array}{rlrl}
f_{c e, k} & =0.85(1.0)(5.63 \mathrm{ksi})=4.79 \mathrm{ksi} \\
\text { Capacity: } & F_{n n, k} & =f_{c e, k} A_{n z, k}=(4.79 \mathrm{ksi})\left(161.9 \mathrm{in}^{2}\right)=775.2 \mathrm{kips}
\end{array}
$$

The load required to fail the back face of Node D can then be found similar to above.

Demand: $\quad F_{u n, k}=0.53 P$

$$
F_{n n, k}=F_{u n, k}=0.53 P
$$

Load required to fail back face of Node D:

$$
P_{n n, k}=\frac{F_{n n, k}}{0.53}=\frac{775.2 k}{0.53}=1,463 \text { kips }
$$

This load will be compared with the loads required to fail the other faces of the other elements to determine which controls the capacity.

\section{B.4.1.3Strut to Node Interface}

Strut-to-node interface is the face of the node that connects the node to the strut, shown in Figure B-5. The length of the strut-to-node interface $\left(w_{s}\right)$ depends on the bearing length $\left(l_{b}\right)$, back face height $\left(h_{k}\right)$, and the strut angle $\left(\theta_{s}\right)$.

$$
w_{s l}=l_{b} \sin \theta_{s}+h_{k l} \cos \theta_{s}
$$




$$
w_{s l}=\left(8.5^{\prime \prime}\right) \sin \left(43.1^{\circ}\right)+\left(13.5^{\prime \prime}\right) \cos \left(43.1^{\circ}\right)=15.7^{\prime \prime}
$$

The strut-to-node interface area can then be found by taking this length times the width of the bearing, which in this case is equal to the beam width.

Strut to node interface area:

$$
A_{n z, s l}=b_{w} w_{s l}=(12 \text { in. })(15.7 \text { in. })=187.9 \mathrm{in}^{2}
$$

This area can then be used with the effective concrete strength to find the capacity of the strut-to-node interface of Node D.

$$
\text { Effective concrete strength: } \quad f_{c e, s}=0.85 \beta_{n} f^{\prime}{ }_{c}
$$

$$
\beta_{n}=0.6 \text { for strut to node interface in CCC node }
$$

Measured compressive strength: $\quad \quad^{\prime}{ }_{c}=5.63 \mathrm{ksi}$

$$
f_{c e, s}=0.85(0.6)(5.63 k s i)=2.87 k s i
$$

$$
\text { Capacity: } \quad F_{n n, s}=f_{c e, s} A_{n z, s l}=(2.87 \mathrm{ksi})\left(187.9 \mathrm{in}^{2}\right)=539.8 \mathrm{kips}
$$

The load required to fail the strut-to-node interface of Node D can then be found similar to above.

$$
\begin{gathered}
F_{u n, s}=0.73 P \\
F_{n n, s}=F_{u n, s}=0.73 P
\end{gathered}
$$

$\begin{gathered}\text { Load required to fail strut- } \\ \text { to-node interface of Node D: }\end{gathered} \quad P_{n n, s}=\frac{F_{n n, s}}{0.73}=\frac{539.8 \mathrm{k}}{0.73}=739.5 \mathrm{kips}$

This load will be compared with the loads required to fail the other faces of the other elements to determine which controls the capacity.

\section{B.4.2 Reaction Nodes}

The nodes above the reactions are both CCC nodes, as shown in Figure B-6 (a). The capacity of nodes A and B are equal since they have the same geometry, materials, and 
demand.

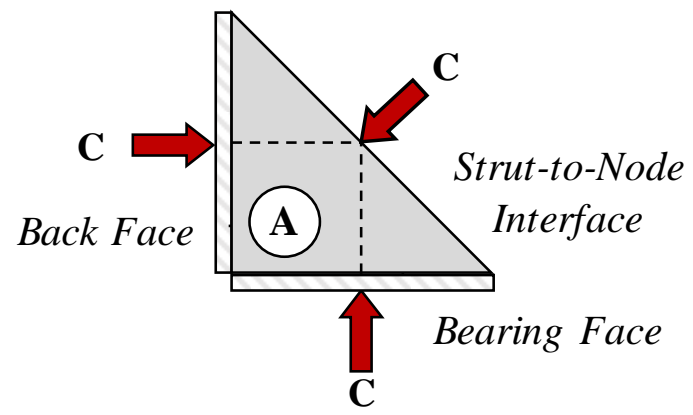

(a)

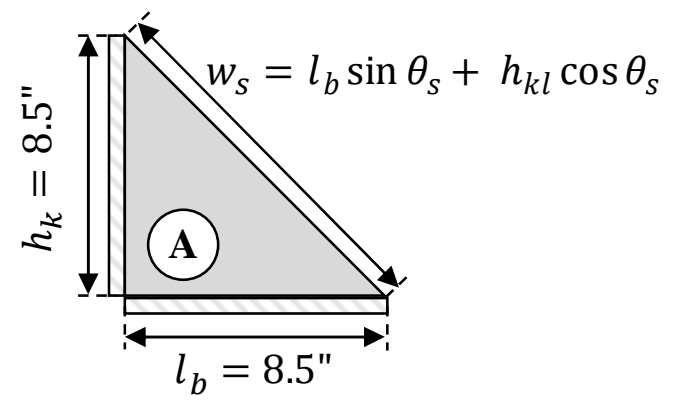

(b)

Figure B-6: Reaction node (Nodes A and B): (a) faces and (b) dimensions

Calculations are provided for determining the capacity of the bearing face, back face, and strut-to-node interface for Node A.

\section{B.4.2.1 Bearing Face}

The bearing face of Node A is the surface where the reaction plate is located. The length of the bearing was chosen as 8.5 inches for the design, shown in Figure B-6 (b).

$$
l_{b}=8.5^{\prime \prime}
$$

The bearing area can then be found by taking this length times the width of the bearing, which in this case was equal to the beam width.

$$
\text { Bearing area: } \quad A_{n z, b}=b_{w} l_{b}=(12 \text { in. })(8.5 \text { in. })=102 \mathrm{in}^{2}
$$

This area can then be used with the effective concrete strength to find the capacity of the bearing face of Node A.

Effective concrete strength: $\quad f_{c e, b}=0.85 \beta_{n} f^{\prime}{ }_{c}$

$$
\beta_{n}=1.0 \text { for bearing face in CCC node }
$$

Measured compressive strength: $\quad f^{\prime}{ }_{c}=5.63 \mathrm{ksi}$ 


$$
\begin{gathered}
f_{c e, b}=0.85(1.0)(5.63 \mathrm{ksi})=4.79 \mathrm{ksi} \\
\text { Capacity: } \quad F_{n n, b}=f_{c e, b} A_{n z, b}=(4.79 \mathrm{ksi})\left(102 \mathrm{in}^{2}\right)=488.6 \mathrm{kips}
\end{gathered}
$$

The load required to fail the bearing face of Node A can then be found similar to above.

Demand:

$$
\begin{gathered}
F_{u n, b}=0.5 P \\
F_{n n, b}=F_{u n, b}=0.5 P
\end{gathered}
$$

Load required to fail bearing face of Node A:

$$
P_{n n, b}=\frac{F_{n n, b}}{0.5}=\frac{488.6 k}{0.5}=977.2 \text { kips }
$$

This load will be compared with the loads required to fail the other faces of the other elements to determine which controls the capacity.

\section{B.4.2.2 Back Face}

The height of the back face in reaction nodes is typically equal to twice of the distance from the tension surface of the beam to the centroid of the tension steel. Unbonded reinforcement attached to a node beam and plate was used in this specimen, so the height of the back face was taken as the same as the height of the node plate, 8.5 inches.

$$
h_{k r}=8.5 " \quad \text { "r" is for reaction node }
$$

This height is multiplied by the width of the bearing, which in this case is equal to the beam width, to find the area.

$$
\text { Backface area: } \quad A_{n z, k}=b_{w} h_{k r}=(12 \text { in. })(8.5 \text { in. })=102 \mathrm{in}^{2}
$$

The area can then be used with the effective concrete strength to find the capacity of the back face of Node A.

$$
\begin{aligned}
& \text { Effective concrete strength: } \quad f_{c e, k}=0.85 \beta_{n} f^{\prime}{ }_{c} \\
& \qquad \beta_{n}=1.0 \text { for back face in CCC node }
\end{aligned}
$$


Measured compressive strength: $\quad f^{\prime}{ }_{c}=5.63 \mathrm{ksi}$

$$
f_{c e, k}=0.85(1.0)(5.63 k s i)=4.79 k s i
$$

Capacity: $\quad F_{n n, k}=f_{c e, k} A_{n z, k}=(4.79 k s i)\left(102 i n^{2}\right)=488.4 k i p s$

The load required to fail the back face of Node A can then be found similar to above.

Demand: $\quad F_{u n, k}=0.53 P$

$$
F_{n n, k}=F_{u n, k}=0.53 P
$$

$\begin{aligned} & \text { Load required to fail back } \\ & \text { face of Node A: }\end{aligned} \quad P_{n n, k}=\frac{F_{n n, k}}{0.53}=\frac{488.4 k}{0.53}=921.5 \mathrm{kips}$

This load will be compared with the loads required to fail the other faces of the other elements to determine which controls the capacity.

\section{B.4.2.3Strut-to-Node Interface}

Strut-to-node interface is the face of the node that connects the node to the strut, shown in Figure B-6. The length of the strut-to-node interface $\left(w_{s}\right)$ depends on the bearing length $\left(l_{b}\right)$, back face height $\left(h_{k}\right)$, and the strut angle $\left(\theta_{s}\right)$.

$$
\begin{array}{cr}
w_{s, r}=l_{b} \sin \theta_{s}+h_{k} \cos \theta_{s} & \begin{array}{c}
\text { "r" is for } \\
\text { reaction node }
\end{array} \\
w_{s, r}=\left(8.5^{\prime \prime}\right) \sin \left(43.1^{\circ}\right)+\left(8.5^{\prime \prime}\right) \cos \left(43.1^{\circ}\right)=12.0^{\circ}
\end{array}
$$

The strut-to-node interface area can then be found by taking this length times the width of the bearing, which in this case is equal to the beam width.

Strut to node

interface area:

$$
A_{n z, s r}=b_{w} w_{s}=(12 \text { in. })(12.0 \text { in. })=144.2 \mathrm{in}^{2}
$$

This area can then be used with the effective concrete strength to find the capacity of the strut-to-node interface of Node A.

$$
\text { Effective concrete strength: } \quad f_{c e, s}=0.85 \beta_{n} f^{\prime}{ }_{c}
$$




$$
\beta_{n}=0.6 \text { for strut to node interface in CCC node }
$$

Measured compressive strength: $\quad f^{\prime}{ }_{c}=5.63 \mathrm{ksi}$

$$
\begin{aligned}
f_{c e, s}= & 0.85(0.6)(5.63 \mathrm{ksi})=2.87 \mathrm{ksi} \\
\text { Capacity: } & F_{n n, s}=f_{c e, s} A_{n z, s r}=(2.87 \mathrm{ksi})\left(144.2 \mathrm{in}^{2}\right)=414.2 \mathrm{kips}
\end{aligned}
$$

The load required to fail the strut-to-node interface of Node D can then be found similar to above.

$$
\begin{gathered}
F_{u n, s}=0.73 P \\
F_{n n, s}=F_{u n, s}=0.73 P
\end{gathered}
$$

$\begin{aligned} & \text { Load required to fail strut- } \\ & \text { to-node interface of Node A: }\end{aligned} \quad P_{n n, s}=\frac{F_{n n, s}}{0.73}=\frac{414.2 \mathrm{k}}{0.73}=567.7 \mathrm{kips}$

This load will be compared with the loads required to fail the other faces of the other elements to determine which controls the capacity.

\section{B.4.3 Tension Steel}

Eight 1.25-inch diameter threaded rods were provided to resist tension forces in Tie AB. The total area of steel provided and yield strength of the steel were:

$$
\begin{gathered}
A_{t s}=8\left(0.969 \mathrm{in}^{2}\right)=7.75 \mathrm{in}^{2} \\
f_{y}=100 \mathrm{ksi}
\end{gathered}
$$

This gives a total tie capacity of:

$$
\text { Capacity: } \quad F_{n t}=A_{t s} f_{y}=\left(7.752 \mathrm{in}^{2}\right)(100 \mathrm{ksi})=775.2 \mathrm{kips}
$$

The load required to fail Tie $\mathrm{AB}$ can then be found similar to above.

Demand:

$$
F_{u t}=0.53 P
$$




$$
F_{n t}=F_{u t}=0.53 P
$$

$\begin{gathered}\text { Load required to fail strut- } \\ \text { to-node interface of Node D: }\end{gathered} \quad P_{n t}=\frac{F_{n t}}{0.53}=\frac{775.2 \mathrm{k}}{0.53}=1,463 \mathrm{kips}$

This load will be compared with the loads required to fail the other faces of the other elements to determine which controls the capacity.

\section{B.4.4 Summary of Results}

The applied loads to cause failure in each different component of the strut-and-tie model are summarized in Table B.3.

Table B.3: Summary of loads required to cause failure in different componenet of strut-and-tie model

\begin{tabular}{|l|c|}
\hline Element & Force to Cause Failure \\
\hline Load Node - Bearing Face & 977 kips \\
\hline Load Node - Back Face & $1,463 \mathrm{kips}$ \\
\hline Load Node - Strut-to-Node Interface & $740 \mathrm{kips}$ \\
\hline Support Node - Bearing Face & $977 \mathrm{kips}$ \\
\hline Support Node - Back Face & $922 \mathrm{kips}$ \\
\hline Support Node - Strut-to-Node Interface & $568 \mathrm{kips}$ \\
\hline Tie AB & $1,463 \mathrm{kips}$ \\
\hline
\end{tabular}

The minimum of these forces controls the design. The strut-to-node interface of the support node (Nodes A and B) has the minimum force (568 kips), which is the estimated capacity for specimen Re-45-Ex. The estimated capacity for the rest of the specimens in the experimental program are summarized in Table 4.3. 


\section{B.5 Overview of AASHTO LRFD 2016 Provisions}

AASHTO LRFD 2016 requires that the reduced design strength $\left(\phi P_{n}\right)$ be greater than the factored element force $\left(P_{r}\right)$ for ties and node faces, as shown in Equation B-10.

$$
\begin{array}{ll}
\phi P_{n} \geq P_{r} & \text { Equation B-10 } \\
& \text { Eqn. (5.8.2.3-1) }
\end{array}
$$

Unlike ACI 318-14, AASHTO LRFD 2016 does not require the capacity of struts be checked, only the node faces, shown in Equation B-11. The node face capacity is dependent on the limiting compressive stress of the node face $\left(f_{c u}\right)$ and the effective cross-sectional area of the node face $\left(A_{c n}\right)$.

$$
\begin{array}{ll}
P_{n}=f_{c u} A_{c n} & \text { Equation B-11 } \\
\text { Eqn. (5.8.2.5.1-1) }
\end{array}
$$

The limiting compressive stress of the node face $\left(f_{c u}\right)$ depends on the type of node (CCC, CCT, or CTT), presence of minimum crack control reinforcement, the face where the nominal resistance is being found (bearing face, back face, or strut-to-node interface), the compressive strength of the concrete $\left(f^{\prime} c\right)$, and any confinement effects from surrounding concrete (accounted for through $m$ ), as shown in Equation B-12.

$$
\begin{aligned}
& f_{c u}=m v f^{\prime}{ }_{c} \\
& \text { Equation B-12 } \\
& \text { Eqn. (5.8.2.5.3a-1) }
\end{aligned}
$$

Note that unlike ACI 318-14, AASHTO LRFD (2016) does not account for the effect of stresses being able to spread along the length of struts or not being able to in members with constant cross-sectional areas along the length of struts.

Benefits from confinement are accounted for when the bearing area $\left(A_{l}\right)$ is smaller than the notional area $\left(A_{2}\right.$, defined in AASHTO) and uniform loading is applied by using Equation B-13. 


$$
m=\sqrt{\frac{A_{2}}{A_{1}}} \leq 2.0
$$

Equation B-13

Eqn. (5.6.5-3)

The concrete efficiency factor $(v)$ depends on the type of node (CCC, CCT, or CTT), the face where the nominal resistance is being found (bearing face, back face, or strut-to-node interface), the presence of minimum strut reinforcement, and the compressive strength of the concrete $\left(f^{\prime} c\right)$. For beams with minimum crack control reinforcement, the concrete efficiency factors $(v)$ are summarized in Table B.4.

Table B.4: Concrete efficiency factor (v), if minimum crack-control reinforcement is provided

\begin{tabular}{|c|c|c|c|}
\hline \multirow{2}{*}{$\begin{array}{c}\text { Node } \\
\text { Type }\end{array}$} & $\begin{array}{c}\text { Bearing } \\
\text { Face }\end{array}$ & $\begin{array}{c}\text { Back } \\
\text { Face }\end{array}$ & Face \\
\cline { 2 - 4 } Strut-to-Node Interface \\
\hline$C C C$ & 0.85 & 0.85 & $0.45 \leq 0.85-\frac{f_{c}^{\prime}}{20 k s i} \leq 0.65$ \\
\hline$C C T$ & 0.7 & 0.7 & $0.45 \leq 0.85-\frac{f_{c}^{\prime}}{20 k s i} \leq 0.65$ \\
\hline$C T T$ & & $0.45 \leq 0.85-\frac{f_{c}^{\prime}}{20 k s i} \leq 0.65$ \\
\hline
\end{tabular}

For beams without minimum crack control reinforcement, the concrete efficiency factor (v) is equal to 0.45 .

\section{B.6 Calculations for Re-45-Ex Using AASHTO LRFD 2016}

This section includes the calculations to determine the capacity of each of the components of the strut-and-tie model using the STM provisions in AASHTO LRFD 2016. As stated above, all the nodes in this member were CCC nodes and no minimum crack control 
reinforcement was provided, so the effective concrete strength could be calculated the same for all nodes. The loading plate was the same width as the specimens, so no confinement benefits were achieved ( $m$ equals 1.0).

Bearing width equal to beam width:

$$
m=1.0
$$

Beams without minimum crack control reinforcement:

$$
v=0.45
$$

$$
\begin{aligned}
& \text { For all faces: } \quad f_{c u}=m v f^{\prime}{ }_{c}=(1.0)(0.45) f^{\prime}{ }_{c}=0.45 f^{\prime}{ }_{c}
\end{aligned}
$$

This effective concrete strength was used for all the following calculations.

Note that no strength reduction factors were used in this example. The goal was to compare the estimated capacity with the actual capacity. The estimated capacity does not include the strength reduction factor.

\section{B.6.1 Load Node (Nodes C and D)}

The nodes located under the loading plate are both CCC nodes, as shown in Figure B-5. The capacity of nodes C and D are equal since the have the same geometry, materials, and demand. Calculations are provided for determining the capacity of the bearing face, back face, and strut-to-node interface for Node D.

\section{B.6.1.1 Bearing Face}

The bearing face of Node D is the surface where the load is applied. Because the load equally distributes to Strut $\mathrm{AD}$ and $\mathrm{BC}$, the length of the bearing face is half of the overall length of the load plate, as shown in Figure B-5.

$$
l_{b}=17 " / 2=8.5 "
$$

The bearing area can then be found by taking this length times the width of the bearing, 
which in this case was equal to the beam width.

Bearing area: $\quad A_{n z, b}=b_{w} l_{b}=(12$ in. $)(8.5$ in. $)=102 \mathrm{in}^{2}$

This area can then be used with the effective concrete strength (from above) to find the capacity of the bearing face of Node D.

Effective concrete strength: $\quad f_{c u}=0.45{f^{\prime}}^{\prime} \quad$ (from above)

Measured compressive strength: $\quad f^{\prime}{ }_{c}=5.63 \mathrm{ksi}$

$$
\begin{array}{cc}
f_{c u}=0.45(5.63 \mathrm{ksi})=2.53 \mathrm{ksi} \\
\text { Capacity: } \quad F_{n n, b}=f_{c u} A_{n z, b}=(2.53 \mathrm{ksi})\left(102 \mathrm{in}^{2}\right)=258.7 \mathrm{kips}
\end{array}
$$

The load required to fail the bearing face of Node D can then be found similar to above.

Demand: $\quad F_{u n, b}=0.5 P$

$$
F_{n n, b}=F_{u n, b}=0.5 P
$$

Load required to fail back face of Node D:

$$
P_{n n, b}=\frac{F_{n n, b}}{0.5}=\frac{258.7 k}{0.5}=517.4 \text { kips }
$$

This load will be compared with the loads required to fail the other faces of the other elements to determine which controls the capacity.

\section{B.6.1.2 Back Face}

The back face of Node D is the portion of the node bordering Node C, as shown in Figure B-5. The height of the back face is equal to the depth of the compression block $(a)$ found above:

$$
h_{k l}=a=\frac{A_{s} f_{y}}{0.85 f^{\prime}{ }_{c} b_{w}}=\frac{\left(7.75 \mathrm{in}^{2}\right)(100 \mathrm{ksi})}{(0.85)(5.63 \mathrm{ksi})\left(12^{\prime \prime}\right)}=13.5 " \quad \text { "l" is for load }
$$

This height is multiplied by the width of the bearing, which in this case is equal to the beam width. 


$$
\text { Backface area: } \quad A_{n z, k}=b_{w} h_{k l}=(12 \text { in. })(13.5 \text { in. })=161.9 \mathrm{in}^{2}
$$

The area can then be used with the effective concrete strength to find the capacity of the back face of Node D.

$$
\text { Effective concrete strength: } \quad f_{c u}=0.45 f^{\prime}{ }_{c} \quad \text { (from above) }
$$

Measured compressive strength: $\quad \quad^{\prime}{ }_{c}=5.63 \mathrm{ksi}$

$$
\begin{aligned}
f_{c u} & =0.45(5.63 \mathrm{ksi})=2.53 \mathrm{ksi} \\
\text { Capacity: } \quad F_{n n, k} & =f_{c u} A_{n z, k}=(2.53 \mathrm{ksi})\left(162 \mathrm{in}^{2}\right)=410.4 \mathrm{kips}
\end{aligned}
$$

The load required to fail the back face of Node D can then be found similar to above.

Demand:

$$
\begin{gathered}
F_{u n, k}=0.53 P \\
F_{n n, k}=F_{u n, k}=0.53 P
\end{gathered}
$$

Load required to fail back face of Node D:

This load will be compared with the loads required to fail the other faces of the other elements to determine which controls the capacity.

\section{B.6.1.3Strut-to-Node Interface}

Strut-to-node interface is the face of the node that connects the node to the strut, shown in Figure B-5. The length of the strut-to-node interface $\left(w_{s}\right)$ depends on the bearing length $\left(l_{b}\right)$, back face height $\left(h_{k}\right)$, and the strut angle $\left(\theta_{s}\right)$.

$$
\begin{gathered}
w_{s l}=l_{b} \sin \theta_{s}+h_{k l} \cos \theta_{s} \\
w_{s l}=\left(8.5^{\prime \prime}\right) \sin \left(43.1^{\circ}\right)+\left(13.5^{\prime \prime}\right) \cos \left(43.1^{\circ}\right)=15.7^{\prime \prime}
\end{gathered}
$$

The strut-to-node interface area can then be found by taking this length times the width of the bearing, which in this case is equal to the beam width. 
Strut to node

interface area:

$$
A_{n z, s l}=b_{w} w_{s l}=(12 \text { in. })(15.7 \text { in. })=187.9 \text { in }^{2}
$$

This area can then be used with the effective concrete strength to find the capacity of the strut-to-node interface of Node D.

Effective concrete strength: $\quad f_{c u}=0.45{f^{\prime}}^{\prime} \quad$ (from above)

Measured compressive strength: $\quad \quad^{\prime}{ }_{c}=5.63 \mathrm{ksi}$

$$
f_{c u}=0.45(5.63 \mathrm{ksi})=2.53 \mathrm{ksi}
$$

Capacity: $\quad F_{n n, s}=f_{c u} A_{n z, s l}=(2.53 \mathrm{ksi})\left(187.9 \mathrm{in}^{2}\right)=475.4$ kips

The load required to fail the strut-to-node interface of Node D can then be found similar to above.

Demand:

$$
\begin{gathered}
F_{u n, s}=0.73 P \\
F_{n n, s}=F_{u n, s}=0.73 P
\end{gathered}
$$

Load required to fail strutto-node interface of Node D:

$$
P_{n n, s}=\frac{F_{n n, s}}{0.73}=\frac{475.4 k}{0.73}=651.2 \text { kips }
$$

This load will be compared with the loads required to fail the other faces of the other elements to determine which controls the capacity.

\section{B.6.2 Reaction Nodes (Nodes A and B)}

The nodes above the reactions are both CCC nodes, as shown in Figure B-6 (a). The capacity of nodes A and B are equal since they have the same geometry, materials, and demand. Calculations are provided for determining the capacity of the bearing face, back face, and strut-to-node interface for Node A.

\section{B.6.2.1 Bearing Face}

The bearing face of Node A is the surface where the reaction plate is located. The length 
of the bearing was chosen as 8.5 inches for the design, shown in Figure B-6 (b).

$$
l_{b}=8.5^{\prime \prime}
$$

The bearing area can then be found by taking this length times the width of the bearing, which in this case was equal to the beam width.

$$
\text { Bearing area: } \quad A_{n z, b}=b_{w} l_{b}=(12 \mathrm{in.})(8.5 \mathrm{in.})=102 \mathrm{in}^{2}
$$

This area can then be used with the effective concrete strength to find the capacity of the bearing face of Node A.

Effective concrete strength: $\quad f_{c u}=0.45 f^{\prime}{ }_{c} \quad$ (from above)

Measured compressive strength: $\quad f^{\prime}{ }_{c}=5.63 \mathrm{ksi}$

$$
\begin{gathered}
f_{c u}=0.45(5.63 \mathrm{ksi})=2.53 \mathrm{ksi} \\
\text { Capacity: } \quad F_{n n, b}=f_{c u} A_{n z, b}=(2.53 \mathrm{ksi})\left(102 \mathrm{in}^{2}\right)=258.7 \mathrm{kips}
\end{gathered}
$$

The load required to fail the bearing face of Node A can then be found similar to above.

Demand:

$$
\begin{gathered}
F_{u n, b}=0.5 P \\
F_{n n, b}=F_{u n, b}=0.5 P
\end{gathered}
$$

Load required to fail

bearing face of Node A:

This load will be compared with the loads required to fail the other faces of the other elements to determine which controls the capacity.

\section{B.6.2.2 Back Face}

The height of the back face in reaction nodes is typically equal to twice of the distance from the tension surface of the beam to the centroid of the tension steel. Unbonded reinforcement attached to a node beam and plate was used in this specimen, so the height 
of the back face was taken as the same as the height of the node plate, 8.5 inches.

$$
h_{k r}=8.5 " \quad \text { "r" is for reaction node }
$$

This height is multiplied by the width of the bearing, which in this case is equal to the beam width, to find the area.

$$
\text { Backface area: } \quad A_{n z, k}=b_{w} h_{k r}=(12 \text { in. })(8.5 \mathrm{in.})=102 \mathrm{in}^{2}
$$

The area can then be used with the effective concrete strength to find the capacity of the back face of Node A.

$$
\text { Effective concrete strength: } \quad f_{c u}=0.45 f^{\prime}{ }_{c} \quad \text { (from above) }
$$

Measured compressive strength: $\quad \quad^{\prime}{ }_{c}=5.63 \mathrm{ksi}$

$$
\begin{gathered}
f_{c u}=0.45(5.63 \mathrm{ksi})=2.53 \mathrm{ksi} \\
\text { Capacity: } \quad F_{n n, k}=f_{c u} A_{n z, k}=(2.53 \mathrm{ksi})\left(102 \mathrm{in}^{2}\right)=258.6 \mathrm{kips}
\end{gathered}
$$

The load required to fail the back face of Node A can then be found similar to above.

Demand: $\quad F_{u n, k}=0.53 P$

$$
F_{n n, k}=F_{u n, k}=0.53 P
$$

Load required to fail back face of Node A:

$$
P_{n n, k}=\frac{F_{n n, k}}{0.53}=\frac{258.6 k}{0.53}=487.9 \text { kips }
$$

This load will be compared with the loads required to fail the other faces of the other elements to determine which controls the capacity.

\section{B.6.2.3Strut-to-Node Interface}

Strut-to-node interface is the face of the node that connects the node to the strut, shown in Figure B-6. The length of the strut-to-node interface $\left(w_{s}\right)$ depends on the bearing length $\left(l_{b}\right)$, back face height $\left(h_{k}\right)$, and the strut angle $\left(\theta_{s}\right)$.

$$
w_{s, r}=l_{b} \sin \theta_{s}+h_{k} \cos \theta_{s}
$$

" $\mathrm{r}$ " is for reaction node 


$$
w_{s, r}=\left(8.5^{\prime \prime}\right) \sin \left(43.1^{\circ}\right)+\left(8.5^{\prime \prime}\right) \cos \left(43.1^{\circ}\right)=12.0^{\prime \prime}
$$

The strut-to-node interface area can then be found by taking this length times the width of the bearing, which in this case is equal to the beam width.

Strut to node interface area:

$$
A_{n z, s r}=b_{w} w_{s}=(12 \text { in. })(12.0 \text { in. })=144.2 \mathrm{in}^{2}
$$

This area can then be used with the effective concrete strength to find the capacity of the strut-to-node interface of Node A.

$$
\text { Effective concrete strength: } \quad f_{c u}=0.45 f^{\prime}{ }_{c} \quad \text { (from above) }
$$

Measured compressive strength: $\quad f^{\prime}{ }_{c}=5.63 \mathrm{ksi}$

$$
\begin{array}{cc} 
& f_{c u}=0.45(1.0)(5.63 \mathrm{ksi})=2.53 \mathrm{ksi} \\
\text { Capacity: } & F_{n n, s}=f_{c u} A_{n z, s r}=(2.53 \mathrm{ksi})\left(144.2 \mathrm{in}^{2}\right)=365.6 \mathrm{kips}
\end{array}
$$

The load required to fail the strut-to-node interface of Node D can then be found similar to above.

$$
\begin{gathered}
F_{u n, s}=0.73 P \\
F_{n n, s}=F_{u n, s}=0.73 P
\end{gathered}
$$

$\begin{aligned} & \text { Load required to fail strut- } \\ & \text { to-node interface of Node A: }\end{aligned} \quad P_{n n, s}=\frac{F_{n n, s}}{0.73}=\frac{365.6 \mathrm{k}}{0.73}=500.8 \mathrm{kips}$

This load will be compared with the loads required to fail the other faces of the other elements to determine which controls the capacity.

\section{B.6.3 Tension Steel}

Eight 1.25-inch diameter threaded rods were provided to resist tension forces in Tie AB. The total area of steel provided and yield strength of the steel were:

$$
A_{t s}=8\left(0.969 \mathrm{in}^{2}\right)=7.75 \mathrm{in}^{2}
$$




$$
f_{y}=100 k s i
$$

This gives a total tie capacity of:

$$
\text { Capacity: } \quad F_{n t}=A_{t s} f_{y}=\left(7.752 \mathrm{in}^{2}\right)(100 \mathrm{ksi})=775.2 \text { kips }
$$

The load required to fail Tie AB can then be found similar to above.

Demand:

$$
\begin{gathered}
F_{u t}=0.53 P \\
F_{n t}=F_{u t}=0.53 P
\end{gathered}
$$

Load required to fail strutto-node interface of Node D:

$$
P_{n t}=\frac{F_{n t}}{0.53}=\frac{775.2 k}{0.53}=1,463 \text { kips }
$$

This load will be compared with the loads required to fail the other faces of the other elements to determine which controls the capacity.

\section{B.6.4 Summary of Results}

The applied loads to cause failure in each different component of the strut-and-tie model are summarized in Table B.3.

Table B.5: Summary of loads required to cause failure in different componenet of strut-and-tie model

\begin{tabular}{|l|c|}
\hline Element & Force to Cause Failure \\
\hline Load Node - Bearing Face & 517 kips \\
\hline Load Node - Back Face & 774 kips \\
\hline Load Node - Strut-to-Node Interface & 651 kips \\
\hline Support Node - Bearing Face & 517 kips \\
\hline Support Node - Back Face & 488 kips \\
\hline Support Node - Strut-to-Node Interface & 501 kips \\
\hline Tie AB & 1,463 kips \\
\hline
\end{tabular}


The minimum of these forces controls the design. The back face of the support node (Nodes A and B) has the minimum force (488 kips), which is the estimated capacity for specimen Re-45-Ex. The estimated capacity for the rest of the specimens in the experimental program are summarized in Table 4.3. 


\section{Appendix C: Campbell Scientific Basics}

\section{C.1 Overview}

As mentioned in Chapter 3, a new data acquisition system was assembled as part of this research. The data acquisition system was used to collect data from all different types of sensors (e.g. load cells, linear potentiometers, strain gages, vibrating wire gages, etc.). The data acquisition system works by collecting readings of voltage, current, resistance, or pulse output signals and then converting these into load, strain, length, etc.

The data acquisition system assembled for this research consisted of equipment from Campbell Scientific (https://www.campbellsci.com/). This equipment was chosen because of its flexibility for use. The system developed can be used for short-term or long-term monitoring in a laboratory or field setting.

This section includes a brief overview of the hardware and software that are part of the data acquisition system. The section also includes instructions for how to set up a basic system using the equipment. Much of this information was obtained during a week-long training session by Campbell Scientific.

\section{C.2 Description of Hardware}

The data acquisition hardware consisted of the following different components from Campbell Scientific:

- CR6 Measurement and Control Datalogger: This is a datalogger that is compatible with their Campbell Distributed Module (CDM) series measurement and control peripherals. This series allows for easy customization of the data acquisition system by connecting the needed peripherals using ethernet cables. 
- CDM-VW305: This is an interface that connects with up to eight VWGs and allows for dynamic reading of the VWG sensor. Previous interfaces only allowed for measurement rates of around $1 \mathrm{~Hz}$. This interface allows for dynamic measurement rates of 20 to $333 \mathrm{~Hz}$.

- CDM-A116: This is a multiplexer interface that allows for 16 differential inputs and four excitation channels.

These components will be described in more detail in this section.

\section{C.2.1 CR6 - Measurement and Control Datalogger}

The CR6 datalogger is the principal part of a data-acquisition system. It is a precision instrument designed for demanding environments and low-power applications. CPU, analog and digital measurements, analog and digital outputs, and memory usage are controlled by the operating system, the on-board clock, and the CRBasic application program, which should be written by users. The application program is written in CRBasic, a programming language that includes measurement, data processing, and analysis routines and a standard. To make this program more user-friendly, BASIC instruction set, Short Cut, option can be used to write programs for many basic measurement and control applications. For more complicated programs, CRBasic Editor should be written. The CR6 with detail of wiring panel is shown in Figure C-1. 


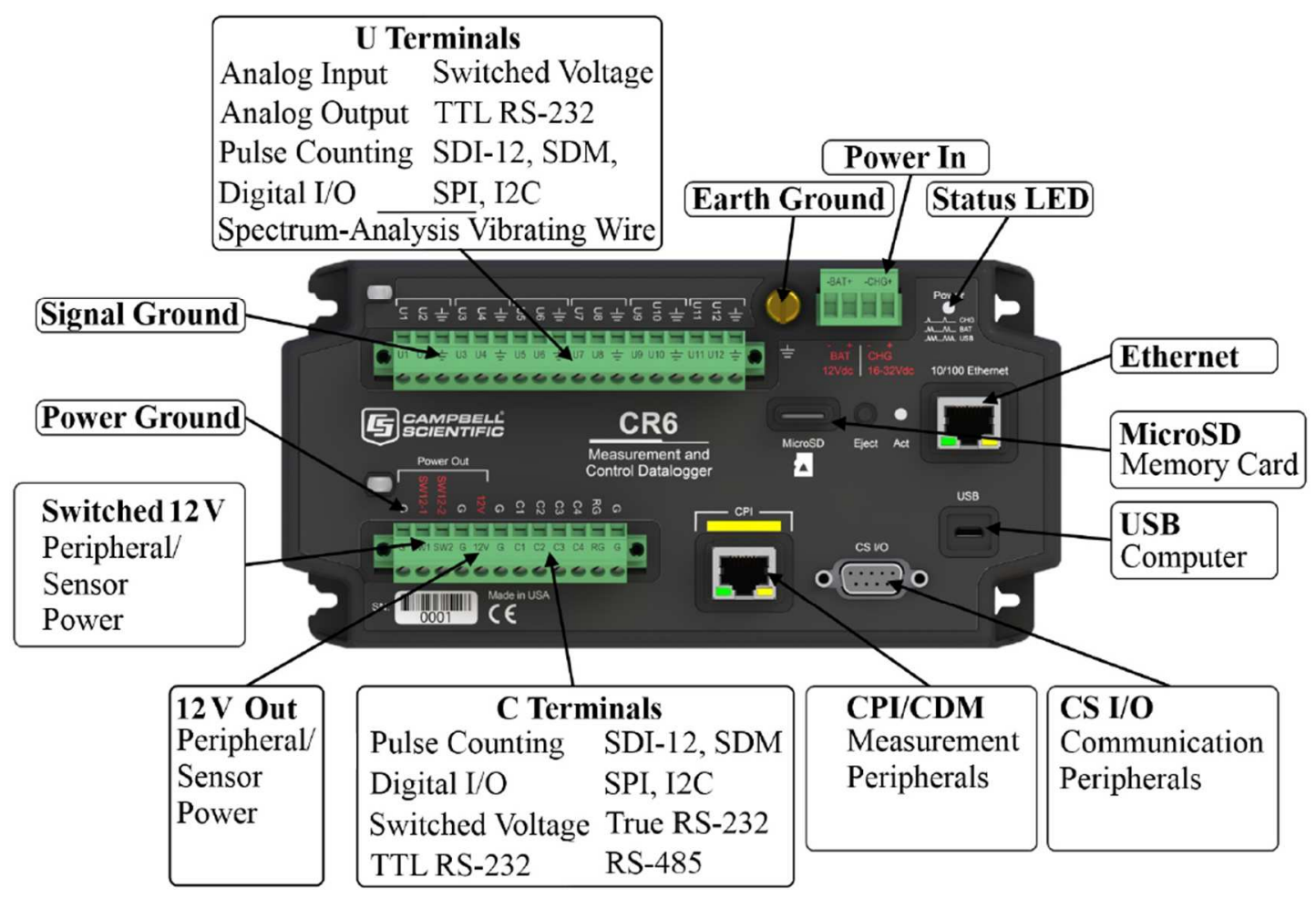

Figure C-1: CR6 with detail of wiring panel

The CR6 requires a power supply. Charger is provided with the equipment. Battery is also can be connected to the CR6. Both charger and battery can be connected to the CR6 at the same time. When connecting power, first switch off the power supply, then make the connection before switching the supply on.

The CR6 is fully operable with power from 10 to $16 \mathrm{Vdc}$ applied to the BAT terminals, or 16 to $32 \mathrm{Vdc}$ applied to the $\mathrm{CHG}$ terminals. Both sets of connectors are found on the green power plug in the upper right portion of the face of the wiring panel. Some functions, such as programming, the setting of settings, and analog measurement, are provided when $5 \mathrm{Vdc}$ is supplied through the USB connection between the micro-B USB port and a PC. Below is the steps toward measuring and collecting data with the CR6:

- Attaching a sensor to the datalogger 
- Creating a program for the CR6 to measure the sensor

- Making a simple measurement

- Storing measurement data

- Collecting data from the CR6 with a PC

- Viewing real-time and historical data from the CR6

\section{C.2.1.1 Voltage and Current Excitation}

Several terminals and terminal configurations are provided on the CR6 to supply switched voltage to peripherals, sensors, or control devices. Some of them are described herein:

- Voltage Excitation (switched-analog output): U terminals are provided for excitation output, supply precise voltage in the range of $\pm 2500 \mathrm{mV}$.

- Current Excitation (switched-analog output): U terminals are provided for excitation output, supply precise current in the range of $\pm 2.0 \mathrm{~mA}$.

- Switched 12 Vdc: SW12 terminals, which is a primary battery and it controls to switch external devices.

\section{C.2.1.2 Grounding Terminals}

Proper grounding lends stability and protection to a data acquisition system. It is

the easiest and least expensive insurance against data loss. The ground termials are signal ground, power ground, resistive ground, and earth ground.

Other ports on the CR6 are different kind of communication ports for different use. For more information refer to $\underline{w w w . c a m p b e l l s c i . c o m}$. 


\section{C.2.2 CDM-VW305 - Dynamic Vibrating Wire Gage Interface}

Vibrating-wire sensors are commonly used in geotechnical or structural monitoring applications to measure strain, load, tilt, inclination, temperature, pressure, extension, and crack movement. Data are stored on a Campbell Scientific datalogger, which is normally used to control the system in field installation. CDM-VW 305 (eight channels) is designed to connect vibrating wire sensors. This instrument is shown in Figure C-2 (a). 


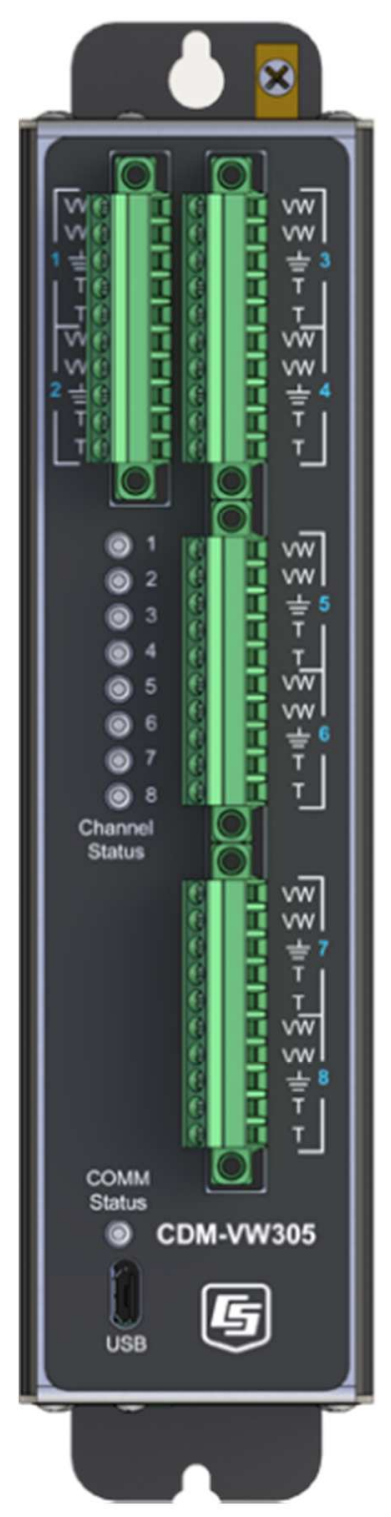

(a)

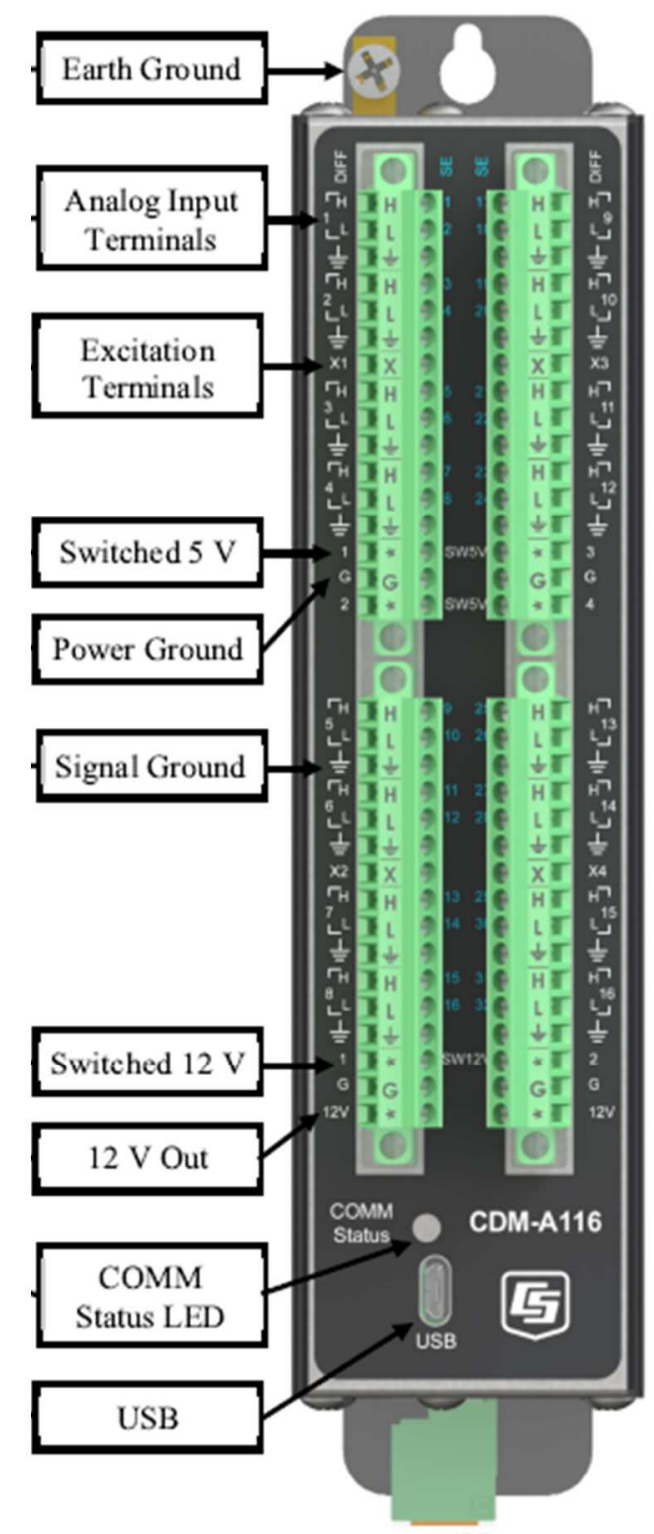

(b)

Figure C-2: (a) CDM-VW 305 and (b) CDM-A116

\section{C.2.3 CDM-A116 - 16 Channel Multiplexer}

The CDM-A116 is a Campbell Distributed Modules (CDMs) for analog measurements. It has 16 analog input terminals to a datalogger measurement system, and 120 CDMs can be 
connected to a single datalogger. This instrument is shown in Figure C-2 (a).

\section{C.3 Description of Software}

As mentioned, a CRBasic program must be written and loaded into the CR6 to read sensors measurements, and store data. Short Cut is an easy-to-use wizard option used to write simple CRBasic programs without the need to learn the CRBasic programming language. Short Cut is an easy-to-use wizard that steps you through the program building process.

After the CRBasic program is written (by using Short Cut or CRBasic option), it is loaded onto the CR6. The instruments require sufficient time for measurements to be made, data to be stored, and data to be retrieved to a PC.

\section{C.4 Basic Setup}

Here is the basic setup to connect the CR6 to PC.

\section{C.4.1 Hardware Setup}

As mentioned before, connect the charger or battery wires to the CR6 and then plug them in. Then connect the USB port to PC with the cable which is provided in the CR6 package.

\section{C.4.2 Software Setup}

The software which is used specifically for Campbell Scientific equipment is LoggerNet. The program is provided with the equipment and should be install on the computer.

\section{C.5 Steps for Setting Up Simple System}

After installing the software, click on the Program $>$ Short Cut icon. The icon resembles a clock face. When the Short Cut window is shown, click New Program. In the Datalogger Model drop-down list, select CR6. In the Scan Interval box, enter 1 and select Seconds 
in the drop-down list box. Then Click Next in the bottom of the page. Note that the first time Short Cut is run, a prompt will appear asking for a choice of ac noise rejection. Select $60 \mathrm{~Hz}$ for the United States and areas using $60 \mathrm{~Hz}$ ac voltage. Select $50 \mathrm{~Hz}$ for most of Europe and areas that operate at $50 \mathrm{~Hz}$. Then, select Full Bridge for defining a load cell and input the information to the software. Add Half Bridge for a linear potentiometer and repeat the input step. This page is shown in Figure C-3.

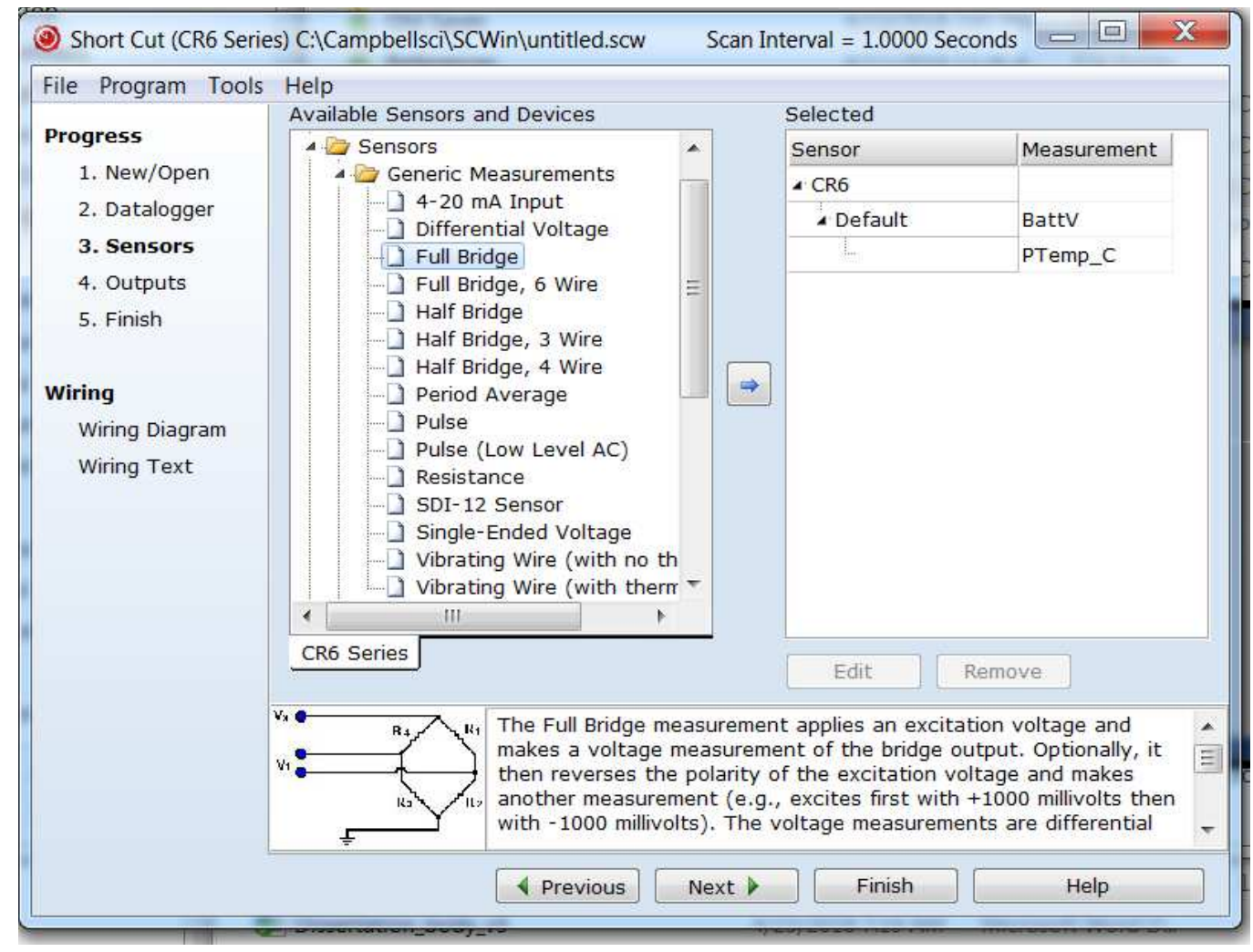

Figure C-3: Sensors and devices window in LoggerNet software

Then, input the information of the sensors to the software.

After adding all your sensors in the software, you can find how to wire the sensors in wiring diagram, in the right side of the window, as shown in Figure C-4. 


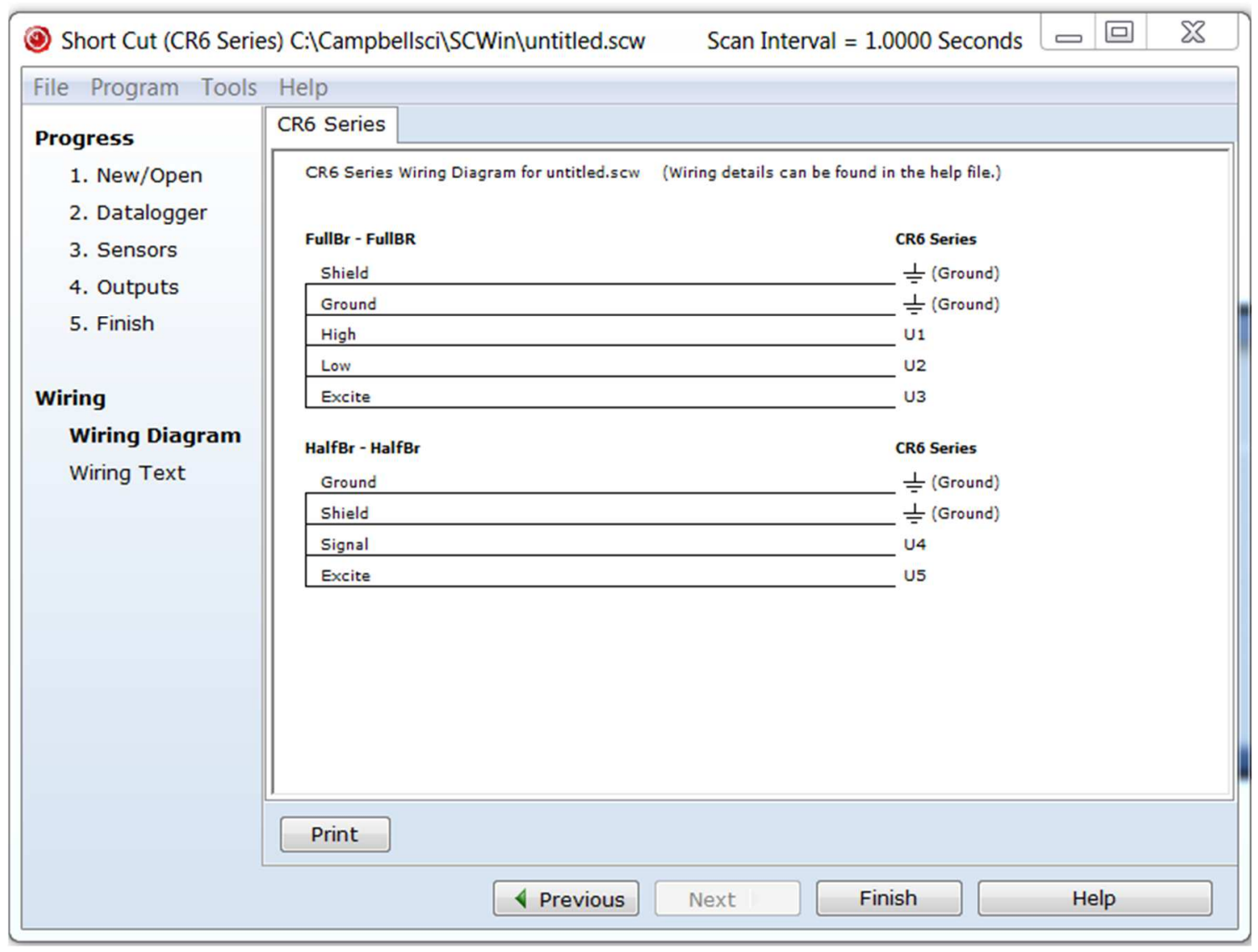

Figure C-4: Wiring diagram in LoggerNet software

Based on the wiring diagram recommended in the wiring diagram, connect the sensors to the CR6. Then click Outputs option to define storing the measurements. In this window, select all your sensors. Based on the number of measurements in one second, average, minimum, maximum, sample, or standard deviation can be selected for the data. Then, click Finish (See Figure C-5). The software asks where to save the program on the computer. Select the folder and save the program. 


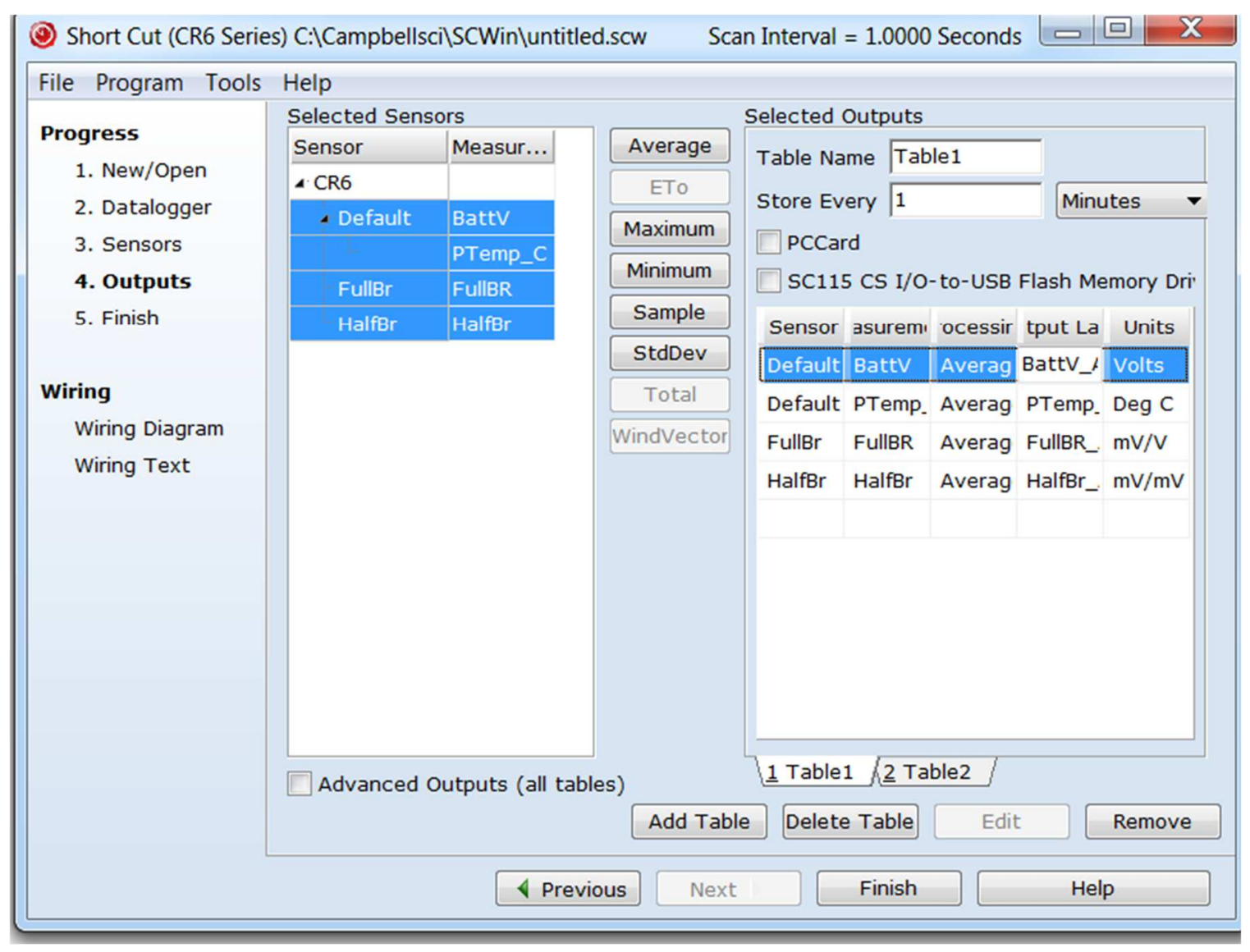

Figure C-5: Output window in LoggerNet software

After saving the program, the software should show the window shown in Figure C-6.

Click Yes and send the program to the CR6. 


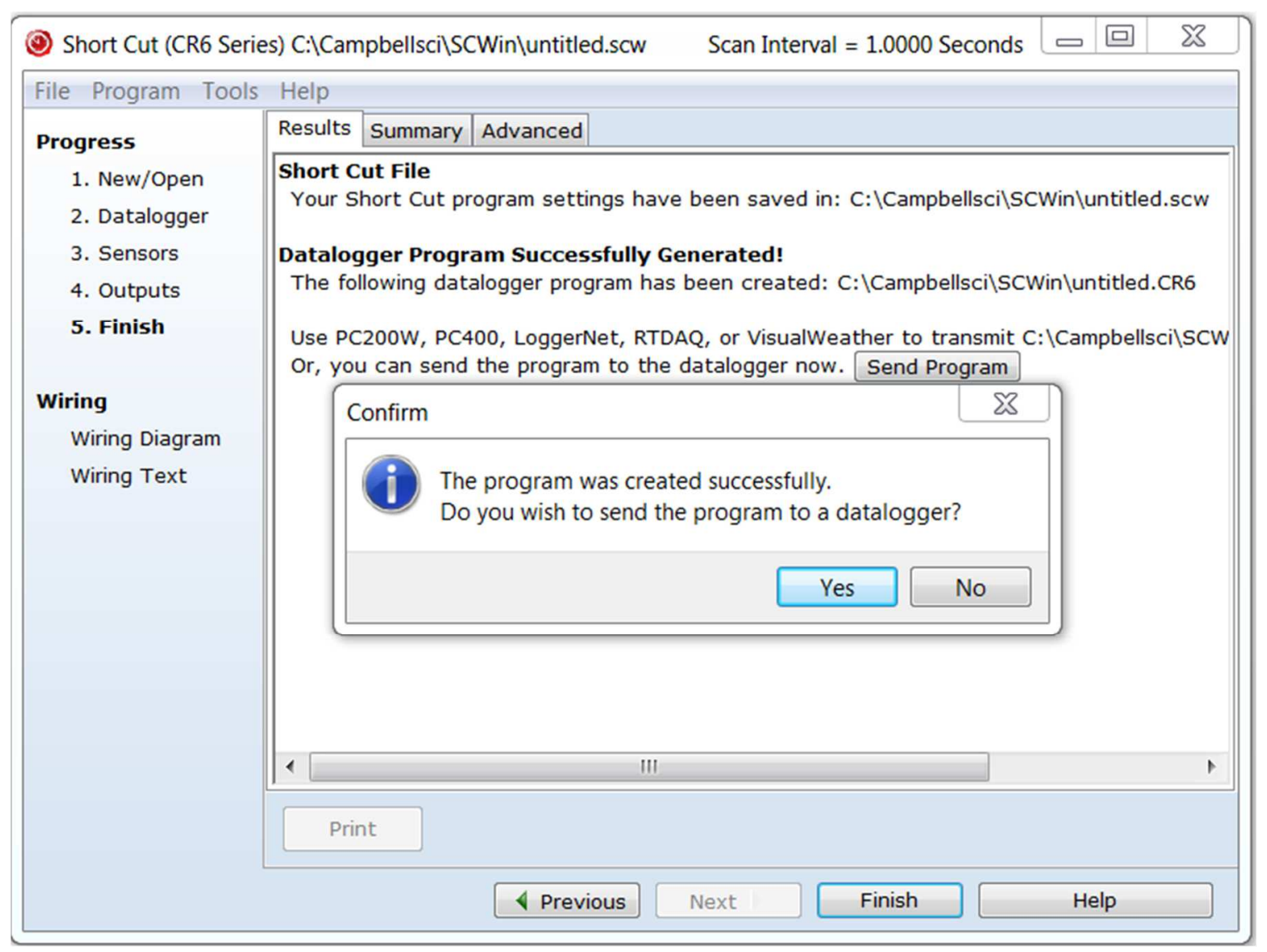

Figure C-6: Finish window in LoggerNet software

Before connecting the CR6 to the program, in the firt path of LoggerNet software, Select Utilities > Device Config Utility. This option is the most versatile configuration tool. Define the CR6 to the software. Make sure in communication port select the port which includes CR6. DevConfig Help guides you through connection and use. The simplest connection is to, connect a USB cable from the computer USB port to the USB port on the CR6. This step is shown in Figure C-7. After defining the equipment, make sure to close this window to go back to connect item. 


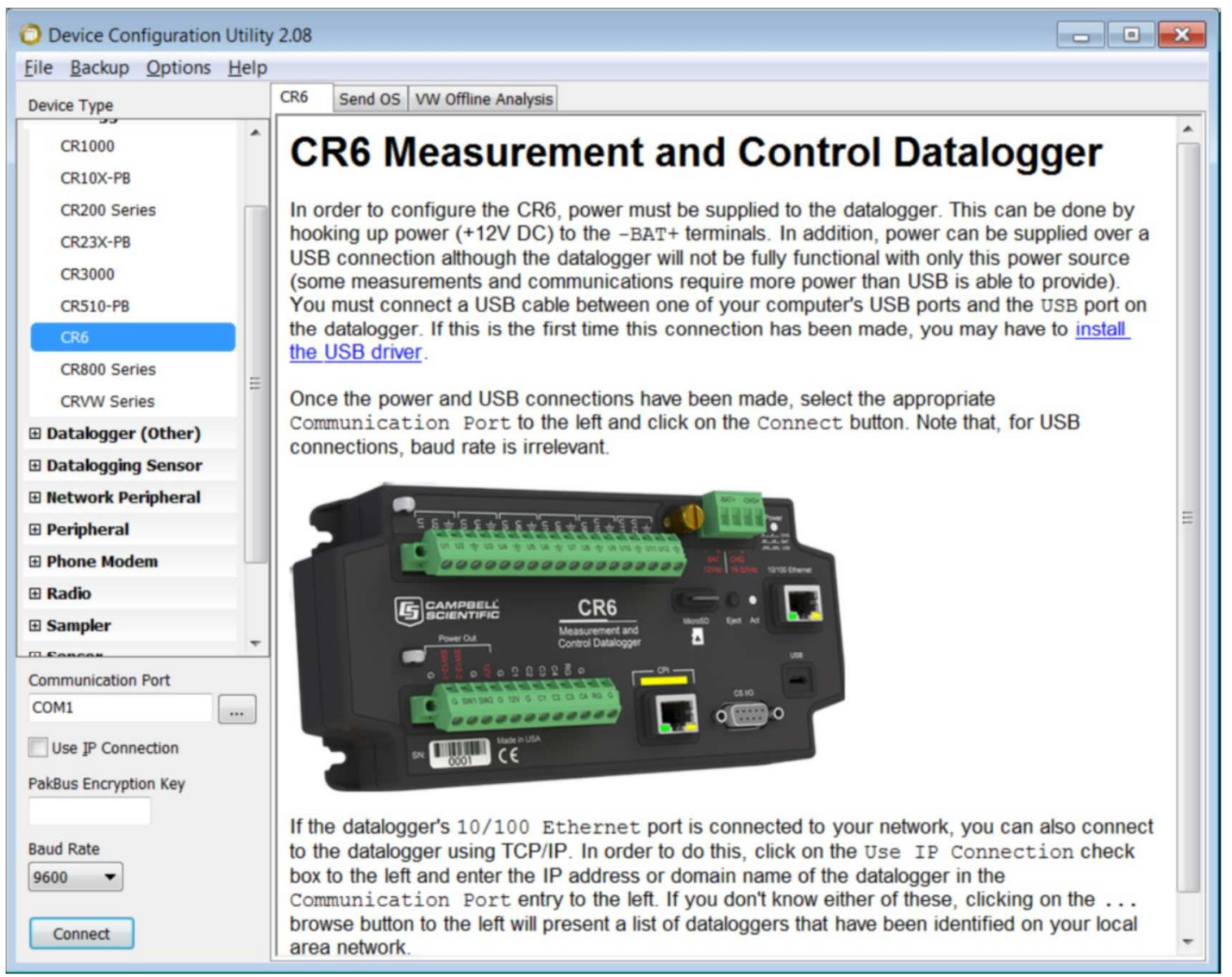

Figure C-7: Device Configuration Utility (DevConfig)

After closing the previous page, click on the Main and Connect items. Click Connect tab in top right corner of the window to connect defined CR6 to the coftware. Then, click Send New tab to choose the program that is already made in the previous steps, and see the data from Table Monitor column. Note that for calibrating sensors in the software, click Datalogger > Calibration Wizard option, as shown in . Select all the sensors that should be calibrated and click calibrate in the next page. Then, click Finish and go back to the Connect screen to read the results. 


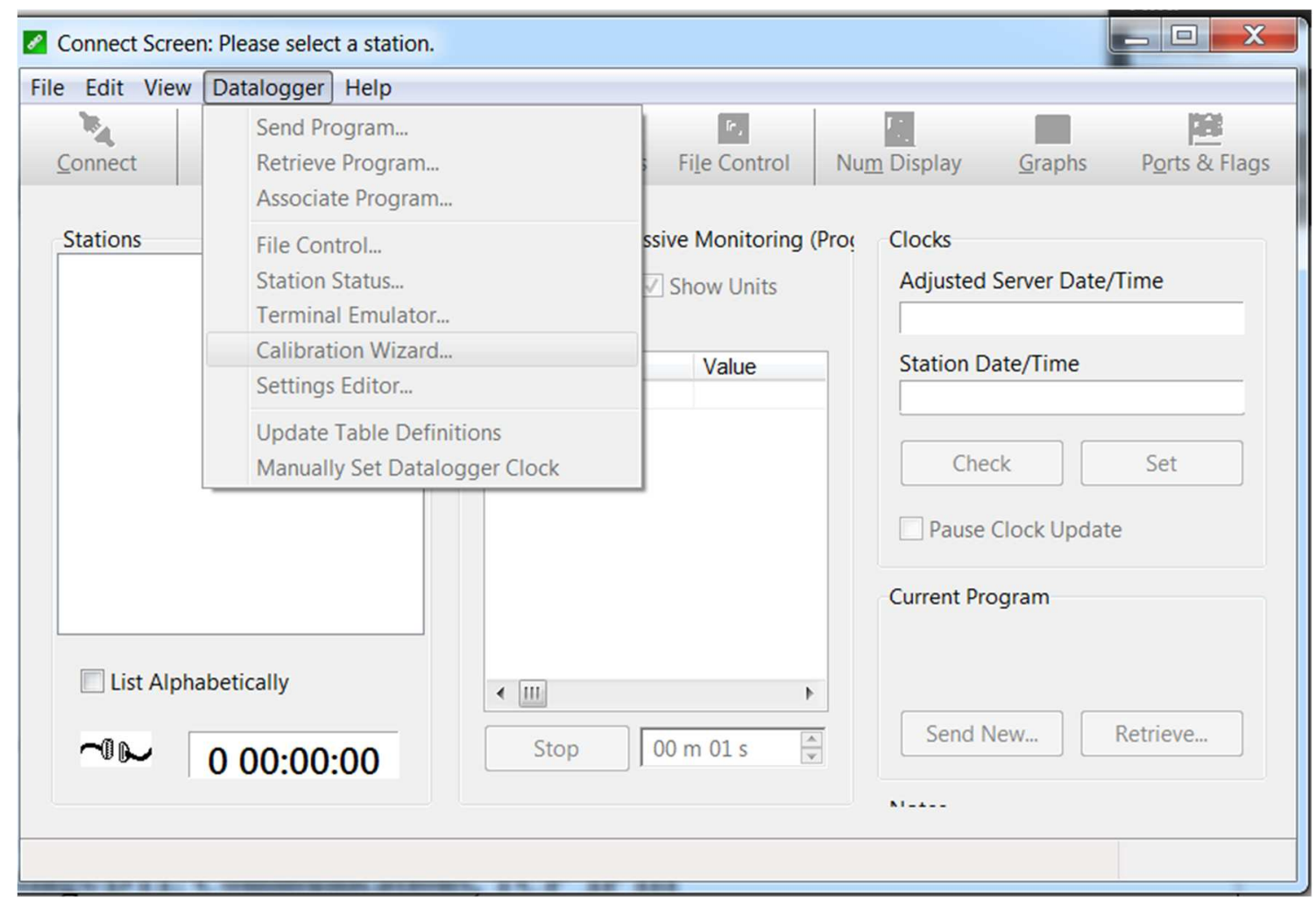

Figure C-8: Connect screen in LoggerNet software

Next chapter provides the CRBasic program, written by Nazanin Rezaei, to connect the sensors and read the data presented in Chapter 4 of this dissertation. 


\section{Appendix D: Campbell Scientific Program in Loggernet}

Below is the program written to be able to have the results from sensors.

'Demonstrate how to use CardOut, DataEvent, and DataInterval to conserve data storage wisely

'Program to measure Geokon 4000 strain gages dynamically

'Originally program was created for $100 \mathrm{~Hz}$ measurement, $10 \mathrm{~Hz}$ data (average) from one CDM-VW300 device (8 VW Strain)

' $100 \mathrm{~Hz}$ measurement, $10 \mathrm{~Hz}$ data (average) from one CDM-A116 device (4 load, 2

potentiometer, 2 string pots, 2 pressure transducer)

'12/6/2016 We are modifying the program to run at $50 \mathrm{~Hz}$

'Constants to for CPI Usage

Const CPI_ADDR $=5$ 'VW305 CPI address \#5

Const CPI2_ADDR = 10 'CDM-A116 CPI addresss \#10

'This Variable is required for the CPISpeed Instruction

Public CPI_Baud=250

'Constants specific to the Geokon 4000 strain gages

Const GageFactor $=4.062$ 'G $=4.062$ - Gage factor taken from sensor manual

Const NomBatchFactor $=0.97$ 'B=0.97 - Batch Factor taken from calibration sheet provided with sensors

'Output will be in Strain, not Digits nor Frequency

Public VW_Strain(8) : Units VW_Strain() = Microstrain 'Measured strain output in units of Microstrain

Public Freq1(8): Units Freq1( $)=\mathrm{Hz}$

Public Digits(8)

Public DigitsBaseL(8)

'Public Therm1(8)

'Public ThermBaseL(8) 
Public DCode(8) As Long 'Dynamic diagnostic code

Public Static_Freq(8) : Units Static_Freq ()$=\mathrm{Hz}$ 'Static $(1 \mathrm{~Hz})$ strain reading in frequency

Public StaticDigits(8) 'Calculated Static (1Hz) Digits output (for troubleshooting)

Public StaticStrain(8) : Units StaticStrain ()$=$ Microstrain'Calculated Frequency $(1 \mathrm{~Hz})$

from static digits (for troubleshooting)

Public Temp(8) : Units Temp ()$=$ DegC ' Temperature in DegCPublic TempBL(8) : Units TempBL ()$=$ DegC ' Temperature Baseline in DegC

Public FreqStdDev(8) : Units FreqStdDev() = Frequency 'StdDev of dynamic strain readings in frequency

Public ZeroMode 'Mode variable for baseline/offset zeroing calibration

'Variables for A116

Public FullBR(6)

Alias FullBR(1) = LoadCell_1

Alias FullBR(2) = LoadCell_2

Alias FullBR(3) = LoadCell_3

Alias FullBR(4) = LoadCell_4

Alias FullBR(5) = PressureTransducer_1

Alias FullBR(6) = PressureTransducer_2

Public LC_1

Public LC_2

Public LC_3

Public LC_4

Public PT_1

Public PT_2

Public LC 
Public FCLoaded

Public Mult_2(6) $=\{1,1,1,1,1,1\}$

Public Offs_2(6) $=\{0,0,0,0,0,0\}$

Public CMult_2(6) $=\{1,1,1,1,1,1\}$

Public COffs_2(6) $=\{0,0,0,0,0,0\}$

Public CKnown_2(6)

Public CReps_2

Public ZMode_2

Public MOMode_2

Public CIndex_2

Public CAvg_2

Public LCount_2

Public HalfBr(4)

Public CKnown_3(4)

Public Mult_3(4) $=\{1,1,1,1\}$

Public Offs_3(4) $=\{0,0,0,0\}$

Public CMult_3(4) $=\{1,1,1,1\}$

Public COff_3(4) $=\{0,0,0,0\}$

Public CReps_3

Public ZMode_3

Public MOMode_3

Public CIndex_3

Public CAvg_3

Public LCount_3

Public HBr_1

Public HBr_2

Public HBr_3

Public HBr_4

Units FullBR=mV/V_Excitation 
Units HalfBr=V/V_Excitation

Units LC_1=Kips

Units LC_2=Kips

Units LC_3=Kips

Units LC_4=Kips

Units LC=Kips

Units PT_1=ksi

Units PT_2=ksi

Units HBr_1=in

Units $\mathrm{HBr} \_2=$ in

Units HBr_3=in

Units HBr_4=in

Public CDM2PTempC(1)'CDM-A116 variables

Alias CDM2PTempC(1)=CDM2PTempC1

Units CDM2PTempC(1)=Deg C

Public Cindex

Public CAvg

Public CReps

'Added by Bill on 12/12/2016

Public StaticDigitsBaseL(8)

'Configure the CDM-VW300 device

Dim Enable(8) As Long $=\{1, \quad 1, \quad 1, \quad 1, \quad 1, \quad 1,1,1\}$

Dim Max_AMP $(8)=\quad\{0.002,0.002,0.002,0.002,0.002,0.002,0.002,0.002\}$

Dim F_Low $(8)=\quad\{400,400,400,400,400,400,400,400\}$

Dim F_High $(8)=\quad\{1300,1300,1300,1300,1300,1300,1300,1300\}$

'Use $\mathrm{Hz}^{\wedge} 2$ (1) instead of $\mathrm{Hz}(0)$ so we can get to digits 
$\operatorname{Dim}$ OutForm $(8)$ As Long $=\{0,0,0,0,0,0,0,0\}$

'Use a multiplier of 0.001 to divide by 1000 and get digits

'Then scale further to get to Strain

Dim VW_Mult $(8)=\quad\{1.0,1.0,1.0,1.0,1.0,1.0,1.0,1.0\}$

'Dim Mult(4) =

$\{0.001 *$ GageFactor*NomBatchFactor, $0.001 *$ GageFactor*NomBatchFactor,

$0.001 *$ GageFactor*NomBatchFactor, $0.001 *$ GageFactor*NomBatchFactor $\}$ 'Digits $\left(\mathrm{Hz}^{\wedge} 2 / 1000\right)$ times $\mathrm{G}$ times $\mathrm{B}$ results in strain

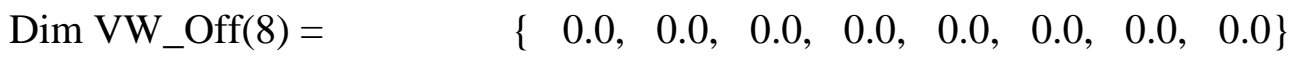

'Use Steinhart-Hart coefficients To get Thermistor output in DegC

$\operatorname{Dim} \operatorname{SteinA}(8)=\quad\{1.4051 \mathrm{E}-3,1.4051 \mathrm{E}-3,1.4051 \mathrm{E}-3,1.4051 \mathrm{E}-3,1.4051 \mathrm{E}-$

3,1.4051E-3,1.4051E-3, 1.4051E-3\}

$\operatorname{Dim} \operatorname{SteinB}(8)=\quad\{2.369 \mathrm{E}-4,2.369 \mathrm{E}-4,2.369 \mathrm{E}-4,2.369 \mathrm{E}-4,2.369 \mathrm{E}-4,2.369 \mathrm{E}-4$, 2.369E-4, 2.369E-4\}

Dim SteinC $(8)=\quad\{1.019 \mathrm{E}-7,1.019 \mathrm{E}-7,1.019 \mathrm{E}-7,1.019 \mathrm{E}-7,1.019 \mathrm{E}-7,1.019 \mathrm{E}-$

7, 1.019E-7, 1.019E-7\}

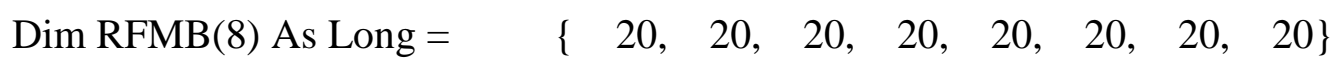

$\operatorname{Dim} \operatorname{RFAB}(8)$ As Long $=\quad\{20,20,20,20,20,20,20,20\}$

$\operatorname{Dim} \operatorname{RFLL}(8)=\quad\{400.0,400.0,400.0,400.0,400.0,400.0,400.0,400.0\}$

$\operatorname{Dim} \operatorname{RFHL}(8)=\quad\{4000.0,4000.0,4000.0,4000.0,4000.0,4000.0,4000.0,4000.0\}$

$\operatorname{Dim} \operatorname{RFHY}(8)=\quad\{0.005,0.005,0.005,0.005,0.005,0.005,0.005,0.005\}$

$\operatorname{Dim} \operatorname{RFOF}(8)$ As Long $=\quad\{100,100,100,100,100,100,100,100\}$

CDM_VW300Config(1,CPI_ADDR,1,Enable(),Max_AMP(),F_Low(),F_High(), _ OutForm(),VW_Mult(),VW_Off(), SteinA(),SteinB(),SteinC(), _ RFMB(),RFAB(),RFLL(),RFHL(),RFHY(),RFOF())

DataTable (static,true,-1)

DataInterval $(0,1, \operatorname{Sec}, 10)$

'CardOut $(0,-1)$ 
Sample (8,Static_Freq(),IEEE4,False)

Sample (8,StaticDigits(),IEEE4,False)

Sample (8,StaticStrain(),IEEE4,False)

Sample (8,Temp(),IEEE4,False)

EndTable

DataTable (dynamic,true,-1)

'CardOut $(0,-1)$

DataInterval $(0,1, \mathrm{Sec}, 100)$

Average (8,VW_Strain,FP2,False)

Average(6,FullBR(),IEEE4,False)

Average(4,HalfBr(),IEEE4,False)

Average(1,LC_1,IEEE4, False)

Average(1,LC_2,IEEE4, False)

Average(1,LC_3,IEEE4, False)

Average(1,LC_4,IEEE4, False)

Average(1,LC,IEEE4, False)

Average(1,PT_1,IEEE4, False)

Average(1,PT_2,IEEE4, False)

Average(1,HBr_1,IEEE4, False)

Average(1,HBr_2,IEEE4, False)

Average(1,HBr_3,IEEE4, False)

Average(1,HBr_4,IEEE4, False)

EndTable

DataTable(CalHist,NewFieldCal,-1)

'CardOut $(0,-1)$

SampleFieldCal

EndTable 


\section{BeginProg}

'Initialize calibration variables for

'Generic Full Bridge measurement 'FullBR()' on CDM-A116 with CPI address 10

Cindex $=1:$ CAvg $=1:$ CReps $=6$

For LCount_2 = 1 To 6

CMult_2(LCount_2)=Mult_2(LCount_2) : COffs_2(LCount_2)=Offs_2(LCount_2)

Next

'Initialize calibration variables for

'Generic Half Bridge measurement 'HalfBr()' on CDM-A116 with CPI address 10

CIndex_2=1:CAvg_2=1:CReps_2=3

For LCount_3 = 1 To 3

CMult_3(LCount_3)=Mult_3(LCount_3) : COff_3(LCount_3)=Offs_3(LCount_3)

Next

'Load the most recent calibration values from the CalHist table

FCLoaded=LoadFieldCal(True)'Initialize calibration variables for

\section{ニニニニニニニニニニ}

'Set CPI Baud rate

CPISpeed (CPI_Baud)

'Was initially $100 \mathrm{~Hz} / 10 \mathrm{msec}$ scan rate

'Scan $(10, \mathrm{msec}, 500,0)$

$\operatorname{Scan}(20, \mathrm{msec}, 500,0)$

CDM_VW300Dynamic(CPI_ADDR,Freq1(),DCode()) 'Get unshifted strain

'Use Mult/Offset to get to strain from Frequency for DVW

'Strain_DVW(1) = DVWMult(1)*Freq1(1) + DVWOffset $(1)$

'Strain_DVW(2) = DVWMult(2)*Freq1(2) + DVWOffset(2)

'Try to do this in the way suggested by ShortCut for static/AVW200, Geokon 4100

'Calculate digits 'Digits'

$\operatorname{Digits}(1)=$ Freq1 $(1)^{\wedge} 2 / 1000$ 
$\operatorname{Digits}(2)=$ Freq1 $(2)^{\wedge} 2 / 1000$

$\operatorname{Digits}(3)=$ Freq1 $(3)^{\wedge} 2 / 1000$

$\operatorname{Digits}(4)=$ Freq1 $(4)^{\wedge} 2 / 1000$

$\operatorname{Digits}(5)=$ Freq1 $(5)^{\wedge} 2 / 1000$

$\operatorname{Digits}(6)=$ Freq1 $(6)^{\wedge} 2 / 1000$

$\operatorname{Digits}(7)=$ Freq1 $(7)^{\wedge} 2 / 1000$

$\operatorname{Digits}(8)=$ Freq1 $(8)^{\wedge} 2 / 1000$

'Calculate strain 'Strain'

VW_Strain(1)=(Digits(1)-DigitsBaseL(1))*0.391*NomBatchFactor

VW_Strain $(2)=($ Digits $(2)$-DigitsBaseL $(2)) * 0.391 *$ NomBatchFactor

VW_Strain(3)=(Digits(3)-DigitsBaseL(3))*0.391*NomBatchFactor

VW_Strain(4)=(Digits(4)-DigitsBaseL(4))*0.391*NomBatchFactor

VW_Strain(5)=(Digits(5)-DigitsBaseL(5))*0.391*NomBatchFactor

VW_Strain(6)=(Digits(6)-DigitsBaseL(6) $) * 0.391 *$ NomBatchFactor

VW_Strain $(7)=(\operatorname{Digits}(7)-\operatorname{DigitsBaseL}(7)) * 0.391 *$ NomBatchFactor

VW_Strain $(8)=($ Digits $(8)$-DigitsBaseL(8) $) * 0.391 *$ NomBatchFactor

'Zeroing calibration for

'Geokon 4100 Series Vibrating Wire Strain Gage calculations 'Digits' and 'TT'

FieldCal(4,Digits(),8,0,DigitsBaseL(),ZeroMode,0,1,40)

'FieldCal(4,Therm1(),8,0,ThermBaseL(),ZeroMode, $0,1,40)$

'Now shift the given Strain using the Baseline/Offset value

'VW_Strain(1) = VW_Strain(1) + VW_StrainBL(1) : VW_Strain(2) = VW_Strain(2) + VW_StrainBL(2):

'VW_Strain(3) = VW_Strain(3) + VW_StrainBL(3) : VW_Strain(4) = VW_Strain(4) + VW_StrainBL(4):

'Zeroing calibration for Geokon 4000 Vibrating Wire Strain Gage

'Strain offset and Temperature baseline readings

FieldCal(0,VW_Strain(),4,0,VW_StrainBL(),ZeroMode,0,1,100) 'Calibrate for 2 seconds

FieldCal(4,Temp(),4,0,TempBL(),ZeroMode, $0,1,100)$ 
CDM_PanelTemp(CDM_A116,CPI2_ADDR,CDM2PTempC(),1,1,15000) 'CDM Address 10

CDM_BrFull(CDM_A116,10,FullBR(),6,mV5000,1,1,2,5000,False,False,100,30000,CM ult_2(),COffs_2())

'Zeroing calibration for Generic Full Bridge measurement 'FullBR()' on CDM-A116 with CPI address 10

FieldCal(0,FullBR(),CReps_2,0,COffs_2(),ZMode_2,0,CIndex_2,CAvg_2)

'Two Point Multiplier and Offset calibration for

'Generic Full Bridge measurement 'FullBR()' on CDM-A116 with CPI address 10

'FieldCal(2,FullBR(),1,CMult_2(),COffs_2(),MOMode_2,CKnown_2(),CIndex_2,CAvg 2)

'Generic Half Bridge measurements 'HalfBr()' on CDM-A116 with CPI address 10

CDM_BrHalf(CDM_A1 16,10,HalfBr(),4,mV5000,13,X4,4,5000,False,100,30000,CMult _3(),COff_3())

'Zeroing calibration for Generic Generic Half Bridge measurement 'HalfBr()' on CDMA116 with CPI address 10

FieldCal(0,HalfBr(),CReps_3,0,COff_3(),ZMode_3,0,CIndex_3,CAvg_3)

'Two Point Multiplier and Offset calibration for

'Generic Half Bridge measurement 'HalfBr()' on CDM-A116 with CPI address 10

'FieldCal(2,HalfBr(),1,CMult_3(),COffs_2(),MOMode_3,CKnown_3(),CIndex_3,CAvg_ 3)

LC_1=((LoadCell_1*112238)-2020.9)/1000

LC_2 $=(($ LoadCell_2*110618) -708.33$) / 1000$

LC_3 $=(($ LoadCell_3*107614) -1856.3$) / 1000$

LC_4=((LoadCell_4*110749)-998.09)/1000

$\mathrm{LC}=\mathrm{LC} \_1+\mathrm{LC} \_2+\mathrm{LC} \_3+\mathrm{LC} \_4$ 
PT_1=(PressureTransducer_1-72.21046)*0.1191195

PT_2=(PressureTransducer_2-78.25637)*0.206855

$\mathrm{HBr} \_1=\operatorname{HalfBr}(1) * 2$

$\mathrm{HBr} \_2=(\operatorname{HalfBr}(2)-0.0097) * 12.82325$

HBr_3 $=(\operatorname{HalfBr}(3)-0.004796411) * 12.6096635$

HBr_4 $=(\operatorname{HalfBr}(4)-0.00769081) * 12.6702487$

'Call Data Tables and Store Data

CallTable dynamic

CallTable CalHist

If TimeIntoInterval $(0,1, \mathrm{Sec})$ Then

CDM_VW300Static(CPI_ADDR,Static_Freq(),Temp(),FreqStdDev()) 'Obtain static frequency

'Zeroing calibration for

'Geokon 4100 Series Vibrating Wire Strain Gage calculations 'Digits' and 'TT'

FieldCal(4,StaticDigits(),8,0,StaticDigitsBaseL(),ZeroMode,0,1,40)

'Calculate static digits reading (for troubleshooting)

StaticDigits $(1)=$ Static_Freq $(1)^{\wedge} 2 / 1000$

StaticDigits $(2)=$ Static_Freq $(2)^{\wedge} 2 / 1000$

StaticDigits(3) $=$ Static_Freq(3)^2/1000

StaticDigits(4) $=$ Static_Freq( $(4)^{\wedge} 2 / 1000$

StaticDigits(5) $=$ Static_Freq(5)^2/1000

StaticDigits(6) $=$ Static_Freq(6)^2/1000

StaticDigits $(7)=$ Static_Freq(7)^2/1000

StaticDigits $(8)=$ Static_Freq $(8)^{\wedge} 2 / 1000$

'Now shift the given StaticStrain using the Offset/Baseline reading to obtain Final/adjusted StaticStrain

StaticStrain $(1)=($ StaticDigits $(1)-$ StaticDigitsBaseL $(1)) * 0.391 *$ NomBatchFactor : StaticStrain $(2)=($ StaticDigits $(2)-$ StaticDigitsBaseL(2) $) * 0.391 *$ NomBatchFactor

StaticStrain(3) $=($ StaticDigits(3)- StaticDigitsBaseL(3))*0.391*NomBatchFactor : StaticStrain $(4)=($ StaticDigits(4) - StaticDigitsBaseL $(4)) * 0.391 *$ NomBatchFactor

StaticStrain $(5)=($ StaticDigits $(5)-$ StaticDigitsBaseL $(5)) * 0.391 *$ NomBatchFactor : StaticStrain $(6)=($ StaticDigits(6) - StaticDigitsBaseL (6) $) * 0.391 *$ NomBatchFactor

StaticStrain $(7)=($ StaticDigits $(7)-$ StaticDigitsBaseL $(7)) * 0.391 *$ NomBatchFactor : StaticStrain $(8)=($ StaticDigits $(8)-$ StaticDigitsBaseL $(8)) * 0.391 *$ NomBatchFactor

CallTable static 
EndIf

NextScan

EndProg 
VITA

\section{NAZANIN REZAEI}

\begin{tabular}{ll}
\multirow{2}{2}{$2005-2009$} & B.S., Civil Engineering \\
& Arak University \\
& Arak, Iran \\
& M.S., Civil Engineering \\
$2009-2012$ & Iran University of Science and Technology \\
& Tehran, Iran \\
& PhD, Civil Engineering \\
& Florida International University \\
$2014-2018$ & Miami, Florida
\end{tabular}

2018 Outstanding Dissertation Year Fellowship (DYF), Florida International University

2017-2018 President, ACI Student Chapter at FIU

2016-Present Transportation Research Board (Reviewer)

2017-Peresent ACI Committee 445 (Shear and Torsion), (Member)

\section{PUBLICATIONS AND PRESENTATIONS}

Klein. G., Rezaei.N., Garber.D., Tureyen. K., January 2018 "Shear in Discontinuity Regions" Submitted to concrete International (ACI Publication).

Rezaei.N., Klein. G., Garber.D., January 2018 "Strut Strength and Failure in Full-Scale Concrete Deep Beams" Submitted to ACI Structural Journal.

Rezaei.N., Klein. G., Garber.D., January 2018 "Effect of Development and Geometry on Behavior of Concrete Deep Beams" submitted to ACI Structural Journal.

Esmaeili. M., Rezaei.N., February 2016 “In-situ Impact Testing of a Light-Rail Ballasted Track with Tire Derived Aggregate Subballast Layer" International Journal of Pavement Engineering 17(2).

Esmaeili. M., Rezaei.N., November 2014 "Investigation of TDA ${ }^{1}$ Effect on Reduction of Train Induced Vibrations" Journal of Transportation Research 10(4), Tehran, Iran.

\footnotetext{
${ }^{1}$ Tire Derived Aggregate
} 
Rezaei.N., Garber.D., October 2017 "Strut Strength and Failure in Full-Scale Concrete Deep Beams" Subcommittee 445-A: Strut and Tie Models, ACI Convention, Anaheim, CA.

Rezaei.N., Esmaeili. M., December 2012 "Experimental study on the Effect of TDA on Track Vibrations Reduction" Second International Conference on Acoustics and Vibration, Sharif University of Technology, Tehran, Iran. 